


\section{DARWINISM AND THE PROBLEMS OF LIFE}




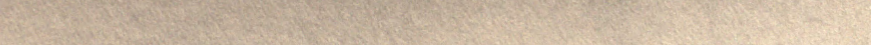

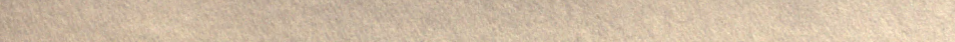

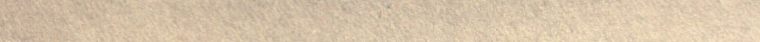

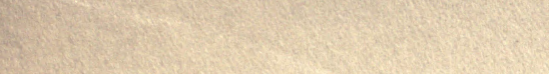




\title{
Darwinism and the
}

\section{Problems of Life}

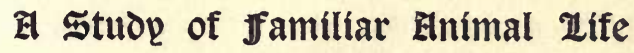

$$
\text { Wows manhos }
$$

BY

CONRAD GUUENTHER, Ph.D.

Professor at the University Freiburg in Baden

TRANSLATED FROM THE THIRD EDITION

BY

JOSEPH MCCABE

\author{
LONDON \\ A. OWEN \& CO. \\ 28 REGENT STREET, S.W. \\ 1906
}





\section{PREFACE}

THE present work had its origin in an attempt to appreciate the range, the foundation, and the value of evolutionary theories. Such a task entailed a prolonged study, not only of scientific literature, but also of works that belong to neighbouring provinces.

The information gleaned from these fields had then to be appraised and put together, and an effort made to reduce it into a harmonious system. In doing this the various theories had to be examined with discrimination, enlarged, and built into the structure. It is, therefore, hoped that the reader will meet many new thoughts in the work.

In the preparatory reading the author had to go through the whole of the relevant literature in various languages. In the book itself he was compelled to restrict himself to what had an essential bearingeither for or against-on the view it presents.

The work has not been written solely for those who are entirely devoted to the study of science. It appeals to all who take an interest in scientific questions; to all educated people who would inform 
themselves as to the actual condition of theories of life.

Its chief aim has been to vindicate the value and importance of Darwinism. The greater part of the work is devoted to proving the truth of this system. On the other hand, every care has been taken to distinguish between facts and probabilities; and it has been clearly pointed out what general deductions may or may not be drawn from Darwinism. The ease with which the theory of evolution is grasped too readily disposes people to regard Darwinism as the one true, natural, and sound view of the worldprocess. And in order to set forth all these questions with perfect clearness, it has been necessary to touch on fields of inquiry which lie beyond the range of biological science.

The manner of presentation is simple, because the work is written for the general reader. No knowledge of science is presupposed; and the reader is briefly informed on all the questions that have a bearing on the theory of evolution. Everything that would interfere with clearness and intelligibility has been avoided. Hence, the founders of the various theories treated are not, as a rule, named in the text; though, to ensure accuracy, their names are given in footnotes. In these notes will also be found the references to the literature relating to the subject, so 
that the reader who desires to go further into the matter will find every assistance. With the same object of making the text clear the various animals have been indicated, as far as possible, by their popular names, but their scientific titles will be found in the index at the end of the work.

The difficulty of many of the questions treated imposed a yet further condition. Problems that are not easily grappled could not very well be put at once before the reader. The book gradually educates him up to the level of these. Starting from familiar objects, it leads him on, almost unconsciously, to problems of increasing difficulty, until he is at length in a position to form an opinion on even the most difficult.

And as it is the purpose of this work to elucidate the theory of evolution only by means of observation, to convince those only who have some insight into the inexhaustible facts of nature that bear witness to it, as many as possible of these facts have been introduced. Nature herself shall teach the reader the truth of evolution. On this account, the first part of the work has been divided, not into problems, but according to groups of animals. These animals, moreover, are generally the familiar ones of our own country. Our indigenous animal-life has been treated very fully. Plants have only been dealt with in so 
far as this was necessary for the reader to understand the questions.

The book will, therefore, make the reader acquainted with the animals that surround him, and teach him to take an intelligent interest in the life of the forest and the field. In this we have the most natural foundation for the thoughts that reach out to embrace the whole of life, and that in the end help to lay open the entire world to the human mind.

\section{CONRAD GUENTHER.}




\section{PREFACE TO THE THIRD EDITION}

Little over half a year has passed since the publication of this work. In so short a space of time there could not be much advance made in science, so that it was unnecessary to make extensive alterations in the text for the present edition. In a few places there have been additions, relating to new investigations; the third chapter, especially, has been considerably modified. No change was needed as regards the view that runs through the entire work, and is summarily presented in the final chapter. I have carefully examined the objections raised on several points, but have found them invalid. However, I thought it proper to put the chief of them before the reader, because I am anxious that he should use his own judgment on the facts independently. I have, therefore, given the objections in the notes, with a few explanatory remarks. Where the objections were due to misunderstanding, I have taken care to make the corresponding passage in the text clearer, or to add further explanations. The purely philosophical questions that are dealt with in the later chapters have not been enlarged on. A more thorough discussion of 
these questions would spoil the unity of the work; it was necessary only to put, at the limits of my science, sign-posts indicating the destination of the roads that start from these points, and distinguishing the right from the wrong way. For the rest, I believe that my treatment of these various questions is not wholly superficial, but sufficiently informs the reader on the substance of them. I am confirmed in this by the testimony of experts.

I have to express my cordial thanks to my colleagues for their friendly interest.

\section{CONRAD GUENTHER.}

FREIBURG, I5th March, 1905. 


\section{TRANSLATOR'S PREFACE}

THE quantity of popular evolutionary literature in our tongue is-apart from works that deal with the subject in its relation to religious controversy-so slight that a fresh work of acknowledged competence should be assured of a welcome. Professor Guenther's work has, however, an especial title to consideration. He has succeeded so well in taking up the position of the average untrained observer for his instructive survey of our animal world that his book will be singularly helpful to thousands who shrink from the usual technical manual. The reader will find himself at first looking out on a familiar world in a familiar way. Gradually he will find the well-known forms and movements suggesting alluring problems to his opening vision, and he will follow the answers to them, given with a logical ease and literary grace that are too uncommon in this department, almost without effort.

Dr. Guenther's facility has not been purchased, as often happens, at the expense of soundness or thoroughness. The limits of the work restrict his plan, but within those limits the reader will feel that he is following a judicious and entirely informed guide. Though full reference is made to the most recent speculations of biologists, it is not books and authorities, but Nature, that the author holds steadily in view, and his personal contributions to its interpretation will command respect. 
The circumstance that the work proceeds on a totally different principle of interpretation than others that I have recently introduced to English readers gave me a certain gratification. It is important to make clear that the superb procession of organic forms across the stage of our planet, which we sum up in the phrase, "the evolution of life," may be presented either in the terms of the older Darwinian theories or of the new ones associated with the great name of Weismann. The fact of evolution now stands solid and towering above all the clash of theories. Even the machinery of natural selection continues its vast work-if it does not increase it-whether or no we accept the transmission of acquired characteristics. It has seemed most expedient to put before the general reader a simple and untechnical interpretation of evolution from the Weismannic point of view (within limits); and it would be difficult to find a more suitable and attractive one than Professor Guenther's Darwinism.

JOSEPH McCABE.

London, October, r 905. 


\section{CONTENTS}

\section{CHAPTER I.-INTRODUCTION}

Animal-life in the forest, the field, and the pond. Variations of animals in different regions. Connection of animals in the same region. Over-production in nature. The relation of increase to the danger of destruction. The struggle for life. Artificial selection. Natural selection. Transformation of species. Different animals of former days as the parents of actual organisms. The theory of evolution. Its predictions. Variation and heredity. Useful and harmful animals. Modification of our animal-world through civilisation

\section{CHAPTER II.-MAMMALS}

Life of mammals. Protective value of colour. Origin of colour. Hibernation. Store-rooms. Increased production or diminished peril of destruction. Why mammals do not multiply more. The play of animals. Explanation of play by rest and the accumulation of energy. Human play. Imitation in play. Explanation of instinct. Instinct and intelligence. Exercise of the mind in the games of children. Pleasure in play. Conscious self-deception, imagination. Play and art. The animal is at the threshold of art. Sense of freedom in play. Games of children. Attention. The use of curiosity. The mind of the animal and of man

\section{CHAPTER III.-BIRDS}

Sexual selection. Choice of females. Rejection of the hypothesis. Advance of the male's senses. Selection of the strongest suitor. Explanation of coyness and the animal coquette. Female selection inadmissible. The love-dance. Selection of the apparent strongest. Colours as means of distinguishing species. Use of sounds. Pairing-calls. Origin and forms of song. Instrumental music of the birds. Migration. Speed of 
flight. Do birds tire? The adaptations of the bird-body. Height of the migration-flight. Origin of migratory birds. Their strength, their power of presentiment. Routes of migrating birds. Their memory and sense of direction. Travelling in flocks

\section{CHAPTER IV.-Reptiles and AMphibia}

Principle of animal-classification. The general properties of animals explained by heredity and adaptation: Darwinian justification of classification. Reptiles and amphibia of former ages. Earlier periods of the earth. How and why the earth has changed up to the present. How the remains of earlier animals have been preserved. Gaps in the remains of extinct animals. Primitive man. Conflicts of extinct animals. Why the gigantic forms of earlier ages became extinct. The death of species. Transformation of species. Why ancient species have been preserved. Why there are still animals of the simplest type. Predominance of a species of animal. Predominance of man. Any variation is possible. Origin of flying animals. Life of our reptiles. Prey. The creeping of serpents. Regeneration, the power to re-form lost members. Its origin by natural selection. Frog-spawn. The skin of amphibia. Repellent and warning colours on nauseous and poisonous animals

\section{CHAPTER V.-Fishes}

Origin of terrestrial vertebrates and of lungs. Similarities in the structure of animals. Transformation of organs. Creation or evolution? Many animals are worse than others in this. Selection only creates what is necessary. Atrophy of useless organs. Rudimentary organs in man. Degeneration of organs by panmixis. Indifferent characteristics of animals. The differences between species are adaptations. Correlation. Animals that are beyond the range of selection, Qualities and quantities. Explanation of atrophied organs by economy of sustenance and negative selection. Impossible to explain many rudimentary organs. The biogenetic law. Gills in the human embryo. Predatory fishes. The rhodeus and the pond-muscle. Senses of fishes, their dangers. History of the eel and the salmon. Artificial selection of fishes 
CHAPTER VI.-TRAcheates

To the tracheates belong spiders and insects. How insects grow. Explanation of the metamorphoses of insects. Protective colouring on the wings of butterflies. The Lamarckian principle refuted by protective colours. Insects that resemble objects. Mimicry. Exhalation from male butterflies. Sexual selection. Origin of flowers due to insects. Parts of the insect's mouth. Refutation of the Lamarckian principle. The coat of insects cannot have arisen by use. Harmonious adaptations, co-adaptations. Co-adaptations that Lamarck cannot explain. Explanation of co-adaptations. Are instincts inherited habits? Instincts that can never be affected by the will. Spider's webs. Care of the young. Instincts that are only used once. Are mutilations inherited? Protective marks, mildew marks, foresight. Infection of embryo. Structure of the embryo. The inheritance of acquired characters is difficult to conceive. Untenability of the Lamarckian principle

\section{CHAPTER VIl.-Crabs and Molluscs}

Economy of nature. The chemical constituents of bodies. Chemical combinations. The elements. The albuminoids. Biogens as constituents of living matter. Vital phenomena and apparent death. Metabolism. Structure of the living substance. Plants the foundation of life. Order of sustenance in nature. Flesh-eating is more natural to the animal than plant-diet. Are all variations useful to animals? Value of selection. Origin of the shells of snails. Change of functions. Development of the crab. Why the embryonic development of an animal reproduces its racial history. Reconstruction of embryogenesis. Uncertainty of the biogenetic law. Parthenogenesis, the development of unfertilised eggs. Significance of the germ-cells. Significance of sexual reproduction. Amphimixis. Plural variations - . -

\section{CHAPTER VIII.-Worms and Coelenterata}

Genealogical tree of the animals. Descent of animals. Descent of man. Preservation of intermediate forms. The earthworm. Regeneration. Leeches. Parasitism. Origin of 
parasites from free animals. Organic changes in parasites. How parasites are conveyed. Exchange of hosts. Life of the chief parasites: Trichinæ, maw-worms, dochmius, tape-worms, etc. Danger of fins. Development of the liver-distoma. Friendships of animals. Symbioses

\section{CHAPTER IX.-PRotozoA}

The animal built up of cells. Principle of division of labour. The greater the division of labour, the higher the animal's organisation. Multicellular and unicellular animals. The protozoa, their form and reproduction. Structure of an animal in its development from the ovum onwards from rudimentary parts. Origin of the germ-cells. Outlines of a theory of heredity. Amphimixis of the protozoa. Origin of sexual reproduction. Formation of seed and ova. Continuity of the germ-cells. Are any animals immortal? Death is not common to all animals. Origin of death. Permanent and temporary life. Has life come from the stars? Origin of life on the earth, spontaneous generation. How it is to be conceived. The first development of living matter. Formation and significance of the cell-nucleus. Significance of the fundamental parts. Relation of the rudimentary parts in amphimixis. When life is extinguished -

Chapter X.-Extensions of the Principle of Selection ANd Other Involuntary Theories

Why there are numerous species to-day. Isolation facilitates the divergence of species. Modification of isolated animals. Movement and alteration of animals. Are species formed by isolation even without the aid of natural selection? Definite variations. Germinal selection. Changes in the nutrition of the embryo are the foundation of variations. Do useless organs disappear through germinal selection? Refutation of germinal selection. Effect of external influences as modifying principle. Orthogenesis. Rejection of same. The mutation-theory. Variations and mutations. Do variations proceed indefinitely? Is there a formative energy in organisms? Mechanicism and vitalism. How are the form and purposiveness of organisms explained? What is to be understood by chance. Absence of purpose in living things. The will to live, the instinct of selfpreservation 
Chapter XI.-The Mechanical Conception of

An attempt to refute the theory of evolution. Establishment of theories and investigation of details. Causes and effects. Infinity of same. Impotence of science. Infinite variety in the products of organs. The infinite diversity of the universe. Purpose. Mechanical and teleological causes. There is no end in the development of animals. Sexual selection, orthogenesis, and germinal selection are teleological. Purification of the theory of selection from teleological elements. There are no higher and lower animals. A high grade of organisation gives no more advantage to an animal than a lower. Natural selection is not an absolute principle of betterment. The scientific method of research. Infinite diversity of the universe. Comprehension of same by concepts. Abstraction of the universal. What a natural law is. Ultimate constituents of bodies. Comprehension of the world by ultimate elements. Mathematics. An ether without properties enables us to grasp the world. Does ether exist? Are psychic processes to be conceived corporeally? The methods of psychology. Consciousness. The world and the soul are only to be conceived as contents of consciousness. Transition from science to theory of

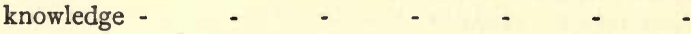

\section{CHAPTER XII.-NATURe, History, and Morality}

Truth of scientific ideas. Why the universal seems to us more essential than the individual. The ideas of animals. Why we take ideas for realities. Thinking realities into ideas. Is there a real world lying behind the phenomenal world? Natural science itself is a human product and pursues an aim. It must not regard itself as the only sound branch of science. The historical sciences. Their method. The historical elements in natural science. The laws justify historical research. The science of evolution rests on probabilities. The origin of the human mind. Had consciousness a beginning? There never were absolutely simple bodies. History and sociology. Origin and development of primitive man. Origin of good and evil. Origin of conscience. Advance of civilisation by tradition. Language. Conflicts of nations. Scientific 
ethics. Restricted and inverted selection in civilisation. The evils of war and militarism. Nietzsche's egoism. Darwinian ideas of the social future. Insipidity of the Darwinian ideal. Social man according to Nietzsche. Natural science knows no idea of duty. It knows nothing of values, and can therefore frame no ethic. Preservation of existence is not preservation of value. Is there a sense of life? Monism. Presuppositions of science. The idea of duty is the beginning of all knowledge. Conclusion

INDEX - 


\title{
DARWINISM AND THE PROBLEMS OF LIFE
}

\author{
CHAPTER I
}

\section{INTRODUCTION}

Animal-life in the forest, the field, and the pond. Variations of animals in different regions. Connection of animals in the same region. Over-production in nature. The relation of increase to the danger of destruction. The struggle for life. Artificial selection. Natural selection. Transformation of species. Different animals of former days as the parents of actual organisms. The theory of evolution. Its predictions. Variation and heredity. Useful and harmful animals. Modification of our animal-world through civilisation.

Wно has not visited the forest on a morning in Spring!

The tall stems of the trees stand out ruddily in the green dawn. The blue vault of heaven breaks through the tree-tops above. The dew-drops glisten like diamonds on the tender moss and the grass-blades; and iridescent prisms flash from the leaves of the shrubs. A mist lies on the glade, and covers with its veil the flowered-starred ground, while the tips of the young firs rise mysteriously from its depths.

Then the morning wind stirs the tops of the trees. A faint rustle passes through the wood. Here and 
there branches and stems give out mysterious creaks and groans.

Now the noises increase.

On the ground a slight stir catches the ear. It is a beetle hurrying by in search of his prey. He runs nimbly over the grass and among the bushes. $\mathrm{He}$ leaps over a scarlet snail, which draws in its antennæ in alarm, and passes swiftly down an ant-track. Before the industrious builders realise the injury done to their laborious construction, he has disappeared in the thicket.

A dreamy murmur fills the ear.

Flies without number are in the air. Their pellucid wings glitter in the rays of the sun, and they poise motionless, as if hanging by a thread. The whole atmosphere seems to vibrate with the tone of the harp. An infinite harmony swells the breast of the traveller.

At last the stillness is sharply rent.

Like the laughter of some spirit of the forest, the loud "gluck, gluck, gluck" of the wood-pecker echoes through the trees, and the ringing tap tells that his fellows are at their carpentering. The cry of the chaffinch resounds; from point after point comes the chirp of the wood-pigeon; and the titmouse utters without wearying its tender call.

Over the clearing is heard the cry of the bird of prey. The mist falls on the meadow. And yonder, where the thick bush marks off the forest from the flower-decked green, a slender deer emerges, lifts up its narrow head cautiously, looks all around, and then bends its neck towards the grass. 
When the sun is at its zenith, life is at its busiest in the field.

A hot fruitful vapour rises from the grass up into the blue air, which is filled with the trilling song of the lark. The ears of corn stand motionless in the dry air; only here and there a blade stirs and betrays the passage of some invisible inhabitant of the field.

But life is briskest in the field at the point where the flower-filled ditches, crowded with rich vegetation, are found. Here the bees and wasps hum from flower to flower: white, blue, and many-coloured butterflies dart about; and the ground swarms with running insects.

Beetles creep up the trunks of the willows that stand at the border, and their leaves are the pasturage of the insatiable caterpillar. On a branch of the tree sits the wood-lark, and begins his song. Then inspiration comes to him; he rises, and mounts to the sky, pouring out his song in triumph as he ascends. At last he spreads his wings, and with long-drawn notes sinks to earth once more.

Now evening approaches, and the rays of the sun fall almost level ; the frogs give forth their round song in the rush-bordered pond.

Here, again, is an entirely new picture.

The great dragon-flies dart rapidly over the water, and their dark-blue wings glint like fairy-eyes from the rushes. A crowd of gnats and May-flies dance above the surface. On it the whirligigs form their endless circles, like shining pearls ; and, like long-legged skaters, the water-ticks glide hither and thither. 
A red-bellied newt issues from the dark depths to get a mouthful of air, and, turning gracefully, sinks again. A large swimming beetle appears, and hangs with its hind part on the surface. The depth of the water is full of water-fleas, which rise up and down unceasingly like unnumbered points.

And when the sun sinks below the horizon, and darkness enfolds Nature in its thick veil, a new life awakens.

The call of the screech-owl resounds plaintively in the wood, bats fly about in the air, and a gentle rustle is heard in the grass.

Fear falls on the man who enters into the soul of the little night-walker, which must make its way in the dark, and must be ready at every step to be seized by some deadly unseen enemy. Never does the eternal carnage in Nature seem so merciless, so terrible, as in the night.

Each hour of the day has its own life.

In the forest, the field, or the pond the picture differs entirely in the morning, at midday, in the evening, and at night. If our path had led us into one of these three regions, as we call the various provinces of Nature, at another time of the day, we should have encountered different animals. Yet the animals of any one region are more closely related than those that live in different regions at any particular time of the day. Forest, field, and pond have their characteristic inhabitants, and outside these regions there is a whole series of others. 
If we examine the brush instead of the open wood we meet animals just as interesting and characteristic; and instead of the field we might have taken the meadow, the moor, or the quarry.

So the life of the pond differs entirely from the life of the brook and the great river. Nay, we might even confine ourselves to the tiniest compass, and examine only a drop of water hanging from the moss. We should find that even in this little realm there are hunters and hunted, and that countless living things find the conditions of their life within these narrow limits.

Every animal seeks what it needs for its maintenance, if not exclusively, at all events mainly, in the particular region in which it lives. The wood-pecker will not leave the wood, for this alone provides him with food in its trees and a sure place for nesting; nor are river-fishes ever found in ponds.

But all animals are not confined to one region. The deer leaves the thicket in the evening to feed in the green meadows; the partridge seeks cover at times in the wood; the water-beetle of the pond may alight in running water in its nocturnal flight.

Other animals have a different habitation at different periods of life.

The young frogs swim about merrily in the water, and resemble fishes in appearance and habits. Afterwards the long oar-like tail is lost, the feet sprout out, and the frog assumes the form of a land-animal. It lurks for flies at the edge of the pond, and only leaps into its earlier element on the approach of danger. 
But Nature may go yet further. It may make the habitation of the young animals fatal to them as adults.

Many insects pass their youth in the water in the form of larvæ, but after their last cast of skin they unfold pairs of wings, and become inhabitants of the air and land. And if any mischance brings them back into their former element, they are doomed, unless a friendly grass-stalk provides the means of safety. May-flies, dragon-flies, gnats, and many others are thus adapted to two regions.

Each region, therefore, is filled with a number of forms of life. These do not live independently, however, but are adjusted to each other. We know, in fact, that if water-fleas are plentiful in a piece of water, the condition of the fishes will be so much better, because they form almost the entire food of the young fishes. We must not forget, moreover, that the plants in any region are important to the animals contained in it. This becomes clear at once when we reflect that it is they that form the nourishment of the plant-eating animals; and that they also provide more or less shelter for the animals, and especially their young, and so cannot be dispensed with.

Thus each region is a self-contained whole, in which plants and animals live in mutual relationship, and the diminishing of one species always reacts on another. But the foundation of all animal-life is found in the soil, the distribution of water and land, light and air, and the climate and other factors that we may call the physical conditions of the place. The totality of animals and plants that live under these conditions and are 
dependent on them and on each other, may be called the "life-commonwealth," or bioccenosis." Thus there are "biocœnoses" of the pond, the river, the wood, and so on; and also biocœnoses of a higher order, such as the fauna-that is to say, the animal-life-of an entire country.

We need only consider any single animal in a biocœnosis to see at once how it is really a member of a community. Let us, for instance, examine the life of the fox. For this purpose we must learn how that crafty thief obtains his prey. But this implies further that we cast a glance at the life of the animals he preys on; we must consider the speed of the mice in order to appreciate the leap of the pursuing fox; we must know something about the hearing of the hare, to understand how reynard can creep up to his victim without being perceived. There is an old illustration ${ }^{2}$ of the interesting mutual relations of fox and hare, which shows very well how two species react on each other in their condition. If we suppose that the hares increase in any region that contains only these two kinds of animals, the result will be that the foxes will multiply in the same district, because the abundance of food will make them stronger, and able to rear a larger number of young. But the increase in the number of foxes will require an increase in the quantity of food; the hares will be less able to escape from

1 This term was first used by Möbius, of Berlin, and was afterwards extended and modified by Hensen and Dahl. Hensen insisted on the statistical method as most important in the study of biocœnoses, so as to discriminate between the normal and the accidental.

2 The instance is taken from Darwin. 
their numerous enemies, and will be decimated. When the foxes find less to eat, they will decrease again, and give more chance to the hares, and thus the balance of vital advantage will oscillate between the two species. This will bring about in time an unstable equilibrium : that is to say, the number of the two species will be constantly rising or falling a little above or below a certain level, but will remain at the steady average.

In reality the situation is rather more complicated, as the fox does not live on hares only, and the hare has other enemies besides the fox. But the fact remains that there is this correlation between the animals of a certain region; and it must be so, otherwise a species would increase indefinitely.

Let us suppose that a couple of foxes were left to multiply in peace. As a rule the fox has four or five young ones, and this for several years in succession. But we will take a case in which a couple bring six young ones into the world once for all; and suppose that three of these are male and three female, and that these three couples have each six young in the following year, so that there are then nine pairs, and so on. In ten years the number of foxes would have grown to 118,098 , and this number would be much greater if each couple cast young more than once, as is the case in real life.

As a rule, however, the animal population of a district remains constant, apart from the interference of extraordinary agencies. If, therefore, each of the couples of foxes in a given wood have five young every year, and this for seven years, or thirty-five in all, it follows that, if the number of foxes is to remain steady, 
thirty-three must die, and only two remain to replace the parents.

It is just the same with all animals and plants. Everywhere there are far more born into the world than can be supported. Take an apple-tree in blossom. If a fresh tree were born of every flower, there would soon be nothing but apple-trees on the earth. But besides the fruit-trees there are myriads of other plants, and each of these has an immense progeny. The earth is not large enough to hold this vast wealth; every corner of it is already occupied. Thus it is clear that over-production in Nature creates an infinity of life only to destroy it.

We may, of course, admire the "inexhaustible riches" of Nature, but on the other hand we must shudder at the tragedy of millions and millions of living things coming into the world only to die, because there is no room for them. However, they all have an unconquerable lust for life, and are impelled by it to fight with all their strength for space with those that already occupy it. Thus there is bound to be an endless strife in Nature. It is the "wealth of Nature" that occasions the pitiless, ghastly, despairing struggle, and converts the earth into a reeking battle-field.

However, we will not regard Nature, so cold and pitiless, with the warm feeling of a human heart. We will seek to detect the causes that lie at the bottom of the facts.

Darwin explained to us the over-production of Nature, by showing how large the posterity of this or that living thing would be. All animals by no means increase at 
the same rate. While the fox has, on the average, four or five young in a year, the hare has eight to ten young yearly, in about five casts, and the mouse as many as thirty. These figures are far surpassed by the fishes; the carp, for instance, discharges 3,700,000 eggs. But the highest number is found in intestinal worms. We learn with astonishment that the maw-worm produces $64,000,000$, and the tape-worm 100,000,000, eggs.

If we now cast a glance at the life of these animals, we find that their fertility is directly related to their peril. The fox has few enemies, the hare incomparably more, and the mouse is, so to say, the piece de résistance of all our flesh-eating animals and birds. The eggs of fishes are much relished as food by many aquatic animals, and the sluggish, defenceless carp only too often falls a victim to the predatory fishes. Much nimbler is the trout, which has also less enemies to fear in its stream, and so only produces 600 eggs a year.

But there are other agencies besides enemies that decimate a species. The young foxes pass their early days in a warm and sheltering structure; much worse is the lot of the hares, which are laid on the bare ground, so that the first arrivals, in the middle of March, nearly always perish; and the ova of fishes are exposed to all kinds of accidents, as they are very easily washed away or dried up. Remember, too, the difficulties that the egg of the cattle tape-worm encounters before it can become itself a sexually mature animal! First it has to be ejected in the human fæces, and then it must be licked up by a cow, in the 
bowels of which it develops into a young animal. This passes into the muscles, and buries itself therein. Then the cow must be killed, and its flesh be eaten by a human being, for it is only in the human intestines that the tiny creature will grow into the adult tapeworm. We can easily see that the tape-worm would soon become extinct if it were less fruitful.

We might go through the whole series of animals, and we should find in every species a confirmation of the fact that every animal's fertility is proportionate to its perils. We may add that it is also proportionate to the food and space provided for it, since it is clear that, if foxes multiplied as mice do, they would soon consume all the animal food in their environment, and would be doomed themselves; whereas vegetarian animals, for instance, would find a far more abundant diet. It is also obvious that animals with a limited habitat must have a low degree of fertility, otherwise they deprive themselves of food, light, and space, and court destruction.

We shall explain at a later stage the fact that each species produces, on the average, just as many young as is necessary for its maintenance, and that, therefore, its production increases in proportion to the dangers it encounters. Here we need only observe that every animal has in itself the power of multiplying indefinitely. Thus is brought about the struggle for life, the unceasing fight for food, space, and light.

This struggle only affects the number of organisms. It restrains each species within the limits that are set to its expansion. But there is another struggle for 
life, the more important one which Darwin immortalised his name by discovering. It takes place between members of the same species, and consists less in an active conflict with a recognised enemy than in an unconscious effort at self-maintenance. In this struggle the best equipped is the victor. Hence Herbert Spencer's phrase, "the survival of the fittest," is preferable to "the struggle for life."

When the foxes in a particular locality are especially menacing to the hares, the first of the latter to be eaten are those that are slower than their companions, or less able to perceive their enemies in time owing to defective hearing or smell. The better equipped hares survive longer, and so are able to bring a more numerous progeny into the world. But since, as we know, the parents transmit their qualities to their offspring, the new generation of hares will be equally conspicuous for speed and sharp senses, if it comes entirely from the finer hares. If there are amongst the new-comers animals that fall considerably below the average, they will be the first victims to the foxes, and leave no offspring. However, this does not go on until all the hares are so equipped that no fox can master them. Among the foxes themselves it is always the individuals that can catch the improved hares that survive, secure the most food, and so leave a larger progeny. Thus the sluggards gradually die out amongst the foxes as well, and only those survive that can capture the quicker hares. This must be met by a new selection among the hares, only those surviving and reproducing that are better equipped 
than their parents; and thus we get a further advance of the good qualities of the hare, which grows on and on, without end, because there is a corresponding advance in the animals that have caused the improvement-in this case, the foxes. Darwin has shown from the example of "artificial selection"-selection by the hand of man-that such an improvement in the characteristics of an animal can probably be brought about by " natural selection."

Breeders have succeeded, not only in increasing those characteristics of domestic animals which they wish to accentuate, but even in producing new ones, and so in converting an animal gradually into one of a quite different appearance. When we look at the races of pigeons to-day, it is easy to believe that we have before us quite different and independently originating species. As a fact, some races of pigeons differ from each other more than the pine-marten from the stone-marten. What a difference there is in the various parts of the body between pigeons! The beak of the turbit, for instance, is hardly visible, while the " carrier" has a long beak with the most curious growth hanging from it. In many kinds the feet are clothed with very thick plumage, in others they are quite bare. And then there are the infinite diversities of colouring!

We find just the same if we take other illustrations. Look at the difference between a pug and a greyhound, or an English race-horse and a Belgian draught-horse! It is the same with cattle and pigs. In every case we find races that differ most profoundly from each other. 
Now, all these different races are not originally independent. It is man who has taken a few primitive types and changed them by selection. In the case of the pigeon it is certain that all the various races descend from one primitive form, the rock pigeon, which is distinguished by black bands on the wings. We see how these modifications can be brought about in the actions of breeders, who are always bringing out new races. They do not accomplish this by crossing; no new characteristics can be produced in that way, but only the existing ones mixed and distributed. Breeders act otherwise. They select from the offspring of a couple the animal that shows a slight trace of the feature that they wish to produce. Thus, if they desire to create a race of dogs with long legs (and there are prizes offered by breeding societies for such objects), they choose one pup from the litter that has longer legs than its brothers and sisters. This is paired with a dog from another litter with specially long legs, and the same selection is made again amongst their pups. This is continued until they get a race of dogs with legs of the required length. The object is attained by the accumulation of insignificantly small variations.

According to Darwin, Nature acts in this way, only on a higher scale. It selects, not only in the interest of one characteristic, but of a number simultaneously. So in the case of the hares, to return to our illustration, it is not merely a question of making them swifter than their enemies, but also of furnishing them with sharp senses, and a higher intelligence to use in choosing places of security. Finally, they must have no con- 
spicuous shade of colour, otherwise the animals would show themselves against the grey soil, and would be more easily found and captured.

All these characteristics of the hare are continually improved by natural selection, as only those can escape their enemies that are best qualified to do so. But as their enemies also are subjected to an improving selection, higher qualifications will be required in the next generation, and so on. In other words, the hares will advance in each generation. It is true that we do not directly observe this progress, but that is only because our life is too short to appreciate the changes brought about by natural selection, which require long periods of time. Natural selection cannot act with the same intensity as artificial selection. In the case of the hare, for instance, not only two or three of the swiftest survive, but a large number, and amongst these many slow ones that have managed to escape destruction by a favourable accident. It is only on the average that the speediest survive, and, in fact, when we take an average of many years, so that it will be thousands of years before any appreciable result can be seen. We do not see the grass growing, but we can prove that it is longer to-day than it was yesterday. So, if we could raise from the dead a man who had seen a hare thousands of years ago, he would find a difference in the hare of to-day. In point of fact, the skeletons of animals belonging to earlier ages prove that they were different then from what they are in our time.

But we should greatly underrate the power of natural selection if we attributed to it only the capacity to 
increase already existing characteristics. Just as artificial selection can produce white pigeons from birds of a grey-blue colour, by choosing in each generation the specimens with the largest number of white spots in their plumage, so natural selection can endow animals with entirely new features. Thus, for instance, our hare is not easy to distinguish from the ground on which it browses because of its grey colour-which is a mixture of brown, yellow, white, and black. ${ }^{1}$ Now let us suppose that a glacial period came over England again, as has happened twice in the history of the earth. The dark-coloured hares would then easily meet the eyes of their enemies on the white snow, but there would be varieties with a rather stronger mixture of white in their colouring. These would be least easily seen, would survive the longest, and bring most young into the world; so that the next generation would in itself be of a lighter shade. Amongst these, again, the lightest would survive best, and this would be repeated in each generation until a pure white coat was produced, as is found in the Arctic hare. We must not forget, of course, that such a modification of colour could only take place if the cold set in gradually, and implied above all the coming of longer and more snowy winters. Natural selection is powerless in face of sudden changes, as it can only modify things gradually. Further, selection only acts generally; every animal does not survive that is modified in the desired direction. But that the modification can, generally speaking, advance

I As mentioned in Weismann's "The Evolution Theory." [English Translation.] 
in this way is due to the fact that the material to select from is inexhaustible, and that immense periods of time are available for the process of transformation.

We see, therefore, that the changes that are brought about by natural selection, through the emphasising of insignificant characteristics, may become very striking. The external difference between grey and white hares is very considerable. It is true that one might claim the white hares to be a variety of the grey ones, and say that the difference between the two forms is not as great as between the hare and the next species, the rabbit. But is there any difference between a "variety" and a "species"? Many writers understand by "varieties" animals with somewhat different features from those of the mother-species, but say that these characteristics vacillate, and are not preserved in the course of generations-are not constant, as the phrase is. We see that this test of the variety does not hold good in the case of our white hares; the whiteness is constant, because all reversions are destroyed. And when it is said that the variety can always pair with the mother-species and produce fruitful offspring, which cannot take place between two different species, the statement is not entirely correct. Many species can be coupled, and beget young that are capable of reproducing. This is the case, for instance, with the wolf and the dog, the carp and the crucian, and other animals, which everybody recognises as distinct species.

We can safely affirm to-day that there are no rigid tests for determining whether certain types of animals are species or only varieties; in other words, there 
is no sharp distinction between a species and a variety.

This modern discovery has thoroughly shaken the old Linnean principle: "There are as many species as there were distinct forms created." We now know that species are changeable, and have actually changed; that one species may be formed from another. The question is often raised, in the form of an objection, why no species has been changed within our experience; in fact, it is urged that history shows the forms of animals and plants to be just the same as they were 6,000 years ago, since the ancient Egyptians depicted lions and other animals just as we have them to-day. The objection seems to have some strength, but we know of several cases in which species have been so much modified within the historical period that they can no longer be crossed with their earlier relatives.

In the year 1419 rabbits were introduced on the isle of Porto Santo, near Madeira, and increased until they became a plague of the country. But the descendants have become very unlike their ancestors, and differ from them in their peculiar colour, rat-like shape, small size, nocturnal habits, and extraordinary savageness. But the most remarkable point is that they can no longer be crossed with the European rabbit, and have, therefore, formed a new species in this comparatively brief space of time. ${ }^{1}$

However, this was an exceptional case. The

1 The facts are related by Ernst Haeckel, who gave the Porto Santo rabbit the name of Lepus Huxleyi. 
conversion of one species into another usually requires a longer period than the whole of human history, the 6,000 years of which are only an hour in comparison with the immense duration of the history of the earth. We saw above that it takes a long time for grey hares to become white; and we know from geology that, as a matter of fact, all the terrestial epochs comprise enormous periods of time. The latest of them, the tertiary period, is calculated at several hundred thousand years. Geology also gives us the best idea of the mutability of species, as we find at the bottom of the sea the remains of animals of remote ages, which are totally different from the animals of our time. Geologists can distribute the various strata of the earth's crust in their chronological succession. These strata are the pages of a book that it has taken millions and millions of years to write. Nowhere in it do we find the animals of our own time, or at all events only in the very latest periods of the earth's history; and the later the remains of extinct animals are, from the geological point of view, the closer do they come to the living fauna. It seems clear, therefore, that the animals of modern times were not present at the first creation of life, but only came into existence at a later date, and succeeded other animals in the dominion of the earth. But whence did they come so suddenly, if they were not evolved from other animals? Every animal lies in the body of another before birth, in the form of an egg or ovum. But, clearly, before our animals appeared there were only forms of a different character ; 
and therefore we may safely conclude that they have been evolved from these, and that in the course of generations the children have diverged more and more from their parents.

If we go further back in the story of the earth's growth, we find that each period of geology has its characteristic animals, which must be the parents of the later and the offspring of the earlier forms. When, moreover, we pass in review before the eye of the mind the animals of the succeeding epochs, we notice something else besides the unceasing changes of form. The older the period we take, the simpler we find the shapes of living things; and the nearer the period approaches to our own time, the more intricate and the higher is the organisation. In the earlier periods, for instance, we find only the lowest forms of vertebrates, and these only very sparingly. Gradually, the number of species increases. Lizards, birds, and mammals appear; and amongst these the higher species come in succession, the carnivores, the apes, and, finally, at the last moment from the geological point of view, we find unmistakable proofs of man's existence and activity.

Hence geology drives us to the conclusion that the animals of our time descend from simpler forms, these from yet simpler ones, and so on, so that only the very simplest organisms can have arisen at the first creation of living things. There was, for instance, a time when only the very lowest types of vertebrates, the fishes, were present on the earth; and while a good many of these fishes were modified in the following epochs 
without going outside the range of the fish-class, others were so appreciably changed as to become salamanders. Geology shows, in fact, that at a certain period salamanders were the only vertebrates on the earth beside the fishes. We do not find these at the earlier stages ; they can only have been evolved from the fishes, as these are the nearest to them of all the animals that lived at the time, and the structure of the salamander approaches so closely to that of the fish that we can conceive the period as sufficient for the transformationa transformation which is far less considerable than the conversion of a worm into a salamander.

From these salamanders the actual salamanders and frogs must have descended on the one hand, and the reptiles, leading on to the birds and mammals, on the other. We may form a picture of the transformation of animals with the figure of the tree. At a certain period a side-branch, the fishes, grew out of the trunk; the branch grew on, and put forth another side-branch, the salamanders, which in turn sent out branches. Thus we can compare the growth of the organic world with the growth of a tree. At first there was a single trunk, the simplest organisms. Branches grew out from the trunk, and in turn produced twigs, until a mighty tree arose with many branches and innumerable twigs.

The view that the animal kingdom was developed in this way from the simplest forms is called "the theory of evolution." 1 It is now generally accepted; there are

1 Also the theory of descent, or transformism. We must carefully distinguish between : I, the statement that living organisms have been developed from other forms, and 2, the theory as to how they were developed, and by what forces. The first is the theory of evolution, the 
few zoological and botanical works written to-day that do not rest on or presuppose this theory. An immense amount of proof in favour of it has been accumulated. Many predictions that were made on the strength of it have been realised by recent research, and prophecies of this kind are, when they are fulfilled, the very best proof of the correctness of the principles they are grounded on.

If, for instance, the birds were evolved from the reptiles, there must have been at a certain stage, since the tranformation was gradual, an animal intermediate between the reptile and the bird-an animal that was really a bird, but still retained unchanged many of the

second the theory of selection; but there are a number of other theories with regard to the mode and agencies of development. These will be given later on. Hence those who accept the theory of evolution are not at all compelled to subscribe to the theory of selection; in fact, there are many evolutionists who reject it. This will be quite clear if we remember that even in the Bible evolution is, in a certain sense, laid down as fact. It is stated in the Mosaic books that all the actual races of men, with their great differences in the colour of the skin, etc., descend from one couple. Hence theologians have seen of late that it is not advisable to reject evolution altogether. In particular, a Jesuit writer, Father Erich Wasmann, one of the first authorities on ants, has accepted the general theory of evolution in his work: "Modern Biology and Evolution." $\mathrm{He}$ holds that in the beginning God created a number of species at all stages of organisation, including man. But these species have not remained unchanged. They were endowed by the Creator with the capacity and the means of evolution. Thus we have an attempt to combine an acceptance of evolution with a belief in the verbal inspiration of Scripture. It is not likely to satisfy the man who seeks thoroughly to understand the world.

The theory of evolution was formulated before Darwin; the theory of selection was created by him. But the theory of evolution itself owed its great advance to Darwin's book, chiefly because he provided the explanatory hypothesis of selection. Hence it is not improper to include both theories under the title "Darwinism." 
characteristics of the reptile. Now, we have found two well - preserved skeletons of a reptile-bird of this character. This "archæopteryx" has the distinctive feathers, beak, pelvis, and feet of the bird, and at the same time an articulated lizard-like tail, teeth, and wellformed toes on its fore-feet, which project far out from the wing and are not found in any actual bird, but only in the reptiles.

A second example:

Our horse has only one toe, and on this the hoof is placed. The other mammals, even the lower ones, from which it must have evolved, have several toes; and thus there must have been at a certain stage horses that had at least rudimentary traces of the other toes, besides the developed one.

As a matter of fact, we have discovered four-toed horses in the geological strata. Indeed, we have brought to light in the successive strata skeletons of horses that illustrate every stage of transition from the ancient four-toed to the modern one-toed horse; and the nearer the remains approach to our own time, the less trace do we find of the other three toes.

We could quote a large number of transitional forms from geology, but will be content with these. Let us recall to the reader the way in which we arrived at our theory of evolution. We sought to show that natural selection can transform one species into another, and we found that such a process has been going on uninterruptedly in geology. The question arises, therefore: Is it natural selection that thus brought about all these transformations? Is this the artist that has produced 
the whole of our living organisms from the simplest forms?

We may at once say that we answer in the affirmative, and that we will justify our answer in the following chapters. We shall even go further, and endeavour to prove that natural selection is the sole principle to be used in explaining the evolution of living things. There are other theories in regard to the transforming agencies in the organic world, and one of the chief of these theories was expounded by Lamarck before Darwin's time, and accepted by Darwin himself. This theory affirms that external influences, such as cold or heat, have a modifying action on a species of animals, and that the modification they produce may be transmitted to offspring. It further affirms that an organ may be strengthened by exercise, and that this improvement in the organ is handed on to offspring, and thus by continued use a change of the organ may be brought about. According to Lamarck, these factors may go so far as to produce new species.

For the moment we will refrain from testing the correctness of this hypothesis, and will return to the general starting-point that led us to consider natural selection and the theory of evolution. But first of all let us put more clearly and succinctly what we have seen as to the changes of species by natural selection.

Natural selection demands two general conditions for exerting its influence. In the first place, the offspring of a parental couple must differ in some degree from each other, or there must be variations; in the second place, the characteristics of the parents must be trans- 
missible to their offspring by heredity. But both these are facts that no one can call into question, as they come before us every day. We see daily how brothers and sisters differ from each other, and at the same time how many peculiarities of the father and mother are handed on to their children. These two factors are the chief means by which natural selection works, producing one species from another. We have seen above the way in which it does this.

Let us recall the process. Every species is found to be over-productive in reproducing itself; that is to say, it brings into the world a larger progeny than there is room for. A great number of these, therefore, must fall victims to unfavourable conditions or to enemies, and these will be-as a general rule, and apart from accident - precisely the least endowed in body and intelligence. In other words, those animals will survive longest and reproduce most which are in every respect -as to inclement weather, enemies, and so on-the best able to resist. Thus the fittest among the varieties that casually arise will be preserved, and their useful characters will be accentuated in the course of many generations, since each new generation over-produces in turn, and natural selection again chooses the best to survive. If the new characters are connected by intermediate forms with those of the parental species, which may have adapted itself to the struggle for life in the original form in some sheltered locality, we may still speak of varieties. If the intermediate forms have died off-and that will quickly follow - it is clear that animals with completely distinct characters will be left, instead of 
animals in which neither the old nor the new features were quite distinct; that is to say, we have now to deal with two species. The differences between them may become so great in the course of time that crossing the two may give sterile offspring, or be altogether impossible. Thus we see that varieties are species in the making; species are varieties that have become fixed.

We know now what natural selection is. The best equipped animals escape the longest from destruction by enemies or from other injury. They are thus enabled to leave most offspring, and the next generation shows an average improvement.

Now let us return to the biocœnoses.

We examined life in a particular region, and concluded that the number of animals in it varies somewhat, but remains about the same on the average. In this we assumed that the locality retains its natural condition, and that, especially, man does not intervene with his artificial culture. It will be quite otherwise if civilisation comes on the scene; then the impenetrable forests will give place to fruitful fields, and boats will shoot up and down the river that flows by. This transformation of Nature must naturally lead to a change in the fauna; and the question arises to what extent this will be modified, and whether man, for instance, can extinguish, with his improved methods of hunting and his instruments of destruction, the animals that are harmful to him and increase those that are useful, in the forests which he leaves standing.

We have to inquire first, therefore, which animals 
are harmful and which useful to man, and, however strange it may seem, this question is very far from being entirely settled. We do not regard the matter from the point of view of the hunter, who takes everything to be harmful that menaces his safety, even if it is a question of animals which are most useful in every other respect. By harmful we mean only what is really injurious to civilisation, or that restricts man's eftorts, while guarding ourselves against too narrow a view. Game, for instance, does a lot of harm in the field and the wood, but compensates us so richly with its flesh that we readily overlook the mischief it does in the corn or on the trees. The field-mouse is always mischievous, and its enemies are useful to us. The chief of these are the owls, which live almost entirely on mice. But we might go further, and regard almost all our birds of prey, except, perhaps, the hawk and sparrow-hawk, as useful on account of their destruction of mice.

We can determine the food of birds of prey with some confidence, but it is not so easy in the case of the insectivorous birds. It is among insects that we find the chief enemies of culture. There are the typographerbeetle and the caterpillar of the processionary butterfly, the pine lappet-moth and the black-arches-all injurious in the wood-the swarm of grass-hoppers, and especially the dreaded migratory locust that so often ravages the fields. The cockchafer is equally injurious in its adult state and when it is a young grub; and whoever has been in a wine-country knows what it means for the dreaded phylloxera to get into the vineyards. But it 
would be a mistake to imagine that every insectivorous bird is useful. We have a large number of useful insects. I need only mention the bee and the silk-worm, and the insects that do us a service by destroying their neighbours. Many a caterpillar succumbs to the large running beetle, many a plant-louse is eaten up by the larvæ of the lady-bird, and it has been observed that trees visited by ants do not suffer from caterpillar-blight. But it is especially the ichneumon-flies, slender animals with long antennæ, darting constantly here and there, that protect us from this blight. These insects have what is called an "ovipositor" on the hind part of the body, with which they stab the caterpillar, and deposit their eggs inside it. The larvæ of the flies develop from the eggs in the flesh of their unfortunate host, and gradually feed on its body from within. The process goes on for a long time, the caterpillar continuing to live and eat, and it is only when it reaches the chrysalis stage that the larvæ creep out, and enter on that stage themselves near, or on, the dead covering of their former host. Many a butterfly-collector has been disagreeably surprised when he caught an apparently sound caterpillar of a cabbage-butterfly in his cage, and found one day an empty shell instead of the expected chrysalis, with the yellow, oval cocoons of the deadly enemy of the caterpillar beside it.

The ichneumon-wasp is so thorough in its activity that it must be put higher than the birds as a destroyer of caterpillars. We must not, for instance, have too great an idea of the work of the cuckoo, which was formerly regarded as the chief agent of destruction of the 
processionary caterpillars, that not only destroy whole forests of oak, but also cause violent inflammation on the human skin by their hairs. It has been proved that most of the caterpillars eaten by the cuckoo were already stabbed by ichneumon-flies. Thus they were already full of larvæ, which would have attacked caterpillars in turn after they had crept out. These were destroyed by the cuckoo; and, as they would have proved the most effective restriction on the plague of caterpillars, we should regard the cuckoo rather as a harmful than a useful bird.

What do we find in the case of other insectivorous birds?

Unfortunately, we have to class many of them as mischievous which were generally regarded as useful. The redstart only too often visits the hive for the purpose of filling its stomach with the useful honeybearers. The fly-catcher destroys the caterpillar-flies -the bitter enemies, as the name indicates, of the caterpillar. The kingfisher, of which anglers complain so bitterly, feeds mainly on water-boatmen, the stinging water-bugs that are very dangerous to the young fishes; it ought, therefore, in this respect to be considered useful.

But we need not delay any longer in determining which animals are useful and which mischievous. I believe that the harm done by the higher animals, especially mammals and birds, is never serious enough to justify us in making every effort to destroy them. We have seen that in a biocœnosis all animals are related to each other, and that the multiplication of one 
species leads to an increase in the number of its enemies. Moreover, it often happens that a disproportionate spread of any particular species carries its own corrective with it; the animals show symptoms of disease, and die off suddenly as if by magic. This was seen, for instance, during the great plague of mice on the Rhine in the twenties; and the plague of blackarches at the beginning of the nineties also came to a sudden stop.

It is true that the injury already done by these swarms of pests is so great that men are not disposed to wait for the end, but make every effort to check their progress. But it is otherwise with animals which cannot multiply in this extraordinary way. These should be spared, I think, even if they do a little damage here and there.

Just as we protect singing birds for their song, we should also try to preserve animals that afford pleasure to the eye. We ought to forgive the squirrel his taste for bird's eggs, or even for the callow young, for we should greatly miss this graceful animal, the ape of our forests, if he ceased to enliven our trees. What does it really matter if the kingfisher does destroy a few fishes a day-and generally fishes that are no use to us! $\mathrm{He}$ makes up for that by his beautiful appearance. How sad it would be if we were to lose for ever the unforgettable moments that come to the solitary dreamer by the stream when he catches sight of this bird with its plumage of jewels! What an impiety to shoot a stork because he has stolen a young hare! When we were children the stork was almost a sacred bird to us with his inexhaustible poetry. Let us leave him such to 
our own children. How fine it is to watch him in his splendid flight !

This "American" habit of looking only to the useful is odious, and unworthy of a poetic and imaginative race. We regard with pleasure the re-birth of the historical sense the increasing regard for monuments of former days. Let us take care, then, to preserve the animals that are as much connected with the poetry and feeling of our race as historical reminiscences.

We may now ask how it is that man is able to extinguish whole species of animals, a thing which no other animal can do?

It is not so much by powder and shot, not so much by snaring and poisoning, as by the changes he makes in the country. In spite of all snares the number of foxes increases steadily in the Black Forest, because it is impossible to dig up their homes in the rocks. The field-mouse has not diminished in spite of all attacks; neither has the lark, though the Italians bring them down in swarms.

It is civilisation alone that changes the fauna of a country. If our forests were not cleared, and our marshes not dried up, the dry branches would still snap under the tread of the bison and the elk, and the wolf would still threaten the flocks. Modern forestry is slowly but surely destroying the wealth of bird-life, as the thinning of the trees and the brush deprives the birds of their nesting-places. It is not cats, or weasels, or foxes, but the disappearance of the thick bushes, that is robbing us of the song of the nightingale. This has been recognised of late 
years, and efforts have been made to plant thickets alongside the railway on some of the less converted estates. In connection with one of these experiments in Thuringia nests have been found on an average every thirty yards, which is a decided success when we consider the dislike of the birds for new plantations. However, the times will not wait; cultivated land is changing its appearance more and more, and our old friends are disappearing. Few of them can adapt themselves to the new conditions, like the black-bird, which is gradually becoming a town-bird, and now pours out its song from the roof of a house or even the chimney of a factory, instead of from the top of a rain-dewed tree.

Other birds are not deprived of their nesting places in the advance of civilisation; some, in fact, find them in greater abundance. The chaffinch, which nests on trees, is never at a loss for a spot, and we hear its jubilant cry the most frequently of all. The spread of the fields gives more room for nesting to the lark, which is also on the increase. This is an excellent proof of the correctness of what I said, since its nest lies in the ground, exposed to innumerable enemies.

But most birds, especially our best singers, breed in the bush, and they are steadily diminishing owing to the destruction of their nesting-places. And the same is happening to the fishes.

The rivers are controlled, and the standing waters, in which the inhabitants like to lay their spawn, are disappearing. The Rhine-salmon comes less and less frequently up-stream, and if it were not for the partial 
remedy of artificial breeding-places, it would have vanished from our tables long ago. The Thames has long been deserted.

We can understand now how it is that civilisation acts in this way on animal-life. We saw, in considering regions and biocœnoses, that physical conditions form the essential foundation of an animal-world. But these are altered by civilisation, and thus we realise once more how fundamental the idea of biocœnosis is.

What can we do in face of this increasing devastation of the country?

Is a time coming when our forests will again have luxuriant under-wood, in spite of the reduction in the output of timber? Possibly. But it seems more likely that civilisation will crush Nature under its iron feet; that the days are approaching when the nightingale and the robin will be legendary shapes in a remote past. Perhaps in those days there will be a race on the earth that will tell, with a pitying smile, how there were once human beings whose heart was more stirred by the song of an unseen bird than by the music of artificial automata. 


\title{
CHAPTER II
}

\author{
MAMMALS
}

Life of mammals. Protective value of colour. Origin of colour. Hibernation. Store-rooms. Increased production or diminished peril of destruction. Why mammals do not multiply more. The play of animals. Explanation of play by rest and the accumulation of energy. Human play. Imitation in play. Explanation of instinct. Instinct and intelligence. Exercise of the mind in the games of children. Pleasure in play. Conscious self-deception, imagination. Play and art. The animal is at the threshold of art. Sense of freedom in play. Games of children. Attention. The use of curiosity. The mind of the animal and of man.

Every friend of Nature, everyone who is acquainted with the life of the forest and the field, knows that there are not too many mammals that now meet the eye of the traveller.

Many a time during a walk through the wood do we see something hopping about here and there, and find on drawing nearer that a squirrel is hurrying with nimble springs to the nearest tree, and climbing up it on the side furthest away from us. Now and again we discover a hedgehog in his leafy hiding-place, or stand by a pond to watch the antics of the water-shrew or the water-rat. If fortune favours us, and we keep quite still, we may see the field-mouse hurrying over the stubble 
It is still better in the evening. Then the lover of Nature takes his place at the edge of the wood with a telescope or glass. There is a rustle in the bush, and a hare springs swiftly into the meadow, looks round, and, if all is quiet, hops farther on. A louder rustle, and deer come slowly out, to enjoy the succulent green or to regale themselves on the toothsome pasture of the nearest clover-field.

But the attentive observer learns a good deal about animals without seeing them. Here the bark stripped from a slender twig in the thicket betrays the proximity of a strong buck; there he notices the much-trodden haunt of the slender deer. On all sides he sees indications of the presence of plenty of mammals; in the winter, especially, he reads whole stories in the footsteps that stand out in the snow.

Over a broad snow-sheet runs the trace of a hare. It can be seen for a long way in an ever curving line. Then it is joined by the track of a second hare, though the two are distinct. Now there is a trodden spot in the snow that catches the eye with its drops of blood and scattered wool ; it is the wooing or bucking-place of the long-eared game. We look again, and see other steps approaching; a fox has crept up to the timid animals. Now there is a deep pit in the disordered snow, its pure white flecked with blood. Reynard's stratagem has succeeded. He has got his dinner.

The life of all our mammals is surrounded by constant dangers. Some of them, in particular, have been subjected to so sharp a selection by the unceasing peril that only the finest can survive the struggle. Thus, 
for instance, the wolf has become so cautious that he often escapes from the most careful traps. The endless attacks upon this dreaded robber have left only particularly cunning specimens in existence.

As a general rule the day's work of our mammals is very monotonous. Brehm has compared it, in his striking way, with that of the birds. The mammals are, he says, not such light-livers as the birds. They have not the liveliness and the unquenchable joyousness of the lovers of the light ; though they have a certain comfort and enjoyment of life. Except in their early youth they refrain from useless exercise of their bodily strength. For the bird, on the contrary, to live is to move and to move is to live. The bird is never at rest, and would like to turn the whole night into day. Its little heart beats more quickly, its limbs are more elastic, more wiry, than is the case with the mammals. The mammal seems only to experience real joy in life when it has packed itself away as comfortably as possible, to sleep, or at least to doze. The bird is a thing of movement ; the mammal, of sensation.

This is quite borne out by their organisation. The mammal, even when it can attain great speed, is tied to the ground, and cannot move anything like so independently as the earth-free bird, which can easily outstrip our swiftest expresses. So it is with most of the arts of movement. What mammal can vie with the nut-hatch in climbing, as it runs, head downwards, up the trunk? Nor are birds backward sometimes at swimming and diving.

But now for the other side of the matter. How 
much the birds are surpassed by the mammals in the life of feeling! The senses themselves are, with the exception of sight, constructed quite differently in the two classes. Think, for instance, of the sense of touch in the whiskers of the cat, and the sensitiveness of our finger-tips. Think of the sense of taste, which is almost entirely lacking in the bird, and the extraordinarily fine scent of the dog, which recognises the track of its master amongst a thousand. Even hearing is far more advanced in the mammal than in the bird, though it has, for the most part, no appreciation of music; but we know that the musical ear has more difficulty in detecting faint sounds than the unmusical.

The intelligence of the mammal has been developed along with its senses. A great advance in this is so peculiar to them that we might almost call it a characteristic of the whole class.

However, even the keenest intelligence would not protect our quadrupeds from destruction, if they were not provided by Nature with other means of escaping. It is their colour, especially, that causes their enemies to overlook them. The hunter often finds that he will pass within three yards of a hare in its bed without seeing it. And how difficult it is for the unpractised eye to distinguish a standing doe from the trees of the forest.

The colour of our mammals varies in all tones of grey and brown, and this is the colour of the ground. An animal with a lighter shade would soon catch the eye of its enemies ; it could not guard against surprises, and would be doomed. Hence, if a quadruped of a lighter 
colour were to come from another locality, it would either be soon destroyed, or those of its offspring would have most chance of surviving which had most greenishbrown in their coats. In favourable circumstances the species might be acted on by natural selection, and "adapted" more and more, until at last its colour was in harmony with its environment.

Where other colours are found at the limits of a country, the animals are affected by these. Our winter is usually so short that hares are not exposed for too long a period to attacks through the contrast of their colour with the snow, besides that the grey tones of the field and wood rarely disappear. It is otherwise in the high Alps. Here, during the long winter, a broad unbroken sheet of snow covers the earth, and a brown hare could not long escape detection. We can understand, therefore, why the Alpine hares are white in winter. In fact, this very species shows clearly how natural selection modifies an animal. The Alpine hare is also found further north in the Arctic hare. While it remains brown throughout the winter in the south of Sweden, further north it assumes a white coat at this season. And the further north we go, the longer does the white coat last, always in proportion to the number of cold months. In the extreme north, where the snow never melts, and where no trees break the dazzling white surface, the Polar hare is white at all seasons, like almost all the other Arctic animals, the Polar bear, fox, owl, and so on.

These adaptations to the winter have clearly been brought about by natural selection. Just as amongst 
our animals those that do not grow a thicker coat in the autumn cannot survive the cold of winter, so among the Arctic hares those have the best chance of surviving which had the strongest shade of white when the fur changed. These favoured ones persisted through most winters, and so would have the largest progeny. But in the southern regions it was no advantage to have a lighter shade at the spring change of the fur; and on the other hand, there ought to be no change of colour when the earth was still clothed in dazzling white. As natural selection continued its work, a species of hare was produced in the course of time in which the change of coat and colour was proportionate to the length of the winter, so that the animals were in harmony with the prevailing tone at each season.

Other animals have different shades of colour at different seasons. Even the doe has a lighter colour in summer than in winter, in harmony with the lighter shade of the green-clothed forest.

Some animals can obtain their food, though often with great trouble, during the winter, but this is impossible for others. These would die if they did not pass the cold period in a long sleep in some warm spot. It is in the summer only that their diet can be had.

Our hibernating animals pass the winter in nests that are completely closed from within, in the hollow trunks of trees and underneath the ground. There they need no food; they fall into a death-like sleep, and slowly consume their fat. Nature makes this "hunger-cure" possible for them by reducing their 
temperature some 45 degrees (Fahrenheit), and causing them to breathe ninety times less than usual. With this diminished vital activity it is superfluous to take food.

The winter-sleep is not always absolute. Thus the dormouse or "seven-sleeper" (Myoxus glis), which has so appropriate a name since its slumbers last for seven months, awakens from time to time, and dreamily consumes some of its store of provisions. Others, such as the hamster, awake in their dwellings as soon as the ground thaws, but do not open the stopped holes; they eat the corn which the hamster especially stores up so abundantly in its home, that the hamster-catchers of Thuringia find their chief profit in the grains, which they clean, dry, and sell as ordinary wheat. Provision-stores are accumulated by almost all hibernating animals, and even by some animals that do not really hibernate. The squirrel stores its food in the clefts of trees, in bushes, and in holes that it digs, and looks it up in winter. Nevertheless, a severe winter kills large numbers of them. Some of their stores are forgotten, others inaccessible on account of the snow; and the enfeebled animals quickly succumb to their great enemy, the marten, from which they could save themselves in summer by their speed, and especially by leaping from the highest point of the tree, a feat that their pursuer cannot imitate.

For other animals the winter is the time of plenty. It was noticed long ago that heaps of earth-worms were stored up in the passages of moles, especially during severe winters; they were not dead, but stupefied in such a way that they could not crawl 
away. Formerly, these were regarded as food-stores for the winter, but it is now thought otherwise. The mole can catch more worms in winter than he can eat; this is all the easier because he can follow the chase with less exertion during their winter stiffness. He then stores up the superfluous quantity in these chambers, which are thus a provision for the summer. The fact that 1,280 paralysed worms and 18 grubs were once found in a mole-burrow shows that these stores may be very considerable.

The winter-sleep enables the adult animals to live through the cold months without food, but the young need nourishment if they are to grow; this is supplied at first by the breasts of the mother, but her supply of milk again depends on a rich and abundant diet. Hence it is that we find the young always making their appearance at the time when food is most plentiful, and the pairing-season is fixed earlier or later to correspond.

Spring is the love-season for only a part of our quadrupeds. The smaller carnivora, such as the fitchet-weasel, have it in March, and the fox has his "rut" in February; the former are pregnant for barely two months, and the latter two and a half, so that in both cases the young see the light in May. Other animals have the pairing-season late in the year, as is the case with the doe, which bears its young for forty weeks, and so has its rut in July and August.

Mammals are far from prolific when we compare them with other classes of animals. But that does not violate the principle we laid down in the first 
chapter, that each animal has the power to multiply so much that, if there were no hindrance, it would gradually people the whole earth. Even a species that has only six young ones in the course of life would increase to $15,000,000$ individuals in 500 years.

We saw that each species bears young in proportion to its peril, and that in each case the reproduction is sufficient to maintain the species. We might now ask whether the rate of reproduction is not increased by natural selection. It is obvious that amongst the hares of a particular district it is not only the swiftest that have to care for progeny, but that those also which bear more young than others will dominate in the next generation. If one hare has ten young and another twelve, is it not more probable that more of the twelve will survive than of the ten, and that the survivors of the larger brood will carry on the higher fertility which they have inherited?

No. The inference is wrong. We know that species have been put in a position to maintain themselves by natural selection. In this there are two chief methods open to selection. Either the multiplication of the species is increased, $c r$ its perils are diminished. The effect is just the same in both cases.

In the case of the hares, and in fact of all the mammals, it is the second method that is chosen. The animals are cunning and active so as to be able to avoid many dangers. Above all, the new brood is protected, especially by finding its shelter and food inside the mother's body at first. It is otherwise with 
the fishes. In their case Nature has chosen the first method. The ova, which cannot save themselves from accident, are poured into the water, where fate decides whether any of them will ever reach maturity; moreover, the little fishes that issue from them are exposed to all sorts of dangers at a time when the young mammals are safe inside the mother's womb. Hence the fishes must produce enormous quantities of eggs. But the result is the same in the long run. Both the mammals and the fishes have the power of maintaining their kind.

But when the maintenance of the species is secured in the case of the mammals by reducing the chances of destruction, the first method is excluded for them. The fishes may mature large numbers of ova within their bodies, but only on the understanding that the eggs are small. If each egg were to attain the size of a fish inside the mother's body, the number of them would have to be very much restricted. Imagine a motherhare with fifty young ones in her body; though even this number is insignificant in comparison with the fishes. She would be entirely helpless, would immediately be devoured, and the capacity of great fertility would die with her. In particular, the young developing within her need food, and this would have to be derived from the blood of the mother, which is vitally necessary for her own maintenance. Finally, the division of the food amongst so many would mean less for each of the young, and therefore a weaker constitution; they would be destroyed at once, and thus again the disposition to high fertility would perish. Think, for instance, of human twins, or of triplets. If such children were 
born and reared without proper aid and the control of a physician, they would hardly survive.

Therefore, mammals cannot multiply more rapidly because the young developing in the womb need plenty of nourishment, and the supply is limited in proportion to the size of the mother. The maintenance of mammal species is secured by the sheltering of the offspring from danger, so that in spite of their small number, they can never be all destroyed; the fishes or tape-worms are maintained by bringing forth an enormous quantity of eggs, so that, though they are helpless against danger, there is every prospect of enough being preserved out of so many to carry on the species. But why one method is chosen in one species, and the other in another, is a question that we will defer until a later stage.

Mammals are not only sheltered inside the mother's body to begin with, but even for some time after birth the mother's eye watches over them unceasingly. They do not need to exert their own strength yet in the severe struggle for life. They pass the first weeks of life in lively play. ${ }^{1}$

Play is the activity of the young animal; it devotes its whole energy and feeling to it. But even after the animal has grown up, and the anxieties of life demand all its faculties, there are times when it remembers its youth, and indulges once more in play. It is the same with human beings. Cricket not only amuses the child, but also provides absorbing interest to adults; and the

1 The remarks which follow on the play of animals generally follow the ideas of Professor Groos, who deals thoroughly with the subject in his "Play of Animals." 
spirit of invention has devised many other kinds of games for man's recreation after fatigue, and to give him pleasure.

But is it true that recreation is the essence of play? Will not the soldier, who has been following the most fatiguing exercises all day long, turn away from play, and prefer to refresh his tired frame with sleep? At all events, he will not indulge in physical games. At the most he may join in a game of cards.

We see from this instance that in many cases it is not the whole man, body and soul, that needs recreation, but only one of the two elements. The mathematician, who has been engaged all day in most exacting mental work, seeks to rest his tired brain in the evening. But during the whole of the day he has felt a twitching of the limbs; his muscular energy has been resting and accumulating, and now impels him to bodily exercise. If, therefore, we want to understand the meaning of play, we must recognise the accumulation of energy as the first cause of it, rather than the craving for recreation. This will become perfectly clear if we think of the games of children, which are the basis of all play. The child certainly does not play because it has a craving for recreation; all its thoughts and actions have the character of play. Nor would it be more correct to say that puppies are seeking recreation when they run and tumble about the whole day long.

It is, therefore, we now believe, an accumulation of energy that leads to play. Let us consider how this comes about in the case of man.

The accumulation of energy in man is brought about 
by the multiplicity of his faculties. He does not need to use all his powers in the fight for his daily bread. One man gains his livelihood by manual labour-he is a mason, an iron-worker, or an acrobat; another makes it by mental work-he may be a scholar or a poet. In others there is an alternation of the two kinds of activity, but one element always rests and accumulates energy; and as the struggle for maintenance does not require this energy, a man turns to sham-work for an outlet for it. He will imitate real work : he will play. ${ }^{1}$

This manysidedness of faculties in the struggle for existence distinguishes all the higher animals from the lower. The energy of the lower animals is entirely absorbed in the search for food, the avoidance of enemies, and the preparations for reproduction. It is otherwise with the bird and the mammal. A successful raid in the morning will provide a family of foxes with food for the whole day, and they laugh at danger in front of their shelter. The warm sun falls on the furry coats of the sated animals; the rest has strengthened their limbs; and the body, with no serious demands on it, will, in the absence of real employment, make a pretence of it. ${ }^{2}$ Instead of his real victim, the fox runs after his brothers and sisters. He plays.

But is it really excess of energy that impels the young

1 This theory, that the essence of play is excess of energy, was first expounded by Schiller in his letters "On the æsthetic education of man." I regret that I have not space to reproduce the beautiful language of the poet. It is marvellous how many philosophical problems - problems that seem to be quite modern-Schiller has treated with felicity. Herbert Spencer has expanded his ideas on play.

2 Spencer joined this idea of pretence or imitation to Schiller's theory of play. 
animal to play? Will not even a tired puppy dart into the water after a piece of wood? Are not kittens sent over and over again in pursuit of a rolling pebble? Is it really excess of energy that makes children play? No. It is not excess of energy; a very little energy suffices. Think of the scholar. He has worked hard all day with his mind, yet he sits down to play cards in the evening. Here he is devoting himself again to the most complicated logical reasoning for the sake of the game.

How does the second principle stand? Is the game an imitation of real work, which man longs for, but has no occasion to do?

This idea also must be abandoned when we reflect again on the chief form of play-the play of young animals. They have no thought whatever of serious work; how, then, can they feel a lack of it, and make a pretence of it? The young squirrels running unceasingly up and down the tree, the young goats butting each other with their heads, and so on, are not making a pretence of doing real work, but are impelled by an irresistible impulse. All animals have their characteristic games even when they grow up in isolation, and so have never seen the real work of their species. A puppy that is early separated from its mother and reared artificially will seize and shake the hem of a coat in its characteristic way, just as a grown-up dog does with cats, in order to break their necks.

We have at last found the nucleus of play. It is an impulse that caused it. Even in the games that imitate the work of the adult, it is an impulse that urges the 
young animal to imitate. The impulse of imitation is peculiarly strong in children and young animals. It is an impulse that their parents have in their young days, and have transmitted to their children. This impulse is the same thing as instinct.

But are we justified in speaking of instinct in the higher animals, and even in man? Are they not endowed with reason, and is it not this that controls their actions ? ${ }^{1}$

No. There are instinctive actions even in man. Pass your hand suddenly before the eye of another, and you will see the eyelid close immediately, without the other being conscious of it. ${ }^{2}$ This closing of the eyelid is called a reflex action, and if we seek to understand it we must first examine more closely the nerve-tracks in the body.

There are two kinds of nerves. The first group is called the sensory nerves; these are they that pass from the skin to the brain (and spinal cord), and conduct thereto every touch from without, every twinge of pain, and every impression made on the senses. When the brain has received the impression in this way, it telegraphs back to the spot whence the message came. For this it uses the motor nerves, which pass from the brain to the external surface and the muscles of the

${ }^{1}$ Büchner and Brehm attack the idea of instinct generally, but it is the old idea of Descartes which assigned reason to man alone, and only credited animals with instinct. They both entirely forget that :here may be other meanings of instinct. Groos draws attention to this.

In what follows I pass over the various theories of instinct, and only give the one that has been most accepted of late. This is the theory of Weismann, and much the most probable. 
body. The proper movement is brought about in this way. In our example the wave of the hand would be the sense-impression; this would be conducted by the sensory nerves to the brain, and from here the closing of the eyelid would be brought about by means of the motor nerves.

But the reflex action does not always consist of a single movement; often many follow upon a single impression, and one of these brings about the other. This is the case, for instance, when we trip over a stone. The shock to the foot is followed by a whole series of movements-a stretching of the arms, a throwing back of the upper part of the body, and several quick movements of the legs.

Here we have reached the transition to instincts; these also are characterised by the fact of a number of movements following upon sense-impression. It is, therefore, only a complicated reflex action when a young, untaught kitten springs instinctively after a mouse as soon as it sees it.

Thus the basis of both reflex and instinctive actions is corporeal, and is found in the nerve-tracks. And as all the organs of the body can be affected by natural selection, it can also bring about changes in the connections of these tracks and can increase the sensitiveness of the nerves. When we thus discover the material groundwork of natural selection, it becomes clear that instincts are subject to it, and modified by it, and that new ones may be brought into existence by it.

Anyone who tries to catch a fly with his hand will see that the little creature is generally off before the 
hand touches it. Its flight is purely instinctive; there cannot be any question of experience, as even the fly that has just issued from the pupa will act in the same way. How has this instinct to fly attained such a perfection? Most certainly by natural selection, since those flies survived longest that had it in the highest degree. Instincts are one of the requisites of an animal's life, and they are therefore subject to natural selection.

The life of the lower animals is regulated by instincts. How complicated these are will be seen when we come to deal with insects. But, clearly, natural selection must often favour instinctive action in the higher animals as well. When the murderous face of the fox suddenly appears before the resting hare, there is not much time for reflection; the best thing for the hare to do is to spring aside instinctively and make off. But does the instinct go any farther? Is the hare's running away also instinctive, and would that be best for the hare? Here we must answer no. In running it is obviously advisable for the animal to reflect. The hare will fly, double, or drop, according to the distance of its pursuer; and this control of the instinct of flight by the intelligence will certainly be a great advantage to the animal, so that the development of intelligence is favoured by natural selection.

Intelligence does more than instinct; it protects the animal even in unforeseen dangers. If you put a mole-cricket on a glass plate its instinct makes it try to bury itself. Intelligence would tell it after a few attempts that it is impossible to scratch up glass, and that flight is the better course in such circumstances. 
But would not those animals be in the best position that had intelligence and instinct highly developed? Will not an animal that makes instinctively for its prey the moment it sees it, secure its object more speedily and certainly than another that has to reflect on its course of action?

It is true that instincts in connection with food and escape might be so perfectly developed in mammals that they would act with absolute precision when they were needed. There are wasps that perform the most complicated actions in laying their eggs, yet these are all purely instinctive, as we shall see in the sixth chapter. But instincts like these require the most intricate nerve-tracks.

Let us consider the complicated fashion in which mammals seize their prey. Who has not seen how a cat, at the sight of a mouse, steals forward, springs, thrusts out its paw, seizes its victim, shakes it, and finally devours it? What elaborate nerve-tracks would be required in it, if all this were instinctive! yet there are still other habits of the cat. In a word, we see that if the complicated life of the mammals were effected solely by instincts, the demands on the nervous system would be so great as to leave hardly any room for intelligence.

We have only the two alternatives: either an advanced intelligence or perfect instincts. In the mammals it is the former that steadily advances, since, as we saw, it can do more than instinct. We might even say that the more sagacious animals are, the more retrograde are their instincts; and they are most 
backward of all in man. In the human species the most intelligent races have the least developed instincts.

It is true in all our mammals the intelligence is so far advanced that their food and flight-instincts can only be in an imperfect condition. But if the alimentary instinct is only rudimentary in a mammal, if the whole of the mechanism that serves for seizing the victim is only feebly developed, how can the animal capture its prey from the very beginning? A cat that sees a mouse for the first time, and has no instinct to tell it how to catch the creature, will certainly not be able to do so if it has had no experience in catching mice. Now we come to the solution of the problem. In the lower animals actions are regulated by instincts, which work faultlessly from the very first, according to their nature. In the higher animals the instincts are feebly developed, and the actions are regulated by intelligence. But the intelligence must be trained, like the powers of movement. For this a certain period is necessary in which every unsuccessful act will not endanger the life. This is the period of youth.

The instincts make their appearance, though imperfectly, in youth; that is to say, at a time when the animal has as yet no serious need of them. During this period the animal can improve the inherited, imperfect impulses by its own experience; and if it is taken away from the mother and her direction, it knows how to catch its prey and protect itself, and will acquire in time the requisite adroitness.

Now, this exercise and training of the faculties takes place in the play of the young. We can, therefore, 
realise the immense importance of play. It is the school in which the animal learns to play its part in the struggle for life. Without these early gambols the animal would be clumsy and stupid when it leaves its mother, and would be quite unfit to meet the stress of life. The animal must play, and must therefore pass through a period of youth. Thus we are now in a position to say that the play is not there because of the youth, but that a period of sheltered youth has been provided by Nature for the purpose of play.

Play is, therefore, absolutely necessary for the young animal. And in order that it may play often, a feeling of pleasure has to be attached to the exercise. It is true that the first impulse to play comes from instinct, which urges the animal to stir itself, especially in directions that have some relation to later life; and we have already seen that the instincts of play are imperfectly developed instincts of food-getting, flight, etc., which must appear in youth and afford the little one a means of acquiring the bodily adroitness that it needs. The exercise of every instinct is pleasant in itself, still we may legitimately speak of the lust for food, for fighting, and even for murder, and make use of the phrase, "to satisfy one's impulses." Nevertheless it is clear that this feeling is much strengthened in play. It is quite certain that even the most incorrigible brawler does not feel as much pleasure in his serious fighting as boys do in their romping. This is even clearer if we take instincts the serious use of which is never agreeable, such as flight from an enemy. With what pleasure children, and even young animals, chase each other 
about! In fact, there is one experience that shows clearly that the animal feels most pleasure in the very form of play which will be of most importance to it when it becomes reality. The harmless doe is hunted throughout its whole life; yet when these animals play together, we notice that the pursued puts his whole soul into it while the chaser is very little interested. It is just the opposite with the carnivores. With these the chaser is the more spirited. He tastes the whole joy of hunting, and in fact, the chase will be the chief purpose of his existence in real life.

What is it, then, that affords the young animal so much pleasure in play? Not only the young, in fact, but even the adult, which is often seen to play. What is the nature of the delightful feeling that play engenders?

It consists, in the first place, of the pleasure that is felt in all energetic action. Then, it is certainly pleasant to see that one can do something-that one has power. In play a man delights to feel that he is "doing something." It is from this feeling that the pup is so ready to tear up boots and other objects; that the cat rolls its ball; that little birds, and often little children, set up prolonged cries, and take considerable pleasure in noise.

It is, further, the sense of overcoming difficulties that adds to the pleasure of play. Swinging, tobogganing, sliding down smooth surfaces, etc., which children are so fond of, is a sort of escape from the gravitation of the earth, and from the friction that makes all movement difficult. All these movements fill us with a peculiar sense of freedom. 
But play is most advanced in character when the playing animal is conscious of its pretended activity; when it knows it is only playing a part. Play is in itself only a pretence, since there is no serious occasion for the exercise of the instinct. We have to learn next, therefore, if the animal knows that it is only making pretence.

This cannot be seriously questioned. Every dog that pretends to bite its companions or master knows that it is playing. We could give many such instances. Remember, too, how animals can dissemble: how a dog that has broken something will pretend to be engrossed in some action or other, with the most innocent face in the world. In this consciousness of pretence we have imagination, or the faculty of taking to be real something that only exists in idea. In play, therefore, we have a conscious self-deception.

Here we find ourselves at the threshold of art, and it will not be without interest to take a peep into this field.

In art we have a conscious self-deception, and play and art are intimately connected, as the very words "playing the piano," "playing a drama," etc., indicate. The impulse to play is the real source of artistic activity both in primitive races and in children. Thus the animal is brought to the very verge of artistic production by its delight in pretence. It does not cross the threshold; because for real artistic creation the aim to influence others by one's make-believe is necessary. This purpose is not present in normal play.

The conscious self-deception in play and art is due to 
a peculiar division of consciousness. Both man and the animal know, when they are playing, that it is a pretence, yet lend themselves to it. We find in other matters a similar division of consciousness, especially in dreams. Here we often give ourselves up to the most fantastic pictures, yet the consciousness of the awakened man often breaks into them, and recognises they are not realities. I have often had dreams in which I was chased by enemies that gained more and more on me. But instead of feeling pain and anxiety I am assured by a clear consciousness that it is all a dream, and I sink peacefully into my dream again, and see my enemies approaching to kill me. I wonder with interest what the moment of death will be like, and await the experiment calmly, saying to myself that my life will not really come to an end in it.

There is a similar duplication of consciousness in play and the enjoyment of art. We are often quite absorbed in a drama we are witnessing, and only brought back to our real selves from time to time by consciousness. We have the same experience in examining paintings and sculpture. A sort of false self is formed in us, full of false feeling, and our real self sinks into the background. Yet we retain a sense of reality, a real pleasure in the unreal; but it passes into the sphere of the pseudo-self, and lets itself be borne by that.

But why do we never confuse pretence and reality in play and in art? Must not our real self recognise that the pseudo-self is only a make-believe?

Our real self knows, or we ourselves know, that 
we are the cause of the phantasm. In this we find the highest pleasure of play and art. The projecting ourselves into the unreal is voluntary on our part, and this feeling of our freedom accompanies us, often unconsciously, as long as we indulge in the fiction. The reality, on the contrary, presses itself on us even against our will; it gives us a feeling of dependence.

Thus it is the sense of freedom that accounts for the highest form of pleasure in play and in art. This sense of freedom gives its peculiar colour to the world of fancy, and consequently "in conscious play the whole pretence of action is converted by the accompanying sense of freedom into something higher, finer, and lighter, which we cannot confuse with the reality of things."

In play we feel ourselves really free. We do just what we wish to do, and we know that we can halt and abandon the play at any moment we desire. We do not feel ourselves to be a link in the pitiless chain of cause and effect; we seem to have escaped from inexorable necessity.

All these feelings are found in a rudimentary state in the playing animal. Now that we have learned the cause and the meaning of play, we will recall the chief forms of the play of animals.

The animal plays on the first day of its existence. The stretching of its limbs, the gnawing of objects, the rolling about, are nothing but play, with the object of teaching the young one to gain control of its own body. And the young animal not only learns to master 
itself in play, but also to control its environment. It learns to appreciate distances, for instance; we see the same in our infants who have to learn gradually that the moon, towards which they reach out their little hands, is unattainable. It has even been said that a human infant learns as much in its first year as in all the others put together; hence the importance of this "experimental play." In this play the psychological factor is the joy of "doing something"; this is seen most clearly in the destructive tendency of young animals, and in their delight in making a noise.

When the suppleness of the little one increases, and it has learned to control its own frame, the play of movement begins. These serve to give the animal the mobility that it will need in the struggle for life. Naturally, in this play the particular movements will be practised which the animal will find useful later on. The squirrel leaps into the air with the most break-neck springs; the marten is equally bent on testing its leaping powers. Aquatic animals practise swimming; animals that live in the air take to flying. Even the buckjumping of the kid, which seems to be mere reckless delight, has its meaning. On the level ground these leaps are puzzling enough ; but on the mountain, the real home of the goat, it is quite indispensable for reaching the higher rocks.

With the play of movement is connected the pretence of hunting. The carnivores practise this in order to creep up to and capture their prey ; and the plant-eaters must learn to escape them. Thus the kitten plays with the mouse, and learns, by a method that is repulsive to 
us, the way its victim runs, so that it can catch them itself when they run free before it, and the mother is not present to paralyse them. Deer chase each other for hours, and so learn to escape when there is serious occasion; young foxes catch each other and duck to avoid each other in front of the den, just as they will do afterwards with the unsuspecting hare.

Then come the fighting-games of the young male. These have to make the animals strong and supple, in order to beat their rivals in the love-conflict later on. The joyous feeling of strength and power may lead in this to a frightful mauling of the weaker.

As we saw, the first impulse to all these games comes from instinct. But there is another element that may cause the animals to play-the passion for imitating. This also is an instinct. We see this at once when we look to the fact that every animal confines its imitation to its own species. The young fox never tries to imitate the bird in flying, but imitates its mother in trying to capture it. We might draw up a special category of "imitation-games." In these the young show what they can do ; they delight in showing that "they can do it also," and strive "to do it better."

The passion for imitation is an impulse that has arisen and is fostered by natural selection, like every other instinct. It leads the animal to learn quickly what it will need in later life, and so to make experiments on its own account. A flock of game will escape easier if it follows unhesitatingly a leader that has scented an enemy, than if each has first to convince itself that flight is necessary. 
There is another matter of great importance to animals, and must be practised in youth-attention.

This is indispensable for every animal. How could an inattentive animal escape its enemy, or how would a carnivore discover and catch its prey without this quality! The cat watches with the most strained attention before the mouse-hole. It sits crouched waiting for the appearance of its victim, all its muscles ready for the unfailing spring and the joint stroke of the paws.

When there is no serious occasion for attention, and it is practised in play, as it were, we call it "curiosity." We see this often enough in animals. The essence of it is that the animal sees a strange object, and wants to learn what it is. Often enough an excessive curiosity leads to the death of the observer; it is well known that one can frequently draw quite close to a marten on a tree and shoot it without it making an attempt to escape, owing to its curiosity at the unusual appearance. Generally, however, curiosity is an impulse of great service to an animal. It is from curiosity that the young animal familiarises itself with its environment, and learns to distinguish between what is good and what is injurious.

We might instance quite a number of other kinds of play, but will bring the discussion to a close. We have, in particular, made no mention of a whole large division-love-play. This, however, is not properly play, because it does not serve for the animal to practise some serious future activity, but is a serious 
activity itself; it is only the psychological factor, the joy of power, that often makes its appearance in it, that justifies one in speaking of it as a species of play. We shall see something about its nature in the next chapter.

In pursuing at such length these observations on the play of animals, and taking our cue sometimes from the life of man, we have not passed the limits of this work. We have learned that many qualities of mind that seem to belong to man alone are also found in the animal. This shows us how untenable is the opinion of those who think they have found in man's mental powers something that distinguishes the lord of creation essentially from other organisms - something that makes the descent of man from other animals impossible. We now know that the theory of evolution need not stop short at man; that even his mind is no obstacle to our admitting his development from animal ancestors. The mind of man does not differ from that of other animals in kind but only in degree, and there is nothing to prevent us from supposing that it has been raised from the animal level by natural selection to its present altitude. Just as Copernicus smote the conceited belief out of humanity that their kingdom, the earth, was the centre of the world, so Darwin has put an end to their assumption that they occupy an exceptional position on our planet. The earth is a stage of a part of the eternal, everchanging world-mass ; humanity is a phase of a part of the ever-advancing world of organic life. 


\section{CHAPTER III}

\section{BIRDS}

Sexual selection. Choice of females. Rejection of the hypothesis. Advance of the male's senses. Selection of the strongest suitor. Explanation of coyness and the animal coquette. Female selection inadmissible. The love-dance. Selection of the apparent strongest. Colours as means of distinguishing species. Use of sounds. Pairing-calls. Origin and forms of song. Instrumental music of the birds. Migration. Speed of flight. Do birds tire? The adaptations of the bird-body. Height of the migration - flight. Origin of birds of passage. Their strength, their power of presentiment. Routes of migrating birds. Their memory and sense of direction. Travelling in flocks.

THE poets have often introduced the song of the bird-as Shelley did-amongst their throbbing lines over the destiny of men. It is natural that the poets should love the birds. From the bird the art that man must slowly learn seems to pour out in rich, inexhaustible flood. The woods and the meadows are enlivened by the songs of the birds. Where would the magic of spring be if there were no singers to proclaim its glory to us?

We often read in books of travel in distant lands that all the splendour of the tropics only awakes a longing for our own forests because there is no sweet song in the glittering birds that complete the fair picture of Nature. Even in Japan, where noble forests 
grow like those of Europe, the traveller seems to find something wanting. For a long time he cannot tell what it is, until at last it dawns on him that it is the stirring song of our birds. ${ }^{1}$

But it is not the song alone that makes us love the birds. To know a bird's nest and watch daily the care of the parents for their helpless young is a source of purest joy to our children. The birds are not far removed from children, and resemble them especially in their liveliness and their unfailing spirits. They seem not only to understand art, but to have also the nature of the artist.

Hence it is that painters feel themselves akin to the birds. A man died in Heligoland in 1897 who had seen the island for the first time as an artist of twentythree, and was so enchanted with the bird-life circling high above, that he devoted himself entirely to the study of birds. We shall have much to say of this Heinrich Gätke by-and-by.

But is not that which gives us pleasure likely to prove dangerous to the birds themselves? It is true that the inhabitants of the air are secured from many enemies by their rapid flight and their great agility. But does not their song bring them to the notice of marauders? We know that many birds have light shades of colour, and these are conspicuous against the background, and must betray their possessor from afar. How could such a shade be brought about by natural selection? And when we see that, as a rule, only the males are brightly coloured, we have a new problem.

${ }^{1}$ So I have heard from many who have travelled in Japan. 
How could natural selection lead to a different colouring of the two sexes?

Darwin put these questions long ago, and as an answer to them he framed his theory of sexual selection as the second great agency in the formation of species. We shall understand this best if we compare it with natural selection.

Both by natural and sexual selection certain animals have a better prospect than others of leaving offspring and so preserving their species in the next generation. In the one case it is those animals that have been able to escape destruction longest, thus reaching the period of reproduction, while the others die off before it comes. In the second case it is the males (sexual selection affects only the one sex) that attain to union with a female, as many of them can never reach love, and therefore never reproduce. Natural selection, therefore, determines which animals will reach the period of reproduction; and among the selected males sexual selection then chooses those that are actually to reproduce. In the one case the "bad" are destroyed; in the other case they are condemned to sterility. In both cases their kind perishes with them.

Thus in natural and sexual selection a few are chosen out of a large number of animals. This is possible for natural selection because more animals are produced than can live; in sexual selection also choice is only possible if the males are so numerous that there are not enough females for all, and some must go without. As a fact, we do find this pre- 
ponderance of males in Nature; even man is no exception to the rule, because there are more boys born than girls every year. If the females are in the majority in later life, that is because the males are at all periods of life exposed to a higher mortality. ${ }^{1}$

Which males, then, are selected?

According to Darwin, there is a double struggle for the opportunity to reproduce. In the first the males fight actively for the possession of the females; the stronger drive away the weaker, the better armed conquer the weaponless. In this way, for instance, the cock's spurs and the stag's antlers would be explained by selection. In the second form of selection the males are chosen by the females. These are supposed not to listen to every suitor, but to choose the one that pleases them most. Thus the bullfinches, for instance, may once have been the same colour in both sexes. Then variations occurred in the males, which showed a shade of red in the breast. This pleased the females, and the continuous selection of the redder ones led to the endowment of the male bullfinches with the bright red breast they now have.

The first kind of sexual selection is based on wellknown facts, and has never been seriously called into question from the Darwinian side; it is really a special case of natural selection. But the second category has a number of opponents, among whom we find the distinguished naturalist, Dr. A. R. Wallace.

In later years the unhealthy life led by men is to blame for this, monotonous labour without regard to the body, and the use of alcohol and tobacco. 
This is intelligible enough. Compare this kind of sexual selection with natural selection. In the latter the idea that there must be selection starts from a fact. In the theory, for instance, that the white hares have been developed from darker ones by natural selection, the fact we start from is that white hares show less against the snow than dark ones; from this we are justified in concluding that the lighter the hares were, the better their chance of escaping the notice of their enemies. But the man who infers from the fact that our actual bullinches have a red breast, that the female had from the first a preference for red, and was pleased with the increase of colour, is building his theory, not on a well-known fact, but on a hypothesis once more. Our explanation is simple enough, if we say: The bullfinch has a red breast, and consequently the females must have always had a preference for red, while the blue-throated warblers had a preference for blue. But the inference is not scientific, or at least not until we have explained why the bullinch prefers red and other animals other colours; and this we cannot do.

Could we not say that the bullfinch got its red variation by chance, and that it was not exactly the colour, but "the stimulus of novelty," that acted on the females? But we must not extend this principle, which we only know in the life of human beings, to animals, especially to those only where we find it convenient. The breast of the male bullfinch, which is supposed to have been grey, must have shown tendencies to all kinds of colours, and if the novelty was appreciated by the females, one would have chosen one colour, another 
a different one. There would not have been a development of the colour of the breast in one steady direction, namely, towards a bright red. If we suppose that only one special novelty pleased, and gave equal pleasure to all the females, we are doing violence to Nature. We must first show that this novelty pleases the female, and why it does so.

We see, then, that this second kind of sexual selection is not satisfactory. How, in that case, can we explain the peculiar characters of the male? What was the origin of the brighter colours, the specially developed feathers, dances, songs, and perfumes, of the males, in all classes of animals? Can we not give a satisfactory explanation of some of them? We shall see.

But must we reject altogether this choice on the part of the females? Is it not blind chance that brings any male to a female and provides it with the fruit of love?

No, certainly not. It is not chance that brings the male to the object of its love. It seeks it of itself. But it is clear that the males which detect the females soonest will attain their purpose first, and that those with inferior organs of detection will come too late, and lose the reward. Thus we see at once that there is a sexual selection which falls into the first category of that group, and enables us to understand how the males of many animals have better sight, hearing, and smell, than the females. These organs must, of course, have been formed and developed by natural selection, since the animals need them for vital purposes; but sexual selection will improve them, as it comes after natural selection and is more exacting. It is, for instance, 
certainly more difficult for a cockchafer to discovet a female of its own kind than the masses of food about it. We understand at once, therefore, why, as a fact, the male cockchafer has a finer scent than the female, and why he has special olfactory organs on his antennæ which can be seen externally from their comb-shape. We find similar structures in other insects, especially several species of butterflies, and in small crabs in fact, they are common in the animal world. Other sense-organs also have been enhanced in the male sex clearly by the same process of sexual selection. Many male insects have much larger eyes than their females, such as the May-flies and the male bees, the drones. We can see the meaning of the large eyes in the forehead of the latter. Of the many drones that follow the one queen in its nuptial flight, one will be particularly favoured in being able to follow the form of the queen as she floats in the blue air, and so catches it.

But it often happens that the males lose the fruit of love when they have tracked the female. When other suitors come on the scene they will hardly withdraw resignedly when they see the place occupied; they will try to make good their lateness by force, and drive away their rivals. A struggle of this kind for the female often takes place, and the victory naturally goes to the strongest and cleverest. On this principle the stronger males are again selected, and thus we can see why the black-cock or the common cock is so much stronger than the hen. In fact, this kind of selection may lead to the formation of "weapons," such as the cock's spurs or the stag's horns. In the latter case 
the animals with the hardest skulls would win at first, and an ever-increasing horn may have been developed from the growths on the bones of the head which were casually produced by the butting. However it may be with these special cases, there is nothing to be said against the general principle.

We have, therefore, given a natural and satisfactory explanation of part of the masculine characteristics. What are we to do with the rest?

The black-cock becomes so intoxicated with its dance on the branch of a tree that, though usually so timid, it cannot perceive the approach of its enemies. This dancing - instinct cannot be due to natural selection, it is obvious, since it is injurious to the animal. But sexual selection may at least have produced it in the beginning, and then the second principle would come into effect. The pairing of the cock has reached such a pitch because the hen always gave the preference to the best dancer.

As we have rejected this theory, must we despair of giving a scientific explanation of the love-dance.

There are experts who will not admit a conscious choice on the part of the females, but have sought to replace it by unconscious preference; in the sense that each female would yield itself to the male by which it was most stimulated. This stimulation would take the form of an enchantment or hypnotism, whether it was caused by the beguiling song or the dazzling splendour of the male bird. The female would, in a sense, lose consciousness from the enchantment, and its resistance to the caresses of the male would be broken. 
But why does the female sex show resistance at all to love, which ought to be urged with all its force by Nature as the great maintainer of life? The desire for love is so irresistibly implanted in every living thing that a curb is absolutely necessary. It will be easily understood that too frequent caresses on the part of the male will not serve their purpose, namely to create progeny, but will enfeeble the female, and so be dangerous to the offspring. Hence Nature has raised a barrier to the onrush of the male sex, and this is the coyness of the female. When there is a conflict of the two powerful instincts, coyness and desire, we describe the female as "coquetting."

The male has to overcome the coyness of the female, and for this the colours, perfume, dance, and song are useful to him; by the improvement of one or other of these features a male will be able to ensnare the female more quickly than his less brilliant fellows. Among the variations that appeared in the male there were some that chanced to stimulate the love of the female. In this sense the "choice on the part of the female" can be be better understood, yet it is not an explanation. It remains a mystery why just this one among many variations should affect the female-should affect all females, in fact. Further, we do not see how it could happen that the character in question should be developed steadily in a particular direction by the female's choice. Is it not just as if the female had before its mind from the first the image of the complete male ornamentation, so that, when the first traces appeared, she helped it along, and only looked to 
ornament in the sense of giving the preference to the males that came nearest to her ideal? As a matter of fact we should, on this theory, have to suppose that the female felt from the first-consciously or unconsciously-an impulse to a certain end. This end was the male ornamentation in its full development, and it would be at length attained by the steady preference of males that come nearest to the ideal. This explanation seems arbitrary and unscientific, because neither experience nor science tells us anything of this mysterious working for a fixed aim; and we shall see in the eleventh chapter that it must be rejected altogether.

We must seek another explanation of the dance and song and colouring. Let us deal first with the dance.

Is the charming of the black-cock really a means of breaking down the coyness of the female? If it were, we should have to assume that the cock must convince itself during or after the dance that its art has been effective; and above all, we should have to suppose that the hen is brought by the dance to look on him with a sort of enchantment. As a matter of fact, we see nothing of the kind. The females seem to be quite indifferent; in fact, in this particular case of the blackcock, they are not very near to the male, and he has to pursue them for some distance after the dance. Then there is the peacock, whose tail is so much admired by human beings; his females seem to be quite unmoved by it, and go on picking up their food trivially, however fine he may look. Has anyone ever 
seen a turkey-hen enchanted by the tail and comb of its mate? I do not think so.

In the case of the turkey, in fact, the idea forces itself on us that the male does not dance for the pleasure of his wives, but from anger and fighting spirit. The inflated, red-combed cock "dances" before human beings and dogs as well as before his hen.

I believe that we have here the key to all these "courtship-phenomena." They are connected with the fights of the males, and must be explained as serving to frighten away rivals. In the first place, it is quite clear that double courtship of a female need not always lead to fighting. If a male on the quest of love finds a rival before him that seems so savage and powerful that he himself would probably come off second, he will generally not fight, but retire into the background and look for satisfaction elsewhere.

But it is obviously not necessary that every fearsomelooking male is particularly strong in point of fact; it is enough that he should seem to be so, as the rivals are then not likely to put it to the test. Means of frightening others away are not uncommon in the animal world. A hunted cat makes its fur stand out so as to seem bigger than it is. We can, in fact, readily believe that the manes of many animals, such as the stag, are intended to make the neck seem bigger and stronger, and so may have been brought about by this sort of sexual selection. ${ }^{1}$

I Weismann thinks that the lion's mane is due to the fact that, in the fights of the males, those had the advantage whose necks were protected by thicker hair from the teeth of their opponents. This theory is unsatisfactory. There are many animals with manes that do 
In the formation of the antlers of the stag it is probable that the fearsomeness played a more important part than the improvement of them as weapons. It is clear that the larger the antlers the more formidable the animal looks. As weapons two sharp spikes on the head would be more effective, as we see in certain deer which have such spikes, and bring down every opponent, even the most powerful sixteen-pointers.

Now let us go a step further. Rival suitors are driven away not only by an appearance of strength, but by confidence of approach. Who has not seen many a little dog frighten away a big cur by attacking boldly ? Even a man is intimidated by the self-conscious bearing of another. It will be found throughout the whole animal world that a reckless onslaught intimidates an opponent.

A male that has stolen a female and shows by his manner that it is not advisable to fight with him will be avoided. He will show this by inflating himself, uttering terrific cries and running about. Do we not see this in the turkey-cock? Is it not clear to any unprejudiced observer that his capering is a war-dance? Do the red-skin braves perform their war-dance to

not bite each other when they fight, such as the stag. My theory, on the other hand, meets these cases as well. We might also regard as means of frightening combative rivals the knobs on the face of the wart-hog, the beards that give a savage appearance to the faces of many apes, the two teeth that come through the upper lip of the boar, and are useless in fighting because they bend downwards, the antlershaped tentacles of the stag-beetle, which can pinch much less than the smaller tentacles of the female, and many other kinds of beetles' tentacles; possibly also the chirp of the male cricket, and other features. 
enchant their squaws? Certainly not. They want to strike terror into a lurking foe, and they intoxicate themselves with their own power. The latter is the psychological element that enters into the dances of animals, and sets them to "games." As a fact, means of frightening and intimidating play a great part in all fights. Think of the war-cry of the Indians, our own "Hurrah," the terrific painting of the skins of savages, and the military moustache. It was this that gave the French warriors their fierce appearance in the later Middle Ages, and played a great part in the Thirty Years' War. 'It does really give a fiercer expression to the face, because it draws up the lips at the corners of the mouth, over the canine teeth; and, to compare human with animal features, we may recall the projecting teeth that were also used for intimidation. The martial moustache has been retained in the daring Hungarian cavalry. But however it may suit soldiers, it does not become the civilian, in whom it forms a ridiculous contrast to the otherwise modest and funereal appearance.

In the instances we have given, therefore, it is a question of selection of the apparently stronger. I believe that this explains the origin of a good many masculine characteristics. It may be asked how far my theory is supported by observation. Certainly, many facts can be quoted in favour of it, such as the wellknown one that a young black-cock dances very gently and stealthily when an older one is about.

An intimidating conduct on the part of the male will have an effect on the female; it will not only keep away 
other suitors, but will hold the females together. It is well known that a stag, or even a cock, treats its dependents roughly, and will not let them break loose. If, then, a male terrifies the female by its appearance and conduct, the latter will be less likely to wander away after forbidden fruit, and will not venture to make too much resistance to the allurements of the male. Unfortunately, many animals take Nietzsche's "little truth" to heart: "You are going to the women? Do not forget the whip." Everyone who has had occasion to observe the love-making of animals in a zoological garden will have noticed that it is more frequently a question of being bullied, than of listening tenderly to the wishes of the male. In fact, amongst human beings it is chiefly the strength that conquers women; not merely strength of body, but the power of thought, of mind and will-in a word, the strength of the whole masculine nature. But in the case of man it is usually a question of choice on the part of the women, and we must exclude this element in dealing with the animals, and recognise force alone; whether this is used actively for the coercion of the female, or her resistance is broken down by the mere perception of it.

Can we explain all the masculine characteristics in this way? Unfortunately, we must admit that we cannot. Colours present the greatest difficulty. Many colours, of course, may be for the purpose of scaring away rivals, such as the red spot over the eye of many wild-cocks, which gives it a fierce expression and makes it look larger. In the case of man the masculine dress at all times is thought to have had its origin in the 
military dress of the particular period; and this was certainly not meant to be merely defensive, but also to make the wearer seem formidable-as, for instance, skins with animal helmets, waving plumes, etc., or at all events to give him a greater appearance of strength and life and boldness, in which bright colours would be useful. But it is impossible for all the details of the composition and design of animal colours to have arisen in this way. It is also inadequate to explain the undoubted fact that they act as distinguishing characters of a species. As such they play a great part in the life of animals; it is easy to see that those animals will propagate best which can recognise their kind most quickly. Perhaps many light colours arose in this way, and they could be preserved and accentuated in the male, but not in the female, which absolutely needs a neutral tint in order to sit unobserved in the neutraltinted nest or on the ground. Only in this way could the mother and her eggs, and later the helpless young ones, escape the fatal eye of their enemies. The eggs of birds that hatch on open nests are also protected by fitting colours that save them from many eyes; while birds that sit in hollows generally have white eggs. There is an exception in a number of blue eggs that are found in open nests. An attempt has been made recently to explain their colour on the theory that the blue is particularly favourable to metabolism.

There are many features that are common to both sexes. These are usually confined to particular spots, and can do no injury to the animal when it sits quietly. In this group we have a whole series of colours that 
are found in the wing-feathers of birds, and are only exposed during flight. It is the same with colours in the tail, which only meet the eye when it is spread. Brighter colours are, as a rule, not found on the upper parts of females, but may be developed in the male; because even if they carry destruction to many of them, the species is in no danger, as the males are always in excess.

But, it will be asked, how can peculiarities of colouring serve as marks of the species, when these generally act at a distance? How, for instance, can we explain the eyes in the peacock's tail? The explanation given above seems to fail here; and as we have rejected that form of sexual selection according to which "the finest eyes" charm the females most, we must find a better explanation.

We have seen that it is very important for all animals to have specific characters, so that the sexes may easily find each other, and be not liable to make the fatal error of confusing their fellows with their foes. It is clear that the specific colours of many species have arisen in this way as means of recognition. But it is also clear that visible characters do not suffice in the case of the birds. The light creature soars high up into the air, and is not tied to the ground like the mammal. With its keen eyes it looks down on a broad expanse of territory. But how can the finest eyes pierce through the canopy of leaves to find its fellows sitting beneath? And how can the nocturnal birds, such as the owls, find each other so well? Even if their eyes can pierce the darkness, they must fail 
to detect their fellows in the wide forest. The mammal has an easier task. He follows the track of his companion with his nose; but the air leaves no tracks.

In all these cases sight is of no use in detecting the species; it has to be aided by another sense-hearing. The voice is developed as a means of recognising the species. But it not only serves the purpose of bringing the sexes together; it is of the greatest importance in the common life of the bird. We know how powerful the social instinct is in birds, and we have learned to appreciate the value of this gregarious sense for the maintenance of the species. Apart from the fact that the young learn continually from the older, they are also protected by them from danger. Every sportsman knows that when he is approaching a flock of rooks, and one member of the flock sees him, it is useless to go any farther. The understanding between the flock can only be brought about by voice.

In the social life of many animals it is extremely important to specialise the call, as it is an immense advantage to the species if the bird can produce different notes. In that case one note will serve to bring the flock together, another to warn them of approaching danger, a third may be the signal for flight. We are, in fact, astonished at the diverse cries of the crows, and the different notes of the blackbird, which is often a herald of warning even to other animals in the forest. Nearly all migratory birds have a peculiar call on their long, nocturnal travels, in which some means of keeping together is necessary. But it is especially the pairing- 
call, for bringing the male and female together, that is peculiarly developed in most birds.

From the pairing-cries, which were at first common to the two sexes, there were gradually evolved sounds that differed for each sex. This was effected by sexual selection, which favoured those males that could make themselves known at once as suitors to the heated females. Quite a number of birds are still at the stage of "sexually different notes." The grey wood-pecker gives out his clear-ringing cry from the highest branch of an oak, and is answered from afar by the different note of his mate. Even the cuckoo is said to have different notes in each sex. When it gives out, in ardent passion, its trisyllabic cry "Cuck-cuck-cuck," we usually hear shortly afterwards the continuous note of the female. It is a sign that the love-message of the male has been heard.

Here we have reached the basis of song-the special call of the male-and it will be asked how the further development, up to the noble song of the nightingale, came about. Again, however, we must depart from the theories, as we have rejected "female choice." Moreover, the song is not mainly intended for the female, since the male usually sings alone, and often, like the blackbird, on the top of a tree, and so is easily seen; while there is no female near to see him. But the song would be just as unintelligible as a means of intimidation; at the most, we may assume that it has become so much developed and specialised because it is useful to the male to let his presence be known far around, so that any unpaired companion may know from afar that the 
lady of the district has a spouse. Nevertheless, this suggestion must not prevent us from confessing candidly that we have as yet no satisfactory explanation of the complicated song of the bird.

And how the songs of the birds differ! The monotonous "delm, dilm, delm, dilm" of the willowwren, the rolling flute-like song of the hedge-sparrow, the strong exulting note of the chaffinch, the rippling song of the black-cap with its bell-like ending, the melancholic, varied tones of the song-thrush, and the indescribable song of the nightingale; what variety in the fulness of tone, in the change of the notes, in the rhythm!

Birds not only sing, but many of them play a very peculiar instrumental music. Storks clap with their beaks, bitterns pump their gullet full of air and give out the powerful bellow that has frightened many a traveller. The spotted wood-pecker and its black companion fasten themselves on the branch of a tree, and with rapid stroke of the beak, helped by the vibration of the branch, send a humming rattle through the wood. Those who go through damp meadows in the spring hear a mysterious tone like that of a hautboy vibrating through the twilight. This is caused by the snipes, whose tailfeathers are set in vibration by the air like the tongues of a reed-instrument, as the bird is descending, and with a peculiar quiver in its wings sends a current of air through them.

Some birds are able to imitate the sounds of others. The jay is a great artist at this work. This pretty but thievish bird, with its fine blue epaulettes, often 
delights in imitating, in the most disconcerting way, all kinds of bird-voices, as well as the neigh of a foal, the bark of a dog, and the swish of the scythe. Its companion in robbery, the wood-chat, strings together the most varied notes, such as the croaking of frogs and a number of other sounds, with the bird-songs it hears, into a charming song. Imitation plays a great part in all songs; in fact, Wallace believes that the song of the bird is entirely due to imitation. That is not correct, however. The bird has an instinct to its particular song, otherwise there would be no specific songs at all. But this instinct, as in the play of animals, may not be developed with full precision, and so the accession of a second instinct, that of imitation, enables the creature to improve its voice by hearing and practice.

What pleasure the bird takes in its song! Anyone who has watched the singer will know this. It is certainly not love alone that inspires its song, as the bird sings long after the love-period is over. During the hatching, we still hear the note of the chaffinch, and the song of the yellow-hammer and the black-cap. In the autumn the voice of the blackbird trills out once more; also the song of the willow wren, and the tender ripple, like the splash of a tiny waterfall, of the redbreast. When the ground is covered with snow in the wood, when the fir-branches bend under their load of snow, and everything sparkles in the sun, we often hear the song of our smallest bird, the wren ; and the waterousel sings its spirited, rippling song by the brook in the severest cold of January, and then, to the astonishment of the observer, dips into the icy flood. 
Otherwise, all is quiet in Nature in the winter. A few grain-eaters, like the titmouse, pick up a precarious living. There is only one bird, the cross-bill, that has its time of plenty in the winter, as the pine cones are then ripe; and we see the wonderful sight of the red and restless gipsy-bird building its nest and rearing its young on the snow-covered pines. But all the birds that live on insects, and amongst these are our best singers, have migrated far away in the autumn, where a fresh summer smiles on them under a sky of perennial blue.

This enormous journey across the Mediterranean to Africa only takes them an astonishingly brief time to perform, as the little birds can attain a very high speed.

Henry II. of France found out in the sixteenth century how fast a bird can fly. A falcon escaped from him at Fontainebleau, and was caught twenty-four hours afterwards in Malta. When we calculate the distance between the two places, we get a speed of forty-four miles an hour; but this is below the mark, as the falcon would hardly do it in one flight and in a straight line.

The expert whom we mentioned at the beginning of the chapter, Gätke, puts the speed of migratory birds far higher. He maintains, for instance, that the northern blue-throated warbler does its journey from Africa to Heligoland in one spring night, because at the time of its migration it has been seen in swarms in Heligoland while only a few stragglers were found in the rest of Europe, and the bird always travels by night. If this were so, its speed would be 209 miles an hour. It is true that the route and the migration of the blue-throat 
are still obscure, but Gätke's calculation must be too high, and we will turn to safer figures. We know from exact observation that wild ducks can fly more than forty-seven miles an hour, and carrier-pigeons seventytwo miles an hour. The highest known speed was reached, according to a careful experiment, by a houseswallow, which travelled from Ghent to Antwerp in 12.5 minutes, and so must have done 186 miles an hour.

The bird can, of course, increase or lessen the speed of its flight, according to need. Hence these figures cannot tell us anything certain with regard to the speed of migration. We know little, moreover, as to the duration of the migration. It seems that many birds make a halt at suitable spots, but others continue their flight without interruption to the end, while the weather permits.

It is marvellous how a bird can maintain such a velocity so long, yet we never see any signs of fatigue in migratory birds. It is only a violent storm that distresses them, and if they are surprised by one at sea thousands of them may perish in the waves. Many species of land-birds can alight in a calm sea without being drowned. Gätke has seen the snow-bunting, the mountain-finch, and the thrush do this.

Most ornithologists believe that it is the altitude at which the migration flight takes place that enables birds to make such long stretches; they say that the birds meet less resistance in the upper air. We are also often reminded of the special adaptation of the bird for flying - the air-sacs that are found in its body and the bones filled with air, which increase the volume of the animal 
and so lessen its specific gravity. The latter point is undoubtedly correct, and it is also true that a thin atmosphere offers less resistance to flight than a denser one. However, the chief use of the air-sacs, which extend in the form of hollow outgrowths of the lungs into the body-cavity and the bones, and between the muscles, is now thought to be that they spare the bird the trouble of respiratory movements during flight. In particular, the reservoirs of air between the flying-muscles are pressed together like bellows by the movement of the wings, and thus to some extent automatically renew the air in the lungs.

Besides this adaptation for flying there are many others. The bird is, as we say, a mass of adaptations. There is on its breast-bone a strong comb to which the flying-muscles are attached; the whole of the shoulder-blade is most beautifully constructed; and the rigid pelvis, formed by the fusion of a number of vertebræ, enables it to keep upright while sitting. In harmony with the laws of leverage all the heavy parts are placed in the centre of the frame; the crop supplies the place of teeth; the muscles of the leg are developed well up in the body, so that the limbs themselves are thin and light; and a particularly good digestion enables it to disburden itself at one effort. In a word, we could show the adaptiveness of every single organ, to say nothing of the feathers. Every stroke of the wings lifts the bird up; and as the wings are lifted the air rushes between the feathers, so that they meet no resistance. A wind coming from the front fills the wings, and enables the creature 
to rise rapidly without any exertion; and they can also easily fly with the wind.

We see, therefore, that the bird is enormously assisted in flying by the nature of its organism. We may now inquire whether the statements made with regard to the altitude it reaches are supported by observation.

When we follow the flight of birds of prey they seem to rise to immeasurable heights, and even the lark often passes beyond our vision into the blue sky. But it would be premature to draw any inferences from this, as we do not know how far we may not be subject to illusion by dazzling. The results of balloon observations are more important. In these an eagle was once seen at a height of 3,300 yards and a lark at a height of $\mathrm{I}, 500$ yards; but there were so few birds at this height that we must conclude they rarely rise above $\mathrm{I}, \mathrm{I} 00$ yards. It was also noticed that a pigeon, which was dropped from a balloon at a great height, first fell downwards, and only found sufficient resistance for its wings to use properly in thicker strata of the atmosphere.

However, these facts gives us no information as to the altitude of the migration-flight, and unfortunately we have not very many observations on this. Gätke was one of the few who have seen swarms of migratory birds go past, and he gives a superb description of one night in October in which this wonderful picture unrolled before him. It was a dark, starless night, only lit by the rays of the light-house which seemed to reach out endlessly into the night. The darkness, 
the perfect silence of Nature, and the consciousness of the nearness of the vast sea, awoke a feeling of sublimity in the soul of the observer. Then the cry of a bird broke the stillness, then a second, and the noise grew louder and louder, until at last countless flocks of birds of all kinds shone like sparks in the beams of the light-house, circling round it like a snow-storm, and then disappearing in the impenetrable darkness. Larks, starlings, plovers, snipes, and many other species were recognised by him. At one time an owl appeared, and then passed with loud flap of wings into the darkness, accompanied by the plaintive cry of a thrush that had been caught in the general turmoil.

When the moon and the stars shone, the sight was less splendid, as the birds then flew higher, and were not caught in the light of the lantern. It seems, then, from Gätke's observations, that the migration does not take place at a great height, at least on cloudy nights; and this has been confirmed by recent

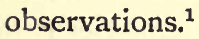

Aeronauts have let loose various birds from balloons, and it was found that in clear weather the birds went straight downwards. But if the balloon was above a thick stratum of cloud, the birds were puzzled and flew hither and thither, and settled on the balloon again; though they immediately left it when it fell below the clouds and the earth could be seen. They then made for the ground. The same thing happened if there was a break in the clouds through which the

${ }^{1}$ Gätke himself held to the theory that the birds fly high. 
earth could be seen from above. In that case the birds at once took their direction, passed through the opening, and flew downwards.

If we compare these observations with Gätke's it seems pretty certain that the birds do not need to rise high during the migration-flight. It is true that the question at what height they fly in clear weather is still far from settled, but we may say that, if they fly at a lower level in bad weather, yet probably reach their end just as quickly, a high level does not seem to be necessary for speed. Hence the rapidity of the migration-flight is not explained by the theory of the thinness of the air.

A second question now arises. When they are at a low level the birds can only see a small part of their route, and none at all during the night; how is it, then, that they choose the right way at such enormous distances? We will approach this question in the method we have used several times already, and inquire how the migratory instinct may have been developed in the course of time.

The actual migratory birds formerly lived, we assume, in southern latitudes, and gradually increased until they over-populated them, and food became scarce. The famine was worse in the dry season, when vegetation shrivels up in Africa, and the insects especially, which form the chief food of the actual migratory birds, were reduced in numbers. The hungry birds were thus compelled to abandon their habitation, and travel in every direction, seeking food and nesting-places in less crowded regions. A number of them came northward; 
and as fresh arrivals from the south came in later years of famine, the place was again too small, and they had to spread in all directions, including the north.

Could the spread towards the north proceed indefinitely? No; because the time came when the wanderers had passed the winter-limit. When the cold season broke on them, the earth became covered with snow, the streams froze, and famine set in again. What happened to the poor birds? Those that remained, waiting for better days, were destroyed, as the lack of food lasted longer than they could endure; others, that fled to the north, east, or west, found the same conditions everywhere and perished also; only those were saved that remembered their origin and the land of eternal summer, and returned southwards.

We may confidently assume that these little creatures, barely escaping from death, would not at once return to the north. But natural selection-for it is with this we have to deal-is inexorable. The birds were back in fully populated lands, and when the nesting - time came in spring there was no room for them; we know that most birds require a certain area for nesting, and will suffer no others of the same species within that area. The wood-pecker, for instance, and a great number of others, including our gentle robin, act in this way. What happened to these birds that had become strangers in their old home? Many of them failed to breed; these were the most timorous who would not return to the north, and died out through leaving no offspring. But there would certainly be bolder ones here and there, who would remember how they had 
nested undisturbed in the previous summer, and fly to the north once more.

This was repeated time after time. In a long period of time and certainly not without enormous numbers of victims, Nature fashioned a provident and hardy race of birds; provident because they would fly south as soon as the cold set in, courageous because they ventured back to their old nesting-places in the spring. Natural selection further regulated the time of flight. The birds were not to start too early from the south, or they would find their old nesting-place still buried in snow : and not too late, or they would not have time to rear their young so as to be able to make the great migration. The young would accompany the older birds when they gathered for departure, and would observe the route so as to be able to teach it to their own young afterwards. And as those that would not make the flight at the proper time were always destroyed, there arose the species of migratory birds which still carry out their flight with such wonderful exactness. ${ }^{1}$

'A German ornithologist, Kurt Graeser, has recently given a different theory of migration. He believes that the migratory birds are the original type, and the non-migratory have descended from them. According to him, the first birds lived on a very different land from what we have now. It had enormous stretches of water, ice-fields, steppes, and forests, which could give no food or shelter to the birds, and had to be rapidly covered in order to reach places with plenty of food. The primitive birds, therefore, must have had the instinct of wandering restlessly and swiftly over the whole earth. Gradually the birds would see that certain places were especially favourable for them. They flew to these more and more, and from this habit was formed the habit of definite migration. Later some of the birds found it better to remain in one place, and were adapted by Nature as required. The author believes that in time all birds would cease to be migratory, and adapt themselves to a different diet and the privation it would entail. 
At first the route was comparatively easy to find; but the further north they spread the more intricate it would become, the more strength it would require to traverse it, and the earlier the start would have to be made. But as they only spread gradually, this advance would be quite possible, as only the strongest would be able to meet the demands of the longer flight, and amongst their progeny, which would go still further north, again only the strongest would survive; so that the power of covering long distances in the shortest

To this theory we may object, in the first place, that there is no proof whatever of the earlier condition of the earth compelling the birds to cover wide stretches. In fact, it is not at all clear that steppes and forests would afford no food and shelter to them. It is just the opposite. It is not sufficiently borne in mind by the author that the migratory birds live on insects, and that the migration is precisely regulated by the alternate abundance of insects in the north and south, and that the use of this rich provision of sustenance is an admirable adaption. It would be a curious retrogression for the migratory birds to adapt themselves to food that is already so much sought by other animals. And to adapt themselves to privation! Further, the basis of selection, the over-production of progeny, is lost sight of, yet this is the principal ground of the migration. In the author's opinion instincts are inherited habits. We shall refute this theory in the sixth chapter; but even if we admitted it, what was the origin of the habit of the primitive birds to fly over the earth? Among the unconvincing objections that the author raises against other theories of flight we find the following: "The birds could not know that there was food for them in the south." But this difficulty only exists in the author's own theory, and for this it is formidable. How could the primitive birds know that they would find plenty of food if they made long and rapid flight over desert wastes? Finally, the whole theory is impossible because a simple reflection tells us that the first birds cannot have been migratory. The birds must have evolved from creeping animals; their ancestors were reptiles, something like the present lizards. It must have taken an enormous period of time for their flying organs to have become powerful wings; only after vast numbers of generations would they be sufficiently advanced to attempt long flights without resting. 
possible time, which excites our admiration to-day, was gradually developed. The faster the birds travelled, the more time they had for breeding, the more young they could bring into the world, and the more quietly they could rear them. Hence the speed of the flight was constantly increased by natural selection.

Gätke raises the difficulty that every blue-throat that must perform this rapid flight lives on the ground, and never really makes use of its wings except during the migration. Just as a man's arm becomes weaker if it is not used, so it must be with the blue-throat, and we cannot see how it will be able to make the enormous distance.

It is true that disuse enfeebles an organ, but as only those blue-throats survived that flew quickly in the migration, their strength was increased so much by natural selection that disuse could not lessen it muchat least, not enough to incapacitate them from flight. One thing is clear. If the impairing of the flying-power by disuse was inherited, the blue-throats would certainly become weaker and weaker. But this is not the case, and so it is clear that Gätke does not impugn natural selection, as he supposes, but the Lamarckian principle, by his difficulty. We will bear in mind this first case in which the principle conflicts with reality.

The second effect of natural selection was to increase more and more the bird's power of presentiment. The wanderers must not wait for the snow and ice to tell them that the winter has come, but must take their flight before these appear. Thus the marmot foresees the 
winter scarcity of food, and stores up grain in its den in the autumn.

Thirdly, the bird's sense of direction had to be improved. Otherwise how could they find their way on the long journey?

There is, however, another theory. Remember how we conceived the origin of the migration. Among the birds that penetrated further north only those survived that flew south at the beginning of winter. May not in some of the birds an instinct have arisen in the course of thousands of years, during which natural selection was at work amongst them, to fly straight to the south when the cold weather set in? These birds would thus be preserved, and might transmit this instinct-which does not differ essentially from the instinct that forces the salmon up the river-in increasing power to their offspring, And may not an instinct have arisen by selection to keep the route unerringly during the migration so that the animals will reach the warm countries in safety? Certainly the formation of a "magnetic sense" of this kind by natural selection is quite possible, and the Siberian traveller, Middendorf, believes it is present in migratory birds. ${ }^{1}$ Such an instinct is not more wonderful in principle than the marmot's instinct to store up grain, or the bees' instinct to build their ingenious cells.

But we know from observed facts that the migratory birds do not regulate their flight by a magnetic sense. They do not fly straight, but follow certain paths which

1 There are many animals with senses that cannot be reduced to any of our familiar five senses. 
often change in regard to the four quarters. A magnetic sense would be expected to guide its possessor in the straightest possible line.

The migration-lines of the birds show, on the contrary, that the travellers know the way to their old home, and that they travel along the same paths as their ancestors did. It is clear that the animals, in their extension northward, only sought localities that promised them sufficient maintenance. A sea-bird, though its nesting-places are spread far and wide over the shore, will not fly over the land, but along the sea, where alone its food is to be had. Now we find that the migration-paths of the sea-birds always run along the shore and never cross any extensive land, although their goal, the winter quarters, could be reached much more quickly by land. These circuitous routes are very striking in many species. The Richard's pipit, for instance, nests in East Siberia, and migrates from Heligoland to West Africa, instead of straight to China. ${ }^{1}$ How can we understand such an aimless direction, unless we admit that the paths of birds follow the ancient line of advance, the recollection of which has been transmitted from generation to generation? The animals spread gradually further and further north, and each time some of the descendants nested in a higher latitude than their ancestors. Hence the further north a species of migratory birds nests to-day, the more nesting-places of their progenitors must they fly over during the migration. And as these nesting-places

${ }^{1}$ Some of these birds, however, must fly to China and Ceylon. We must suppose that this variety has spread from the south of Asia. 
could only be where there was means of sustenance, the line of migration must pass over these localities, and so follow the ancient line of expansion.

This is seen in the paths of all migratory birds. River-birds travel along the rivers, though also over high mountains, as here also there are streams and lakes that afford them sustenance; while marsh - birds go round the marshless hills. Land-birds go straight ahead over the country, and only halt at the sea, and diverge along its shore. The fact that European birds still cross water, namely, the Mediterranean, is explained by the circumstance that there was not always water where the waves roll to-day. In the earlier periods of geology there were bridges of land from Africa to Europe, through Malta and Sicily as well as at Gibraltar. Over these the birds could advance gradually towards the north, and as a fact we find that the sea is only crossed by them at these points.

Let us now picture the migration to ourselves once more. A pair of birds travel to the north, rear their young there, and return with these in the autumn to the old home. In the spring they all return to the nesting-place of the previous year, but some of the young go still further north to build their nest. The journey in autumn will consist of two parts for these. They have already done the larger section of it twice with their parents; the second is the stretch from the nest in which they themselves were reared to the new home that they have made. But both sections of the journey are only the first part of the journey for their offspring, as these will add to it by advancing further 
north. In this way, from the fact of each succeeding generation adding a piece, however small, to the original journey, we get in the course of an enormous period the gigantic travels of our actual migratory birds. And as the route is only a little longer in each generation, selection does not make too exacting a demand on the birds, and there will always be some that can perform the longer journey.

Thus the power of flight has been strengthened gradually, and the sense of direction has steadily increased up to its present pitch. This sense consists especially in a marvellous memory, which has grown steadily as the route lengthened. If we did not know that it had been built up gradually, we should hardly be able to understand to-day how the birds can retain an impression of the routes they have only travelled over twice with their parents. But this memory is not so much a capacity for observing the path over the regions they have traversed as the power to keep the various directions that they took in their flight, and so there must also be a sense of orientation, or direction, that enables the birds to keep their way even when they are turned aside. That they do not need to any great extent to look down on the country is clear from the fact that night-time is often chosen for the migration. Nevertheless, they do need some sight of the earth, however faint and shadowy, otherwise they would rise above the clouds, and would not fly so low in bad weather.

However, this enormous development of memory in the migratory birds is not altogether strange. Even 
amongst men there are memory-prodigies. Who has not heard of the Hindoo who could repeat, word for word, long stories that he had only heard once. If circumstances arose that brought about the survival of such men alone, there would soon be a race on the earth with prodigious memories.

Nor is there anything mysterious about the sense of orientation that enables the bird to keep the right direction when its eye cannot see any point to guide it. There are men that can find their way in the forest without any path or track. We read that the Indians never went astray in it. We are, moreover, assured by some writers that dogs which have been taken away for hours together in closed carriages or trains will find their way home by the shortest, and a quite unknown route, when they are set free. Here we have something exactly similar to the migration of the bird, which, though it has been taken a long journey in the darkness of night by its parents, has retained the direction so well that it can follow the same route without guidance in the following year, and never go astray.

Finally, we must observe that the migratory birds are greatly assisted in keeping to the right way by the fact that their social instinct is developed especially strongly at the period of migration, and vast flocks of them make the journey together. Whether some older bird that knows the route from having migrated several times leads the way, has again been called into question of late. This is not necessary, however, as we have seen. In any case, it is an advantage to travel in flocks, because a large number of birds will be less likely to 
go astray than a few ; and the considerable power of communicating which the bird has will certainly help them to reach their goal more safely.

It was, therefore, an iron necessity that implanted the instinct of migration in the bird's breast. Their wonderfully developed faculty must have been purchased at the price of innumerable victims.

It was necessity also, that compelled our ancestors to migrate. They were forced to leave the primitive home that had grown too small for them, and was overwhelmed with other peoples. They were driven into lands where the hot sun melted down their northern vigour like snow, and where the dark waves of southern races passed over their blond and handsome features. So perished heroic races. But others remained, and retain the spirit of the old vikings in the life of Europe to-day. 


\section{CHAPTER IV}

\section{REPTILES AND AMPHIBIANS}

Principle of animal classification. The general properties of animals explained by heredity and adaptation. Darwinian justification of classification. Reptiles and amphibia of former ages. Earlier periods of the earth. How and why the earth has changed up to the present. How the remains of earlier animals have been preserved. Gaps in the remains of extinct animals. Primitive man. Conflicts of extinct animals. Why the gigantic forms of earlier ages became extinct. The death of species. Transformation of species. Why ancient species have been preserved. Why there are still animals of the simplest type. Predominance of a species of animal. Predominance of man. Any variation is possible. Origin of flying animals. Life of our reptiles. Prey. The creeping of serpents. Regeneration, the power to re-form lost members. Its origin by natural selection. Frog-spawn. The skin of amphibia. Repellent and warning colours on nauseous and poisonous animals.

THE man who devotes himself to the study of living organisms is overpowered by the inconceivable variety of their forms. He would have to despair of ever obtaining a grasp of the world of living things if he had not in language a means of ranging a vast number of forms under one convenient name. With one word he can designate countless numbers of animals, each of which is different from the other, by ignoring the differences between them and fastening on what is common to all the individuals. The word "fox" enables us to grasp a countless number of animals, by representing to us the common element of them all. 
Science pursues the same method. It seeks the common element in wider and wider groups of animals, and overlooks what is individual. Fox, wolf, weasel, marten, are regarded in their common features, and described as "carnivores" or carnassia. All "species" are distributed in "orders" of this kind. The work is carried even further. Some of the orders of animals are found to have features in common, and these are bracketed together as "classes." Finally, the "classes" are distributed into "stems." Thus the vertebrate "stem" represents what is common to the five "classes," mammals, birds, reptiles, amphibians, and fishes, namely, the possession, first of all, of an internal axial skeleton. This feature is not found in the other stems, the members of which are at the most covered externally with hard parts.

It is the merit of Darwinism to have established that there are in the nature which we really know no "species," but merely a countless number of individuals, each of which is unlike the other. Darwin has shown, in fact, that the feature which is common to certain forms, and enables us to grasp them as a "species," is not always absolutely fixed. When, for instance, we find that a number of individuals agree in having "long ears" and so can be formed into a species, differing from another or short-eared species, we see also that there are other animals with ears of intermediate length. Such animals could with equal right be put in either of the two species.

But while Darwin has destroyed species as realities, he has at the same time fully established the idea of the 
species. Formerly the common element that made it possible to distribute organisms into species, orders, etc., was taken for granted without discrimination. Darwin, and a few students before his time, have tried to show why there are common features amongst living things.

There are two laws that explain these common elements in the animal world. One is the law of adaptation; and we shall see later that adaptation to precisely the same conditions can bring such very different animals as worms and spiders to resemble each other. The second is the law of heredity. According to this law organisms have more in common, the closer their blood-relationship is. Any person can verify this from human life. However, it is not as simple as it seems at first sight, and we shall see, when we deal with the phenomena of heredity, that frequently men who are only distantly related resemble each other more than brothers and sisters.

The law of heredity gives a general validity to the classification of the animal kingdom, as it was set up formerly on the ground of common features; we have much the same arrangement when we classify them according to generic relationship. There are, however, many exceptions, and these are explained by the first law. Animals were formerly classed together which resembled each other externally through some similar adaptation. But the more thoroughly they were investigated, the more they were found to have in common with different animals, and they are now distributed in other orders and classes. This common 
element, which is due to the law of heredity, affects animals far more profoundly than the common features due to similar adaptations, which are generally external.

In our time it is sought to base classification exclusively on the law of heredity, all animals being regarded as a gigantic family and classified according to their degree of kindred. Thus the classification of animals has been intrinsically justified by Darwin. The common element on which it is now built is scientifically explained by the law of heredity.

In the present chapter we have to deal with two classes, the reptiles and the amphibians, and we can do this the more easily as both classes have few representatives in Europe. Reptiles and amphibians require heat. The temperature of their blood rises with a higher external temperature, and gives more vigour to their vitality. Hence it is that we meet more species of the two classes the further south we go, and more highly coloured and powerful animals in proportion to the length of summer in the district. The giants of the reptile class and the largest amphibians live in the moist tropical forests, where the rays of the sun are almost unendurable to us. The serpents wind through the bush like living branches of trees, the crocodile lurks in the broad river for the animals that come to drink, and the voices of the tropical frogs resound at night like the roar of oxen.

At one time it was different here.

Many millions of years ago, in what are called the Jurassic and Cretaceous periods, there were large 
numbers of huge reptiles in our own latitude. Where the wind now sweeps in long waves over the fruitful corn-fields, it then lashed the waves of a vast sea. In this ancient sea the plesiosaurus, a gigantic reptile with legs shaped into huge fins, swam hither and thither. .A head armed with sharp teeth crowned a neck eight yards long. It towered far above the water, and when unsuspecting fishes came along, the head shot down with terrific force, to emerge again with the captured prey.

The ichthyosauria were no less deadly to the fishes and still more to the cuttle-fishes, or huge polyp-shaped molluscs. Something like dolphins in shape and size, these reptiles disported themselves in great swarms in the sea. There were also reptiles on the land. The colossal dinosauri broke with heavy step through the thickets, one of them, the cetiosaurus (of which the brontosaurus was an American cousin), having a ridiculously small head. Another huge animal was the iguanodon. Like the modern kangaroo, the monster stood on its great hind-legs and heavy tail, and tore off masses of leaves with its small fore-limbs to thrust in its horse-like mouth. In spite of their huge size the dinosauri were harmless vegetarians. They had deadly enemies in the megalosauri, gigantic carnivores with teeth as sharp as knives.

Even the third element, the air, had its reptiles at that time. The pterosauri flew from tree to tree, spreading out the flying membrane that stretched from their enormously long fifth finger to the legs, and even to the tail. The best known of these flying lizards is 
the pterodactyl. It was not itself very large, but it had relatives with wings that measured eight yards.

We have to go further back in the history of the earth for the period when the amphibians flourished most. The largest forms of this class lived in the Permian and Triassic periods. These were the stegocephala, huge beasts that lay in ambush for their victims in the prickly thickets. The yard-long jaws of the mastodonsauri were armed with numbers of sharp teeth ; their belly and skull were protected by powerful armour, and they had, besides the two eyes, a third or cyclopean eye in the middle of the forehead.

The fact that the amphibians were before the reptiles in the history of the earth is a proof that the latter descended from the former. Geology shows that the succession of the five classes of vertebrates was the same in the history of the animal world as it is in our classification. The earliest geological finds known to us are remains of fishes alone, and these increase in variety. The first amphibians appear in the Carboniferous period, and they are followed in later epochs by the reptiles. In the Jurassic strata we find the first bird, the archeopteryx, of which we spoke above; and the mammals do not reach the height of their development until the Tertiary period.

But, it will be said, fishes are highly organised animals, and according to our theory there can only have been extremely simple organisms in the beginning. How is it, then, that we find fishes in the oldest strata ? ${ }^{1}$

${ }^{1}$ To be quite accurate, in the second oldest, the Silurian. But as these fishes bave an advanced organisation, it is clear that there must have been fishes in the oldest period known to us, the Cambrian. 
For the simple reason that, though these strata are the oldest known to us, they really represent terrestrial epochs that had many predecessors; but we have no documents relating to these periods. The book of the history of organisms only opens for us when there is already an immense wealth of forms on the earth. Besides fishes, there are crabs, mussels, and other animals, the development of which from the lowest organisms must have taken enormous periods of time. At first there must have been merely particles of living substance, and in comparison with the countless series of modifications that lead from one of these to the fish, the very much shorter series between the fish and the mammal is insignificant. We may say, therefore, that the pages of the archives of the earth's history that have been preserved only relate to the "modern period" of organic life, and that "antiquity" and the "Middle Ages" are lost to us, and will never be recovered.

The earlier of the geological strata lie below the later; the most recent lie at the top of all. As geologists penetrated deeper and deeper in their examination of the strata, and still found animal remains in the earliest deposits, there suddenly appeared, below the earliest fossiliferous layer, one that had no organic remains whatever. Experts still differ about these empty masses of rock. Many regard them as the crust that was formed when the surface of our planet, at that time a mass of molten liquid, cooled down. At this period of incandescence there cannot have been any living things, and we ask for the strata that lie between this crust and the deposit that contains 
the earliest animal remains. Here we find a yawning gap. No one can say what has become of the missing strata. Many think that they are at the bottom of the sea; others see them in the upper layers of the nonfossiliferous rocks, which have destroyed all the remains of animals in the incalculable lapse of time, and owing to pressure and decomposition. However that may be, we must take into account the fact that the whole period from the first appearance of life on the earth up to the development of these highly organised animals is hidden from us.

Moreover, our discoveries in the periods known to us are very defective.

In the fossil remains or impressions of former animals we have, as a rule, only the hard parts of organisms. Hence animals that had no hard parts could leave no trace of their existence. There is also another circumstance that tells us the remains we have represent only a small portion of the animals that lived at that time. The strata that contain the fossils are formed exclusively in water. The rivers carry stones with them from the mountains, grind them up into fine mud, and convey this to the sea, where it sinks to the bottom and covers up any remains of animals that lie there. These deposits of mud are gradually converted into solid rock containing the animal remains; and when the sea recedes, the rock becomes the basis of new land, and may be elevated into a mountain by the creasing of the earth's surface. If one of these strata is left dry for a long period, and then covered by the sea once more, a new stratum is formed on top of it. But there will be 
a wide gap between the new organisms and those buried in the older stratum, representing the time during which the earlier stratum was dry land. Thus we can understand the gaps in the passage from one species of fossils to another. Further, we can see from the nature of this sole means of preserving animal remains that land-animals can leave us no trace of their existence, or at all events only if they are carried into the water by accident and deposited quietly at the bottom of it.

But there will be a still further reduction in the number of animal remains preserved. All the seas of former days were not fed by rivers that brought mud to them, and in those without slimy bottoms animal remains would decay. Moreover, remains might not be preserved that fell into the water at places where the rivers brought down coarse debris into the sea, which would grind everything up.

Further, when the fossiliferous strata were raised out of the sea their contents were exposed to fresh dangers. An enormous amount was destroyed by weathering, rain, floods, and surge, carried away by the rivers and ground down into mud again, and so had to begin the cycle afresh. And when the crust of the earth burst, became creased or folded, and threw up chains of mountains, many remains were squeezed until they became unrecognisable.

Besides all this, the sea still holds from us incalculable treasures, and there are others in lands that have not yet been opened up. When we furttor remember how few of the remains that are found come 
into the hands of experts, we should not be surprised that we have not fossil remains of all the transitional types. We must not expect to find the remains of long series of ancestors of any particular species, showing us how it was gradually converted into a different one. We must not question the theory of evolution because no human skeletons have been preserved in which the non-human element predominates.

If, then, such discoveries are made, if the famous Steinheim snails ${ }^{1}$ bring before us the conversion of one species into another in all its stages, and if the Neanderthal skull and other human remains give us information as to a primitive humanity, we must learn to appreciate the fortunate accident to which we owe the preservation. As a matter of fact, however, we shall claim full credit for the theory of evolution precisely because the evidence of geology, in spite of its incompleteness, affords striking testimony to the truth of it.

We regard the remains of those monstrous reptiles with astonishment, and ask how it was possible for such powerful creatures to become extinct. We find, however, that towards the close of the Cretaceous period gigantic sharks appeared, measuring twentyeight yards in length, and we can well believe that they finished off a good many of the ichthyosauri. But

${ }^{1}$ These snails are found in immense numbers in the Steinheim deposits. One stem-form has divided into four groups of varieties, and the transitional forms have been admirably preserved. The stem-form is lowest in the strata, the transitional forms higher up in proportion to their divergence from it. 
how could the sharks develop to such a size, as they only appear at a time when the reptiles had long dominated the sea, and had been a danger to the ancestors - probably much smaller - of the sharks? We can hardly admit that the sharks would be developed so much more rapidly than the great marine lizards. In fact, we saw in the first chapter, in the instance of the fox and the hare, that two species that live in a biocœnosis cannot extirpate each other, as the strengthening of one species involves at the same time more protection for the other.

An effort has been made to explain by means of an example how a species that has lived with another for thousands of years may at last bring about its destruction. The process is supposed to have taken place between the machærodus and the glyptodon, mammals of the American Tertiary period.

The glyptodons were animals about three yards long, something like the modern armadilloes, which developed a powerful armour as they increased in size, and this protected the bearer, like the shell of a turtle, and was very thick. It afforded excellent protection against most enemies, but not against the machærodus, a tiger that also grew bigger and bigger, and stuck its enormously long canine-teeth, with edges like razors, into the glyptodont, in order to suck its blood, as its enormous teeth did not allow it to rip it up. We can easily understand how armour and teeth were improved by natural selection; in other words, how those glyptodons lived longest and reproduced most whose armour was impenetrable to 
most of the tigers, and how, when the weaker individuals had died out, only those tigers could survive whose long teeth could bore through the hard coat of the glyptodons. In this way the balance would change from side to side for ever, and it could never come to pass that "even the stoutest armour would no longer protect the victim, and the huge glyptodons be gradually extirpated." 1 Natural selection could only strengthen the armour of the armadilloes if it was near the limit-that is to say, if a slight thickening made it impenetrable for a large number of tigers. If the latter could suddenly overcome all the glyptodons, they must have lengthened their teeth to the extent of two generations of growth; and that would be a leap upwards in the evolution of the teeth, not a gradual advance. It is only on the latter, not on leaps, that we must rely in the modification of species by variation. We must, therefore, trace the extinction of the glyptodons to another cause. One might say, of course, that there were limits in the nature of the animal that would not allow the indefinite modification of an organ, and so after a certain time the armour of the armadillo could grow no thicker. Must there not be some provision that trees do not grow up into the sky? But we shall see in the eleventh chapter that this phrase, however imposing it may seem, explains

${ }^{1}$ Weismann. It is further said that the tigers got the advantage of the armadilloes by sticking their teeth into the unprotected neck. But that can hardly have been the case, as then natural selection would only have to form and strengthen a plate for the neck, and the dorsal plate would remain as it was, not being subject to attack. 
nothing, and we will keep clear of all attempts to explain things in this way.

Once the armadilloes disappeared it would be all over with the machærodi as well, since they lived exclusively on them; their long teeth prevented them from tearing up or eating other animals like the other carnivores. But would it not be possible for the teeth to be gradually reduced by natural selection? No; because the teeth were too long for the slight reductions that variation might afford to enable the animals to adopt a different diet, and so avert famine.

These two species, mutually affecting each other in their modification, could only be destroyed by some accident or other extirpating one of them. We can only suppose that, as a rule, it is external events that come to affect and destroy the relation of two species. If, for instance, in our old illustration of the fox and the hare, the mice increased enormously from some circumstance or other, the foxes, which feed on mice also, would propagate more freely owing to the abundance of food. If the mice then died off from some disease, we should find the numerous foxes reduced entirely to eating hares, and they would soon extinguish them altogether.

This illustration shows clearly what must happen for a species to be entirely rooted out-namely, some sudden accident. Dangers that arise gradually can be met by a species, which will be gradually modified. The danger must always be just great enough for individual variations of the menaced animals to escape it; and in the next generation only 
so much greater that new variations may again arise and preserve some animals from it. But if the danger arises suddenly, or is suddenly increased, the whole species affected by it must die out, as no single variation is considerable enough to evade it.

Thus the disappearance of the mice in our illustration is a sudden phenomenon that at once causes the hares to face an excessive number of enemies, which formerly only took part of their food from the hares. There was not time for the hares to change sufficiently to meet the numbers of foxes; their fertility could not at one stroke be increased enough to cover the enormous disappearance. There was no time for the selection of the fittest. If we assume that something of this kind took place in the case of the ichthyosauri, we can understand their extinction. The most probable contingency is that the sharks came in great numbers from another region into the sea where the reptiles were, probably driven out by geological changes. They increased at the expense of the ichthyosauri until the latter were completely extinguished. But the sharks could not suddenly reduce their fertility and size, and therefore had to go themselves on account of the lack of food.

We see, then, that a species can be extirpated by some event that occurs suddenly, in this case by the immigration of sharks. Physical changes have a similar effect. If vast steppes took the place of the rich vegetation of the Jurassic and Cretaceous periods, the herbivorous dinosauri would be without food, and would be destroyed. We do not know anything about 
their extinction, but must not forget that they might be converted into smaller types of animals; if, that is to say, the change in the vegetation took place gradually, and the smallest individuals, or those that required least food, were constantly selected. Another reason why they could not persist in their old size is that the very thick skull they had may have been a very good protection; but it meant only a very small brain. But a small brain would be quite insufficient to keep up the vital energy required in the active life on the steppes.

The pterosauri seem to have been really extirpated, not transformed, as we do not find their descendants in the birds. These flying lizards had naked bodies, and it is possible that a sudden lowering of the climate might account for their disappearance. The rapid setting-in of severe cold would not give them time to protect themselves by developing feathers, as their relatives, the birds, had already done. All reptiles are sensitive to cold in a high degree, as we see very clearly in the lizard, which only displays its full vitality in the sun. Hence it is that the giant-reptiles can only be maintained in warm countries, the tropical zone alone harbouring the mightier specimens to-day.

Thus a change of climate that alters a country may either compel a species to change, or, if it sets in with comparative swiftness, extinguish it altogether. But there is a third contingency. The species in question may migrate. In this way the species that lived in Germany during the glacial period retired to the North and to the Alps, where they are still to be found. 
Very few of them adapted themselves to the new conditions.

Physical conditions are bound to modify a group of animals when they change themselves, as we saw in the first chapter. This applies not only to changes of climate, but to volcanic changes, the drying-up of seas, the sinking of continents, and the folding of the earth's crust to form mountains. It applies also to modifications caused by human culture. Most of these factors may come into operation gradually, and modify rather than destroy species. In fact, even civilisation, which acts comparatively quickly, can modify species of animals if the nature of them is such that only slight variations are required to let them breathe the new atmosphere. We have an instance in the abovementioned case of the blackbird.

But there are also changes that arise quite gradually, yet extinguish a species. When, for instance, a continent sinks below the waves, however slowly, the landanimals living on it will be destroyed. What happens is, not that those animals are selected which are most accustomed to the sea, but the animals squeeze into the ever-decreasing territory, and when the time of the last subsidence comes it is too short to transform them into aquatic organisms.

We see, therefore, that animal species are only destroyed when sudden changes set in that make their former habits impossible; in other cases natural selection is given time to modify them.

The word "sudden" must not, of course, be taken too strictly. When an animal has, in the course of 
hundreds of thousands of years, been transformed from an arctic to a tropical organism, from one with a thick fur to one with a thin coat, it is clear that a fresh lowering of the temperature will be "sudden" even if it takes several thousand years; this period would not suffice to bring back the thickness of the fur which it took such a long time to abolish. Just as we speak in geology of "recent" times, although they may be hundreds of thousands of years away, so in the geological sense the word "sudden" may involve enormous periods. It means merely-so rapid that even favourable variations have not been able to meet the requirements of the change.

One more question. Can natural selection do everything, if it has time and material enough? Is it omnipotent in this respect? Can it transform any aquatic animal into a terrestrial one, and provide any land-animal with wings if it becomes necessary? This is answered in the negative by most scientists. Many of them grant some species the capacity of developing and deny it to others. They say there are four different types of animals: persistent, elastic, rigid and plastic. The persistent types retain their form for immense periods; there are still in our seas organisms that can be found in almost the same form in the oldest strata. Elastic types tend to revert always to the earlier form: rigid types have only a very slight power of adaptation, and generally perish when their environment changes: plastic types continually assume new forms as the conditions change, and thus conform themselves into new species. 
But it seems very questionable if there really are these different types of animals. Even the persistent types have been at one time evolved from lower organisms, and were therefore once plastic; their persistence is not an eternal and unchangeable feature. That many animals have remained unchanged for very long periods is clearly due to the fact that this form was the most suitable for the environment in which they lived. We must not forget that it is not absolutely necessary that all the individuals in a species shall be modified so as to produce a new one. Let us take the case of a species of aquatic animals in a pond. The scarcity of food caused by their multiplication will put those in a more favourable position that can travel on to the land and adopt a different diet. But if a large number of the animals leave the water, there is no longer any need for the others to become land-animals, as they have now plenty of room and food. Natural selection means pressure; new species are only formed when they must change in order to avoid destruction.

This is quite clear when we consider the origin of migratory birds. Here it was the migration that created the species, the animals wandering into new regions for which they needed new characters. Migration is an important principle in the formation of species generally. Thus the flying insects that reached certain small islands lost their wings and became a new species, because in this case natural selection always favoured the worst fliers; the good fliers were the first to tumble into the water. Animals usually only rise to more 
complicated and higher species when they reach special localities. We shall see this in a later chapter.

The physical conditions of our planet are always changing, it is true, and on this account the animals of to-day are, generally speaking, different from those of former times. But, on the one hand, there are undoubtedly spots on the earth in which the changes have not been very great, such as certain parts of the deep sea; and, on the other hand, many animals can retain their simple form in spite of considerable changes. Thus we can understand why the very simple organisms from which all living things have been developed are still found in every drop of water.

We will inquire further into the conditions that bring about the conversion of part of a species into a more complicated one, and leave the other part at the same stage of organisation. We have to-day not only the final twigs of the tree of evolution. We have worms, insects, vertebrates-in a word, living things at every stage of organisation. But most animals have changed, even when they have not gone beyond the range of this fundamental form. The reptiles that live to-day differ from those of former times, yet they are reptiles, and only a part of them chanced to get into such special conditions that birds were developed from them; and these were so favourably placed that they grew in number and variety of species, as the new element they had found had room for adaptation in the most diverse directions. But geology tells us of animals that have persisted in almost the same form for incalculable periods ; and we must assume that some very exceptional 
conditions made this persistence possible. As a matter of fact, such animals are very rare.

We must not say that the higher animals are better adapted than the lower. Higher only means, in the scientific sense, more complicated, not better. The bacilli that carry on the struggle of life and death with man to-day show clearly how they, the lowest organisms, have equipped themselves to meet the highest.

It is said that the Jurassic period was the age of reptiles. That is not correct. There were far more species that were not dependent on the giant lizards than species that were. Was the swarm of insects, or were the snails, subject to them? And if we take their size and variety as a symbol of predominance, we should have to say that the whales and elephants are the lords of the world to-day, if not the insects, which have more species than all the other classes.

No animal species has ever dominated a period of the earth's development, since there were always other creatures that were overlooked by them and had no relation to them. It is only since the domination of man began that we speak with some justice of a king of nature, as his civilisation is able to alter the fundamental conditions of animal life. But even here we are only partly correct. There are still countless species of animals for whom this dominion has no meaning.

We come to the conclusion that the species that have remained unchanged since remote ages have retained their form because they had no enemy that compelled them to change, and because within the limits of their own species they grew to meet the physical conditions 
of the period. They were never faced with the alternative of changing or dying. If this alternative had been forced on the generations very gradually, and always in proportion to the possible latitude of variation, we may confidently assume that they would not have failed to meet it because of some necessity for remaining unchanged.

We may also suppose that in all species of animals any change is possible if there is time enough for it. We are bound to admit this if our conception of the organic world is a scientific one. The tenth and eleventh chapters will tell us more of this. We will only say for the present that every particle of living matter has the tendency to vary. Every organ, every part of an animal, may change; and this change will in certain circumstances become the basis for selection. How much the structural plan of an animal may be transformed is seen very well in the intestinal worms, some of which have lost the alimentary canal altogether, and take their food through the skin. The nearest character will, of course, be used for change. And with what enormously different means it may be effected is well seen in the wings of animals. In bats and birds the fore-limbs have been converted into organs of movement in the air ; in the former the skin forms the air-beating surface, in the latter the feathers. The birds come from the reptiles - probably leaping reptiles. The feathers had already been developed, as a warm covering, from the scales, and amongst the leapers those certainly had the advantage which had the longest quills on the forelimbs, so as to act as parachutes in falling. This was 
the beginning of the organ of flight, and it was steadily improved. In this case the feathers afforded an easy basis for the making of organs of aerial movement. In the flying squirrel it was lateral folds of the skin; also in the flying reptile, in which they were further supported by projecting ribs; and in the flying fish the already flattened breast-fins were converted into organs of flight. The development of wings in the insects was very different. In their case a small projection developed at each side from the central body of the coat, and grew into two horizontal plates; with the central part of the body these formed a sort of shield that carried them through the air, like a parachute, when they leaped. The insects were originally jumpers, as the lowest species still are. But there are higher species, such as the grasshoppers, that only use their wings for leaping, so that we can well imagine that the insects that could save themselves by the longest leaps away from their enemy were those whose lateral plates were most extensively developed. This use of the plates was fastened on by natural selection for further development, and it at last produced a joint by means of which the plates could be worked backwards and forwards by muscles. Thus the wings were made, and were modified in each species in harmony with its vital conditions. ${ }^{1}$

Let us return from the past to the present.

The actions of reptiles and amphibians are mainly

1 Other experts think that the wings of insects have been formed from what are called their trachea-gills. These are small articulated plates in the abdomen of May-fly larvæ that live in water, and serve for breathing. But the wings are situated right in the middle of the insect's body, and so the theory given in the text is more probable. 
determined by instincts, and they have therefore no period of protected youth. When the little reptiles issue from the eggs, which have been hatched under the action of the sun's rays in a moist place, they have nothing to expect from their parents. All their instincts are rigidly formed from the first; their mobility is considerable at once, and the young of the viper have their deadly weapon, the poison, from the first day.

Still, some of the reptiles, especially the lizards, have a certain amount of intelligence. If a caterpillar creeps across their path, they know that the victim cannot fly away quickly, and they observe it with a certain curiosity for some time. Then the head is suddenly lifted up horizontally, and the snout, pointing downward, pounces on the prey. It is crushed with rapid movements of the jaws, brought into the right position and swallowed, and the little tongue passes for some time afterwards over the nose, as if it were smacking its lips after the delicacy. A quicker insect, such as a grasshopper, is not watched for some time, but is captured at one swift bound.

The serpent takes a great deal more trouble in capturing and swallowing his food. The smooth adder seizes its prey, which generally consists of lizards, winds itself quickly round it in three coils, lifts up its head, and opens its jaws wide to swallow the head of the victim. But the lizard also knows the only way in which it can escape, and opens its mouth wide; if the snake approaches, it tries to seize its lower jaw, and if it gets hold of it will not let it go until the snake 
releases it. Very large lizards often escape death in this way.

The defenceless frog, on the other hand, is completely at the mercy of its enemy, the ringed adder. When one is after him, he makes desperate efforts to escape, his usual measured jumps becoming gigantic in his anxiety. A plaintive cry comes from his throat, and he often abandons himself to his fate by crouching down, when he is seized by the snake. If the snake grasps his head the end is comparatively speedy, but it often seizes the foot first. It then forces itself, as it were, over the leg, its teeth gripping further and further forward; as these do not serve for masticating but merely for holding, in the snake, and as they are directed backwards, they easily allow anything to enter the mouth but prevent it from dragging or falling out. When one leg has disappeared down the snake's throat, it tries to grasp the other by a quick jerk, and if it succeeds its teeth go farther over the frog's body. The head of the snake swells prodigiously, there is a last desperate croak from the frog, and the jaws close over it like a living tomb. Surprise is often felt that such large frogs can be taken into the small head of the snake, but it is capable of enormous distension at the back; the anatomic foundation of this is that the bones of the lower jaw articulate with those of the upper jaw, which are drawn out far behind, and enlarge the gullet considerably when they open across.

Poisonous snakes go to work in a different way. These hunt almost entirely during the night, as they are generally nocturnal animals. The best way to catch 
the common viper is to make a fire in the wood at night. The unusual light attracts them, and they approach in amazement and stare curiously into the flames. During the day-time they are sluggish, and they coil themselves into a disk, with the head lifted up threateningly when a man approaches. We do not know much about the viper's method of hunting, but it is supposed that it gives the mouse, which is its chief article of diet, a deadly bite, and lets it die before swallowing it. It also penetrates into the dwellings of the mice; we can imagine the consternation of the little creatures when they suddenly see their enemy's eyes, sparkling with death, before them in their holes, and have no means of escape. There has been a good deal of inquiry into the viper's terrible weapon-the poison. If the wound is immediately sucked out and bound up the bite is not fatal, but there are frequent fainting-fits, and the final symptoms of the disease only disappear after six weeks. The best treatment of the wound is with permanganate of potash, and an ancient and constantly verified remedy is to drink a large quantity of alcohol.

The movements of the serpent are peculiar. They have no limbs, and can only glide along with the aid of the whole body. This motion has been compared to the progress of a rowing boat, because the serpent's ribs act like oars. The ribs articulate with the vertebral column and have free terminations, but are connected with muscles in such a way that they are pushed forward and pulled back again, which gives rise to serpentine motion. Other muscles, however, connect 
the ribs with the ventral plates, all of which end in a sharp edge, directed inwards. Hence when a rib is drawn forward, the edge of the corresponding ventral scale is brought into a vertical position and must take a grip in front; on account of its sharpness it cannot slip back, and when it is drawn to the body by the next movement of the ribs, the body itself must slide forward. By working the apparatus rapidly and extensively the serpent advances quickly enough, but can, of course, always be caught up by a human being. The lizards also have the aid of this winding of the body in running, and make use of the tail for the purpose; hence a lizard with a broken tail cannot get along nearly as quickly as one that has the full use of that organ.

Everyone who has tried to catch one with the hand knows that the lizard's tail is easily broken off. If you take hold of it by the tail, you will be sure to find this quivering vigorously in your hand, and its former possessor hurrying away without it. This is a great advantage for the animal; the number of tailless lizards one sees in nature show best how often the species is saved in this way. The chief enemy of the lizards, the smooth adder, generally catches them by the tail when it is after them; and if the tail breaks off and dances about in a lively way before the eyes of the snake, the latter eats it and the lizard is saved. The best way to catch lizards without injury is to take a long grass-stalk, make a loop at the end of it, and slip it carefully over the animal's head. It does not suspect its danger, and is captured by lifting up the stalk.

But nature, which has given this means of escaping 
to the lizard, has also endowed it with the faculty of creating a fresh one if it is lost. Three weeks after the removal of the tail there is a leathery prominence at the wound. This continues to grow, and forms a new tail, which is so much like the old one that it takes an expert eye to see the difference. However, the new one never becomes as long as the old one, and it may take two years to become perfectly similar to the old one in colour and shape.

The faculty of re-making lost limbs is called regeneration, and it forms a fitting transition from the reptiles to the amphibia. These have an even greater power of regeneration than the reptiles. It is true that a frog's legs do not grow again if they have been cut off, as many peasants believe, when they throw the poor creatures into the water again after amputating them; but the tailed relative of the frog, the newt, can reproduce a great part of the body. Its legs grow again when they have been cut off, the skin always heals, and even a new eye is formed when one has been torn out. The newts are exposed to the attacks of a large number of enemies; fishes, birds, and their own relations, are continually after them, but it is especially the large water-beetles that often clip off their legs with their sharp jaws, or bite off an eye. Hence the power of regeneration is confined to parts of the body which are apt to be frequently lost in this way; this happens especially to the newt's legs. The lizards are not easily grasped by the leg by their enemies, and so this has not the power to reproduce itself, as their tail has. A poisonous snake is never seized by the tail, because 
every animal knows that the only way of avoiding the fatal bite is to grasp it by the neck; and as for most animals, and a good many human beings, serpents are always serpents, the dread is extended to the adder. As a result of this we do not find the faculty of regenerating the tail in any serpent.

Thus we see that the power of regeneration has been developed by natural selection wherever it is necessary -where a species is constantly exposed to mutilation. This faculty is increased in proportion to the frequency of the mutilations, and is not found at all where it would be of no avail, where the enemies of a species destroy the whole animal when they catch it. It is on this account that we do not find any faculty of regeneration in the frog ; its enemies do not tear off pieces of it, but kill the whole animal, as we know to be the case with the stork, ringed adder, fox, weasel, hedgehog, and the innumerable other enemies of the frog. There is one animal, however, that mutilates the frog before eating it, and that is the tortoise. These approach the frog from the depth of the pond, as it sits unsuspectingly on the edge, seize it suddenly by the leg, drag it under the water, get the leg as far down the throat as possible, and then cut it off from the body with their sharp claws. When they have swallowed the leg, they tear other parts from their unfortunate victim, until nothing is left but the skeleton. In this case it would certainly be an advantage to the frog if it could escape after the loss of one leg and form a new one. But it is exceptional for a frog to be captured by a tortoise, partly because they live chiefly on insects, snails, worms, fishes, and 
salamanders ; partly because the animals themselves are rare. Natural selection does not provide for exceptional cases; it only brings about adaptations that meet average needs. A character can only be preserved when the majority of the animals that did not possess it would come to grief on that account. When a particular danger only threatens a species now and again, the animal that escapes it through some peculiar characteristic will have no prospect of bringing this to predominate in the species generally. The characteristic in question will soon disappear owing to crossing with others; while the majority, which do not possess it, will survive, because the danger is too infrequent to cause it to be selected. When we find in the animals that they only react by adaptations against dangers that are common in their life, this is an excellent proof of the operation of natural selection.

We shall make the acquaintance in later chapters of other animals that have a high power of regeneration, but will for the moment cast another rapid glance at the mammals and birds. If we bring before our minds the enemies of the various species of these two classes, their methods of attack, we see at once why they generally have no faculty of regeneration. It is true that the beak may be reproduced in the bird, and it is this especially that is exposed to injury, as it is the main implement and the weapon of the inhabitant of the air. Further, the skin can be regenerated in mammals; and if a wound we have received were not closed by scar-tissue, an infection by bacilli would inevitably follow. And when we consider the absence 
of regeneration in various parts of animals that have otherwise a high power of regenerating, its origin as an adaptive phenomenon becomes perfectly clear. The newts that re-form eyes and legs cannot regenerate internal organs. If we cut the lungs out of a triton, or the ovary or any other internal organ, and sew it together again, there is no regeneration of the part in question. Why? Because such a mutilation is hardly possible in nature, and so could not be provided against.

While the newt has this admirable power of regeneration to protect him against his enemies, the frog owes its maintenance generally to its enormous fertility. Their eggs, the familiar frog-spawn, are not only poured into the water in large numbers, but are also provided with a peculiar protective structure, which consists of a jelly surrounding the egg. This jelly prevents the eggs from being dried up or crushed, and especially protects them from enemies. Birds, fishes, crustaceans, and other animals are unable to eat the eggs, because they slip out of the mouth again. Everyone knows how difficult it is to handle frog-spawn. The transparent balls of jelly also act as lenses for focussing the rays of light, and thus attract movable plants, such as certain algæ, that produce oxygen, which is good for the eggs. The jelly also lets the rays of light pass direct to the eggs, and keeps them there, so that they are practically surrounded by glasshouses. The spawn is slightly heavier than water, and if a high temperature causes an increased outflow of gas from the plants, the bubbles collect on the spawn, and bring it to the surface, where it receives the full 
rays of the sun. When it is very cold, the outflow of gas ceases, and the spawn sinks to the bottom of the water, and is protected there from the wind and frost.

The wonderful contrivances of the frog-spawn show that all the stages of the animal's career are subject to natural selection. Only those animals have a prospect of transmitting their character to the next generation which lay eggs that will escape the eye of the enemy and the injury of bad weather. Whole pages might be written on the adaptations of the eggs in the early stages of the animals, and we shall see more about them later on.

We must not leave the amphibians without drawing attention to one of their best adaptations. This is the character of their skin. It is not merely that this represents the chief breathing-organ in this class, and so enables a lungless frog to survive longer; it also affords the greatest protection to the animal. The secretion of the cutaneous glands of the amphibians is well known, and a good many legends have been told of the salamander, which has been credited with the power of remaining unhurt in fire. There is this much truth in them, that the animal can remain for some time over a gentle fire, as its glands give out their secretion more freely under heat. But the purpose of this juice is to disgust the enemies of the frog. This is chiefly attained by the offensive smell, but also by the corrosive nature of the fluid. The toadsecretion is not poisonous for human beings, though it causes inflammation if it touches the eyes, but it may be fatal to small animals. 
Most of the amphibians that secrete offensive matter are brightly coloured. The fire-salamander catches the eye at once with its bright yellow spot on a black ground, the newt or water-salamander has a yellow belly, like the ringed snake; the latter have been seen to throw themselves on their backs at the approach of danger, so that the yellow under-side is suddenly presented to the astonished pursuer.

Light colouring is very common amongst malodorous and poisonous animals and plants. Of plants we have, for instance, the fox-glove, the laburnum, and many poisonous fungi; but as the flowers of most plants are brightly coloured-for reasons that we shall see in the sixth chapter-the poisonous flowers are not very conspicuous. This is more the case with the animals. Besides our amphibia, a number of malodorous and nasty-tasting butterflies and many marine polyps are brightly coloured. Offensive and poisonous organisms show red or, more generally, yellow colours; it can hardly be a matter of chance that in the colourlanguage of lovers yellow is regarded as a sign of hatred and aversion.

It is easy to see why natural selection has given a striking appearance to poisonous and obnoxious animals. It is an advantage to them to be recognised at once as inedible and dangerous. What use is it to an obnoxious animal if the assailant does not know that it has a nasty taste, and has to convince himself of it? The victim has generally to die under the test. So their poison is of no use to poisonous organisms if their enemies do not know them. The enemies die also after eating them, 
but this is a revenge that cannot bring the slain animal back to life.

In the case of many animals, such as the butterflies, one bite is fatal, and hence those poisonous and obnoxious animals were always selected which were calculated by their appearance to prevent enemies from trying whether they were edible or not. It is important, further, that all the marked animals should have as nearly as possible the same indication. Then carnivorous animals will not test the edibility of any new offensive creature that crosses their path, but will remember their experience of similar creatures and leave it alone. Hence it is that so many poisonous organisms have yellow colouring. There are even edible animals with the colour because it affords them protection; the value of this adaptation, which we will examine more closely in the sixth chapter, is obvious. Possibly this is the explanation of the two bright yellow spots at the back of the head of the ringed adder, which have given occasion for the pretty saying, that the snake, as the harmless creature is popularly called, wears a crown.

Natural selection has also given many amphibians a protective colouring, instead of the disgusting and warning colours. A toad closely resembles a clod of earth, the brown frog is not easy to distinguish from the soil, and the tree-frog can hardly be detected in the green foliage. The latter can change its colour-not voluntarily, but it assumes shades from brown to green according to its disposition, the weather, and the environment. 
The amphibians and reptiles may live for a considerable number of years, though our own species are not so ancient as the crocodile, of which the blacks say there are specimens that have sunned themselves on the same sand-bank day after day as far back as the memory of their fathers and grandfathers goes. It seems, however, that the tortoise may live for a hundred years, and toads have been kept in confinement for thirty-six years; they are not infrequently kept, as they are the most intelligent of the amphibia, and sometimes answer to their names. But the stories of toads living for decades inside blocks of stone must be relegated to the realm of fables. It is true that they can go a long time without food, and a much longer time with little food; this is due to their almost perfect digestion. But air and moisture are absolutely necessary for them.

It may happen that a toad falls into the shaft of a well during its nocturnal rambles, and, while its companions hunt and love and rear their progeny in the garden and the field, it is condemned to maintain a pitiful existence on a few insects, and so may become as "old as the hills."

Even the animal has its destiny. 


\title{
CHAPTER V
}

\author{
FISHES
}

Origin of terrestrial vertebrates and of lungs. Similarities in the structure of animals. Transformation of organs. Creation or evolution? Many animals are worse off than others. Selection only creates what is necessary. Atrophy of useless organs. Rudimentary organs in man. Degeneration of organs by panmixis. Indifferent characteristics of animals. The differences between species are adaptations. Correlation. Animals that are beyond the range of selection. Qualities and quantities. Explanation of atrophied organs by economy of sustenance and negative selection. Impossible to explain many rudimentary organs. The biogenetic law. Gills in the human embryo. Predatory fishes. The rhodeus and the pond-mussel. Senses of fishes, their dangers. History of the eel and the salmon. Artificial selection of fishes.

As we make our way down from the sunny heights of the forest-crowned hills to the green valley, we often halt for a moment, when our eye falls on the brook by the way, and catches sight of a trout. We admire the ease and restfulness with which the animal meets the rush of the water over the stones.

But there is something more wonderful in the power of the fish to penetrate into the depths of the sea, and remain there without any exertion of the muscles. As a fact, the fish can halt at any depth without moving a fin; it has a special organ that enables it to do this. The swimming-bladder is the name of this organ, and 
anybody who has ever killed a fish will remember the large structure filled with air. The bladder is surrounded by muscles, and when it is compressed by these the fish descends in the water. As the fish has about the same specific gravity ${ }^{1}$ as the water, it becomes heavier when the air in the bladder is compressed, and so descends; when the pressure is relaxed, the air expands in the bladder, the volume of the fish is increased, it is specifically lighter, and it rises to the surface. Pressure on the front part of the bladder causes the head to sink; pressure at the back sends down the tail.

In about half the species of fishes the bladder is connected with the gullet by a duct. This is especially developed in the dipneust or mud-fishes, which live in tropical waters that dry up in the rainless season. In many species the bladder is double. When the water disappears from the pond they live in, and they find themselves on the mud, the bladder takes over the function of breathing from the now useless gills. They absorb the oxygen from the air that presses into the bladder through the gullet, while the carbonic acid that must be given off from the fish's body passes away by the bladder and its duct.

The mud-fishes are most interesting to us, because they show that an organ which seems to make its appearance suddenly in the land-vertebrates is really found in a rudimentary form in the fishes. If we had not the mud-fishes, we should scarcely be able to

1 The reader will know that we mean by specific gravity the number of times that a body is heavier than an equal volume of water. 
imagine how the first land-animals could breathe, as they would need an organ in some proportion to their size. How could this be formed so quickly, seeing that natural selection only builds up gradually from small beginnings? The mud-fishes remove the difficulty. They afford most striking testimony to the theory of evolution and natural selection, as they show that where selection required a large organ as the beginning of the lungs, it was forthcoming. It is well for us that in the peculiar localities where land-animals arose some of the transitional forms are still preserved; the more so as geology could give us no information on the transformation, since soft parts are never fossilised. ${ }^{1}$

The transition from the fishes to the amphibians is seen, not only in the mud-fishes, but in the development of every frog and salamander. The larvæ of the amphibians, when they issue from the egg, breathe by gills, which closely resemble those of the mud-fishes. In fact, the whole organisation of the larvæ is closer to that of the fish than to the adult of the species they belong to.

Even the adult amphibians very much resemble the fishes; all vertebrates must do so, in fact, if they have descended from the fishes. We know how natural selection, which must have brought about the transformation, works. Variations in different organs of the parent species, which are trifling at first, are emphasised in the course of several generations.

1 There are, however, recent experts who think the lungs were formed, not from the swimming-bladder, but from sac-shaped folds or outgrowths of the fore-part of the gut. 
Hence in the comparatively brief period-geologically speaking - since the appearance of the fishes, no species could be developed from them with a fundamentally different structure from their ancestors.

There are no organisms that descend from the vertebrates, and differ from them so widely, as the fishes do from the insects; the chief reason is, that there has not been sufficient time for such a transformation.

We can understand, therefore, why the structure of all vertebrates is essentially the same. All of them have an internal skeleton, and have the organs of nutrition and reproduction on the ventral side, and the nervous system on the dorsal side. But the similarity goes still further, and this also is clearly the effect of natural selection. Selection always builds on a given material; it makes use of actual adaptations, preserves them when change is unnecessary, and modifies them when some new adaptation of the species requires it. If, for instance, there was already amongst the fishes a skull with the function of protecting the brain, there was no need for the formation of a new structure to contain the ever-growing brain in the classes that developed from the fishes. Therefore, the bones of the fish's skull were retained in the new classes, and were enlarged and modified according to need. As a fact, even the human skull is generally composed of the same bony plates that we find in the fishes. It is well known that students used to be puzzled by the fact of the upper jaw of all vertebrates containing four pieces of bone, while in man it had only two, until Goethe discovered 
the two "intermaxillary bones" in the child, and showed that they fuse together in the adult, and cannot be distinguished any longer from the other two jaw-bones.

It is the constant practice of natural selection to build on actual material, and that is the quickest way of accomplishing anything. Hence, when the amphibia took to living on land, and needed support for the body and organs of locomotion, the four fins of the fish were converted into the limbs of the land animal. In the lower fishes the joint of the jaws is formed of two bones, which are replaced in the higher ones by a greater development of the articulating bones. The abandoned bones are found in the higher animals only in the internal ear, where they still form a joint as the "hammer" and the "anvil"; but instead of mastication, it serves for conducting sound.

We could show that nearly all the organs of the vertebrates are found in all the five classes, and have always the same fundamental form and structure. We have seen in the previous chapter that Darwinism explains these similarities, great and small, by the law of heredity. The children of a certain couple of human parents are more like each other than their children will be-or brothers and sisters are more like each other than cousins-and it is just the same with animals. Birds are nearer to reptiles than to amphibians, because if we look upon the actual reptiles as brothers of the actual birds, the actual amphibians, will be their cousins. It was from reptiles that the birds descended, and the ancestors of all 
reptiles consisted of a pair of amphibians that reached special conditions, and so their offspring formed a new class. These amphibians lived about the end of the Carboniferous period. Their ancestry coincides with that of the other amphibians living at the time, whose descendants are found in our frogs and salamanders; earlier still, it is a pair of fish ancestors that led to the beginning of the amphibians in a particular locality.

This similarity of organisms is a hopeless puzzle for the theory that all our animals were created separately. On that theory it is unintelligible why some animals so closely resemble others in structure, others still more, and others not at all. It can give no explanation of these facts. Moreover, it cannot explain why certain species seem to be in a much worse position than others. Thus, for instance, the circulation of the blood is clearly worse in the frog than in the bird. The frogs have only one chamber to the heart, and this has to receive both the usedup blood from the body and the fresh blood from the lungs with its new oxygen. The blood mixes in the single chamber, and the body is not supplied entirely with fresh blood, but with the mixed fluid, which passes from the heart into the body. In the bird the chamber is divided by a partition; the fresh blood from the lungs passes into the left half, and is conveyed in its purity from this to the body, while the right chamber receives the used-up blood and drives it to the lungs to be renewed.

The birds, with their constant supply of pure blood, 
are obviously better off than the frogs, in which the oxidised blood that should go to the body is always mixed with the bad. Why were the frogs placed at this disadvantage at creation? Have they less right than the birds to a good constitution?

Natural selection explains the riddle. From the heart of the frog has been developed that of the amphibian, then that of the reptile, and from this in turn that of the bird. When the amphibians appeared, the heart was at the stage of development in which we still find it in that class. This structure sufficed for those descendants that remained amphibians, but not for those that became reptiles and birds. In the case of the latter, the heart had to be improved, because the more energetic vitality of the two new classes required a better supply of blood. Natural selection only produces what is necessary; the amphibians had to retain the old heart, because they did not need a more advanced one.

But all the organs cannot be retained when a species is transformed into a different one.

When complete land-animals had been formed from the fishes, the gills became useless. In fact, they would be injurious to the new organisms, as they perforate the sides of the gullet, and would allow foreign bodies to pass too easily into it. Thus, for instance, it often happens to the greedy perch that his prey sticks in his gills from trying to swallow it too quickly, and both animals perish. As soon, therefore, as the gill-clefts ceased to be absolutely necessary for breathing, they had to be got rid of by natural 
selection on account of their dangers, which were increased by life on land. Here we have for the first time the negative action of natural selection. We see that it can not only create new organs, but also destroy actual ones when this becomes necessary for their possessor.

It often happens that when an organ has to be adapted to a new function parts of it will degenerate.

When the fore-extremity of the reptile was converted into a wing in its descendants, the birds, it was useful to the latter to have the new organ in one piece, in order to work it like an oar. Projecting fingers would have offered resistance to the air, and would have brought continual wounds to the bird by getting broken off. Hence, in the interest of the flying-organ, the fingers had to disappear. As a matter of fact, in the bird's wing to-day we find only the rudiments of five fingers, though the archæopteryx had them well developed and active. There are plenty of instances of a similar decay in the interest of a unified support; amongst others, we might mention the leg of the birds and the ungulates. What seems to be the knee in the fore-leg of the horse corresponds to our wrist. The large bone that passes from this to the joint of the hoof is the upper part of the middle finger; it has been developed to this extent because it can bear the weight of the body better as a single support. But at the side of it we find two other small bones, which are attached to the joint above, and are called the styloid bones. They have no function, and cannot be understood except 
as relics of the second and fourth fingers; we can recognise them as such the more confidently as we can trace in geology every stage in the gradual degeneration of these fingers in the horse's ancestors. These degenerate structures are known as rudimentary organs; they lend great support to the theory of evolution. If the animals were created separately, why were they endowed with these quite useless appendages? We can only understand them when we admit that they were fully developed and useful, in the ancestors of the particular animal, and that in their descendants, which had no further use for them, owing to change of habits, they could not entirely disappear, because the animals had inherited them and transmitted them in their turn.

We find rudimentary organs of this kind in almost every species of animals. Man himself has a large number of them-nearly a hundred. Amongst others there are the last two ribs, the wisdom-teeth, a process of the shoulder-blade-the caracoideum, a vesicle in the brain that we call the pineal body, and the wormshaped appendage of the cœcum. The latter is not only superfluous, but even dangerous, on account of the inflammation (appendicitis) that may be set up in it by the penetration of foreign bodies. There were vegetarian mammals amongst our ancestors. And in plant-eaters the cœcum is often indispensable, and is often longer than the whole body of the animal.

In the same way the caracoid process of our shoulderblade is an important bone in reptiles, amphibians, and birds; and in the pineal body we have the last relic of a 
cyclopean eye that was used by the ancient amphibians, and resembles a small eye in a certain living reptile in New Zealand. The more we examine the anatomy of the animals, the more rudimentary organs we discover. In the whale the pelvis and hind-limbs remain as shrunken relics buried in the flesh; and amongst the serpents there are species that still show rudiments of the pelvis.

In the case of many of these organs the reduction is due to natural selection, which has a much greater significance in this direction than most experts admit. But it does not explain every case; above all, we can only understand with its aid how an organ can be reduced to a body that is indifferent for the lifepurposes of an organism. We have already spoken of those island-dwelling insects that have had their wings reduced to small relics, because those that could fly well were too frequently carried by the wind into the sea. In this case natural selection had to reduce the wings until the insects could not raise themselves with them any longer. There its function ceased. It could not make the wings any smaller, because if no insect could fly any longer, there was no ground for selection, and for the function of flight-the sole cause of selection-it was a matter of complete indifference whether or no the wings were reduced by another fraction of an inch.

There are also insects in Europe that never fly. These are the females of most of the bombycidx. When they emerge from the pupa-covering, they remain in the same spot, and are sought and fertilised by the active males, and then lay their eggs. The reason for 
this peculiar instinct may be that, in the first place, the animal, which is well adapted to the bark of the tree, protects itself and its eggs best by remaining still; and, secondly, that the body is too much burdened with eggs to be able to fly. If it is better for the animal not to fly, this instinct suffices to prevent it, and natural selection has no occasion to reduce the wings, as has been done with some of the silk-worms, such as the orgyia, the wings of which have shrunk into small relics. But if the disuse of flight depends only on the overloading of the body with eggs, we do not very well understand the reduction of the wings at first sight. Can it be useful for the butterfly to have the nourishment that usually goes to the wings diverted to the rest of the body and the eggs? When we remember the enormous multiplication of the black arches which still have wings of the full size, we shall not attach much value to this economy of food. Nor can we quite admit, in the case of the whale, that those individuals always had an advantage whose hind-limbs were a trifle shorter than those of their comrades, and so required slightly less food. In view of the enormous mass of muscle and fat in the colossus, this slight economy could never become a matter of life and death, even if it is useful at all to the other organs.

But, we may further ask, is natural selection bound actively to reduce an organ that has fallen into disuse? Do we not know that such an organ must deteriorate when selection ceases to affect it? Every organ only advances from the fact that the individuals that have it in a poorer form are destroyed. When it becomes a 
matter of no consequence whether an organ is in good or bad condition, those animals will survive and reproduce who have it in an inferior form; this inferior organ will be transmitted to the young, and the number of individuals of that kind will increase in every generation. For instance, there is no need for civilised man to have good eyes. Those with poor sight can earn their bread and bring up a family, by using glasses or adopting a field of work in which shortsightedness does not count.

This process, in virtue of which even the inferior specimens are preserved, reproduce, cross constantly with the others, and so affect each generation more and more, when natural selection ceases, was first pointed out by $\mathrm{W}$ eismann and given the name of panmixis. But the effect of panmixis is not as simple as it seems at first sight, and it must not be exaggerated. It cannot bring about the reduction, but only degeneration of an organ. We will now see how this takes place.

In a complicated organ, such as the eye, for instance, a number of different parts co-operate to discharge its particular function. All these parts form a harmonious whole, and if the organ is to be improved, they must all be modified in the same direction. An organ of this kind is like a regiment of soldiers marching in rank and file. Order is only preserved as long as each individual remains in his place, or moves just in the same way as the rest. If one marches in one direction, another in another, the unity of the whole is destroyed, and the greatest confusion prevails.

The harmony of the parts of an organ is secured by natural selection. The parts of the eye vary like 
every other living thing. If the eye is to retain its efficacy, no part must be greatly altered unless the other parts change in the same sense. If one of the parts of the eye is suddenly and separately developed in an animal that absolutely needs good sight, it fails in the struggle for existence, and with it disappears the inharmoniously developed eye. There is only one way of improving the eye, but there are plenty of ways of spoiling it. Hence if selection no longer watches over the harmony of an organ, each part will vary on its own account; one part will advance in this direction, another in that, and the end of it will be the spoiling of the whole organ.

It is clear, then, that panmixis, or the mixture of all possible animal variations without weeding out the bad ones, must lead to the degeneration of an organ. But does an organ become smaller when selection ceases to act? Diminution of size is the chief characteristic of rudimentary organs.

Certainly, when natural selection no longer prevents the reduction of an organ by cutting off all variations towards diminution, these will persist and be transmitted like the rest. But are there not always variations in the direction of increased size? Why should the reducing tendencies suddenly prevail? Natural selection cannot influence variations; it can only accept or reject those that are offered to it.

As a matter of fact, it has been proved beyond question by a number of investigations that variations towards increase and decrease - plus and minus variations, as we call them - are as a rule equal in 
number. Hence if selection ceases to weed out the one group, all the animals will come to reproduce and cross with each other; in the general mixture the plus and minus will neutralise each other. The larger variations cannot prevail in the succeeding generations, because they are affected by just the same number of smaller variations. An organ that is subjected to panmixis will thus become neither smaller nor larger, but remain of the same size. It will become one of what are called the indifferent marks of the particular species - a mark that has no connection with the essential life of the animal, yet is tenaciously retained in the structure. Are there any of these indifferent marks in the organic world?

In the first place, it is always precarious to describe certain characters of animals as indifferent. In earlier years all that we have recognised to-day as adaptation was regarded as a mere mark of the species. Every year there are fresh discoveries of adaptations; we are constantly finding an important vital significance in parts of animals that had been regarded as of no consequence whatever,

Nevertheless, they may be indifferent organs, and we can easily imagine how they may arise. When one species is formed from another, a whole series of organs are modified to meet the new conditions. But the new species will also inherit from the parent species features that were necessary to the ancestors in their particular conditions, but have no use in the new environment.

If these organs were in the way of the new life, they would, like the gills of the fish and the fingers on the 
bird's wing, be reduced by natural selection until they were harmless; but if they were of no consequence either way to the new species, they would remain unchanged in size, because their plus and minus variations would neutralise each other. They would only change their size in the event of the total size of the new species having to be altered.

The province we have now entered is a very delicate one, because, as I said above, we can never know whether a characteristic of an animal, the use of which is not visible, may not be indispensable all the same. In any case, it is certain that indifferent features do not form the chief criteria of species and classes, as has been said; nor is it true that the adaptations are not concerned in the discrimination of species. It has been justly replied to these writers that it is precisely the adaptations that constitute the species or the class as such. What else is left in the whale if we take away its adaptation to aquatic life? What becomes of the bird, which, as we saw above, consists entirely of adaptations to aerial life? If we look at species in this way, we feel inclined to say that there is nothing indifferent in an animal.

Hence we see the rise of new species especially in the selection of new adaptations. In this, indifferent organs may be taken over; in fact, it is possible for them to appear for the first time. Darwin himself established a law that he called the law of correlation. According to this, the various parts of the animal body mutually affect each other in growth. Everybody knows, as a matter of fact, that organs that. 
seem to have nothing to do with each other may influence each other. Thus, when a man is emasculated, he retains the high voice of the boy, and never grows a beard. Women who are about to become mothers suffer from nausea, vomiting, and a number of other afflictions. In a word, we have numerous proofs of the co-operation of different parts of the body.

Thus, when an organ has been adapted to new conditions and modified in the making of a new species, a structure may arise in another part of the body from a chain of causes that escapes our scrutiny. We put chandeliers in our rooms to light them, for instance. But we heat them at the same time, as well as illuminate them. This is a constant and necessary concomitant of the lighting. We had no intention of causing it, but we have to reckon with it because we cannot have the gas-light without it. ${ }^{1}$

Owing to correlation many organs may be preserved that are of no consequence to the animal's life. Other and important organs prevent them from changing their dimensions or quality, because they are in some way or other connected with them, and as they themselves must remain in the interest of the species, they retain the others with them. However, we will make as little use as possible of this principle of correlation, because we know little about the mutual relations in the animal body, and so the whole principle is not well grounded

${ }^{1}$ Many writers explain in this way the colours of the various races of men. They think it is a necessary concomitant of the adaptation of the skin to different degrees of heat; the skin does, in point of fact, behave differently in relation to perspiration and immunity against fever. 
on facts, and lends itself to abuse and misuse in all sorts of cases. Many Darwinians hide behind this principle whenever they cannot discover real explanations.

We saw that an organ from which natural selection has removed its hand remains of the same size, but deteriorates in quality. How is it with an animal that is outside the range of selection? We see this in the case of our domestic animals. Apart from cattle, horses, pigs, and fowls, and especially dogs, of which we produce larger and smaller races by artificial selection, and the organs of which have been modified by selection, we see that, as a matter of fact, the size of domestic animals generally remains the same. Take, for instance, the cat, the fallow deer, and the common pigeon that is found on every roof. The parts of these animals scarcely change in size, though they do in another particular-colour. The reason of this is that qualities do not vary in two opposite directions, that neutralise each other in crossing, but in several. Still, there are colours the microscopic structure of which compels them to appear either in a light or a dark shade, and these will be preserved in panmixis.

As a general rule, however, the colours of animals must be preserved by natural selection; this is seen in many wild as well as tame animals, the variations in the colour of which clearly involve no danger to the species. Take the varying colours of the common viper, or those of the male hedge-lizard. But there are also colours in which variation is only possible in one direction so that they can never be neutralised. The Alpine hare is pure white; and as there is nothing whiter than white, 
all shades of this animal's colour must be darker. Here we have a clear case where natural selection keeps a thing at a certain height. As a general rule, we do not find it to do this, but to tend uprwards. ${ }^{1}$ Nothing is absolutely good. The eye of the mammal seems good to us, but the bird shows that there are better ones. However, even if selection remains at a certain level in the case of many qualities, it certainly never does that with quantities, as in that case it would have to weed out plus and minus variations. But as these neutralise each other by panmixis, there is no need for the action of natural selection.

We know now, therefore, that panmixis cannot reduce the size of an organ. How, then, can we explain the rudimentary organs?

This would be easiest to do, it is clear, with the Lamarckian principle. The organ that is no longer necessary, this theory would say, is no longer used. It grows weaker and weaker by the disuse, and is transmitted to offspring in an enfeebled condition. This continues until the organ entirely disappears owing to the steady inheritance of the results of disuse.

But we saw above that the wings of the blue-throated warbler, though they are not used, are found in each individual of the strength and size that the long migration requires. This circumstance led us to distrust the Lamarckian principle, and as we shall conclude in the sixth chapter that it is completely untenable, we will not delay with it now, but try to explain the rudimentary organs by other means.

1 Or, of course, downwards. 
We have already recognised the significance of selection in the reduction of organs. I may remind the reader of the wings of the island-insects and the fingers of the bird. There are snails, too, with small shells right at the posterior end. They feed on earthworms, and it is possible that their malformation is due to the fact that the snails with the smallest shells were best able to follow their prey into their holes. There may be many cases that selection can explain, but as we saw, it cannot explain all the rudimentary organs.

Another principle is that of economy of nourishment. Every animal, it says, has a limited amount of nourishment in its body, and if one of its organs is to grow bigger, the material for it must be taken from another part of the body. If, for instance, in a certain species the strongest possible support for the body is required, as in swift-running animals of a certain weight, the shinbone must become thicker, as this is always the chief support of the body. In that case natural selection will always choose the animals with the strongest shin-bones (tibiæ), and possibly at the same time, indirectly, select smaller calf-bones (fibulæ)-if, namely, the shin-bone has obtained its increase in size at the expense of the fibula. Now, there is certainly only a limited quantity of nourishment in the bones, and it seems possible that for one bone to become larger it must take the food that would have gone to the other bone. In this way the continuous selection of strong shin-bones might gradually bring down the fibula to the dimensions it actually has in the horse and the bird. 
But on the other hand, any animal can take up a position without displacing another one, and we can imagine cases in which, when variations occur in the tibia and fibula, the former may be larger and the latter no smaller, or both bones may be stronger. Such variations have then a greater quantity of nourishment in the body. But perhaps the growth of the tibia at the expense of the fibula is the most frequent and normal variation, and natural selection had especially to deal with individuals that had a larger tibia and smaller fibula. If such variations were more common than those that had the greater amount of nourishment, the fibula would be bound gradually to disappear.

We might give a further extension to our principle, and say that nature always chooses the nearest way; and appeal to physical forces that also do this. In that case the body would be bound first to use up the already existing and now superfluous elements in its further construction. Yet when we reflect that, on this assumption, many indifferent characters must disappear, we shall not be too hasty in applying our principle. We have as yet made so little progress in studying the nature of the body! We must, therefore, modestly admit that our actual knowledge is not sufficient to explain the rudimentary organs. Selection and economy in food may be the cause of the reduction of a good many organs, but certainly not of all ; and panmixis only explains the deterioration, not the diminution, of an organ. Weismann has recently tried to enlarge panmixis with his theory of germinal selection, and has credited this with the power of making organs 
rudimentary. But we shall see later on that we cannot accept this principle.

However, there has been one result from our inquiry. Although we were unable to discover the causes that account for the rudimentary organs, their existence is a convincing proof of the theory of evolution. We cannot understand the existence of these useless organs unless we suppose that they had a purpose in the ancestors of their possessor, and were then fully developed; and that they had to be transmitted steadily to posterity by the force of heredity. These useless appendages can never be reconciled with a theory of creation.

Still greater is the testimony to the evolution of organisms of the rudimentary organs that appear and disappear in the lifetime of an animal.

We said at the beginning of this chapter that an amphibian shows, in the course of its early development from an aquatic to a terrestrial animal, how a salamander or a frog must have evolved from a fish in past ages. We find similar reproductions of its evolutionary history in ancient times more or less in the embryonic development of every animal. All living things descend from protozoa, the microscopic beings that we find in a drop of water; and every animal begins its life at the same stage, since the ovum entirely resembles one of these protozoa. After the protozoa came the polyps, from these the worms, and from these again the fishes. Now we find in the development of every vertebrate ovum, including the human, stages that may be compared with those three forms. Haeckel gave the name of "the biogenetic law" to this phenomenon, and attached a 
very great importance to it. It is believed to complete our geological discoveries. Just as the various epochs in the earth's growth show first lower then higher organisms, so we find the same gradation once more, in a condensed form, recapitulated in the embryonic development of every animal.

We shall deal more fully with the significance of the biogenetic law in the seventh chapter. Here we will only point out by means of it why rudimentary organs appear and disappear in the evolution of animals. This we find to be the case. The human ovum needs nine months for its development. In the fourth week it has made considerable progress, but is very unlike a human being, and much more like an animal. It clearly shows slits like the gill-clefts of the fish on each side, and has a striking resemblance to the fish in the arrangement of the heart, the blood-vessels, and the bony skeleton. The clefts are of no use whatever to the unborn child, and they soon disappear again. We may confidently say that there is no stronger proof of man's descent from the fish than these gill-clefts, which are still retained in the descendants of the fish-men - in virtue of the law of heredity, although they have had no purpose or use for millions of years, and they disappear in the further course of development.

Thus we have got back to the fishes from which we started. They are not only of importance as the lowest class of vertebrates on account of their structure, but their life gives us an interesting illustration of the working of natural selection. The struggle for life is found amongst them in unsparing form. Except the 
white fishes which feed on green plants, and the carps that stick their heads in the mud to find the plants, and especially tiny animals, they are all predatory animals, and do not even spare their own species. Anglers have often found a pike in the stomach of another one, and a third pike inside the second one. The pike is the most voracious of the fishes, and is rightly described as the shark of inland waters. It is even dangerous to small ducks; and young sand-martins, sitting on a branch over the water, often find their grave in its stomach. It has even been seen to suffocate swans by dragging them under water. It is from one to two yards long, and weighs up to 70 pounds. It generally chooses the night for its predatory excursions. During the day it hides amongst vegetation, and only waylays an occasional victim. If one comes near it, it darts out, gets its fang-teeth into it, releases, and then grasps again and swallows it. If the victim hurries away, it leaps after it, and is very active in every respect. It fears only the stickle-back and the perch, on account of their spikes; but it sometimes captures even the perch, and holds it until its spikes drop from exhaustion, and then swallows it.

The perch itself, however, comes next to the pike in voracity. It waylays small fishes behind the pillars of bridges or at the edge. When a swarm of small fishes approaches, it darts amongst them like a hawk, and seizes its victim. The perch-pike is less murderous; in spite of its size, it is not as quick as the ordinary perch, and its gullet is not expansive enough to take in large pieces. But the smooth eel-pout, with flat head and 
wicked-looking eyes, is the companion of the pike and perch in slaughter. It waits until dark in the thickest vegetation in clear, swift-running water. Then it glides slowly along, using every stone and piece of wood as cover, towards the edge ; it leaves no cover unsearched, and darts like an arrow on everything that is eatable. The most comprehensive predatory of German waters is the shad. It grows to a length of four-and-a-half yards, and weighs up to 400 pounds. This is another nocturnal fish, but its bristles can also be seen moving about in search of prey during the day. It eats ducks, and even dogs, and the bodies of children; even living children have to beware of it, as the inhabitants of the Danube provinces, where it is still often found, know. Much larger, but much less dangerous, is the sturgeon, which gives the best caviare. It grows to a length of eight yards, and weighs sometimes I,000 pounds. With the equally large and harmless giant-shark, it is the biggest fish on the earth.

The small fishes have their revenge on the larger ones by eating them in their early stages, and so prevent them from increasing too much to their own cost. When the trout has cast its spawn, the bullhead gets to work. It places itself vertically over the eggs with its head down, makes them rise by a movement of its fins, and swallows them one after another. The trout in turn has a taste for the young bullhead; we always find the bullhead in a stream which contains trout, or vice versâ. They keep each other balanced.

The means by which fishes protect themselves against enemies are very varied. The harmless tench 
buries itself in the mud; the bullhead expands its gill-covers so that the spines stand out; the perch elevates its spine-fin, and in the stickle-back the spines are raised in a fixed joint so that it does not lower its weapons even after death. In this way it is safe from most enemies; only the salmon and torsk can swallow it with impunity. It can also protect its young. The male, which is the more lively of the two sexes in this species, and reveals every emotion by a pretty play of colour, builds a nest of root-fibres and vegetable matter which he glues together with a sticky substance that oozes from his sex-opening. Then, by a show of colour, by graceful movements, and, if that does not avail, by pushes, he induces a female to lay its $68-80$ eggs in the nest. When that has been done, the male seeks other females to fill up his nest; and when he thinks he has enough eggs, he improves the nest, and watches it most carefully. Every creature that comes near is furiously driven off; these are generally of his own species, as they have a great liking for the eggs. His watchfulness doubles when the little stickle-backs appear. They swim away over and over again, and he brings them back in his mouth, and puts them back in the nest. He does not relax his care until the young can easily support themselves, and then he leaves them.

The bullhead also defends the eggs and the young for some time, and the way the Rhodeus amarus takes care of its young is most peculiar. This is one of the prettiest of German fishes on account of its graceful movements, and the male has also such glowing colours in the spawning season that the whole animal seems to 
be lit up by an internal fire. The female is recognisable at this time by a long ovipositor, into which it forces an egg or ovum. With this it swims to one of the larger painter's gapers, which stretch out their respiratory and cloaca-opening sluggishly from the sand. The fish drops its ovum into this, and the male, its whole body quivering, pours its seed over it. The mussel tries to get rid of the unwelcome foreign body by violent contractions, but does not succeed as a rule. The egg passes into its gill-chamber, and the little creature that develops from it forms a sort of transverse swelling behind its head, with two processes that help it to strengthen its hold. These projections afterwards disappear and the fish abandons the home of its childhood, which had sheltered it completely from danger.

But the mussel has its revenge for this involuntary shelter. When the hour comes for its reproduction, it thrusts out its brood through the opening. The young mussels fall to the bottom of the water, open the shell, and send out a long thread. This has a sticky surface, and gets entangled with the threads of other young mussels, so as to form a firm and complicated net, from which the little animals hang. If a fish-it is generally a rhodeus or a perch-runs into the net, the mussels come into contact with its body, and immediately bring their shells together, and the sharp edges press deep into its flesh. A growth is formed in the skin of the fish at the injured spot, and at length covers the whole mussel. It then lives at the expense of the fish, though it does not 
do it much injury on account of its smallness. Its organs are gradually developed, and when it is quite ready it releases itself by vigorous movements from the skin, and follows the adult life of its species at the bottom of the water. It is a remarkable and interesting correlation of two very different animals.

Other fishes meet the danger of destruction by producing enormous masses of eggs. In some these eggs are poisonous, as in the case of the pike and the barbel; in the latter case, in fact, the whole fish is poisonous at the spawning season. It is often compared to the pig, as it always remains at spots where sewage runs into the water. It is even believed that human corpses are its greatest delicacy; a large number of barbel were found on the bodies of the slain in the Danube in 1683 , at the siege of Vienna by the Turks, while none were seen on the bodies of animals. Barbel are sometimes taken from the inside of dead bodies.

Fishes know their enemies well. It has been observed, in fact, that they have a memory; that fishes at which a diving-bird was set first circled round it with curiosity, but when it had caught several of them, hid themselves, and were very cautious afterwards. They also learn to recognise the servant that brings their food; but the statement that they gather for food when the bell rings rests on unsafe observations. It is very probable that they have no sense of hearing. Their ear serves only as a sense of equilibrium; fishes from which the ears have been removed cannot keep themselves upright in the water, 
but answer to sounds in the same way as normal ones. When fishes come up to be fed, it is because they detect the steps of the keeper by the shaking and follow them, or else they see him bringing food. They have not a great cutaneous sensibility, otherwise they would not bite over and over again when they have been let loose by the angler. ${ }^{1}$

The fishes have many enemies, but the worst of them all is man. It is not so much his various ways of capturing fish that decimate the class as his civilisation that injures them as it spreads. Sometimes it is factories that pour their poisonous waste into the waters, and kill thousands of fishes every year. Fishes are always very sensitive to bad water. The tench is the only one that can thrive in water that is poor in oxygen, and the mud-fish, which foretells changes of weather twenty-four hours in advance by its restlessness. This fish can also take air by the mouth at the surface of the water. The air passes into the alimentary canal, and is used up there, so

1 According to the latest works of the American expert, Parker, it seems that there are fishes with a sense of hearing. In the first place, he says, certain fishes of the order of the "plectognathi" (well-known specimens of these are the trunk-fish and the globe-fish, the prickly, swollen, globular animals that are often seen in show-cases and dealer's shops), must be able to hear, because they make sounds themselves. Many of them only do this in the male sex, and so the sounds may be only used within their own species. These are conjectures, but Parker has proved the sense of hearing with some confidence in the case of one fish. This is the fundulus heteroclitus, or toothed carp, an American fish. The very careful experiments that Parker made with the fish show that it can hear; and the same result was obtained on making an anatomical examination of its ear. It was much more like the ear of the higher, hearing vertebrates in structure than the usual organ of equilibrium of other fishes. 
that the alimentary canal serves as respiratory organ in this curious fish. ${ }^{1}$

But the regulation of rivers does even more than factories in reducing the number of fishes; it deprives the fishes of their spawning-places just as the cutting away of the underwood in the forest deprives the bird of its nesting-place. The regulation of the rivers dams them up and deepens them, and thus does away with the shallows and the side-pits. It is just in these places that most fishes lay their spawn, as it cannot be swept away, and it receives plenty of sun. The pike likes to spawn in flooded meadows. The ruffe is the only exception. It wanders in troops in the spring from its standing waters into the rivers, until it finds plenty of reeds, amongst which it lays its eggs.

Many fishes travel in this way. Even the heavy carp turns up the stream, when it is in free water, and leaps over high obstacles, in order to lay its spawn in quiet water near the source of the river. The minnows travel in swarms to the mountains when the water becomes too hot for them, and leap over rapids and weirs. Sturgeons pass from the sea into the rivers in spring. But the most famous travellers are the eel and the salmon.

The reproduction of the eel has only been cleared up very recently. $U_{p}$ to that time the most extraordinary stories were in circulation about it, as no ova had ever been found in it. Some maintained that the eels coupled with snakes; others that they arose from mud

1 If the animal is taken from the water and squeezed round the body, the air rushes out with a loud and plaintive noise. 
or putrified bodies of eels; others that they were formed from dew and honey. The greatest importance was always attached to their intestinal worms, which were claimed to be their young.

We should know that our river-eels are all females, and that the males, never more than half a yard long, live exclusively in the sea or in brackish water. Every autumn great swarms of female eels, that have passed their fifth year, travel to the sea, while others remain in the fresh water, and settle down to their winter sleep in the mud. The former make steadily down stream; never on clear nights, and preferably when a storm darkens the sky, and the water is lashed by it. When they reach the sea, the males join them, and the eggs are laid in the deepest parts of the sea, and fertilised by the male. The young eels issue from the eggs, but they are so unlike the old ones that they have always been described - they have long been known-as a particular species of fish. ${ }^{1}$ They are so completely transparent that one can read any kind of print through them, and they are not noticed in the water, as a rule; in shape they are flat and lancet-shaped. Gradually, in the course of a year, they become darker and serpentshaped, and then - from May to July - the young animals travel up stream. They may be seen in countless swarms in the under-current of rivers. It is said that in the year 1667 three million pounds of them were taken in five hours in the Arno at Pisa. In the Elbe a black streak has often been seen moving upwards

${ }^{1}$ Grassi and Calandruccio have shown that the Leptocephalus brevirostris is the eel in its early form. 
along the shore; if water was drawn at this time, it was sure to contain numbers of small eels. As the large locks now hinder the advance of the young eels, fish-ladders have been fixed in the wood in most places - that is to say, bands of moss that remain always moist, and enable the tiny animals to climb up. The higher they penetrate, the more the males hang back; many believe that the fresh water turns the young, sexless animals into females, but that has not yet been proved. The young mature quickly, and feed by preying on fishes, snails, insects, and carrion; also on crabs when they are removing their shells and are still soft. Eels have often annihilated all the crabs in a given locality. It is a mere myth, of course, that the eel goes on pea-fields and feeds on the plants.

The salmon acts in the opposite way from the eel. It spawns in fresh water. In the sea it lives on small fishes of all kinds, and becomes very fat. When the ice disappears from the rivers, the salmon gather at the mouths in companies of thirty or forty, and remain for a time in the brackish water, so that the salt-water in their bodies may be gradually washed out by the fresh; too sudden a transition would be fatal to them. They then press steadily up stream. All obstacles are overcome. Weirs and rapids are taken in leaps that sometimes reach the height of four yards. Only very high waterfalls stop them. The young are in front, then the older females; these are followed by the younger males, and the rear is formed of the older males-though an old and strong fish seems to lead them, as a rule. During the whole time they are in fresh water the 
salmon take no food, and the roe-the ova and seedmature at the expense of the fat and the muscles. The old males now develop a bright red colour on the belly, and at the tip of their lower jaw is formed a strong, upward-pointing hook; this is often so long that the mouth cannot be closed. ${ }^{1}$ The swarms separate at the spawning places, in the streams that flow into the rivers. In the shallow parts of the streams, especially underneath small waterfalls, the female brushes aside the pebbles with her tail, and lies down in the hollow, to deposit her eggs at the bottom. The male remains about a yard above, and ejects his seed into the water; this is conveyed by the current to the ova and fertilises them. When the spawning is over, the two sexes, fearfully emaciated and exhausted, return to the sea, and recuperate there. Many of them, however, perish on the way.

Many salmon pass up river during the spring also; they do not spawn, but feed for a whole year as riverfishes, and do not descend to the sea until the next year with the comrades they meet in the meantime. They have the fattest and reddest flesh, and are called winter salmon. They are the dearest. The salmon going up stream have also red flesh; those going down have white flesh, and are easy to catch on account of their exhaustion, but are less valuable. The worst fishes are the shore or black salmon, which never enter fresh water. They live on the sea-shore and seem to be permanently sterile. Their flesh is quite white and hard.

1 Many believe that the hook is used as a weapon in the fight for the females. The point is not yet settled. 
The regulation of rivers has greatly reduced the number of salmon. The time has gone when more than a thousand could be caught at one spot in a day; when servants stipulated in their contracts that they should not have to eat salmon more than twice a week. In the Rhine it is gradually disappearing, as the mouth of the river is almost entirely cut off by Dutch fishermen at the time for coming up. In other rivers there has been an artificial stimulation for the salmon population. There are special places in which not only the eggs that have been found are hatched, but the eggs are obtained from the body of the ripe female by pressing it (also in the case of the trout), and the sperm taken from the male is poured over it. The young ones develop in vessels full of water, that is kept fresh and circulating, until they are big enough to make some resistance, when they are put in the streams. In this way an artificial substitute is found for the shallow waters, and thousands of fishes are reared every year.

For a long time our fresh-water fishes were threatened with a growing danger of extinction, until at last the spread of knowledge enabled us to meet most of the difficulties. Angling societies have been formed, and fish-culture and protection are spreading more and more. Angling is still common enough, and is regarded as a good form of sport. It is true that we no longer see boats gliding over the river during the night with torches in the bow, throwing a red light over the slender form of the salmon-fisher and his glistening harpoon; but the angler sits under the trees 
by the still water absorbed in his work. Lights play on the water, and the wide straw-hat of the solitary fisher. The fishes splash here and there, and the angler waits patiently for the approach of the invisible inhabitant of the stream. 


\title{
CHAPTER VI
}

\author{
TRACHEATES
}

To the tracheates belong spiders and insects. How insects grow. Explanation of the metamorphoses of insects. Protective colouring on the wings of butterflies. The Lamarckian principle refuted by protective colours. Insects that resemble objects. Mimicry. Exhalation from male butterflies. Sexual selection. Origin of flowers due to insects. Parts of the insect's mouth. Refutation of the Lamarckian principle. The coat of insects cannot have arisen by use. Harmonious adaptations, coadaptations. Co-adaptations that Lamarck cannot explain. Explanation of co-adaptations. Are instincts inherited habits? Instincts that can never be affected by the will. Spiders' webs. Care of the young. Instincts that are only used once. Are mutilations inherited? Protective marks, mildew marks, foresight. Infection of embryo. Structure of the embryo. The inheritance of acquired characters is difficult to conceive. Untenability of the Lamarckian principle.

WE now turn to the animals that we meet most frequently at every turn. These are all alike in having the body covered externally with hard parts and jointed, like the legs of the "articulates," as we call the stem to which they belong. Some of these animals breathe by means of gills; these are the crustaceans. The others breathe by means of what are called tracher; to this group belong the spiders and insects, which will engage our attention in this chapter. The tracheæ are a system of greatly ramified tubes, which end in a network of very fine microscopic branchlets, and pervade the whole animal. The air enters into the trachea by external I 84 
openings or spiracles, reaches every organ and every part of the body, and conveys to them the oxygen that they vitally need.

There is an immense number of species of the tracheates. We now know some 250,000 forms of insects alone, although the tropics, their chief abode, have only been superficially explored as yet. Such a number as this is only possible because every available position in nature is made use of; and for that reason we find particularly complicated and striking adaptations among the insects.

We need only glance at their colours to see full confirmation of this. The collector cannot easily discover a tree-locust on a tree, as it is coloured green like a leaf; and its relatives, the grasshoppers, are just as difficult to find, as their green-brown tint harmonises with the grass-grown ground on which they sit. The mole-crickets are quite dark brown; these are found chiefly on brown earth, and dig holes, in front of which they sit and sing their concerts.

We could find an obvious protective colouring in almost every species of insect. Moreover, the colour changes at different periods of the insect's life. The eggs of most of the insects are green, like the leaf on which they are deposited. The larvæ that issue from the eggs have a protective colouring, which is different from that of the adult insect in proportion as their habits differ from those of the adult. The larva and the imago, as the full-grown, sexually-ripe insect is called, often look like two totally different animals. This is explained in the following way. 
All the articulates, tracheates as well as crustaceans, can only grow periodically, because they are clothed with a hard coat of mail. This armour completely encloses the animal, and the muscles are attached to it, and find in it the necessary resistance for the pull on the bones that they effect.

The coat is too rigid and solid to allow any expansion of the body it encloses. The insect can only increase in size, therefore, by bursting the shell; and this it does at certain places and times. When the armour is thus broken, the soft-skinned animal creeps out of it.

Underneath the shell of every insect there is a layer of skin which has the function of secreting the material of the coat, much as our salivary glands secrete saliva. This skin now forms a new shell while the old one still covers it, so that when the insect emerges from the broken one, the new coat becomes visible. It is, however, soft at first, and the insect can expand and grow in it. But it soon stiffens in the air, and then becomes a dead mass. Underneath it a new coat is secreted, and this will replace it in turn when the time comes.

The growth of the insect at each cast is accompanied by other changes. In many insects the wings make their appearance; they were wanting in the larvæ, were visible as short stumps at the first cast, and increased with each succeeding one until they reached their full size at the last; in these cases the insect is thus turned into the imago, or adult and mature organism. This gradual growth is found in the dragon-flies, moths, locusts, and others. 
As the air is cut off from the larvæ it was useful for them to have different adaptations from the imago. While the latter flies easily out of reach of its enemies, the creeping larva can be caught at any time, and so urgently needed protective colouring so as to escape notice in its surroundings. Thus the larvæ and imagines were selected in different directions according to their different conditions of life, and came to differ more and more.

In the case of moths and grasshoppers, there is not a very great difference in habits between the larva and the imago; the latter hardly use their wings except to lengthen their leaps. Hence the larva does not differ so much from the imago, and is merely without the wings, or has shorter wings.

It is otherwise with beetles, flies, bees, wasps, and butterflies. The vital activity of these insects chiefly centres about their power of flying; some of them hardly move in any other way. But the air is only opened to them after the last cast of the skin. The gradual transition of the larva into the imago would clearly be very much out of place here, as the two stages are so very different from each other; during such stages of transition the animal would be neither adapted to its larva-surroundings, which it cannot leave because of the absence of wings, nor would the imperfect characteristics of the imago be of any use to it. We understand, therefore, why natural selection has cut down these transitional stages as much as possible, so as merely to let the larvæ grow in the first and most of the other casts, without changing 
their form, which protects them so well. Gradually only two casts remained for the transformation into the totally different imago. All the organs of the imago had to be formed in this short period. But this meant such a revolution in the animal's frame that the vital functions, movement and nutrition, were impossible. Hence we see that the animal remains, during the stage between these two casts, in a state of immobility that may be compared to that of the ovum. We call this the pupa. In the last cast of skin, the pupa covering is thrown off, and the wings, which were formed under it, make their appearance fully developed.

Thus bees, fies, beetles, and butterflies only grow in the larva stage, as caterpillars or grubs. If we take two beetles that seem absolutely like each other, and only differ in size, they are not a younger and an older animal, but different species.

The material for studying the adaptation of larva is inexhaustible. When the butterfly-caterpillars leave the egg they are generally green, and difficult to distinguish from the leaf they are on. Identical colour of this kind can, however, only protect small animals; larger ones are sure to attract attention on the grass or the leaves, because there is no purely green spot large enough to cover them. As a matter of fact, the caterpillars of the grass-butterfly (satyridæ), when they are of a certain size, have light and dark longitudinal stripes over their whole body, and thus lie in the same direction as the blades of grass and the shadows, which are always vertical on the grass. The caterpillars of the hawkmoth, which live on bushes and trees, have stripes 
down the sides, which stand at the same angle to the length of the body as the side-ribs of a leaf do to the central rib. This colouring gives great protection to the caterpillars, as it divides their body into sections just as the ribs do the leaf.

In the pupa stage, when the insect cannot fly, it is especially important to have protective colouring; and it is, as a fact, very common amongst pupæ. On the other hand, a flying insect cannot have protective colouring because of the constant change of the animal's background; moreover, a flying object is always easy to see. Hence it is that the upper surfaces of the wings of many butterflies are of a light colour, so that the marks for recognising the species are well in evidence. But the insects are not always flying; they often rest, and could then, especially when they are asleep, be surprised by enemies. They therefore need a protective colouring, though this is only necessary at the parts that are seen when the animal is at rest.

From this we can understand why nocturnal butterflies (or moths) and diurnal butterflies have protective colouring at different parts of the body. The day-lepidopters fold their wings over them when they are at rest, so that we only see the under-side. This alone, therefore, has a protective colour in their case. We have a striking example of this in the tortoise-shell butterflies. In the day peacock's-eye and the black butterfly the very light colours of the upper-side of the wings disappear when they are folded. The dark brown of the under-side now makes the creatures hardly distinguishable in the 
dark corners and crevices in which they rest. The colours of large and small tortoise-shell butterflies and the painted lady are lighter. They usually sit on the road, and seem to disappear suddenly after one has been watching the flying, prettily-coloured insects.

The disposal of the wings is different in the nightlepidopters. With these the fore-wings cover the hind ones roof-wise, and so we often find very light colours on them-as, for instance, in our red underwings or tiger-moths-and never on the fore-wings, which alone are visible when they are resting. On these there is a mixture of different colours, with zigzag streaks and lines running between them; the whole taken together gives so good a picture of the bark of a tree or a wooden wall that even the experienced naturalist often overlooks one of these moths in examining the trunk of a tree. The intricate design is always the same in every detail, and it has very well been compared to an impressionist landscape, in which all kinds of scrawls seem to be thrown together irregularly, though it will be found to be a picture on moving away from it a little. Natural selection easily explains a colour-design of this kind. All variations in the animals are preserved and selected that help on the resemblance to the bark. In one part the zigzag lines were developed, in another spots, in a third the dark ground-colour. As all these selected variations repeatedly crossed with each other, their descendants came to possess the different features together, and steady selection of the combination helped to make the deception more complete. 
While natural selection thus enables us to understand the origin of protective colouring, we can see no application in this case of the Lamarckian principle. The protective colours of animals cannot possibly have been raised to their present condition by continuous use and inheritance of the results. In the first place, it is impossible for an animal to become green because it takes to sitting on leaves; and in the second place, even if the animal knew that it would be an advantage to be green, it could not change its colour by an effort of will. It has been stated that the light causes the colours, and that the animal's skin photographs the surroundings, to some extent. It is striking, for instance, that in many day-butterflies, which draw the fore-wings between the upward-folded hind wings when they rest, so that only the tips of the fore-wings can be seen, these are only protectively coloured like the back wings just to that extent, while the unseen part of them is often very lightly coloured. Thus the back wings and the tips of the front wings have exactly the same colour-design. And the colouring of the tips of the front wings is more or less extensive according to the habit of drawing the wings in more or less thoroughly. We find this difference in such apparently similar butterflies as the large and small tortoise-shells. But in the butterflies that do not draw in their front wings the whole surface is protectively coloured.

If, however, it seems on superficial inquiry that the light may have produced the colours, and was only able to do this on the exposed parts of the wings, we shall be compelled to abandon the hypothesis on further 
reflection. We do not see why the light does not cause light colours such as those hidden in the folded wings. How, moreover, can we suppose it to create so intricate a colour-design? And if the skin has the capacity to bring about a protective colouring, we may very well ask what was the origin of this capacity, as very few animals possess it. But we need not delay with these theories; they are completely refuted by one single fact. The protective colouring does not arise when the animal exposes its wings to the light, but in the earlier stage of the pupa. Long before it issues from the pupa all the colours are present on the wings folded up under the pupa-shell. And in the pupa the position of the wings is reversed; the front wings always cover the hind wings, in such a way that the protectively coloured under-side of the front wings is turned away from the light. Hence the light does not touch any of the protectively-coloured parts during the development of the colours. We may add that the thick, dark pupa-covering does not admit the penetration of the rays of light ; and that many caterpillars pass the pupa-stage underneath stones, and the night-butterflies even underground.

We must therefore exclude the action of light altogether in the formation of the colours of butterflies. The fact that their front wings have protective colouring just in so far as they are visible can easily be explained by natural selection. We know that selection only continues its action until what is necessary has been attained. Those butterflies survived which had the most deceptive colouring; but the variations that 
had protective colouring on the unseen parts as well were no better off than their comrades. They were therefore not specially selected, and they lost their shades in their descendants by crossing.

The animal is still safer when its colouring is associated with certain peculiarities of shape so as to imitate an object.

The outer side of the wings of the tortoise-shell butterfly has zigzag lines, so that it looks like a decaying leaf when at rest. In the lappet-moth there is a most deceptive resemblance to a heap of dried oak-leaves owing to the colour and the crinkled edges and position of the wings. One of our moths, the Xylina vetusta, looks just like a broken piece of wood - an effect which is increased by the creature "shamming death." There are also many geometer-moth caterpillars that closely resemble twigs, and even have warts on their bodies that look like the unopened buds on the twig. Further, the animals stretch themselves out stiffly when at rest, and then rise up at a steep angle from the branch on which they are, so that they look just like an offshoot of it.

But the adaptations of insects go a good deal further than this. They not only imitate lifeless objects, but even other animals that are not likely to be touched. Bees and wasps are generally protected by a sting, and most animals know these weapons and respect their owners. We must not be surprised to learn, therefore, that certain harmless insects have the dangerous aspect of the stinging insects, and so enjoy the same immunity. A species of fly, the Eristalis, strikingly 
resembles the bee, and the hornet is closely imitated by the bee hawk-moth, which has assumed the transparent wings, the shape, and the yellow abdominal bands of its model. This imitation of living models is called mimicry, and we find innumerable instances of it in the tropics. ${ }^{1}$

The light colours that many insects show when they are flying, and that are of great importance to them, as it is by means of these that the sexes find each other and maintain the species, are often different in male and female. In the case of the dragon-flies the

${ }^{1}$ The imitation of objects is very common among tropical insects. There is a leaf-butterfly, the callima, the wings of which, when folded, not only have the form of a leaf with a stalk, but even a long central rib with side branches-looks, in fact, so much like a dried leaf that it takes an expert to recognise the animal at rest. There are also locusts that have wings most strikingly like leaves, and other locusts that are almost indistinguishable from twigs; many naturalists have thought them to be twigs when the natives brought them.

Mimicry also is wonderfully developed in the tropics. In South America there are black, yellow, and red butterflies, the heliconides, which are not eaten by birds and reptiles on account of their repulsive smell and taste. Other butterflies, originally white, have adopted both the appearance and the habits-such as slow flying-of these malodorous butterflies, and constantly mix amongst their models, which always fly in swarms. Thus the white are protected as well as the heliconides, though they have not the same nasty taste.

In this case selection has coloured the females earlier and more thoroughly than the males, some of which still have the pure white of their ancestors on the hind wing, and some on the upper side of both the front wings. Selection does not act as powerfully in the males as in the females, and their transformation is slower. The males are always more numerous than the females, as a matter of fact, besides that one of them suffices for the fertilisation of a number of females; moreover, their death does not involve the destruction of a number of eggs. If the species is to be preserved, it is the females especially that must be cared for. 
female body is usually of a greenish shade, while the males prefer bluish colours; in the Libellula depressa this passes into white, which is the colour of the thick abdomen in this species. In others the males have beautiful dark blue wings, which give them a fairy-like appearance, while those of the females are colourless. Among the butterflies the argus and small copper butterflies have their pretty light colouring only in the male sex; the females have an indifferent appearance.

Other "masculine characteristics" are developed among the insects. In many butterflies the males give out a strong scent; it is a charming coincidence in nature that the butterflies that seem, in form and colour, to be the flowers of the animal world, have also very often the perfumes of their models. One can easily perceive this odour by holding to one's nose a male cabbage-butterfly, which differs from the female by the absence of the black spots and borders on the wings; it gives out an agreeable pungent odour. The argus butterflies, the mother-of-pearl, the convolvulussphinx, and many others, have a male scent. In all cases the odour is restricted to special scales. The dust of the butterflies, which is so easily brushed off with the hand, consists of very delicate and tiny scales, which are for the most part connected with small glands. Some especially large glands secrete an odorous matter, and let it pass into a peculiarly shaped scale which is called a scent-scale. These scales are often closed by special structures, so that they only pour out their perfume at the will of their owner. It appears, therefore, that in this case the perfume is really meant for the 
enchantment of the females, and we are faced again with a problem that we cannot solve. In this case there is less objection than elsewhere to the second form of sexual selection. It is not called upon to explain the origin of the perfumes, but only its increase in the male sex. The odour certainly came into existence as a distinctive mark of the species, as it is also found in the female sex, though in so weak a form that our nose cannot perceive it. But it can easily be proved to be present by placing a female of some species of night-butterfly in a wire box before the window. A number of males will presently be found in it, and they can only have discovered by smell the presence of the object of their desire. Hence if a female knows the odour as a mark of the species, it will be much more affected by it when its strength increases. Possibly this is the root of its advancement.

The union of the sexes is sometimes stormy among the insects. The females of the large dragon-flies often fly in obvious fear from their spouses. In the case of other insects it is the male that must be careful. It happens only too often that the love-sick male cricket is devoured by the callous female. In fact, in the case of the mantis or praying insect, a green locust whose front legs are lifted up as if in prayer, though they are really only for the purpose of grasping its prey, the male is generally devoured during, but at least always after, union. It has even been observed in the case of this species that the female bit the head off the timidly approaching male; the trunk, nevertheless, performed 
its task, and was then in turn taken into the stomach of the insatiable female. In the case of the spiders, too, the male must approach the female with caution as she sits in the middle of her web, because she has a habit of biting to death without much examination every living thing that comes into her net. But in this case the female signifies its compliance to the hesitating male. She travels down, and hangs, head downward, by a thread on which the union takes place.

We have already compared the butterflies to flowers. That was merely a superficial comparison, but we shall now see that there is an intimate connection between insects and flowers, because, strange as it may sound, most flowers owe their origin to insects.

We must go back a little in order to explain this statement. In the plants, also, a union of male and female generative products is necessary to produce a new organism. The male products, which correspond to the sperm of the animal, are called "pollen"; it consists of an immense number of very tiny grains. The pollen of the lily must be known to everyone, as it is this that colours the finger yellow when you insert it in the flower. This pollen has to unite with the female product, which in turn may be compared to the ovules of animals. The plant " egg," which is found also in flowers, but only in small quantities, is in this case enclosed in a capsule that is called the "seed-bud" or germ, and is drawn out in a long stalk called the "pistil " above. At its upmost point, the "stigma," a grain of pollen touches it in fertilisation, passes gradually through 
the pistil to the egg, and coalesces with it. Then, as a rule, the germ drops off, tumbles to the ground, and the fertilised egg within it grows into a new plant. In ordinary usage we call the fallen germ the "seed."

In the parent-forms of the actual higher plants there were male and female blooms, and the pollen was produced by the former in vast quantities and scattered far and wide by the wind. In this way a grain would fall on the stigma of a female plant and it would be fertilised. This is still done in the case of a great many plants, such as the grasses, the conifers, the birch, the hop, and many others. The male blooms were constantly visited by insects, as the pollen was an excellent food for them, and this visit of the insects became the starting-point for natural selection which made the conveyance of the pollen to the female flowers safer, instead of leaving it to the chances of the wind.

Fertilisation was easier in those plants which offered some attraction to the insects, as after visiting the male flowers there were always a few pollen-grains sticking to their body, and when an insect in this condition entered the corresponding female flower, it was natural for some of the grains to be brushed on to the stigma. We can understand, therefore, why little pits came to be formed in the female blooms of many plants, in which a sweet fluid was secreted that attracted the insects. The willows have remained at this stage, but in their case the male flowers also secrete honey, and thus it is secured that both kinds of catkins will be visited by the insects and fertilisation obtained.

However, this form of conveying the pollen left a 
good deal to be desired. It would often happen, for instance, that an insect would fly from one male flower to another, and not visit a female catkin until much later. In this way a great deal of pollen would be lost, and so we can understand that a different method would lead to better results. We still find in the poplars, which have the same kind of catkin-blooms, a pistil with a stigma and germ suddenly appearing as an abnormality in the middle of a male flower; this union of male and female in one flower is called hermaphrodism. These hermaphrodites were preserved by natural selection, as they had a great advantage in the conveyance of pollen from flower to flower. An insect that covered itself with pollen dust in one flower found a pistil in the next one on which it could brush the dust, and did not fail by going exclusively from one male flower to another. Hence the hermaphroditic flowers increased, and a struggle sprang up amongst them for the visitors, those being most favoured that were most attractive to the insects. The chief means was, of course, the honey on which the insects fed; and those flowers had an additional advantage that drew attention by their conspicuous colours, and so invited the insects from afar. This was the origin of almost all our actual beautifullycoloured and marvellously-shaped flowers. Nature does not revel in a superfluous wealth of colouring; this has only been developed for the sake of the insects, as no plant of this kind can reproduce unless it is visited by insects. A second source of attraction was provided in the scent, which, of course, was especially useful 
during the night. In fact, many plants that are only visited by hawk-moths only give out their perfume at night when these moths fly. Many will have already seen this in the case of the caprifoliacex.

At first sight it would look as if those flowers were in the best position in which the honey was most exposed, and which were visited by as many insects as possible. But that is not the case. In the first place, many insects are so small that they can eat the honey without rubbing against the pollen, and so they are useless to the flowers; and in the second place, the flower will have a much better chance of being fertilised if only a few species of insects visit it. When a certain kind of flower is liked by a particular insect, this will be the more likely to return to it, and not waste its pollen on other flowers. On this account the honey that was at one time exposed in many flowers has sunk deeper into them, and thus can only be reached by the more intelligent insects. The effect is enhanced by the curling of their leaves so as to form a tube which varies in thickness, and so admits different kinds of insects. In some flowers the tube is so narrow that it takes the long proboscis of a butterfly to reach the honey. Others have adapted themselves to flies, and give out the smell of carrion, which attracts these alone. In the aristolochia the long and narrow tube is further provided with hairs on all sides that point downwards; these let the fly in, but prevent it from escaping. The insect is kept captive until it is covered with dust by the stigma at the bottom, when the hairs wither, and it can get away. In this way the restless fly is compelled to do its duty. 
It would take too long to enumerate all the adaptations of the flowers to insects. The most familiar of all is the meadow-sage. In this the bees in search of honey press on a small mechanism by means of which the filaments, at the tip of which the pollen hangs, bend down on it and dust their hairs with it. The bee then leaves the flower, and another comes which has already been covered with pollen in this way. But in the meantime the pistil with the stigma, which had up to that time been hidden, has come to the opening. The second bee has to rub its body against the stigma in order to reach the honey, and so cause fertilisation.

We thus see that the origin of the flowers affords a striking proof of the power of natural selection, and this will be particularly clear if we consider the relative imperfectness of the adaptations. Selection only acts in so far as a change is urgently necessary for the preservation of a species. Many flowers can only be fertilised by bees, but they also receive the visits of many other insects which rob them of their honey without doing them any service. However, it is clear that further contrivances for excluding these other insects are not necessary, because the maintenance of the species is sufficiently assured by the bees, whose visits are frequent enough to fertilise and bring new plants into existence.

The alteration of the flowers was bound to have an influence on the insects. When those of the flowers were constantly preserved that had the longest tubes, because they kept out mischievous visitors and so were most frequently fertilised and left most progeny, there must have been a corresponding selection among the 
insects; the butterflies with the largest probosces would have the advantage because they would find most food, and their ova and seed would be the most vigorous. Thus the characters would mutually affect each other.

It is not only the proboscis of the butterfly, but also the mouth-parts of other insects, that have been modified by a correlative selection with the calices of flowers. In the ancient insects the eating organs consisted of masticators, as we still find in many orders, such as the locusts, moths, and beetles, because they chew their food. But in the bees a part of the mouth was converted into a long licking tongue; and in the butterflies two masticators have blended to form the long tube of the proboscis.

In other insects there have been different modifications of the mouth-parts. The masticators of the gnats have been converted into long stilettoes. The larvæ of the dragon-flies, which live in the water, have developed the lower parts of the mouth as pincers, with a long retractile stalk, and able to seize an animal at some distance when they are suddenly thrust out. We should never come to a stop if we were to examine all the adaptations of the mouth-parts of insects. We will desist, however, and briefly consider the other parts of the insect body.

The wings have entirely disappeared in the flea; in the fly the back pair has degenerated, and in the strepsitera $^{1}$ the front pair. In the earwig the wings

1 The strepsitera, to which belongs, for instance, the "Stylops melittæ," have some peculiar adaptations. The larvæ, which jump briskly on their six legs, force their way into the bellies of bees and 
are folded together, and can only be opened with the aid of forceps at the extremity of the abdomen. In the beetles, only the hind wings are used for flight; the front wings form a cover for them. There is equally endless variety in the legs of insects. In the mole-cricket the front extremities have been converted into shovels; in the grasshoppers they have become a powerful leaping apparatus.

The skeleton of the articulates, with all these peculiarities, is of the greatest theoretical value. It provides ample material for the refutation of the Lamarckian principle, as it is Weismann's merit to have shown. We saw above the way in which insects grow. Underneath the shell the skin secretes a new one, but this is soft and elastic, and only hardens when the old one has been cast off. All the characteristics of the coatits thickness, its different kinds of hairs and other outgrowths-are already formed before the old coat is cast off. When this is done, the new one appears in full development; it hardens and grows no further, as our bones do, because it is an excretory product of the underlying skin. As soon as the shell comes to light, the skin which has produced it loses its connection with it; it has to begin immediately the work of secreting a new coat.

wasps, though not deeply, and become pupæ there. From the pupæ issue the insects that have become males, and fly away with their large bird wings. The females do not leave the pupa-covering; they are without wings or legs, and like grubs, and remain in their wasp until a male comes to fertilise them. The larvæ develop from the fertilised ova in the mother's body, and then break out of the mother's back, and in their turn make their way into wasps. 
These peculiarities of the coat cannot be explained by the Lamarckian principle. We will not speak of the hairs and protuberances, as to which it is quite unintelligible how such structures, which only act when they are formed and have never been used, can be strengthened by exercise. But let us take a simple case. The Lamarckians would explain in the following way the hard inner edge of the crab's pincers, which grow in the above manner. The shell of the pincers was thin at first. The crab then formed the habit of seizing its prey with the pincers, and using them as a weapon. By the continuous pressure of the claw-fingers on the inner side in bringing them together, the shell gradually hardened at the edges, in much the same way as the fingers of seamstresses or violinists develop a harder skin by pressure. Once the inner edge of the crab's claws had become thicker by this continuous use, and it came to have young ones, these would have a thicker shell at the part in question from birth, owing to heredity, and it would be increased in the course of generations until the actual claws were formed.

The comparison with the skin of the finger seems to be helpful, but we have really to deal here with two totally different facts. The human skin is alive, and the living substance can certainly be strengthened by use, as the muscles of the athlete's arm show. But the crab's shell is dead; and dead structures do not become better, but, if anything, worse by use. They get used up, like a steel spring that has been long in use.

When the coat was still connected with the living skin, when it was still in the process of being formed 
from the skin by secretion, it could not be altered by use, because it was the old, overlying shell that was then in use. The characteristics of the articulate skeleton cannot, therefore, have been developed by use, as in each case they were fully developed before use. When a crab casts its old coat, it appears in the new one, which is still soft, but soon sets. But the soft shell has all the protuberances and thick parts, and does not differ in the least in structure from the hard one. Moreover, it would not help even if the soft shell could be modified by use. The soft crab refrains from using his soft claws, with which he could do nothing. He creeps under a stone and waits idly until the coat is firm enough to protect him.

To this view it has been replied as follows. The shell may not be able to thicken from pressure, but the skin that is forming the new coat underneath it may. Pressure in the old shell affects the underlying skin as well, and its function, the secretion of a new shell, will be proportionately stimulated, and produce it in a thicker condition. Hence when the crab continually uses its claws and so presses on the inner side of them, this pressure will act through the shell on the skin beneath it ; this will do more work, and at the next cast of the coat the inner edge of the claws will be thicker.

But why should the skin act more and not less vigorously under pressure? It is not at all agreed that it secretes a thicker and not a thinner coat, when it is pressed through the overlying shell. And even if we admit that its activity is increased by pressure, how did this capacity come into existence? 
However, we need not linger with these objections to the theory. There are certain facts that completely demolish it. These facts are the casting of the skin of beetles, flies, wasps and butterflies. In all these animals the coat of the imago is formed underneath the pupa-cover. The legs are pressed against the body, the wings folded, and everything enclosed by the pupa-skin as in a parcel. But the pupa scarcely moves, and so there can be no pressure to act through its shell on the underlying imago skin. And even if a pupa happened to be exposed to pressure, the stimulus would act equally on all parts of it, as in the pupa they are all folded together, though in the adult insect they must be wide apart and differ very much in thickness, as they do in point of fact. Finally, it is precisely the thin parts of the imago coat that lie directly underneath the pupa skin; many of the thick parts are protected from pressure by the overlying wings.

It is clear, therefore, that in the secretion of the imago coat the skin cannot possibly be influenced by pressure. Nor even immediately after the emergence of the insect. The imagines of the insects enumerated may expose their coat to all kinds of pressure, as much as they will, the underlying skin will never be caused thereby to secrete a stronger coat, because in these insects it has no further activity in the imago. No butterfly ever casts its skin; this is done by it several times as a caterpillar, and once as a pupa. None of the characteristics of the coat of a bee, the wingnervures, the thick and thin parts, the various kinds of hairs, the eye-facets-none of these things can 
have arisen by use and the inheritance of its results, The whole coat, with all these prominences, is a dead structure; it can only be worn out by use, as it has no living parts to replace or increase what has been used up. The animals retain this shell until they die; no new one is formed underneath it, and there is no coat-producing skin there to be influenced by pressure or use. Hence the peculiarities of the imago coat of these insects cannot possibly be explained by the Lamarckian principle.

But they are explained by natural selection. Every living thing varies, and so there will be a slightly different imago formed under the pupa-cover of each separate insect. When the animals issue forth, their variations come to light, and are selected or rejected according as they are useful or otherwise. They will either be preserved and accentuated by continuous selection, or they will disappear. And as the Lamarckian principle cannot possibly have formed the details of the coat of these insects, but natural selection may have done so, we have a right to assume that the shell of the crustacea and of the insects with gradual growth was not brought about by the "inheritance of functional modifications," but by a process of selection.

There are certain adaptations which many experts think cannot be explained by natural selection, but only by the Lamarckian principle. These are what are known as "harmonious adaptations" or co-adaptations.

There were in former ages stags with antlers six and a half yards high. The animals could, of course, only 
support these heavy antlers on their heads if they had skulls of proportionate thickness and necks strong enough to sustain the ponderous head. Even the animals' shoulders and other parts of the body must have been powerfully developed. We see, then, that strong antlers involved a whole series of co-adaptations; that is to say, it was not enough for variations with larger antlers to appear among the stags, but in these very cases there would have to be also a number of other organs modified in a definite direction. But this could not be expected in variations. They depend on chance; each varies on its own account, and there is no hand guiding them from some higher standpoint. If one amongst a litter of stags has larger antlers, it is possible that it may also chance to have a stronger collar, but some of the other parts will certainly be found to be weaker; it is too much to expect from chance that so many organs should vary in the same direction. The reader will be able to follow the argument best by imagining a game with twenty dice. The different numbers that come out on top will represent the variations arising at each throwcorresponding to each litter of young. As it is demanded in the case of the stag that some animals shall appear with, let us say, ten definite variations, we must require that ten of our dice will throw the number six. Certainly one of the dice, possibly two, will throw a six after several attempts, but it is improbable in the highest degree that ten dice will give that number, however often they may be thrown.

The Lamarckian principle meets the difficulty. 
When from any cause the antlers of the stag became larger, they exercised a pressure on the skull, which led to its thickening, and the other parts of the body would be equally strengthened and modified by the pull of their burden. These variations were transmitted to offspring, and if a still stronger pair of antlers arose in the next generation, and was selected, it found better support, and would in turn improve this by its pressure, and so the advance would gradually continue.

This kind of explanation seems simple enough, but there are certain co-adaptations that it cannot cover. This is the case with the insects once more. We have already seen that the cutaneous skeleton of these animals is dead, and can only be used up, not strengthened, by exercise. Now, the peculiar fiddling apparatus of the field-cricket only makes its appearance at the last cast of the skin. It consists of two very different parts - a bow, which is represented by a specially modified nervure of the wing, and the side across which it is drawn. The latter is a part of the inner surface of the hind leg, which is equipped with a number of little teeth; it is these that give out the chirping sound when they are rubbed. Here we have a co-adaptation that the Lamarckian principle cannot explain. Two organs that lie in different parts of the body are modified in the same direction, so that one can only co-operate with the other; but they can neither have arisen nor been improved by use. They only make their appearance at the last cast of the skin, and when they rub together they only wear themselves, since they are dead structures, and the underlying 
skin cannot be stimulated by the pressure to form stronger parts, since its function ceased at the last cast of the skin.

In the same way we find many other co-adaptations in the coats of bees, wasps, butterflies, etc., in which the last cast is the abandonment of the pupa-skin, when they first receive their specific features, such as wings and so on. Hence when we find on the fore-legs of bees and wasps certain structures consisting of two parts forming a ring with teeth in its inner side, through which the antennæ are drawn to be cleaned, we have a structure that cannot have arisen by use. The same may be said of the mouth-parts of these insects. In the gnat there are at least eight parts that are all modified in the same sense as stabbing-bristles and suctorial apparatus; they are all about the same length, and can only act in conjunction. The antlers of the large stag with the thick skull and the proportionately modified other parts are not more wonderful than the parallel development of the mouth-parts of the gnat. When the Lamarckian principle is admitted on the ground that it is said to meet difficulties that natural selection cannot explain, we see that this is not the case. At all events, it does not do away with the difficulty of co-adaptations, because there are co-adaptations that it cannot explain.

But are co-adaptations really inexplicable by natural selection? Selectionists say they are not, and they are quite right. In the first place, artificial selection shows that harmonious variations do actually take place. Think of the dachshund, which has been brought to its 
present form by a continuous selection of the shortestlegged pups. In its variations there were always corresponding modifications of the other organs, such as, broader paws, thicker legs, and changes in the bony structure and length of the body. The latter feature is absolutely necessary to secure mobility in a low animal, as we see in the case of all short-legged or legless animals, like the marten, the lizard, or the serpent. Just as, in the selection of the dachshund, all the corresponding variations appeared quite spontaneously, without the vital activity of the developing variety being drawn upon, that might also happen in the parallel case of natural selection, and therefore in the selection of the giant antlers of our stag. We must not forget, moreover, that an organism is a harmonious whole, in which continuous selection has brought about an ever improving co-adaptation and co-operation of the various parts. Hence, when the variation of a longer bone occurs in a leg, the corresponding muscles, blood-vessels, and nerves are also usually longer. It has even been discovered that when fly-maggots are kept without food, the flies that issue from them are smaller than usual, but have a complete harmony of the various organs. Selection has led to this harmony, and it preserves and increases it; every organism that lacks it will be crushed out as a cripple. Moreover, natural selection can often develop similar organs in different directions. We see this in the legs of the leaping mammals, in which the hind legs are much longer than the front.

Further, co-adaptations may often be brought about 
by combination. It is clear that natural selection may attain the same end by different means. When, for instance, the herons began to seek their food at the bottom of the water, selection favoured not only those with long legs, but also those with long bills and long necks. The end was reached by all three modifications, and so they were equally selected. The continual crossing of the three characters gave rise to the actual herons, which have all three of them.

Finally, we need not suppose that the co-adaptations must arise simultaneously, and it is precisely in this that the chief difficulty was found. Remember our illustration from the dice. We can easily get our ten sixes if we throw until a six turns up, then leave this standing, and throw again until another six appears, and so on until we have got our ten sixes.

Natural selection may act in the same way. In the giant stag first large antlers were favoured; they were, of course, not immediately so heavy that the animals with weaker skull and neck were incapacitated, because all variations are small at first. When a race of stags with large antlers had thus been formed, and continued to increase, the time came when only the individuals with strong skulls could carry the antlers with ease. Then the thicker skulls were selected. Thus all the co-adaptations might be selected successively; even if they were wanting at first, they were bound to appear in the course of a long period, and would then be favoured. But even if they were wanting at first, the animals with the larger antlers were not necessarily incapacitated. We must not forget that use in the 
course of an individual life certainly strengthens an organ, though the result of it is not, in my opinion, inherited. As the antlers of a stag need years to grow, and their weight does not increase so very much in each year, the head and neck will become stronger under their increasing burden, so that an old sixteenpointer can bear a considerable weight. However, this strengthening by use can only advance to a certain point, as we see in the old illustration of the man who carried a calf every day and so was able to lift it even when it had grown into an ox. The man could never have lifted two oxen, even if he had begun with two calves. Hence there came a time in the development of the giant stag when the antlers were so heavy as to interfere with the mobility of the animals; then the animals were selected which had a stronger constitution from birth.

Hence, as the co-adaptations do not need to appear simultaneously, but may be selected successively during long periods, they present no difficulty to natural selection. The Lamarckian principle is not only inapplicable to a number of co-adaptations, but it is wholly unnecessary for explaining harmonious adaptations. $^{1}$

1 Weismann further instances the many co-adaptations of the ant and bee-workers, whose frame cannot have been formed by the inheritance of the effects of use, because the workers inherit nothing, since they do not reproduce at all. The queens, which give birth to the workers along with the rest, have a totally different structure. Weismann explains the case by a selection of stocks. Those stocks were always preserved, the workers of which took most care of the eggs and the stock. At the same time those queens were selected which were not only the best queens, but also brought the best workers into the world. 
There is still one province in which the Lamarckists think their principle is indispensable ; this is the province of instincts. It is said that we cannot understand these except as inherited habits.

We saw above that instincts are grounded on complicated reflex actions. It is just as difficult, moreover, to put limits between instincts and voluntary actions as it is between reflex actions and instincts. It is certain that actions which were at first voluntary and have often been repeated become at last instinctive. There is the pianist, for instance, who practises a piece consciously and with an effort of will. In the end he will play the piece quite instinctively, often while he is thinking of other things altogether. With many people it is entirely instinctive to take out their watch at night, or to clean their teeth-in fact, to perform a large number of actions which were at first controlled by the will. That voluntary actions may become instinctive by frequent repetition is as certain as that organs become stronger by exercise.

Hugo von Buttel-Reepen, the leading authority on bees, has shown at length how we may conceive the origin of the bee-state by selection. At first there were a few living females, which laid their eggs in sheltered hollows and provided them with food, as many wasps still do. Then those females were selected that remained with the eggs and watched them until the young issued. The next point was that the first females to come from the eggs took a part in the watching of the rest of the eggs and larvæ. After this there was a more and more complete division of labour, in virtue of which the older female was turned exclusively into an egg-laying machine, and the others worked for the community. The great advantage of the state is that, even if numbers of the feeders of the swarm are destroyed, there is always a sufficient number left to supply its needs. The limits of the present work unfortunately forbid me to enlarge further on this interesting subject. 
It has been claimed that voluntary actions of this kind that have become instinctive, or habits such as these, may be inherited. That, however, is not found to be the case with the pianist; his son must learn the art himself laboriously. It is the same with reading and writing.

Thus we see from the start that all voluntary actions that have become instinctive are not inherited. It is true, say the Lamarckians, that all habits are not transmitted, but the instincts we find in the animal world are inherited actions that have passed from voluntary to instinctive. There are instincts so wonderful that we can only conceive them as impulses perfected by intelligence, which have reached their present height by the inheritance of such usage during a long series of generations.

But when we examine the impulses of animals, we find that in a large number of them this conception is quite impossible. There are instincts which it is impossible to imagine as having ever been initiated by the will of the animal, or having been improved by use. This is clear in the course of one of the most original impulses - that of flying from enemies.

When a fly darts away from the hand that tries to capture it, this is certainly not a voluntary act that has become a habit by practice and been transmitted as such to posterity. It can hardly be supposed that the fly kncws what it is to be killed. Nor can it ever learn by experience how swiftly it must fly, as every insect that does not get away promptly loses its life. Finally, the action is clearly seen to be unintelligent from the fact 
that the fly constantly returns to the same spot, although it has barely escaped from the hand of the catcher a number of times. The fly is certainly not an intelligent animal, otherwise it would know that the spot was dangerous. Clearly, in its flight we have an instinct that causes the animal to fly away quickly, by a sort of reflex action, when a body approaches it rapidly ; an instinct that was not initiated by intelligence, nor practised.

We must equally discard the Lamarckian principle as an explanatory factor in dealing with the instincts that accompany protective colouring. The murderous mantis, which is of a green colour like the surrounding grass, steals very slowly on its prey. The xylina, that looks like a piece of wood, shams death; that is to say, remains quite motionless, and finds excellent protection in this way. Can these animals know that their colour is only useful to them if they act in accordance with it?

Butterflies that are not eaten on account of a nauseous taste or smell are distinguished, as we saw, by glaring colours. They fly slowly, because it is best for them to be seen clearly, so as to be recognised from afar as inedible before a bird can seize them. No one, surely, will suppose that these animals are conscious of the advantage they have in flying slowly.

There are, nevertheless, intelligent tracheates whose instincts might seem to have been originally acts of intelligence, which they have improved by reflection, and have transmitted the results to offspring. I refer, especially, to the spiders. 
When a garden-spider is preparing its web, it first climbs to a high point, gives out two threads from its spinning glands and attaches them. It then lets itself down by the two, either to a branch that lies right below it or in a slightly oblique direction; it accomplishes the latter movement by swinging itself about. One of the two threads is again attached and drawn tight; the other is bitten off, and is carried by the wind until it reaches a branch that lies on a level with the upper point. The spider crawls up it, draws it tight, and attaches it. It then lets itself down and prepares the second vertical thread. It furnishes the horizontal thread either in the way we have described or by making a circuit, passing from one point to the other on the ground, spinning its thread all the time and drawing in the long thread with its fore-legs and fastening it. When it has thus prepared the frame of the net, it runs to the centre of the horizontal thread, and lets itself down vertically to the lower one, and thus forms the diameter-line. Then come the radii from the centre; these are fastened to all the required points, when the spider has reached them by means of the existing threads. Last of all the concentric lines are made by passing from one radial line to another. The whole web is often made in a single night.

The work of the house-spider is simpler. It draws threads backwards and forwards across a corner, and lurks in the tube it has spun. Very remarkable, again, is the conduct of the large water-spider. It breathes the air, although it lives in the water, and has in the hairy coat that clothes its abdomen a means of retaining 
air underneath the water; this gives it a bright silvery appearance. The water-spider makes underneath the water a diving-bell as large as a wall-nut, bringing down in succession from the surface the air-vesicles it has wound round. It usually lives in these bells, and stores its prey there.

If it were said that intelligence prompted the spider to modify its web in this way, and practice had made it perfect, the claim would not apply to the bell that the water-spider constructs for its young, which is closed below as well. The spider cannot possibly know that the eggs and the young that issue from them need air. But if the one web has been produced without intelligence and practice, it may very well be the same with the other.

We are, in fact, compelled to exclude the influence of intelligence in this care of the young by the tracheates, because the parents only make the shelter for them, and never see their offspring, and so cannot know their needs. The black water-beetle spins two plates, lays its eggs inside, and weaves the edges together. It thus forms a raft, one side of which is drawn up in the shape of a little horn, so that it always floats with this uppermost. Still more complicated is the case of the predatory wasps. These powerful creatures fall on an insect, probably a caterpillar, paralyse it by a sting, and drag it into their nests, where they lay the spoil in a cell, deposit an egg on it, and cover up the cell. The larva develops from the ovum, and feeds on the victim, which has been prevented from decaying by being merely paralysed. Sometimes, indeed, the egg 
is suspended over the victim by a thread, so that the convulsive movements of the caterpillar may not injure the larva, which can always retreat by the thread. Here again we must discard the supposition that the wasp executes all these details because it knows what will be good for the larva. And the instinct cannot have been perfected by practice, because they lay very few eggs in the course of their life.

There are, moreover, plenty of instincts that only act once in the lifetime. In these cases it is frequently clear that the Lamarckian principle entirely fails, because here there is no practice whatever and consequent improvement.

An insect only passes into the pupa stage once in the course of life, so that this act and the preparations for it have not been practised. But these preparations are amongst the most wonderful and most complex instincts. The matter is comparatively simple in many of the day butterflies, such as the common white ones. These, while in the caterpillar stage, spin a thread round themselves, and hang down by it from a wall. The thread must be just as long as the thickness of the pupa, otherwise it may either be pressed or fall out. How can the caterpillar know how thick it will be in the pupa stage? And how can it practise spinning its thread when it only does this once in life?

The larva of the large stag-beetle passes into the pupa stage in a hollow ball of clay prepared by itself with polished walls. In the insect that will become the male this is much longer, because of the large antler-shaped jaws, than in the case of the future females, 
whose tentacles are small. Here the constructive instinct differs for the two sexes. But in neither case can we suppose that the larva knows what sort of tentacles it will have. The clay-ball, moreover, is only formed once in life, and there is no possibility of practice.

One of the most complicated pupa-coverings is the web of the small nocturnal peacock's eye. In this case there is a hole for creeping out in the spun capsule, but in order that the enemies of the pupa may not crawl in by it a bundle of stiff silk-bristles, with points directed outwards, is spun over the hole, and acts as a weel. The bristles are easily pushed aside by the butterfly when it issues forth, but they prevent an entrance from without. Here, again, there can be no question of practice, as the caterpillar only makes the web once in its life, and makes it-must make it-correctly on this single occasion. The intelligence of the caterpillar, moreover, has certainly nothing to do with the work, as it cannot know that it will need special protection during the pupa stage, and that this complicated structure on its home will keep off its enemies.

We see, therefore, that the Lamarckian principle entirely fails to explain many instincts. There are instincts that can never have been acts of will and intelligence, and others in which the element is entirely wanting to make them instinctive even if they had once been voluntary actions - namely, practice or repetition-as they are only performed once during life. ${ }^{1}$ If the complex instincts we have described cannot

${ }^{2}$ Instincts of this kind are Weismann's chief objection to Lamarckism. 
have been brought about on Lamarckian principles, we must discard them in the case of all instincts.

But we have already seen, in the second chapter, that instincts present no difficulty to natural selection. Instincts vary, just as the parts of the animal body do, and so can be selected and improved. They are adaptations, and are often only of use in the circumstances in which their possessors usually live; they are, therefore, relatively imperfect, as we should be bound to expect in view of their origin by selection. A cricket that saves itself in nature by digging swiftly into the ground repeats the movement even on hard gravel or on a glass plate, when it would do better to run away. A bee stings a human being, whose skin closes over the wound, and retains the sting with its barb, which is fatal to the bee. Its sting is only provided against its chief enemies, the insects, whose coat remains open after the wound is inflicted, and lets the sting out again. The imperfectness of these instincts tells very clearly of their origin by natural selection.

Hence, though many scientists retain the Lamarckian principle because a number of the characteristics of animals seem to them inexplicable without it, we have seen that these characteristics are also found in circumstances where the Lamarckian principle cannot be admitted at all. We found this in the case of the skeleton of insects and their co-adaptation. We now find it also in their instincts.

The Lamarckians, however, retain their theory exclusively, though they know it cannot be proved. How 
often it used to be said that mutilations were inherited, yet all the alleged proofs of it have been found invalid! There is not a single case in which a pup has been born with its tail cut off, or an individual born, amongst the Semitic races that practise circumcision, with that particular mutilation, though it has been practised by them for thousands of years. It has been found just as impossible to prove a case of a change that had occurred in an animal's lifetime being transmitted to its young. We sometimes read in sporting papers that red spots have been found on the young in the womb of a deer at the spot where the ball struck the mother. That would be a very sudden inheritance of acquired characters! Many people still believe that pregnant mothers can influence their offspring by fear, that the child will have burn-marks if the mother has seen a big flame before birth; it is quite arbitrary to call the red spots burn-marks, instead of blood-marks, or anything else. It is also thought that crippled limbs from a fall can be inherited.

These beliefs have not been sustained by scientific inquiry. The many cases that have been investigated by experts have generally been explained in the sense that the feature in question was already in the family as a congenital characteristic. Not a single case has been established scientifically in which an acquired character, a mutilation or a habit, to which there was not a predisposition, was transmitted to children.

It is, of course, a different matter with infection and poisoning. These affect the germ; they taint the whole body, and do not leave the ova and sperm 
untouched. But in these cases the germ is not modified in a particular direction, but is diseased, like the whole body. This is what we have in cases of syphilis or alcoholic poisoning. The infection of the germ is brought about either by minute organisms that penetrate to it, or by alcohol, which naturally reaches the germ as it courses through the whole body.

The Lamarckian principle cannot, therefore, help us in explaining certain characteristics of animals, because it does not explain many of them; in the second place, it cannot be proved; and in the third place, it is not an explanation at all.

Natural selection rests on two causes, both of which have been demonstrated-on the variations of animals and their inheritance, and on over-production and the destruction of a certain percentage which this entails. But of the two postulates of the Lamarckian principle only one has been established, and this only in certain cases. This is the statement that an organ is strengthened by use and enfeebled by disuse. The second postulate - that these changes affect the germ in precisely the same sense-is a hypothesis that has not only never been proved, but itself requires explanation.

We must certainly admit that the ova-and also the sperm-that mature within an animal are infinitely complicated structures; and that in each ovum there is an enormous number of minute particles, each of which forms a certain organ when an animal develops from the ovum. But these particles are not miniatures of the subsequent organ; they have a totally different form.

Hence the stimulus that modifies any organ of the 
mother must penetrate to the ovum, must make its way through all the particles, without affecting them, and must influence precisely that particle which will form the same organ in any child that may develop from the ovum. But as the particles have quite a different form from the organ in question, the stimulus, when it has reached its object, must suddenly transform itself in a mysterious fashion, much as electricity is converted into sound in the telephone.

Let us take the case of a woman strengthening the muscles of her arm by bending and stretching it. Even if this stimulus penetrates as far as the ovum, there is no arm there for it to strengthen in the same way, there is merely a minute point that will form the muscle later on, but at the time has nothing muscular about it. The stimulus must, therefore, transform itself in order to influence this point so as to produce a stronger arm subsequently than it was originally calculated to do.

By what means, moreover, will such a stimulus be conveyed? By the nerves? By the blood? These can at the most only convey a fuller or thinner supply of nourishment to the ovum. How, then, can they be the means of influencing just one particle, and that in a qualitative sense? When a woman, for instance, injures her eyes by too much sewing, the most that can be done is for the particle which will form the eye of her child to receive a worse supply of nourishment. But why should that make the child's eye short-sighted, instead of smaller?

There are other hypotheses as to the conveyance of the stimuli that affect the body to the ovum, but they 
are all grounded on precarious conjectures, not on facts. Hence the chief postulate of the Lamarckian principle itself requires explanation. Then there are the numerous categories of facts in which the principle entirely fails. There are so many characters of animals that have never been exercised because they only act when they are already there-such as colouring. How could any conceivable exercise of the salivary glands bring about the poisonous character of many serpents? Use can at the most cause the glands to secrete a larger quantity, but not a different product? And how could the spines of the hedgehog arise from its being often bitten in the skin by its enemies? The thorns that protect plants from being eaten are also just as impossible to explain as due to use.

We must, in fact, be very careful with the word use or exercise. We often read in Lamarckian literature that pressure will in one case lead to a less development of the parts pressed, and in another case to a stronger development. ${ }^{1}$ The first postulate of the theory is therefore unsafe in many cases. It lends itself far too much to being used as a mere phrase that explains nothing. This organ must have been strengthened by exercise, they say, knowing neither if it was in reality much used, nor if exercise would modify it in the

1 Thus in Plate's works pressure generally has a strengthening effect, but in the case of the hermit-crab, the abdomen of which is buried in a snail-shell, the steady pressure is regarded as having a weakening effect and leading to the disappearance of its coat at this part. In general, however, Plate makes a moderate and judicious use of the Lamarckian principle. He recognises its weak points, but thinks it is necessary for the explanation of certain phenomena. 
particular direction. And when the same stimulus is said to weaken in one case and strengthen in another, we shall do best to discard an explanation that is unworthy of the name.

It might still be said: We admit that the chief postulate of the Lamarckian principle has never been proved, but that is because we know so little about the conveyance of stimuli in the body. Still, the principle has one advantage. It unites a large number of cases under a single head. Thus we trace all the cases of falling to terrestrial magnetism without knowing its real nature.

But it is precisely the element which gives any value to such a concentration-the embracing of all falls that we observe under one law-that is lacking in the Lamarckian principle, which always leaves gaps that it cannot explain. And apart from the fact that the principle cannot explain the origin and transformation of the organic world as a whole, it proves useless even in small groups of cases, and it has to leave gaps in those where its action seems most probable, such as the co-adaptations.

There is only one phenomenon in the organic world of which selection does not give an entirely satisfactory explanation. I mean the rudimentary organs. But even here the Lamarckian principle is of no use to us, as it cannot have acted in many of these cases, and so we know that rudimentary organs may be brought about without its aid. There are some in the coat of insects ; I need only recall the degenerated wings of the orgyia, which consist mainly of shell. In this case the inactivity 
ought to preserve rather than injure the wings, since dead structures are all the better for being spared, as anyone can see in the matter of his clothes. Hence, the wings ought to have been used up and atrophied precisely in the case of the flying insects, and have been preserved in the case of the non-flying, such as the orgyia. There are many rudimentary organs in the coat of insects. To these the Lamarckian principle is inapplicable, and so once more we must discard it as unsafe and only explaining a part of the instances.

To conclude; no case has ever been known of the inheritance of the effects of use and disuse, and so the Lamarckian principle has not a single established fact to support it. Its possible sphere of action is very limited; even amongst a given class of phenomena it has always to leave inexplicable gaps. There is an enormous number of instances to which it has no application. Of the two postulates on which it is based, the first is only certain in a few cases, and at the most merely possible in the majority. The second postulate is not an established fact, but a pure theory; a theory, moreover, that is difficult to imagine, and in its turn postulates all sorts of phenomena and relations of most of which nothing is known. Finally, the Lamarckian principle is an obstacle in the way of a unified conception of things, such as it is the chief aim of the theory of evolution to build up, and can never be reconciled with it. We shall see more of this in the eleventh chapter.

But I think we have now said enough to deprive the Lamarckian principle of all power to modify the forms of the organic world. 


\section{CHAPTER VII}

\section{CRUSTACEA AND MOLLUSCS}

Economy of nature. The chemical constituents of bodies. Chemical combinations. The elements. The albuminoids. Biogens as constituents of living matter. Vital phenomena and apparent death. Metabolism. Structure of the living substance. Plants the foundation of life. Order of sustenance in nature. Flesh-eating is more natural to the animal than plant-diet. Are all variations useful to animals? Value of selection. Origin of the shells of snails. Change of functions. Development of the crab. Why the embryonic development of an animal reproduces its racial history. Reconstruction of embryogenesis. Uncertainty of the biogenetic law. Parthenogenesis, the development of unfertilised eggs. Significance of the germ-cells. Significance of sexual reproduction. Amphimixis. Plural variations.

In every pond there are living at a certain depth innumerable tiny creatures up to the size of a pin's head. They pass up and down unceasingly, and travel backwards and forwards through the water. Every hour swarms of them are devoured by their countless enemies, yet we see no sign whatever of a diminution of their numbers. The heat of summer broods over the pond, the vapour rises to the clouds, aquatic plants come to the surface and wither in the heat; in a short time there is, instead of the pond, a dry earth-pit covered with animal remains. In the autumn the rain sets in, the ground is moistened, little pools are formed, and soon the rich colours of autumn are reflected on the surface of the 
pond. The little creatures have returned as if by magic, and fill the water once more. Other aquatic animals were unable to sustain the drought, but they are there again as soon as the water covers the bottom; the interval seems to have had no effect on their life.

These minute animals, which fill the ponds and seas in such numbers that every cast with a fine net brings up a mass of their bodies from the bottom, are called water-fleas. They belong to the gill-breathing articulates, the crustacea. They have a shell, and grow by casting the skin, like all other articulates.

The small crustaceans play an important part in the life of a pond, as most of the fishes and a good many other animals could not exist without them. These build up their frames with the flesh of the little crustaceans. The water-fleas form a tooth in the great cog-wheel of the earth's round. It turns on and on; substances are formed from stone and water; from these is built up the living matter that appears first of all in the tiniest organisms; from these are made larger and larger animals which will decay in turn, until the turn of the wheel is complete, and the stone and water are there once more to provide material for the fresh start.

In order to understand better this "economy of nature," we must begin a little further back.

We know that the mass of the earth, with all the rocks, the water, and the air that surrounds our planets, consists of elements, of which more than seventy are known. These can combine in so many different ways as to produce the immense variety of forms of matter that we see every day. Such elements are, for instance, 
oxygen, hydrogen, nitrogen, carbon, all the metals, sulphur, phosphorus, and others.

These elements may unite in two different ways to make up the materials we find in nature-in simple mixtures or in chemical combinations.

A mixture can easily be understood. We may take a piece of copper, for instance, file it down, and mix it up thoroughly with ground sulphur so as to form a greyishgreen powder. This seems to be quite homogeneous, but we find that it is not if we examine it under the microscope. If we apply a higher power, we see clearly that the new powder consists of grains of sulphur and copper, lying side by side.

But if we heat the mixture until it becomes incandescent, and then let it cool, we get a black substance in which we cannot detect, under the most powerful microscope, a single grain of sulphur or copper. A new body has been formed, and this cannot at once be separated into its constituents, as the mixture could be. The new body has also different properties from its constituents; they have, as we say, entered into a chemical combination. In the present instance the compound is called sulphuret of copper.

There are vast numbers of these chemical compounds in nature. Water is one, for instance; it consists of hydrogen and oxygen. On the other hand, the elements that form the chemical compounds are rarely found in a free state in nature. Iron, for example, is never found pure, but always combined with sulphur in sulphuret of iron or other forms.

It is possible to break up chemical compounds into 
their constituents by a method that we call "analysis." But this analysis can only continue until we reach the elements. It is the characteristic of these that, however much you subdivide them, the particles are always of the same kind. They consist of a single form of matter. Take gold, for instance; however small it is ground up or chemically divided, it remains gold.

We have now analysed all the substances on the earth, including the substance of which living things are composed. It has been found that the living substance contains just the same elements that we find in the lifeless crust of the earth, in the inorganic world, as we say. It is true that only a few of the elements-twelve in number-are found in living matter; these are, especially, carbon, hydrogen, sulphur, nitrogen, and oxygen. But while the elements of organisms are the same as those of the inorganic world, they enter into different compounds in living things from those we find anywhere else. Of these compounds it is especially the albuminoids that distinguish the living substance and are never absent from it. They are very elaborate compounds; we have succeeded in analysing them, but not in building them up from their known elements, because we do not know the arrangement of these, nor the forces and concomitant circumstances in which the elements enter into an albuminous combinationin the way that we found heat uniting sulphur and copper into sulphuret of copper.

Thus there is no difference in principle between the composition of living and lifeless matter. Nor is there any essential difference between the forces at work in 
each substance. The only difference is that we always find in the organic world certain very complex chemical compounds, especially the albuminoids, that are not found in the inorganic.

But important as the results of long chemical research are, we must not exaggerate them. The living substance is as enigmatic as ever, because we only know its composition after death. The analyses that have acquainted us with its constituents had to kill it before any result could be obtained. We may, nevertheless, assume that the organic substance consists chiefly of albuminoids in life as well as after death, but their behaviour is very different in the two cases. We can preserve dead albumen for a long time, if we keep bacteria away from it, without decomposition setting in, whereas the albuminous matters in the living state are continually breaking up even under normal conditions, and the more readily the stronger the stimuli that act on them. We must, therefore, draw a profound distinction between living and dead albumen.

This has induced many scientists to discard the name "living albumen," and replace by the term "biogen." We know very little of the real composition of these biogens. As they pass into dead albumen when the organism dies, it is very probable that they closely resemble it in texture, and especially that they contain no different elements. But certainly the grouping of their elements is different from in dead albumen; it is, in particular, looser, as only in that way can we explain the ready disintegration of the biogens. It is 
precisely in this looser texture that we find the centre of gravity of the whole life.

The living substance has distinctive properties which we call the phenomena of life, and which are familiar enough to everyone as nutrition, movement, irritability, and so on. When these properties disappear we say that the organism is dead.

All the vital phenomena, however varied they may be, are based on one property of the living matter, namely, its interchange or circulation. The fundamental quality in this is "metabolism"; that is to say, the living substance breaks up of itself unceasingly and regenerates itself, and in doing so thrusts out matter from itself and takes in new matter from without. As it is the living albuminoids that behave in this way, we may say: Life consists in the metabolism of the biogens.

This metabolism ceases when life has left the body. We have, in fact, every reason to believe that the metabolism is suspended in "sham death," even when it is voluntary, as in the case of the Indian fakirs. The trance or simulated death of the fakir may last for six weeks. Many of the animals, also, fall every year into an apparent death-condition, and awake to new life in proper conditions. The seeds of plants may lie for years without vital functions, yet germinate when they are put in moist earth. The very finest methods have failed to detect any trace of giving-off matter in these seeds. But it is untrue that the grains of wheat taken from Egyptian tombs thousands of years old grow into plants. They decay when they are put in water. 
The constant renewal of the disintegrating biogens is effected, therefore, by the taking-in of matter. This must, of course, contain the elements of which the living substance is composed. These elements, we know, are found in inorganic nature. Thus the organism is like a laboratory, in which chemical compounds are constantly set up and taken to pieces again. The requisite elements are taken from the earth, the water, and the air. These are first of all united in simple combination in the organism, and from these more complex ones are formed, and so the activity of the living substance goes on until the albuminoids are produced. The albuminoids are converted into living albumen, or biogens, by rearrangement of their constituents. Here the highest point is reached. The series of changes then descends once more. The living albumen becomes dead, this disintegrates, more and more simple compounds appear, and in the end combinations of the simplest nature.

But, we may now ask, who represents the chemist in this living laboratory, the man who chooses and brings together the requisite substances?

The new biogens are formed from the old. The dead albumen that is imported into the body is converted into living by the biogens. When these have created new biogens, they break up, but owing to their activity before death the body loses none of its living albumen.

However, the conversion of dead into living albumen is only the last part of the work done in the body. Who selects the matter that is to be taken into the 
body out of the number of substances found in nature, and who converts them into dead albumen by progressive combinations?

First of all, we must explain that the forces that can do this are only present in the plants. These alone have the power to select the requisite elements for making albuminoids out of water, air, and earth; animals have lost this power. The latter must always obtain their albumen ready made, and their biogens will then convert it into living albumen. Animals perish if only supplied with inorganic matter, as their biogens then find no albumen that they can convert into particles like themselves. They cannot make a beginning with inorganic material, as their substance has not the power to put it through the long series of combinations that are necessary for the production of an albuminoid.

Thus the whole animal world is based on the plants. These alone have retained the power to form living matter out of inorganic substances; they are now the sole laboratory in which albuminoid substances are prepared. This can be done, however, only by the green plants; the others, such as the fungi, need organic nourishment, like animals. The green in the plant consists of microscopically small granules of chlorophyll; they have the power, under the influence of sunlight, of gradually creating organic matter from the necessary elements of the air, earth, and water. The plants are the foundation of life. They alone can cover the steady return of living substance into inorganic matter, during its disintegration, by re-forming organic from the 
inorganic. They thus exercise their power, not solely for themselves, but also for the whole animal kingdom. The animals can only cover their loss of organic substance from disintegration by obtaining albuminoids ready made, which they merely convert into living matter. They either take their food from the plants, or they satisfy their need of organic food by devouring their fellows, and these must have built up their frames on vegetal matter. The groundwork of all life is found in the plants; without them the animal world is unthinkable.

Let us now consider a world in miniature, a pond, in order to see the successive steps in the provision of food. There must first of all be plants, if any living substance is to be formed at all. In the pond these are chiefly algæ, tiny green vesicles, which often swim freely about. These algæ form the food of the water-fleas, the crustaceans of which we spoke at the beginning of this chapter. Most of the other animals live on these fleas, as also do the fishes, which feed almost exclusively on water-fleas in their earlier stages. The fleas are, therefore, an important connecting link in the economy of Nature.

Even from this instance we see that it is not the higher plants that form the groundwork of the nutritive scale. This will easily be understood from the fact that the higher plants are very complex structures, with their stem and roots, leaves and flowers; they must have been developed at a late date, when there were already plenty of animals. Thus the first "angiosperms"-or all our foliage-trees and shrubs, and many of our herbs 
-only appeared about the Tertiary period, and so come after many groups of vertebrates, such as the reptiles, had reached their greatest height. In fact, the whole intricate mechanism of the plants-the leaves, flowers, etc.-only came as an adaptation to life on land; marine plants have remained at the primitive stage of seaweeds and algæ.

The plant-eaters are, of course, older than the flesheaters, since the first animals can only have had organic food in the shape of plants. But we must not generalise too much on the strength of this fact. Once the world was filled with the tiniest animals, the higher animals could be developed from them, and grow and advance at their expense. It has been rightly pointed out that animal food comes more naturally to the animal than plant-food. Every animal has been accustomed to an animal diet in its earlier period, whether this consisted of the yolk of an egg or the milk of the mother. The break from this early diet to plant-food with its hard substance, the cellulose, is very considerable, and we can understand why the higher plants have been avoided and the earlier vegetal diet retained.

The chief difficulty in following the food-series occurs in connection with the land-animals. In the sea there are lower algæ that are eaten by the smallest animals, and these in turn are devoured by the larger. Here nearly all are carnivores; vegetarians are very rare amongst the larger salt-water animals. We can thus see that these tiny, lowly algæ provide the organic matter for the whole animal life of the sea, since this is prepared from inorganic substances by the algæ 
alone; it then passes through the whole series of animals until it reaches the great monsters of the deep.

It is otherwise on the land. Here there are none of the lower algæ and the minute animals that we call the protozoa. We have, therefore, to construct a different diet-series.

It is clear that all the higher characteristics that the plants developed on land first put in their appearance as root, stalk, leaves, and fibres, without being devoured by the animals. The leaves were not used as food until some time afterwards. It is probable that at first the land-plants only served as food for the animals after they had decayed, and so been modified by bacteria. The earthworms, which are certainly ancient species of animals, still feed in this way. Other animals may have lived directly on the fungi, which were certainly nearer to the diet they had been accustomed to from their early days than the green plants. The fungi have a similar composition and nutritive value to the animals. They have no green colouring matter, but feed on organic matter that the green plants have made.

There is only a step from the eating of decayed plants to the eating of carrion, and this comes close to flesh-eating. We can best understand the flesh-eating animals if we assume this to have been the development of their diet. We are speaking, of course, only of the original animals; in the higher ones the food changes according to the adaptation. Thus our former statement, that a flesh diet comes more naturally to an animal than a vegetal diet, is not inconsistent with the 
ruminants. Natural selection can certainly cause the adult animal to adopt a diet different from that it was accustomed to in its youth.

We have a good illustration of such a development of diet in the second great group of animals with which we have to deal in this chapter, the "molluscs." The chief representatives of this stem amongst us are mussels and snails. Of the latter, the land-covered snails eat fungi or mould, and the road-snails fungi. But a few species in each family have taken to a flesh diet. They can, of course, only catch slow animals such as earthworms or other snails. And it is only certain species of snails that they eat, while avoiding the rest, possibly because they are protected by a strong slimy secretion.

The mucus is a general characteristic of the snails. Our water-snails use it for creeping on the surface, many experts believe, and as a fact this seems to be the simplest explanation of the mysterious progress of the pond-snail on the surface of the water, with its body bent downwards. The snails which seem to have the flat part hanging in the air, and to creep on this, give out a long slimy thread and glide along this.

The water-snails have a peculiar organ that enables them to rise or sink without effort, as the fishes do. This is their breathing organ, a cavity in the body that opens externally by an orifice. The animal sinks by compressing the cavity, and rises again by dilating it.

The respiratory cavity is the lung of our molluscs, and is found both in the land and water-snails, as the latter are land-animals that have passed into the water, and must come to the surface to breathe and close the cavity 
below. However, the ancestral forms of the snails are in the sea, and are gill-breathers. How were the lungs formed when they came to live on land? The organ for breathing air could not be large enough from the start to perform its function. How was it possible, then, for variations which represented the rudiment of an organ that could not yet act, and so were useless, to be preserved and favoured by selection?

Here we have what is considered to be the radical objection to the theory of selection? The action of natural selection is made possible by the variations that bring about differences between animals, and cause some of them to be retained and others extinguished on the ground of their better or worse qualities. But these variations are insignificant in themselves. Hence if an animal only differs very little from its fellows, we can hardly say that it has on that account more chance of surviving or perishing than they.

Let us take an instance. In the craw-fish the eyes are fixed on mobile stalks, and so the animal, the whole fore part of the body of which is rigid, is able to see over a larger area. In its ancestors the eyes were set deep in the head, as is still the case with the centipedes and the smaller crabs. According to our theory, those crustaceans must have been selected whose eyes stood out a little higher than those of their fellows, so that they were favoured in the struggle for life. But, it may be asked, could this trifling elevation of the eyes really be such an advantage to its possessor? The field of vision would only be the smallest degree larger than in the other crabs. If individuals arose amongst those 
early crabs that had eyes already projecting on small stalks, we should acknowledge that these had an advantage, as they would perceive their enemies or their food quicker than the others. In a word, the changes that any organ or character of an animal shows at birth must generally be so slight that they can have no selective value; that is to say, their owners cannot be so much better situated on account of them as to escape the destruction that falls on their fellows.

Above all, it is said, we cannot see how complex organs and instincts can have a selective value from the beginning. The trunk is indispensable to the elephant. It uses it as a weapon, conveys food to its mouth with it, and cannot lift objects from the ground, or drink, without it ; these are all actions that it could not perform without the trunk on account of its short and stiff neck. But the trunk is only useful at its actual length. If the ancestors of the elephant had noses of ordinary length, like the tapirs, they would hardly be able to perform one of the above functions, and they would not have any advantage in variations that added a small fraction of an inch to them. We cannot admit, therefore, that the first slight lengthening of the nose was so useful that the elephants which did not possess it were the first to perish. In other words, we do not see that these nasal variations would have any selective value.

However, let us take an instance from amongst our own animals. Take the shell of the snails. This is certainly useful to the animals, as they can withdraw into it and find shelter from their enemies and from bad weather. But the shell did not appear at its full size all 
at once; it must have been small at first, so that the animal could not retire into it. Thus the shell was of no use at first, and so the snails in which it first made its appearance could not have been favoured by natural selection.

Nevertheless, the origin of the snail's shell by natural selection is not so unintelligible at all. It has been said that the ancestors of the snails were animals that migrated from the depths of the sea into the surge-zone. These were at first devoid of shells, and clung to the rocks with their foot. The force of the surge must have destroyed numbers of them, tearing the animals from the rocks and dashing them against the stones. Those had an advantage, therefore, which had some feature that modified the force of the surging masses of water. This was a slimy layer that made the back of the animal smooth, so as to give no point of resistance to the water. All snails do, as a matter of fact, secrete this slime, and we can conceive this faculty to be increased by selection. But selection altered the quality, as well as increased the quantity, of the secretion. It was useful for this to become thicker and thicker, and thus at last the shell was formed, covering the snail like a shield. Each small variation was useful from the first, as we saw, and as the variations affected the whole dorsal surface of the body they led in time to the formation of a structure covering the entire animal. When the snail took to further migration and to the land, other variations would be selected until the snails' house was formed, however small it may have been.

We must be careful in urging the objection that many 
organs could not have had a selective value from the first. Even such complicated structures as the wings of birds and insects could arise gradually, as we saw in the fourth chapter, and were clearly useful from the start. Further, it has been rightly pointed out that sudden crises may occur in animals after periods of rest. During these the utmost demands are made on the bodily and mental constitution of the animals in the general devastation, as the stronger often fall upon the weaker members of the same species. Large numbers of animals perish in a severe winter, and we may assume that even a slight variation in the thickness of the fur or the feathers may save an animal from destruction. It has also been said with truth that in the migratory birds, for instance, slight advantages in the power of flight may do much, as the effects accumulate in the course of the long journey. Cyclists know that if they are to win a race every small part of their machine must be as light as possible.

It is often difficult to imagine how an organ can have arisen by natural selection, yet we detect a means on further reflection. The origin of the wings and of the snail's shell seemed for a long time to be a hopeless enigma, but the solution was at length discovered. If we can find the answer to these really difficult questions, we may hope to do the same for the remaining problems in connection with the evolution of animals or organs. But above all we must not at once throw the blame on the theory of selection when we cannot find the solution, but must remember the imperfect condition of our knowledge. We cannot 
determine the origin of any organ with certainty, as we have no absolutely certain documents. We construct the development of animals and their organs with the highest probability, once we have established the fact that they must have been evolved. The soundness of the theory of selection is by no means shaken by quoting organs the origin of which we are not at present able to explain.

We will not attempt at the moment to settle completely the difficulty that arises about the selective value of variations. We will merely refer to a subsidiary principle which provides a simple solution of the difficulties that are found in regard to the usefulness of the first variations of many organs. This is the principle of change of function.

We became acquainted with this principle in describing the conversion of the swimming-bladder of the fish into the lungs of the amphibia. Something similar happened in the development of the land-snails. In the marine snails the gills lay in a cavity that opened externally, and there were several blood-vessels in the wall of it. In the pulmonary snails also the respiratory organ is a cavity which differs from the preceding one chiefly in the absence of gills, and in the fact that the blood-vessels in its lining are so numerous and ramified that the air can give its oxygen, which penetrates through their thin walls, to the blood. These lungs are one of the best conceivable instances of the gradual transformation of one organ into another. They show, in the first place, that here, where natural selection needed an extensive organ from the first, there was one ready to 
meet the requirement; and in the second place, it is clear that here the smallest variations had selective value, because as they passed on to the land every advance in the ramification of the blood-vessels in the lining of the cavity meant a richer supply of oxygen, and secured a longer life.

There are plenty of examples of organs that had at first a certain function, and were enabled from their constitution to take up a secondary one. If a change took place in the habits of the animal, this second function might become the principal one; in fact, the first might gradually disappear, and the organ would be correspondingly modified. We have a process of this kind in the limbs of the craw-fish. It has feet on what is called its tail, as well as the five pairs of legs, of which the first bear the claws. The animal's tail is really its abdomen, and must not be compared to the tail of the vertebrate; the alimentary canal runs through it. The legs on this abdomen were at first clearly for swimming, but were also used by the female for carrying the eggs. The second function became more important when the animal took to crawling as its chief method of locomotion, and so the abdominal legs became smaller and smaller by selection, and are now only useful for carrying the eggs; even in the male they are used in connection with reproduction.

Other legs of the craw-fish have undergone an even greater transformation. All the limbs of the crustacea were originally legs, even the feelers, or antennæ, that act as organs of smell or touch, and the masticating apparatus. Most of the masticating organs look very 
much like feet, except that the first masticators are shaped like two strong teeth. But, it will be asked, how do we know that these and the antennæ were originally legs, when they have no resemblance to legs?

The answer to the question is given by embryology. In the case of a good many crustacea the ovum produces an animal that is very different from the adult, and is known as a nauplius-larva. It is unarticulated, and has a simple organisation and only three pairs of legs, with which it swims about with a kind of hop. The larva gradually grows; its hind end lengthens and breaks into joints, on which new limbs sprout out; these differ in number according to the number possessed by the adult of the particular species. But the original three pairs of limbs of the nauplius are converted into the two pairs of antennæ and the first masticators. These have therefore been developed from legs, as we clearly see.

There are crustaceans that have become parasites; they cling to other animals, and feed on their vital fluids. These have changed their form so completely that they may be taken for a piece of the intestine or at all events a worm, but never for a crustacean. The most curious, perhaps, is the sacculina, a crustacean that settles on the abdomen of a narine crab and is shaped like a sac; widely branching root-fibres proceed from this and penetrate the whole interior of the crab and suck its blood. Yet this organism, so little like an animal, is a crustacean; in its youth it has the form of one, and it emerges from the egg as a nauplius that cannot be distinguished from the nauplii of other 
crustaceans. In fresh water, also, there are crustaceans that have assumed the most curious shapes owing to parasitism, such as the Achtheres percarum, a parasite of the perch.

The crustacea are particularly striking illustrations of the biogenetic law that we mentioned in the fifth chapter. The crustacean reproduces in its ontogeny-its development from the ovum-the course of its phylogeny, or ancestral development in past ages.

In the above-mentioned parasites we can understand why they cannot give up the free-living stage of their ancestors in their development. How could they reach their host-how could the animal, for instance, that comes from the sacculina egg reach its crab, if it could not swim freely about at the beginning of its career, and then settle like a plant on its victim?

There are only a few animals in which it was necessary to retain the ancestral stages. In many cases it will be an advantage to the animal to be as fully developed as possible when it leaves the egg, so as to reach sexual maturity quickly and provide offspring. The whole development has, therefore, to take place in the egg, as is the case with the birds, and individuals of this kind are protected by the shell of the egg or within the mother's womb. But a development of the animal within the egg implies a certain size in the egg, because, whilst the free-swimming larva can obtain from without the necessary nourishment for its growth, the animal in the egg is restricted to the supply of food inside the shell, or to the substance that we call the yolk. Eggs with much yolk can, in view of 
their size, only be produced in small quantities; but on the other hand, the amount of nourishment provided enables the young in them to run through the stages of development more quickly than the free larvæ, which have to struggle laboriously for the matter with which to build up their frames.

When an animal is brought by natural selection to develop in the egg instead of as a free larva, a number of changes will follow. All the characters that can only be of use to a free-living larva are cut out in the embryonic development as so much waste of time and material, and only those ancestral stages will be retained that are necessary for the further development of the specific marks of the animal. Here we come to the essence of the biogenetic law. It is not a law of absolute and universal validity, like the law of gravity, otherwise every animal would have to reproduce exactly in its embryonic development the stages of its ancestry, which is not the case. It is no more than a postulate of the action of natural selection. All the characters of animals must arise in connection with others already existing; nothing can be developed suddenly and without intermediate stages. Hence if a new organ has been formed from a previous one by gradual modification, it must follow the same line in its development from the ovum to the adult, because the ontogeny also can only proceed gradually. Thus the biogenetic law demands that just as an animal could only develop further in its ancestral history on the strength of qualities already existing in its predecessors, so in its individual growth it must build gradually on the actual. 
And this is, in the present case also, the succession of ancestral stages.

When an adult animal is modified by natural selection, this modification will be the last to appear in the development of its descendants. It is always the terminal stages of animals that are vitally affected by selection. But the further the modification of the new species proceeds, the more will the embryonic development be affected. The organs that assume an increasing importance and range in the transformation will no longer find time for their development in the final embryonic stages, and their formation will be pushed further and further back, since those animals will always have the advantage in which the organ is formed first, and so most completely developed. Thus the most important organ in man is the brain. This enormously complicated structure naturally requires a very long time for its construction, and so we can understand why it should be one of the first organs to appear in the embryonic development, and why in the human embryo its size is altogether out of proportion to the small body. But it is utterly wrong to conclude from this that the human embryo with its large head and small body must prove according to the biogenetic law that man's ancestors were similarly misshapen.

In the transformation of species many new organs become larger and more important than the old ones, and these will accordingly, if they continue to be necessary but can be quickly developed, only be formed at the close of the embryonic life. This in itself will so modify the individual development that it will be almost 
impossible to gather the ancestral history from it. But the effect will increase if many of the organs of the ancestors are no longer necessary, and are not found in the adult animal. It is true that these will still have to appear in a rudimentary fashion in the embryonic course, but those animals will be steadily selected in which they take a shorter time and are less in size, as they then leave more room to the other organs. In the end they will be forced out of the embryonic development altogether. This must, of course, take place gradually, and if we find the gill-clefts of a fish still appearing, and then disappearing, in the human embryo, it only proves that the time when our ancestors had the fish form is not yet very remote, from the geological point of view. ${ }^{1}$

Finally, natural selection will modify the ontogeny by means of new structures arising. Thus in many ova and larvæ special contrivances have been selected; and as the embryonic development proceeds it must be affected still more owing to the particular method of receiving nourishment and the special position. The insect pupa is a new structure of this character; the insects cannot possibly have had pupa-like ancestors, as they would never have been able to nourish themselves. We saw in the preceding chapter how the formation of the pupa came about.

All these divergences, modifications, and new formations, of which there is an immense number, must alter

1 For a brief account of the line of man's ancestry the reader may consult Haeckel's "Last Words on Evolution," of which an English translation has just appeared. (A. Owen \& Co.) [Trans.] 
the course of the individual development to such an extent that in no single case will it faithfully recapitulate the ancestral history. It is only rarely that the biogenetic law will help the student to trace the stemhistory of an animal. That is not the purport of the law. It serves rather to make more intelligible the action of natural selection, which can only build upon previous structures in the transformation of animals. When we find ancestral traits in the embryonic development of an animal, it is a proof of the theory of descent, but we must not demand such fortunate accidents. The ontogenetic evidence for phylogeny has been so much distorted by natural selection that it is probably the worst we have. It can only rarely serve to illumine the darkness that lies on the past history of organisms, and then generally only in conjunction with the other two sources of evidence, the structure of animals and the geological discoveries.

We started from the larva-form of the crustacean, the nauplius. In that shape many crustaceans, such as the small hoppers and the branchiopods, leave the egg, and gradually pass into the adult form in the course of their free life. Other crustaceans pass through the nauplius stage in the ovum, and issue from it at a more advanced larva stage, the zoea, which has a larger number of legs and an abdomen. This is the case with most of the higher crustaceans, such as the sea-crabs, which would otherwise have to delay too long in the larva-stage on account of their elaborate articulation and numerous extremities. It is clearly better for the animal if the time is not too protracted until it begins to lay eggs, 
and so to maintain the species; because during that period it is exposed to all sorts of dangers. The crawfish, which is closely related to the marine crab, issues fully formed from the egg. This, again, is an adaptation, because the animal lives in running water, and cannot use a larva-form which from its structure is intended to float in the water. The stones afford shelter to the young animal, and it can take refuge under them. It is already a miniature of the adult.

Among the lower crustaceans, also, the copepoda and water-fleas, there are differences of development. The copepods, which swim about in countless numbers in most ponds, lay a large number of eggs, and carry them about for a long time in a little sac. These numerous eggs have to be small, on account of the lack of space and the slight quantity of food available for each; and as they contain little yolk, the animal can only develop in them up to the nauplius-stage, and must then issue forth. It is otherwise with the waterfleas or daphnidæ. In their case only a few eggs are laid, and they have consequently more yolk. They also lie in a special breeding-chamber under the mother's shell, and are washed with a fertilising fluid. Thus we can understand how, in the case of the daphnid, the whole nauplius-stage can be passed in the egg, and from it issues a completely developed water-flea, only differing from the adult in size.

The number of the enemies of the daphnidæ is enormous, and as the animals lay only a few eggs, they could not survive if they had not a special adaptation in connection with their fertility. They multiply 
parthenogenetically: that is to say, they lay eggs which develop without being fertilised by a male. From these eggs females only are produced, and they in turn lay eggs that do not need to be fertilised. Hence the water-fleas that appear in the spring are followed by several generations of the same sex; towards the end of the summer their number is enormous, and then at last males are developed from a few of the eggs. These fertilise the eggs of the last generation of females, which are only laid in small numbers, generally only one or two. They are larger than the summer-eggs, and have plenty of yolk, because they have not the benefit of the fertilising water of the mother. They have a thick shell, and fall to the bottom, where they may be frozen in, or may lie uninjured without water. In the following spring they produce the first generation of females.

Parthenogenesis brings up the number of daphnidae in the course of the summer to a huge figure. We saw in the first chapter that a couple of foxes will, if they have three male and three female young, and these three pairs give birth to the same number and so on, increase in ten years to 118,098 individuals. But if the first pair of foxes only gave birth to females, and these could multiply parthenogenetically, the number would rise in ten years to $60,466,176$, or incomparably more. With larger figures the effect is still more stupendous, as there is question of a geometrical progression. Hence the increase due to parthenogenesis is so great that though the numbers of winter eggs in each case is small, the total is very large on account of 
the number of parents. They serve to secure the maintenance of the species during the unfavourable conditions.

The daphnidæ are not the only animals whose eggs develop without being fertilised by the male. Quite a number of other species are associated with them in this respect. Many species of small mussels increase parthenogenetically as a rule; amongst many of them no males have yet been discovered, though they have been carefully watched for years in an aquarium. Parthenogenetic reproduction is also found in the branchiopods and some other species of crustacea, the gall-flies whose sting causes the gall-nuts on our trees and shrubs, and many lice, including the dreaded phylloxera. They are especially animals that enjoy from time to time very favourable conditions, which they can make use of for most prolific reproduction, and then pass into very dangerous and unfavourable conditions, which they survive in the shape of fertilised and hard-shelled eggs. Hence in this case fertilisation is not directed merely to the multiplication of the species. The best instance of this is the phylloxera.

In the spring the egg of the phylloxera produces a female which multiplies parthenogenetically to an immense extent, as the animals have an unlimited supply of food in the shape of the vine-tendrils. All these females are wingless, but after several generations the eggs produce winged females which fly from stock to stock and spread the species. They lay two kinds of eggs. The larger produce females and the smaller males. Both are very small and wingless, and cannot feed themselves. After 
their union the tiny female lays a single egg, which lasts through the winter, and makes a beginning of a new parthenogenetic generation in the following spring.

In this case it is clear that the union of male and female does not lead to multiplication. On the contrary, there is only one egg, and so one individual, from each pair. If the phylloxera depended on sexual propagation alone, it would soon become extinct. Its propagation and multiplication are exclusively parthenogenetic.

But why do the males appear at all, we may ask, when the phylloxera reproduces so much better parthenogenetically? And when we see that these animals can dispense with sexual generation, why is the same process not possible in other cases? What advantage is it to organisms that a new individual can only be formed by the union of the generative products of two sexes?

We call the ovum and the sperm by the common name of "germ-cells." They are both the germs of the new individual, and originally either the ovum, as in our illustration, or the spermatozoon, could develop quite independently into an animal. We shall see more about this later on, but may point out here that the spermatozoon and the ovum are structures of equal value as regards heredity. The ovum contains the bodily and mental characteristics of the mother and her ancestors; the spermatozoon the features of the father and his ancestors. And just as a new individual can be formed in the ovum from these characteristics by a certain composition, as the above examples show, so there is no essential reason why one should not be 
formed in the same way from the spermatozoon. The fact that the latter is much smaller and differently shaped from the former is due to an adaptation which we shall deal with later. This distinction only appeared when it was no longer possible for the ovum or spermatozoon alone to develop into a hew animal, and a conjunction of the two was needed. The blending of the two germ-cells, the spermatozoon and the ovum, is called amphimixis. ${ }^{1}$

It was the introduction of this into the organic world that deprived the two germ-cells of their independence; from that time there could be no reproduction without union of the sperm-cells and ova.

As a matter of fact, amphimixis provides the start in the formation of new individuals in the case of most animals. But this is only its subsidiary purport, and not the ground of its introduction, since the germ-cells can grow into new individuals without amphimixis, as we see in the daphnidæ and phylloxeræ. Its chief significance is that before a new individual is formed the characteristics of two animals must be blended. The qualities of the father are contributed by the spermatozoon: those of the mother by the ovum. Thus the new individual has a selection of paternal and maternal traits and of the ancestors on either side. The nose, for instance, may follow that of the father, or of the mother, or of any ancestor. How it is that

1 Weismann has shown that amphimixis (a name he has himself invented) has originally nothing to do with propagation. It was he who first adduced the parthenogenetic animals in proof of this conception, and we shall generally follow him in our further observations on amphimixis. 
of the many noses that are in a sense contained in the fertilised ovum only one is developed and not several, and what forces cause one property to be derived from the father, another from the mother or an ancestor, are questions involving general theories of heredity with which we shall deal later. We will be content here to establish the fact that there is a mechanism in the fertilised ovum that builds up harmoniously the new individual from the many characteristics it contains, by always selecting one quality out of several equivalent ones.

The great value of amphimixis is, then, that it adds new and different paternal qualities to those that the new organism receives from the mother, so that it has a choice, and has a greater variety in its composition than it would have without amphimixis. It is true that even parthenogenetic offspring do not entirely resemble the mother, because each ovum contains variations, and many of the mother's characteristics appear slightly changed in her progeny. Nevertheless, such offspring will be more uniform in structure than others that suddenly receive a series of characteristics of a totally different individual.

For these the constant re-combination of characters in the offspring is of the greatest value; it gives a wider field of operation to natural selection. It enormously increases the adaptive capacity of the animals, and the variations from which one animal would arise here, and another there, are united in one individual. It is due to amphimixis, therefore, that co-adaptations do not need to be selected slowly and successively, but may 
appear simultaneously, as we saw in the instance of the heron, in which one animal is favoured on account of the length of its neck, another on account of the length of its bill, and their offspring may inherit both features. In this way amphimixis may easily bring about a difference between two similar structures. A hare, for instance, may inherit short fore legs from a short-legged mother and long hind legs from a longlegged father; and as this combination is useful in view of its leaping, it may be further selected. Thus coadaptations are facilitated and accelerated by amphimixis; the animals that are subject to it will be selected first, and so we can see why amphimixis would be retained in most animals, and why it is so wide-spread.

But it is also useful to organisms in another respect. When an organ varies in any animal-let us say it becomes larger-it may, of course, become smaller in the next generation, but may just as well become larger. Many experts believe, in fact, that there are definite directions of variation; that some internal or external principle often presses them in the direction they have once taken. We will discuss later on the possibility of this, but we can in any case imagine that variations, especially those that are only in two opposite directions, may take the same direction for some time.

If any organ does vary in this way it may very often be injurious to its possessor and bring about its destruction. Excessive variations of this kind must often appear, as chance may frequently lead to the variation of an organ in a particular direction during several generations. Amphimixis prevents animals from 
being destroyed on the ground of these excessive variations; it does not allow too great an advance of the variations, because it crosses these animals with others that have not the variation in question, or have one in the opposite direction, so that the normal standard is reached again in their offspring. Thus excessive variations tend to disappear in the general crossing, as amphimixis has an equalising effect.

We have already seen that the indifferent characters of animals are preserved in the general crossing, because the plus and minus variations neutralise each other. Without amphimixis the variations would diverge in all possible directions, and each animal would separate further and further from the others. It would be impossible to comprise a definite group together as a species. Definite species are maintained entirely by amphimixis. As the law of heredity explains the resemblances of animals, so amphimixis explains that its action marks off definite specific types from each other in the world.

A further result of this levelling tendency of amphimixis is that isolated changes, even if they are useful, cannot modify the species, because they are lost in the general crossing. It is only when the majority of a species that live together vary that the character in question will be impressed on the whole species by natural selection; in other words, only plural variations are taken into account by natural selection. The majority have, of course, only to influence the survivors. If, say, a third of a species is extinguished every year, it is sufficient if a little over a third of the species has 
the favourable variation, as the new character will then predominate in the surviving two-thirds and be continuously incorporated by amphimixis in the animals that do not possess it, but survive, because the destruction of the species is not great enough to involve them. Thus amphimixis conveys a favourable variation to animals that did not possess it. It quickly generalises useful varieties, and the modification of the species proceeds more rapidly than it could do without amphimixis. But it is clearly of great importance for a useful variation to spread quickly to a large number of animals, because of the great dangers that the animals encounter from other sides against which the new variation affords no protection. It is also due to crossing that organs which have fallen into disuse slowly disappear in all individuals of the species.

When we are asked if it is not expecting too much of chance to demand that a variation shall occur in the majority of the survivors, we can answer "No." There are many changes that must be in one of two opposite directions, and in these cases plural variations are quite natural. There are many other variations in which totally different characters may appear plurally, such as the three lengthened parts of the heron we spoke of previously and various shades in the protective colouring of butterflies' wings, if they increase the deception in any way. In the case of many organs the only question is whether they are better or worse, and all variations that fall in the first category are preserved as plural variations.

In this way a gradual transformation of the species 
is brought about. Still, natural selection may, of course, act with such intensity as to give predominance to a small number of animals that possess a variation, and leave all their fellows to be destroyed. Thus in very severe cold a few deer with particularly thick coats may be preserved.

It is due to amphimixis alone that the species remain within their limits for thousands of years. If the variations were not constantly neutralised, they would long ago have modified animals so much that they would no longer have the least resemblance to their ancestors. If it were not for amphimixis there would not be to-day any fishes resembling the fishes of earlier days.

On the other hand, amphimixis allows no division of a species. How can a new species be developed from an older one, and this be preserved, if the promiscuous crossing is continually at work destroying or generalising all new characters? In that case, we can safely say, there would not be a number of different species if there were not a force that prevented the crossing of the members of the new species with those of the parental stock. We have alluded several times already to this force. It is isolation. We shall deal with it in the tenth chapter, and see why there are many different species, when we have learned why the species may be arranged in a system according to their greater or less resemblance, and why there are unifying types of species. But we have other questions to answer first. 


\title{
CHAPTER VIII
}

\author{
WORMS AND CCELENTERATA
}

Genealogical tree of the animals. Descent of animals. Descent of man. Preservation of intermediate forms. The earth-worm. Regeneration. Leeches. Parasitism. Origin of parasites from free animals. Organic changes in parasites. How parasites are conveyed. Exchange of hosts. Life of the chief parasites, trichinæ, maw-worms, dochmius, tape-worms, etc. Danger of tænia. Development of the liver-distoma. Friendships of animals. Symbioses.

WE have already passed in review three stems of the animal world : the vertebrates, articulates, and molluscs.

We may regard these three groups as sisters, as they proceed side by side from a fourth or parental stem. This consists of the worms or vermalians.

The worms are primitive forms whose origin goes back long before the geological records commence. It is their simple organisation that makes it possible tor stems to develop from them in three such different directions.

We have, then, so far considered the three chief branches of the tree of organic development, and we now come to the trunk in which the three branches unite. From this point we shall follow the stem down to the lowest point of its roots. That is as far as the eye and microscope can reach. The ultimate fibres of 
the roots are so fine that they lie entirely beyond our range of vision.

The protozoa represent the point at which the root becomes thick enough to be seen by us. These are the simplest organisms known to us, and their origin goes back to an incalculably distant period. From them were developed the cœlenterata, which we will consider at the close of this chapter. After these come the platodes -animals that approach closely to the cœlenterates in structure ; in both, for instance, there is only one aperture in the body, and this has to act both as mouth and anus.

From the platodes (or "flat worms") descended the round worms, which have mouth and anus, and an alimentary canal suspended in a spacious body-cavity. However, their organisation is still very simple. Their type of structure is retained fundamentally in all the higher animals, as they are the ancestors of the vertebrates on the one side, and the molluscs and articulates on the other. We may mention as a fourth daughterstem the echinoderms, the star-fish and sea-urchins, of which there are many species in the sea.

It was a fortunate chance for science that the transitional forms from the vermalians to each of the four stems are still in existence. Where they are missing, the gap is filled by larvæ forms. Thus the larva of certain molluses and of the echinoderms resembles a certain order of worms, the microscopic rotifers that are found in all water. The lowest forms of the vertebrates lead on to a group of animals called the tunicates, which have a good deal of affinity to the worms in their structure. 
The round worms do not represent the highest class of the vermalians. There is a much more advanced section, the annelides. To this group belongs the earthworm; it has a very elaborate structure, but its marine relatives are much more highly organised. They are predatory animals with sharp eyes, and swim briskly in the water in search of their prey.

From the annelids have come the articulates: the crustaceans on one side, and the tracheates on the other. Of the former no transitional form has been preserved, but this is not so with the latter; in fact, this particular animal, the peripatus, is the most typical instance of a transitional form that we know. Halfannelid and half-myriapod, it seems to have one organ of the worm-type and another of the tracheate. The peripatus is found in various species, but only a very ferw; and this is true of all transitional forms. It is clear that animals of this kind, which have neither the adaptations of their ancestors nor their descendants in complete form, are easily crushed out by the two, and can only be preserved in sheltered localities. When we recollect, in addition, the eternal changing and readapting in nature, we are surprised that any typical transitional form has chanced to survive to our time; but we must not ask the theory of descent to justify itself by producing actual instances of transitional forms.

When we say that the vertebrates have been developed from the vermalians, it must not be supposed that any living animals, such as the maw-worms, were their ancestors. We cannot assume that these ancestors had relatives whose descendants are still 
preserved quite unaltered. The maw - worms, for instance, have many adaptations that they have acquired since that time in the course of the earth's development, and we do not know if they had not at that time adaptations that they have since lost. Thus we cannot form any absolutely safe picture of the primitive worms that became, in certain circumstances, the ancestors of the vertebrates. We can only say that they had the worm-type; that their principal organs had, in general, a structure and arrangement more closely resembling that of the worms than any other living animals.

Thus the statement that "man descends from fishes" does not mean that we have ancestors who resembled any of the actual fishes, but that at a certain period they were gill-breathing, aquatic animals with a structure to which the nearest approach is found among the fishes of all actual animals. So, again, man does not descend from the apes, as is often said, but from beings that must probably have resembled the actual apes more than man. The apes have not been fixed in their organisation ; they have diverged steadily from their ancestors by constantly acquiring new adaptations. Their ancestors were probably brothers of man's ancestors, but that does not justify the above statement. On the strength of this probability we may, at the most, say that man and the ape have a common ancestor. ${ }^{1}$

${ }^{1}$ There are scientists who do not admit that man had ape-like ancestors. They believe that the apes are no more clearly related to man than the ruminants or carnivores, or, especially, the kangaroos. This view, however, has few supporters, and its arguments are not at all convincing. 
The most familiar representative of the present stem is the earth-worm. It is true that most people's acquaintance with this animal is superficial, as its subterraneous habits prevent more than a few from knowing it thoroughly. For a long time, in fact, the animal, which is not merely harmless but extremely useful, was decried as injurious, and there are still people who kill it whenever they find it.

Darwin was the first to show that the earth-worms are indispensable to the plants. He pointed out that they act as ploughs in loosening the earth. The animal feeds on the digestible elements in the soil. It eats its way through them, as it were, passing them the whole length of its alimentary canal, and then ejecting them, which is always done on the surface. Thus the finer constituents of the soil are constantly brought to the top by the worms, and we have always good soil there. The many passages that the worm leaves behind it in its travels loosen the ground more and more, and as they fall in, the elements of the soil rub together and grind one another. Finally, leaves and other bodies are drawn by the animals into their tubes, ground up, and brought to the surface again. However strange it may sound, we have to admit that the whole mass of the fruitful surface of the earth has passed through the alimentary canal of earth-worms, and passes through the same process every few years.

Man's attempts to trap the worm have, fortunately for it, hardly any success. But the defenceless animal has a good deal to suffer from other enemies. Besides 
moles, shrew-mice, birds, lizards, amphibians, insects, and many others, it is the myriapods, especially, that pursue it into its own tubes. We often see the worm creep in terror from its passages in full daylight to escape these dreaded enemies.

The danger of being captured is less fatal to the earth-worms than to other animals, as they have a great power of regeneration, and can lose a part of their body without perishing, because they can replace it. One can cut a worm into two parts, and one partoften the second one as well-will always regenerate the lost piece. If it is cut into several pieces, there is never more than one new animal, and often none at all; and if it is cut longitudinally into two halves both of them very soon die.

Here again we see that the power of regeneration is an adaptive phenomenon, and does not act in rare situations. What generally happens is that a piece is torn off an earth-worm, and the rest of it retreats underground. This mutilation would soon extinguish the animals if it were fatal to them; and the other injuries happen too rarely for natural selection to have provided a remedy against them.

In the near relatives of the earth-worm, that live in water, such as the lumbriculus, the regenerative power is much higher. One of these animals has been cut into fourteen pieces, and thirteen of these formed new worms. These animals are devoured on all sides, and their enemies, the water-insects, have sharp jaws with which they cut pieces out of them. There are various species of aquatic worms, and in each of them it can be 
shown that the regenerative force is proportionate to the kind of mutilation to which they are most frequently exposed.

Thus the leeches, which are dreaded and not much exposed to mutilation, have no power of regeneration. The medicinal leech is still very common in France and Hungary, and is a great trouble to bathers, as it gathers in swarms at the first splash. Much less troublesome are the large leeches that are found in the ponds, and known as horse-leeches; these may be taken in the hand without fear. Their teeth cannot bite through the human skin; they can only pierce the mucous lining of the nose, the mouth, and other parts. One species of the horse-leech, the Aulastomum gulo, feeds on snails, and does not generally indulge in blood-sucking: the other species, the Hamopis vorax, may become a great nuisance by getting into the throats of horses and cattle when they bathe, and attaching themselves to the soft parts. But this hamopis plague is only found in North Africa.

There is also in our ponds a worm about as thick as a violin-string, and sometimes a foot in length. It looks like a horse-hair, and, as a matter of fact, the rustics have in many places fastened on to it the legend that it is a living horse-hair, travelling about in the water and able to penetrate the human skin. In reality the animal is quite harmless, and is, in fact, unable to maintain itself ; it lives only a short time, and uses this for laying its eggs. From these develop tiny larvæ with a pointed, zigzag boring apparatus, which pass through the skin of May-flies and gnat-larvæ, live in them for some time, 
and surround themselves with a capsule. If the larva is eaten by a larger insect, the capsule bursts in its stomach, the worm becomes free, and develops to the adult stage in its new host; it abandons this home in wet weather, and returns to the water to lay its eggs.

The life-story of this Gordius aquaticus brings us to one of the most interesting phenomena of the animal world, parasitism. There are many parasites among its relatives, the nematodes, which form the lower class of the round worms; but there are still more amongst the platodes. Generally speaking, the vermalian stem is the richest in parasites in the whole animal world, the articulates alone approaching them in this respect. In comparison with the parasites of these two stems, the rest are insignificant; the protozoa alone of other groups provide a large number, including the notorious malaria parasites. In the plant world again we have the bacteria and other fungi.

Rudolf Leuckart, the chief authority on the subject, defines parasites as creatures that find food and shelter in a living organism. According to this definition there are, of course, parasites amongst the plants, some with other plants, some with animals, as hosts. In our view of the origin of living things all parasites must have descended from free-living organisms.

This statement can easily be proved in the case of animal parasites. We have already seen something of parasitic crustaceans. We saw that they pass their youthful stages as free organisms, and can hardly be distinguished from those of other crustaceans. We may now add that we find a large number of transitional 
forms amongst the parasitic crustaceans, some of which are entirely like the free animals, and differ from them, perhaps, only in having longer claws, with which they attach themselves for a time to other animals and derive their food from them. But the longer the animals live on their hosts the more profoundly are they modified; the legs, which are no longer necessary, degenerate more and more, the sense organs disappear, even the alimentary canal may atrophy, and the animals feed, as the sacculina does, in plant fashion, by means of roots passing into their host. The structure is also entirely changed by the enormous development of the sexual organs, which are of great importance in every parasite.

Of the tracheates there are lice and fleas, which ordinary folk call insects. Here again there are animals that have been most curiously modified. We have an instance in the Pentastomum tanioides. This animal, which looks very much like a tape-worm, as its name suggests, and has very little of the characteristics of a spider, to which it really belongs, lives-though rarelyin the nasal cavities of the dog. The eggs pass through the nostrils to the ground, and when a hare or rabbit takes them into its stomach with the grass, larvæ issue from them, pass through the stomach into the liver of the ruminants, and cover themselves with a membrane, inside which they cast their skin several times in the manner of the articulates. When they have grown bigger, they break the capsules, and disperse through the various passages of the liver. They then bury themselves in capsules once more, and if their host is devoured by a dog or a fox they develop into sexually 
mature animals inside it. They are often so numerous in the hare as to cause its death. They are less dangerous to man, who also may be infected with them, the eggs being received on the hand from the dog's sniffing and being passed to the mouth.

This pentastomum is a thorough parasite, and changes its host ; this, as we shall see presently, is characteristic of the majority of intestinal worms, which are, so to say, the most complete parasites. We can, however, find transitional forms even amongst these, leading gradually to them from their free-living relatives. Amongst the nematodes many species are still perfectly free; among the platodes the tape-worms descend from the suctorial worms, and these are closely related to the turbellarians, small, flat, dark or light worms that we find in every pond.

Parasites are, therefore, animals that have adapted themselves to living on other animals. This kind of life is clearly a very safe one. Living in the warm interior of the host, the parasite is almost entirely sheltered from climatic troubles, and has nothing to fear from direct enemies. Finally, it riots in an abundance of food, and this is often brought to him already digested. This is the case with the parasites of the alimentary system, which are surrounded with a constant stream of nourishment, and have often even lost their own alimentary canal, as the food can pass directly through the wall of their body, without having to undergo further changes within the body of the parasite.

Thus we find no alimentary system either in the 
tape-worm or the echinorhyncus, ${ }^{1}$ and in the nematodes it is at least very much simplified, and is devoid of the subsidiary glands such as the liver and other appendages. The locomotive organs of the parasites are equally degenerate, and are replaced by clinging apparatus. There is bound to be such an apparatus in external parasites, otherwise the unwelcome guest could easily be rubbed off when they are not concealed from their host by a thick coat of hair. And clinging organs are necessary in intestinal parasites, as they could not stand against the pressure of the fluid food if they were not attached, and would be forced out at the anus. It is only the maw-worms and other threadlike worms that can maintain themselves in the gut owing to their shape alone. As they are long, at the end thin, and round, the chyle runs past without bearing them along with it.

Being cut off from the outer world, the parasite has no need of sense-organs, and is usually without them. Its respiratory organs are less altered, and hence it is that the gill-breathing crustacea only attach themselves to aquatic animals, and the air-breathing tracheates only, as a rule, to land-animals. The ancestors of the intestinal worms breathed through the skin, and this has been preserved in their descendants, who can do so because they are constantly bathed in the fluids of their host that contain oxygen. It is due to this way of breathing that they are found both on land and

${ }^{1}$ These are round worms, often of a considerable size; their snout is equipped with spines with which they fasten themselves to the wall of the gut. They are generally found in fishes and aquatic birds, more rarely in mammals, and very rarely in man. 
water-animals, and are therefore the most widespread of all parasites. In many of the tracheates parasitism has gone so far that their respiratory organs have been affected. Thus the pentastomum we referred to above has lost its tracheæ, and breathes through the skin, like the worms.

We have now seen that the nature of parasitism entails a simplification of many organs, but other organs are all the more elaborately developed in parasites. These are the sexual organs. In the first place, it is very easy for the parasite to supply them with plenty of food. It is devoid of so many organs that require their proportion of the food in other animals. Hence we find, as a matter of fact, the sexual organs of parasites swell in proportion to the thoroughness of their parasitism. When we study the anatomy of a distomum we have some difficulty in finding the other organs on account of the pronounced sex organs. In the tape-worm the other organs occupy an evanescent space in comparison with the testicles, the ovary, and their glandular appendages.

It is not merely possible, but necessary, for the parasites to have this preponderant development of the sexual organs. It is just as difficult for the parasite to maintain its species as it is easy to support itself. When the host, especially of internal or fixed parasites, perishes, the parasites must die also, as a rule. Hence its ova must always be conveyed to new animals. In the case of the sacculina this is comparatively simple, as we saw in the last chapter. From the egg is developed an active larva, which seeks a new host. But 
how can this be done on land, and in the vertebrates that shelter most of the parasites? In some cases, such as the gourd-worm (distomum) and the broad tape-worm, an active larva develops from the egg, falls into the water and enters a mollusc or a fish. But in this the animal has not reached its definitive host, the sheep or man. The larva has to be conveyed from the interior of the aquatic animal to the stomach of the mammal, and this is done by the former being eaten, consciously or unconsciously, together with the larvæ by the eater.

This passive transition, which we shall study more in detail afterwards, is the only possible means of surviving for most parasites. In only a few cases is an active larva developed from the egg; as a rule the eggs must be licked up and taken into the mouth of a host, and even then the end of the parasite's development is not reached. The host must be eaten, and the larve pass in its flesh into the interior of their principal host, where they come to sexual maturity. Thus chance plays a great part in the maintenance of parasitic species, and in view of the slender prospect that the individual egg has of ever being developed, we can understand why they are laid in such vast numbers, sometimes up to $100,000,000$.

The eggs, which lie on the earth after leaving the host and usually have to wait a long time before they reach the stomach of an animal, need a high power of resistance. As a rule they have a shell and plenty of yolk; this in turn requires organs in the mother's body that are capable of meeting these demands. Hence there are yolk-bodies and shell-glands, as well as 
large ovaries, which greatly complicate the sexual apparatus.

In fact, we very often find both sexes united in one parasite, and we then call the animal an hermaphrodite. This is not difficult to understand. The parasite is often alone in its host, as is generally the case with the tape-worm; and it has then to develop both spermatozoa and ova, or remain barren. Sometimes, it is true, there may be two or more tape-worms in one host, and this is more frequent in the case of other parasites. Then mutual fertilisation is possible. Hermaphrodism has been introduced amongst the parasites to prevent the animals that live in isolation from perishing without doing something towards the maintenance of the species.

We have now examined the organisation and habits of parasites from our point of view, but there is one point we have not yet considered-the change of hosts. This plays a very important part in parasites, and we have already referred to several that pass their early stage in one animal and come to sexual maturity in another. An attempt has been made to explain this remarkable phenomenon by regarding the first host as the original one, in which the parasite became sexually mature in former ages. After the rise of the vertebrates it adapted itself to these, so that the parasites taken with the flesh of the first host into the alimentary canal of the second did not die, but only reached sexual maturity there, as the conditions are the best conceivable for parasites in the vertebrate. A good deal can be said in support of this view, especially 
the fact that the stages of the parasites in the first hosts have some resemblance to their primitive forms, from which we may infer that these stages were at first sexually mature animals.

However, we will not linger over these theories, but pass on to study the life-story of some of the chief parasites. In this we shall see what a wonderful adaptiveness there is in these creatures.

One of the worst human parasites is the trichina. The man who is visited by this dire guest has often to pay for it with his life. It is chiefly on its account that the examination of meat has been introduced, and this and the now prevalent custom of killing in abattoirs have greatly diminished the danger from trichina.

The trichina is found in a large number of animals, but only one of these, the pig, calls for our notice. It often lives in great quantities in the flesh of pigs, in the shape of a small white point; this is a capsule, and the tiny worm is rolled up spirally inside it. If the pig's flesh containing the capsules enters a man's stomach, the capsules burst and the little worms issue forth; they travel into the small intestine and there reach sexual maturity within a few days. The females give birth to an enormous number of young, and then die. The young pass through the wall of the intestine, which they can easily do on account of their small size and pointed shape, and travel gradually by the blood-vessels into the man's muscles. There they feed for a time on the decaying muscular matter, until this in turn secretes a membrane to protect itself against the parasites. This 
membrane is strengthened by the worms themselves, and coloured white by deposits of lime. The animals have now entered on a condition of repose, and will only re-awaken into life when the muscles they reside in reach the stomach of a new animal. When this capsule stage is reached-about three months from the first infection-the danger is over. But many people die before this through the irritation of the intestines, and especially through the inflammation of the muscles affected.

When the trichinæ enter human beings their career is virtually over, because no one can be infected by eating human flesh. It is otherwise with the animals. Rats are the chief victims of these parasites, as in their case the cycle of migrating and capsulating begins afresh, the dead or diseased rats being eaten by their fellows. This would not affect human beings if the rats did not make their way into pig-styes, where they are eaten by the pigs when they die, or even when alive. Thus the worms capsulated in the rat's flesh pass into the stomach and the muscles of the pig, and may come to infect human beings.

Among the nematode worms there is a large number of parasites. Most of those in Europe that can infest human beings are of a harmless character. The human maw-worm, the female of which measures up to ten inches, and the much smaller oxyuris (two-fifths of an inch), are common in children. These two species have no temporary host; their eggs, and often the whole animal, are passed by human beings, and if they find their way into the human intestines once more, they 
develop at once..$^{1}$ This can easily happen in bed, and also in other ways. One of the chief transporters of them is the fly, which settles on excrements as well as on food.

But though these worms are often present in great quantities, they are generally only a nuisance and very rarely dangerous. The latter applies more frequently to a relative of theirs, the Dochmius duodenalis. This worm, somewhat larger than the oxyuris, has strong jaws with which it attaches itself to the wall of the intestine; it pierces this with the stiletto it has in its mouth and causes frequent hemorrhage, sometimes causing death and always anæmia. The ova of the parasite are ejected by the anus, and develop in mud or moist earth into tiny larvæ, which give fresh dochmii when they re-enter the human intestines. Hence the disease occurs particularly in people who are compelled to drink muddy water, like the Egyptians, or any who work much in moist soil, such as brick-makers. It is on this account that the workmen in the St. Gothard tunnel had to suffer so much from dochmii. It was through the tunnel that the worm was introduced into Germany.

In these instances we have followed a simple development of parasites, but we now turn to animals with a much more complicated life-story. These are the

1 In the case of the oxyuris the eggs develop very quickly, so that self-infection is always occurring, but the egg of the maw-worm needs months before it will develop into a new animal if re-introduced into the human body. In this case, therefore, the infection is not so direct as in the oxyuris; it usually comes about through drinking meadowwater, or putting grass in the mouth, which may also bring one the much more mischievous echinococcus that we will describe presently. 
platodes ("flat-worms"). We will begin with the most familiar order, the tape-worms.

There are two tape-worms especially that are parasites on the human intestines, the Tania solium and the Tania saginata. Both consist of a series of connected segments, very narrow at the head and broadening towards the end. At the end, also, the sections are sexually mature, and contain a vast number of fertilised eggs; these are detached from time to time, and pass out with the excrement. The sections of Tania solium are comparatively inert after ejection, but those of Tania saginata can crawl about; they often make their own way out of the anus, and have been seen to climb up the wall of a room.

The two also differ in the armament of the head. In Tania solium there are four suctorial disks which cling to the wall of the intestine, and are assisted in this by a fringe of hooks. The latter are not found in Tania saginata, yet it is more difficult to get rid of, as its suctorial disks are larger and more powerful. Often a slight remedy will bring away the greater part of the body, but that is no use to the patient, as the head is able to form new parts.

If the sections of Tania solium that contain the eggs lie on the fields amongst human excrements and are eaten by pigs, which do not disdain such food, the shells of the eggs burst in the pig's stomach. A tiny creature emerges, bores its way through the wall of the intestines, and gradually reaches the muscles. Here it assumes an oval shape, and forms a membrane round itself, which is further strengthened by a secretion from the 
pig's muscles. Fluid passes into the capsule from the surrounding tissue, so that it may swell to the size of a pea. The animal itself remains at the globule-stage, and grows very little inside it. It forms the head of a future tape-worm, and remains at this stage in the muscles of the pig. At this period it is known as a scolex or measle-worm.

If the infected flesh of the pig is eaten by a human being, the measle-worms are set free, and the small tapeworm head makes its way into the intestine, and attaches itself to the wall. The vesicle hangs on to it for some time, but is at last cast off, and the head begins to form the segments until the animal has reached its full size of more than three yards.

The development of the $7 \frac{1}{2}-8 \frac{1}{2}$ yards long Tania saginata is similar to this. But in this case the eggs must be taken into the stomach of a cow, if they are to become scolices; the pig digests them. Hence it is that in this case the parts of the worm have developed the power of motion, as the cow does not eat fæces like the pig; but it can very well happen for the cow to swallow a part of a tænia clinging to a blade of grass, or grass covered with its eggs. But there is a second difference of more importance to human beings. While the eggs of Tania saginata may safely be eaten by human beings, as they cannot develop in their alimentary canal, it is otherwise with Tania solium. In the latter case infection is possible, as the eggs produce larvæ in the human intestines as well, and these pass into the muscles, and enclose themselves in capsules as large as peas. If they 
reach the eye - which has often happened - they cause blindness, and it is still worse if they reach the brain. Hence a man who is infected with Tania solium is in a condition of great danger to himself and those about him, as new infection is very possible. It also happens that in vomiting the sections pass from the intestine into the stomach, and the larvæ are set free there. This is a moment of great danger to the patient, as it is always the larvastage that may cause death; the adult tape-worm is not dangerous. A man with Tania solium should, therefore, get rid of it as soon as possible.

Still worse are the scolices of the Tania echinococcus. This tape-worm is only one-fifth of an inch in length, and is found in large numbers in the intestines of the dog. The detached parts are very active; they climb up stalks of grass, and are likely to be eaten by hares, as well as by cattle, sheep, or pigs. The larvæ that develop pass into the muscles, but before the formation of the head begins, they grow so large and soak up so much fluid that they cause blisters as big as a child's head, which are generally fatal to the victim. The head of the echinococcus does not begin to form until after this swelling. Man may eat these larvæ with impunity, as they do not develop into tapeworms in his intestines; ihey do so, however, in the dog. But if the eggs of the echinococcus get into the human mouth and stomach-and the dog will often give them an opportunity to do this, as it licks its anus as often as it does the hands (or even the 
mouth) of its master ${ }^{1}$-the large vesicle is formed in the muscles, generally in the liver, but sometimes in the brain. Death follows in most cases.

Thus the Tania echinococcus and the Tania solium are found in man in the shape of scolices, and these particular tape-worms are accordingly to be dreaded. Another parasite of the human intestine is the broad tape-worm, the Bothriocephalus latus, which grows to a length of thirteen yards. We have referred previously to its migration. Differently from the tania, it develops from the egg a larva that enters a fish, if it reaches water, and incapsulates itself, without forming a vesicle. It at once forms the head of the future tape-worm, which develops in a new host that has eaten the fish. Human beings get the worm by eating underdone pike or turbot.

This kind of migration brings us to the other parasitic platodes, the suctorial worms. They are rarely found in man, and are never dangerous-in Europe, at all events. ${ }^{2}$ But they are a great plague to other animals, such as sheep, birds, and frogs. The fluke or gourd-worm, shaped like the kernel of a gourd, the Distomum hepaticum, is found in the sheep's liver, or rather in its gall-duct. Its eggs pass by the gall-duct into the gut, and then out with the excrements. If they fall into water, minute, lancet-

${ }^{1}$ People should, therefore, be careful with dogs. They should at least wash their hands after touching them, and should never let dogs kiss them.

${ }^{2}$ In Egypt the Bilharzia hamatobia is one of the most dangerous parasites. It lives in the human blood-vessels, especially the portal and urinary veins. 
shaped creatures develop from them; these swim about, and bore into a water-snail, in the interior of which they grow into tube-like bodies. Inside the tubes are a quantity of small, tadpole-shaped creatures. These abandon the tube and the host, and seek a new victim, inside which they incapsulate themselves; though they may do this, without migrating, on aquatic plants. If the sheep eat these plants, the distoma develop from the capsules in their intestines, and pass on to the liver. The other species, which have incapsulated in a second host, reach sexual maturity when the new host is eaten.

The adaptations of the distoma are enormously varied, and may be very complicated. Especially interesting is the Distomum macrostomum, which is found in birds. When the eggs of this animal reach the plants that grow on the edge of brooks and ponds, they are swallowed by the snails, which gnaw the plants. In these they develop into curious tubes that surround the intestines of the snail, and also run out into its feelers, which they distend and distort into thick tubes. Inside the tubes, especially those in the antennæ, the young distoma are developed, and the tubes containing them now become coloured with green and white bands, and move about. The movement increases, the snails' antennæ burst, and the tubes fall to the ground, where they creep about and look very much like insectlarvæ, or caterpillars. The birds really take them to be edible animals of that kind, swallow them, and so take the brood of distoma into their bodies, where they reach sexual maturity. Here we have a most peculiar case of 
adaptive colouring. Most animals need their colouring as a protection against their enemies, but in this case we have organisms that are coloured for the purpose of getting eaten. However, the life-story of the animals enables us to understand this remarkable adaptation.

We will not explore any further the interesting field of parasitism. We have examined the various forms of parasites and their habits so closely, because they make it so clear that there are no insuperable limits fixed to the variations of animals. As a matter of fact, we dare not say that natural selection could not give wings to a horse. If there were some necessity and sufficient time for such a transformation of the horse, the required variations would certainly not fail. The creation of a pegasus is not more wonderful than the transformation of a spider into a tapeworm-like animal. Natural selection is omnipotent in the creation of forms of life. It is restricted by no limit that lies in the nature of things.

There is a certain resemblance to parasitism in a phenomenon that leads us on to the cœlenterata. This is symbiosis, or community of life.

When we put water and plants from a pond into an aquarium, we often notice on the glass, some time afterwards, a green tube, as thin as a needle, with long threads hanging from the end of it. If a water-flea touches one of these threads, it remains sticking to it, and is conveyed into the tube, where it disappears.

This small, tubular creature is the green waterpolyp, one of the few fresh-water representatives of the cœlenterata, which are found in many brightly 
coloured species in the sea-medusæ, anemones, sponges, etc.-and are one of its chief ornaments. One other relative of the green polyp, the brown polyp, is often found in our waters, and also the fresh-water sponge, which is often found on pieces of wood and branches at the bottom of ponds.

Let us return to the animal we mentioned first, the hydra, or green polyp. When we examine it with the microscope, we find that its colour is due to very small granules that pervade the animal. These granules are independent organisms, algæ, that live in the polyp, without suffering any injury, or doing any to the hydra. The joint living is beneficial to both organisms. The alge have a pretty well-assured maintenance in the cœlenterate, while this in turn benefits by the oxygen they secrete. Here we have a case of symbiosis-a joint life of two organisms, based on mutual advantage.

There are a large number of these symbioses. Certain marine crustacea, that live in snail-shells, always carry on them anemones, cœlenterates that secrete a stinging substance when they are touched that paralyse many organisms. The sea-anemones have this advantage from the transportation that it enables them to obtain food more easily than they would do otherwise, since they have no power of locomotion. On the other hand, the crustaceans are protected by the anemones from their enemies, because if one attempts to drag them from their shell, the cœlenterate plies its batteries and the assailant has to withdraw. There is another instance of symbiosis in the relation of ants and lice. We generally find ants running about on plants with 
certain species of lice on them, and it is easy to see that the lice have the advantage of being protected from many enemies by the presence of these stalwart companions. On the other hand, the ants are fond of the freces of the lice, which are as sweet as honey. ${ }^{1}$

Symbioses between plants and animals, or between plants and fungi, are much more common than between two species of animals. That is easily explained. Animals are rivals in the struggle for life, but plants have a different kind of food and respiration; in fact, the latter difference makes the proximity of plants healthy, and often indispensable, for animals. The fungi are in the same position as the animals.

Hence besides the hydra, certain protozoa are inhabited by green algæ; and the best known instance of a symbiosis between fungi and algæ is found in the lichens, which are not single organisms, as one would infer from their appearance.

1 There are also symbioses between higher plants and animals. Thus in South America the trees are threatened by the leaf-cutter ants. They cut off the leaves with their shear-like jaws, and gather them into heaps, on which they grow fungi. Certain plants, the imbauba, or chara, are protected from these enemies by harbouring fighting ants of a different species, which drive off the leaf-cutters when they come. But in order to induce the tree-ants to remain outside the tree, so as to perceive the approach of the enemy - which would often be impossible if they were always inside-the tree has developed special nutritious pods at the threatened points-the stalks of young leaves-which the ants constantly gather for their young inside, and so they are always found at these spots.

This case, again, cannot be explained on the Lamarckian principle. The nutritious pods that are formed by the plant for the ants, and that are wanting on trees related to the imbaubas which have no ant-guests, cannot have been produced either by the will of the plant or the repeated bites of the insects. Hence the explanation of symbiosis as an inherited habit does not hold in this instance. 
Symbiosis exhibits an entirely new side of natural selection to us. In this case the principle that seems to be the foundation of all life, the struggle of all against all and the crushing of one organism by another, is thrust aside. Symbiosis teaches us the omnipotence of natural selection more clearly than any other phenomenon in nature. 


\title{
CHAPTER IX
}

\author{
PROTOZOA
}

The animal built up of cells. Principle of division of labour. The greater the division of labour, the higher the animal's organisation. Multicellular and unicellular animals. The protozoa, their form and reproduction. Structure of an animal in its development from the ovum onwards from rudimentary parts. Origin of the germ-cells. Outlines of a theory of heredity. Amphimixis of the protozoa. Origin of sexual reproduction. Formation of seed and ova. Continuity of the germ-cells. Are any animals immortal? Death is not common to all animals. Origin of death. Permanent and temporary life. Has life come from the stars? Origin of life on the earth, spontaneous generation. How it is to be conceived. The first development of living matter. Formation and significance of the cell-nucleus. Significance of the fundamental parts. Relation of the rudimentary parts in amphimixis. When life is extinguished.

To a certain extent we may compare organisms to edifices in our towns. Just as our buildings differ enormously in size and structure, yet are generally composed of the same elements, the bricks, so we find the same elementary units in all vegetal and animal bodies. In the course of its embryonic development every organism is built up like a house. Its life begins with one structural element. To this numbers of fresh ones are added until at last the highest point is reached; the living thing has attained its full size, and it would be idle to attempt to count its constituent units. 
The fundamental elements of organisms are called cells. ${ }^{1}$ With a few exceptions the cells are too small to be seen with the naked eye; they can be seen with the microscope as corpuscles of various shapes. But all of them contain a frothy, fluid substance, protoplasm. Inside this is a tiny vesicle, the nucleus. This in turn has the same texture as the protoplasm of the surrounding cell-body. Only the nucleus is enclosed by a delicate membrane, while there is no membrane enclosing the entire cell, at least not in most animal specimens. Plant-cells have always a membrane, sometimes a comparatively thick one.

Thus the principal characteristic of a cell is its nucleus. But this is not the whole of its contents; it has other invariable elements besides the nucleus. The nucleus itself is not a simple structure, but always contains certain compact particles which are comprised together under the name of "chromatin." It is believed that these contain the matter that is the vehicle of heredity. On this view they are the most important parts of the cell.

Thus the protoplasm of which the cell consists contains a number of deposits, and this shows that it is not a formless mass. It is especially the frothy character of the protoplasm that gives it a definite structure. ${ }^{2}$ We know from the seventh chapter that

1 The cell was discovered in 1667 by Robert Hooke, who examined a cork, and found that it was composed of cells like a honey-comb. The term "cell" is still retained, though we now know that the cell is a solid particle, and often has no membrane at all, so that it has no resemblance to the honey-comb cell.

'The theory of the frothy structure of protoplasm was advaniced by O. Bütschli, and has generally displaced other theories. 
the chemical constituents of the organic substance are living albuminoids, the biogens. Now, we know that this substance has a definite form, protoplasm.

Although the cells may differ widely in form and size, the organs of animals would not be so varied as they are if the cells could not give out different kinds of products. Our skin and viscera consist directly of cells, but they only form the basis of the muscles and bones.

But, it will be asked, how can the cells create anything new?

These elementary units of the organic body feed and grow naturally in virtue of the nourishment circulating in the body. However, they do not need the food solely for their own growth and the maintenance of the vital activity; from one portion of it they form special substances which they eject at their surface. Thus the skeleton of the articulates was formed as a secretion of the cell-layer of the underlying skin, and our bones and muscles, also, are the secretory products of large numbers of cells. These products have a function; they serve for support or movement, like the bones and muscles, or for the conducting of stimuli, like the neural substance. On the other hand, the cells that have produced these substances renew and nourish them.

The great advantage of this kind of organ-construction is in the division of labour, a principle that is also found in civilised life, and forms its foundation. It is at work not only in the body politic, but in every warehouse and factory. This alone makes it possible, for instance, to build a good house; this can only be done if one part of the workers looks after the building, another the 
wood-work, a third the locks, another the painting, and so on. Then each section knows its own business, and can pursue it with effect.

The whole organisation of the higher animals rests on the principle of the division of labour. If each cell had to discharge all the vital functions, they would restrict each other. The secretory product only discharges one function, and so is not distracted by other duties in doing so.

The lower we descend in the animal scale, the less division of labour do we find. Thus, in the animals with which we concluded the preceding chapter, the polyps, we find only two kinds of cells-as a rule, at least-which clothe the inner and outer surfaces of the sac-shaped body. The internal layer of cells accomplishes digestion; the external keeps the animal in touch with the outer world. Both of them are equally engaged in movement. In the further course of animal evolution the external stratum of cells was differentiated into skin and nerves; the internal divided into the alimentary canal, with its dependent glands, and the muscles and bones.

In harmony with the theory of descent we must assume that in certain ancestors of the polyps there was as yet no division of labour; that each cell had to discharge every function. And these mulberryshaped animals must in turn have had ancestors that consisted of a single cell.

The embryonic development of every animal establishes some such series of ancestors. Every animal begins life as a single cell, the ovum. To this succeeds a 
homogeneous cluster of cells; and from this is developed the polyp stage, consisting of two layers of cells. The development then continues its course.

Geology can tell us nothing about the first living things. Apart from the fact that they must have appeared at a time of which no evidence has been handed down to us, they may have had no hard parts, and so could not possibly be fossilised.

But may not these lowest animals have survived to our own time, without having abandoned their unicellular character? As a matter of fact, there are not only polyps to-day, but there are millions of minute organisms in every drop of water that consist of a single cell. These are the protozoa.

Since the whole body of the protozoa is a single cell, it cannot be large, nor have different organs, as the organs consist of several cells of different kinds. It is all the more wonderful to find that natural selection has created an infinite variety of forms among the protozoa. There are the amœbæ, small pieces of protoplasm with a nucleus, which move about something like beer-froth on a glass plate. If a tiny alga-granule lies in the way of one of these animals, it moves towards it and surrounds it, and the alga finds itself inside the amœba. Gradually we see a change in the alga-granule. Its digestible parts are assimilated by the protoplasm of the amœba, and the indigestible remainder is thrust out at some point.

The movement of the amœbæ is merely a sort of flow, with constant changes of its shape, but the "flagellates" have on their cell-body one or two lashes 
which carry the animal along swiftly by beating the water. These, and still more the higher protozoa, the "ciliated infusoria," need a special motor apparatus, because their cell-body is surrounded by a delicate membrane; it gives more firmness to the animal, but prevents the flowing movement of its substance. While the flagellates have their lashes or whips, the whole skin of the ciliated infusoria, or special parts of it, is covered with countless hairs or "cilia," which strike the water in a uniform direction, like a row of oars, and force the animal forward. Further, the clothing of the skin of these animals prevents them from feeding as the amœbæ do, and so the infusoria have a special opening in the skin, through which the food can enter the protoplasm and be ejected again. Round this aperture, especially in the sedentary vorticellæ, there are long lashes that cause a small whirlpool in the water and so bring the food down into the animal. Naturally, unwelcome foreign bodies are often brought into it in this way, and have to be ejected again.

Thus we see that the single cell is capable of very different adaptations, and so we cannot be surprised if the cells that compose the higher animals assume such enormously different forms. But while the cells of the latter are usually selected only in one direction, the cell of the protozoa has to advance in every possible direction. In the protozoa the one cell discharges all the vital functions, locomotion, nutrition, respiration, and reproduction.

The latter function is accomplished in a very simple way in the unicellulars. Let us take the amœba, for 
instance. The particle of protoplasm that constitutes the animal contracts from two opposite sides. It becomes thinner and thinner in the middle, until the cord that has kept the two halves together gives way. During the division the nucleus also has been drawn out and constricted, so that when two animals are found instead of the one, each of them has a half of the nucleus. The two pieces of the amœba then quickly feed themselves up to the normal size of the species, and each half of the nucleus attains the size of the whole one. The essence of reproduction is the same in all the protozoa: the animal splits into two halves, and thus the "mother" divides into two "daughters."

The cells of the higher animals multiply in the same way as the protozoa. The only difference is that in their case the cells remain united after the cleavage, whereas in the protozoa they become independent, and go their own ways. Hence the development of a multicellular animal is as follows. The ovum, which always consists of one cell, divides into two daughter-cells; these again divide into two, and thus four are produced. After the next cleavage there are eight, then sixteen cells, and so on, until we have a compact cluster of cells. The cells then arrange themselves; they lay themselves in two strata, and form a sac. Thus they reach the polyp stage, and the differentiation continues. Some of the cells secrete muscular matter, others the skeletal matter, until the whole complicated animal is constructed.

What a wonderful development! How is it possible that from this repeated cleavage we get, not an irregular 
cluster of homogeneous cells, but a harmonious whole, the very different parts of which always come to lie at the right spot? We must admit the impotence of science in face of these embryonic mysteries. We know nothing of the forces at work here; but we can say with some confidence that no supernatural power controls the development of an animal, so that each separate process shall bring it a step nearer the complete construction. The co-operation of the parts has clearly been brought to its present height by natural selection, and the forces at work in embryonic development are certainly not different from those that we know in organic nature as attraction and repulsion, strain and release.

We saw in the sixth chapter that there are in the ovum minute particles that represent the rudiments of the future organs. We may now add that it has been claimed that these particles are the chromatin that is found in the nucleus of every cell, and so of the ovum, in the shape of a number of minute corpuscles. ${ }^{1}$ We know that this chromatin also divides in the cleavage of the cell, and this is done by so fine a piece of mechanism that one daughter-nucleus receives just as many halves of the particles as the other. If this substance epresents the rudiments of the future organs, as we have good reason to believe, the ontogeny of an animal would run somewhat as follows. In the first,

${ }^{1}$ We know from the following experience that the nucleus is the chief constituent of the cell. It has been proved experimentally that in protozoa that were cut into piees, only those parts remained alive and grew into fresh animals which contained a fragment of the nucleus. Pieces without nucleus died; even pieces of an amœba without nucleus could not creep along, but floated about aimlessly in the water. 
and generally in a few of the further, cleavages of the ovum the halves of all the rudimentary parts pass into each daughter-cell, and they complete each other, so that the first segmentation-cells have still the power of constructing the whole organism, because they have the rudiments of all the organs. But in the further course of development the rudimentary parts, which have not yet made any use of their power to form organs, enter into action. When the number of cells is large, the dividing cells receive all the rudimentary parts, but these do not remain united in the nucleus of the new cells; some of them pass into the protoplasm of the cells, and thus give a definite character to them. When, for instance, the development has proceeded far enough for the construction of the alimentary canal to have begun, the alimentary basic parts pass out of the nuclei and give the new cells the character of alimentary cells. The cells that afterwards separate from these are, therefore, devoid of the alimentary parts. As they divide further, the other bases of the various organs pass out of their nuclei; the nerve-parts convert certain cleavage-cells into neural cells, and so on. In a word, the basic or rudimentary parts continue to work until the construction of the organism is completed. Naturally, this description of the process does not rest on observation, but is a theory, founded by Weismann ; but it must be admitted that it makes the embryonic development intelligible. ${ }^{1}$

This continuous transfer of the basic parts does not

${ }^{2}$ The above is an outline of Weismann's "germ-plasm theory," the most elaborate theory of heredity that we have. 
affect all the cells. In the very first segmentations of the ovum, in which none of these parts come into play, but are equally distributed among the daughter-cells, certain cells were separated that retained all their rudimentary parts, and therefore the power to build up a complete organism. These were the germ-cells. While the great mass of the cells differentiated more and more in the course of development, these remained inactive, or only divided in such a way that all the rudimentary parts were retained in their daughtercells. Hence the germ-cells persist through the whole embryonic development, and only come into prominence when it is over, and the animal is fully formed. The inactive basic parts that they have all retained then enable them to produce a new organism under proper conditions.

Thus the multicellular animals multiply by means of germ-cells. How has this method of propagation arisen out of that of the protozoa?

In the protozoa the single cell is also the germ-cell, as it has to undertake all the vital functions. Every cleavage of the unicellular being is a reproduction.

There is a certain animal in our fresh waters called the "pandorina." It consists of sixteen cells, all homogeneous, and each of them discharging all the functions. Each of the sixteen can reproduce the animal, by detaching itself from the cluster and subdividing until it makes sixteen cells. Hence in the pandorina each cell can act as a germ-cell. There is no division of labour.

The next step brings us to the "volvox," a green 
globule about the size of a pin's head, consisting of a number of cells. It is often found in large quantities in our ponds. In this animal we have the first division of labour. Most of the cells have taken charge of the functions of movement and nutrition; a few others of a different shape are responsible for reproduction. These lie in the centre of the other cells, and can by repeated cleavage create a new animal, which detaches itself from the mother and swims about. If the parent has given up all its germ-cells, it dies off, since its other cells cannot produce germ-cells.

There does not seem to be anything more wonderful in the reproduction of the protozoa. Two quite equal halves are formed by cleavage, and each of them has only to grow, not to form anything new. It is the same with the pandorina, only in this case the cleavage is repeated three times, and produces sixteen cells which remain united. It is in the volvox that the marvel of heredity first appears. Here the germ-cell reproduces not only its kind, but also the very different cells of the body. But there is no sudden leap from the protozoa to the volvox. There are many protozoa in which the fore end differs a good deal from the hind end; and when such an animal divides, each half must reproduce features that it does not possess. Mere growth could not convert fragments of these animals with different parts into whole individuals.

We can more or less understand the mystery of heredity with the aid of the above theory. Even the protozoon contains rudimentary parts in its nucleus, which can build up the different parts of the cell 
body. When the animal divides, each piece receives halves of all the basic parts, and therefore those also that can supply the part that is wanting in each half. So it is with the pandorina. In the volvox two cells result from the germ. One of them contains all the rudimentary parts in a state of quiescence; this is the germ-cell, the rudimentary parts in which wait until the animal is fully grown. But the other cell continues to subdivide, and as it does so the rudimentary parts come into play, and produce the various volvoxcells with all their peculiarities. The process is the same in all the higher animals. There is always one section of the cells arising from the ovum that contains all the rudimentary parts in a state of slumber, as it were; these are the germ-cells. On the other hand, the parts come into play in the body-cells, and give distinctive characters to various groups of cells. At the same time these cells lose the particular rudimentary parts from their nuclei, and can never build up an entire organism, as the germ-cells do. ${ }^{1}$

We have not taken into account the fact of sexual generation. But we said in the seventh chapter that

${ }^{1}$ This is Weismann's theory. There are many exceptions, in which body-cells have in their nucleus the quiescent basic parts of all the sections of the body. We see this, or instance, in the phenomena of regeneration. Here, if certain parts of the body are cut off, the rudimentary parts that were quiescent in the cells of the contiguous parts come into play, and re-build the last fragment. Plants have rudimentary particles at all possible parts of the body, because any sprout can reproduce a new plant. In fact, in certain plants, such as the begonia, even the leaf-cells have these quiescent rudimentary particles. If a begonia-leaf is set in moist soil, new plants grow from it. 
"amphimixis" has originally nothing to do with reproduction.

This is perfectly clear in the case of the protozoa. If we glance at the transitional forms between the unicellulars and the multicellulars, we shall see how "sexual" reproduction came gradually to spread.

In the unicellulars the whole animal has to unite with another to give amphimixis. This is really what happens. Two protozoa, apparently of the same size and appearance, put their cell bodies together, and coalesce into one mass. After a time they separate again, and the process of amphimixis is over. Here we see clearly that amphimixis does not aim at multiplication in its original form, because there are two animals both before and after it.

Do the protozoa confirm the view we adopted in the seventh chapter that it is the object of amphimixis to give the new organism a choice of the characteristics of two "parents," so as to make it more capable of different adaptations? That is really the case. The various characteristics of an animal's frame are based on the rudimentary particles of the germ; in the case of the protozoa, in which body and germ are one, this means in the nucleus of the cell. Now it has been noticed that during the conjunction of two protozoa the nucleus of one of them divides, and transfers one half to the body of its companion, where it blends with the half that has remained there. Hence when the animals separate once more, the nucleus of each contains a half of the rudimentary particles of the other protozoon as well as half of 
its own. These particles are, therefore, mixed and combined afresh through the amphimixis.

Moreover, the protozoa have two nuclei. It is only the smaller of these that contains the rudimentary particles and mixes them in the manner described. The larger one has only the function of attending to the animal's nutrition, movement and respiration. During the amphimixis it dissolves, and is afterwards reconstructed by the small nucleus.

As a rule there is a cleavage, and therefore a multiplication, of the protozoa that have separated after the conjunction has been completed. But the chief method of reproduction amongst them is non-sexual, that is to say, cleavage without amphimixis. In the multicellular animals amphimixis is always followed by multiplication. How could the germ-cells, the only ones that can enter into amphimixis in such cases, return to the bodies of their bearers after the act! If the amphimixis is to have any result, two germ-cells must leave the parent bodies, combine, and produce directly a new animal, which will have the united rudimentary particles.

This is how the process of amphimixis takes place in the pandorina, which has no division of body and germcells. Any cell in the cluster may in this case detach itself, combine with another that has separated from some other animal, and with it build up a new animal. Reproduction after amphimixis is only occasional in the pandorina; as a rule it multiplies sexually, as stated above.

How does the process take place in the volvox, in which there are two different kinds of cells, body and 
germ-cells? In this case, naturally, the germ-cells alone enter into amphimixis. The division of labour has advanced so far in the volvox that the germ-cells which reproduce the animal in the non-sexual way we have described cannot enter into amphimixis. A different kind of germ-cells has been provided for this; these also are found in the cell cluster of the volvox, but they are only formed from time to time. In fact, there has been a division of labour even amongst these sexual germ-cells. There are two kinds of them produced in the same animal, so that at the proper moment a volvox has four sorts of cells-body-cells, asexual germ-cells, and two kinds of sexual germ-cells.

One of the latter kinds is comparatively large, and is only formed in small numbers; and they resemble the asexual germ-cells. The cells of the other kind lie in packets, each containing several, in the volvox body. These cells are very small and have mobile lashes, like the body-cells. They break away, when they are mature, and seek another volvox, and combine with its sexual germ-cells of the first kind. The product of the fusion then dissolves, and develops into a new animal.

In the volvox we have the same features that we find, essentially, in all the higher animals. In these, however, the asexual germ-cells have generally disappeared; they are common only in the plants, in the shape of spores. With the disappearance of the asexual germcells the animal is now reduced to one method of reproduction, that following upon amphimixis. Nevertheless, the cases of parthenogenesis show that natural selection can impart even to the sexual germ-cell, the 
whole structure of which is framed so as only to divide and develop after amphimixis, the power of developing without union. Apart from these the importance of amphimixis led to the disappearance of the asexual germ-cells, and the animals were forced to effect amphimixis if they wished to multiply.

It will have already occurred to the reader that the inactive sexual germ-cells of the volvox correspond to the ova of the higher animals, and the active germ-cells to the spermatozoa; even in man the latter have retained the lashes of their flagellate period. But, whereas in the volvox the same individual produces both kinds of germ-cells, as is the case with many other animals, which we call hermaphrodites, we find most animals divided into male and female, each with only one kind of germcells. These are matured at special parts of the body, namely, in the ovaries or testicles, as the case may be. They have diverged more and more from each other in structure. In this the chief principle was the division of labour. The germ-cells had to find each other, and had to provide a certain amount of nourishment for the development of the young after combining. The first function devolved on the spermatozoa, which are endowed with mobility according to the requirements of each species. As a rule they are equipped with mobile lashes, and are produced in enormous quantities, which is facilitated by their smallness. They can be small, because they do not need to contribute any nourishment for the new organism, but only the paternal characters that are found in their nucleus. The food is provided by the ovum, and so this may attain considerable 
size. The yellow of the hen's egg, for instance, is at first a single cell while it is still inside the hen. The nucleus of this cell is small, but the cell body takes up an immense amount of yolk, and then the whole is surrounded by the white and the shell; these are later products, superadded to the yellow. When the egg is laid, it is, of course, fertilised, and there have already been a number of cell cleavages, so that the white dot on the yellow yolk, the "scar" as it is called, is really a somewhat advanced embryo.

Continuous adaptation has brought about great differences in the form of the spermatozoon and ovum in the various animals. It is obvious that those animals will always be favoured by selection whose germ-cells were the surest to find each other; animals whose spermatozoa, for instance, were not active enough to reach the female ova could not reproduce, and their sluggish sperm-cells would die with them. Thus we can understand why in the case of organisms that eject their seed into water, it is produced in large quantities and is very mobile. In these cases it is largely a matter of chance whether a single spermatozoon will find its ovum. When it does reach one, the physico-chemical nature of the two cells attracts them to each other and fuses them together. Even then it is no light task for the mammal spermatozoa to pass up the oviducts to the ovum in the ovary, and this explains their number and activity.

However, I have not space to deal with either the great diversity of form in the animal ova and spermcells or the interesting relation in which we always find 
them to the life of the particular species. Their admirable adaptations are easily understood. They are the maintainers of the species; in a sense they are its most essential element. If we recall our account of the embryonic development, it is clear that the germ-cells of living animals must have existed, in a sense, since the beginning of life. The germ-cells are never created afresh; they are always formed by segmentation from the germ-cells of the parents. Let us, for a moment, ignore the fact that there are two kinds of germ-cells, and consider the process of phylogeny (or ancestral development) in the case of an organism that has only one kind of germ-cells. These cells contain the basic particles of a new organism. They divide and subdivide. One portion of the cells again receives all the basic particles, the other portion only a part of them, and this grows less and less as the cleavage proceeds, because the organs are gradually formed. The cells of the various organs cannot give birth to an entire organism, because they contain only a few of the basic particles; they have the most diverse functions, and afterwards die off. Not so the germ-cells. These form a chain that may be infinite in length. They perish, of course, if the animal they are in perishes, and they can also be destroyed by poison like all living matter; but under the proper conditions they go on to build up a new organism, and so on. Hence they have been compared to a root stretching under the ground, that brings forth plants above the surface under certain circumstances and at certain times. These plants grow and perish, but the root remains; it grows on and on, and 
thus constitutes the persistent ground-work of the changing forms of life.

Hence the germ-cells are the main trunk of the organic world. In them are contained the basic particles; and as these vary they give birth to ever-new forms of life. If the new variation is useful in the struggle for life, the animal is preserved, and with it the germ-cells. These produce their kind, in unbroken continuity, and so continue their life-creating action. It is the germ-cells that vary of themselves, and so determine the whole variability of organisms. The body-cells cannot affect them; they merely represent the house which, by its superiority or inferiority of structure (which, however, it owes to the germ-cells), enables them to continue their course, or suffers them to be cut off. ${ }^{1}$

As each germ-cell forms another germ-cell, together with the organism, this does the same, and the process may go on indefinitely, there seems to be something immortal in the germ-cell. How is it with the protozoa? In these the body and the germ are one; the germ-cell

'There is a novel of Grant Allen's, "A Terrible Inheritance," in which a young man suddenly remembers certain details in the life of his mother before marriage, and the youthful escapades of his father, without having been told anything about them. The story is, to some extent, an attempt at a practical application of the Lamarckian principle, and really amounts to a reductio ad absurdum of it. While the youth was merely a germ-cell in the mother's ovary-and in the father - she is supposed to have suffered a powerful emotion that was deeply imprinted on her. The germ-cell is supposed to have been influenced in the same way. The cell shared the experience in a sense, and its memory-elements are supposed to have been so acted upon that when the cell became a human being, he could recall the conduct of the mother. 
does not build up a temporary body-shell, but only germcells. These are, of course, bodies, but there is nothing temporary formed from them; they in turn create only cells that have the power to live on. Every protozoon multiplies by dividing into two. If dangers are avoided, these animals will continue to live, divide into others, and so on; in a word, it is possible that one of these animals may never become a corpse. The protozoa seem to have, as Weismann puts it, a potential immortality; that is to say, they have in their frame a capacity for living indefinitely. This is, of course, only a capacity. No one questions that they may come to a violent end. But it is not in the nature of their structure that they are menaced with senile decay and death, and that life itself gradually uses up their substance, as is the case with the body-cells of the higher animals.

It has been objected to this view, that the protozoa have no natural death, that at each cleavage the individuality of the mother comes to an end. "Individual" means "indivisible," and it is clear that the mother dies when it divides into two daughters, as these are two new individuals.

Weismann, however, considers that the characteristic of death is not the destruction of individuality, but the appearance of a corpse. We will not stay to discuss whether this conception is correct, but will go to the heart of the problem. The protozoa have, Weismann says, the faculty of not being permanently used up by metabolism, and this can be called metaphorically, with some propriety, immortality. But is there really in the 
protozoa nothing that ever compels them to become corpses? This seems to be correct. There can be no such necessity in the protozoa, otherwise there would be no protozoa to-day that are fragments of their ancestors, though the parts have fully developed in turn. When a protozoon is split into two daughters there is certainly no corpse to be seen, and it is the same when the daughters in turn subdivide. Here we have a difference between unicellulars and multicellulars. In the latter it is only the small particles in the germ-cells that are immortal. The germs divide. But only one part, the newly divided germ-cells, have the power to carry on the life. The other part, the body-cells, are used up by metabolism, and must perish. The unicellulars divide, but in their case both halves can carry on the life indefinitely.

Natural death is not, therefore, a necessity for all organisms, but has only made its appearance with the multicellulars. In their case the germ-cells convey the living substance to their descendants; when they leave the body, it is useless for the maintenance of the species, as it has not the power to create new organisms. Weismann believes that we have here the chief reason of the introduction of death into the organic world. The body becomes superfluous and disappears, like all useless organisms, when it has secured the maintenance of the species by the transmission of its germ-cells. However that may be, we see that the division of labour amongst the several groups of bodycells could not be very considerable unless they made no claim to indefinite duration. Many cells, in fact, have 
precisely the duty of dissolving themselves; and it is possible that most cells only do their work so well at the cost of using themselves up in the process. They can do this, because the propagation of the species is secured by the germ - cells, which perform their duty the more confidently when the body they are in is in a good condition. The more advanced the body is in organisation, the better will be the nutrition of the germ and the greater its security from dangers.

It may be asked whether there is not some such division of labour within the one cell of the protozoa; whether there are not in these animals also parts that can only discharge their function for a certain time, and must then decay and be reconstructed by the permanent parts of the cell.

This is really the case. In many of the protozoa only the nucleus and a small part of the protoplasm are divided in non-sexual multiplication, for the greater part of the cell-body dies. Hence there are a number of protozoa in which we constantly find dead parts. In fact, it looks as if dead parts are continually being extruded from all protozoa. It has been proved by careful experiments that protozoa perish if they are impeded in their amphimixis. Thus amphimixis is necessary for the protozoa. ${ }^{1}$ It is true that they usually propagate asexually, but from time to time their body has to effect an exchange of basic particles with another one.

${ }^{3}$ I cannot go any further here into the introduction of amphimixis into the organic world. Weismann has attempted to trace it to its ultimate roots. He believes that it arose in the earliest, unnucleated living things, and had a favourable influence on their metabolism. It was, therefore, a process of adaptation. 
But if any protozoa must submit to amphimixis in order to preserve the species, there are in the group parts that are subject to natural death. We have described above how in the amphimixis of the unicellulars the large nucleus, which undertakes the vital functions, dissolves, and thus represents the corpse. It does not alter the case essentially that this corpse is small in proportion to the animal; in many of the higher animals the germ-cells are much larger than the body-as in the case of the frog's eggs. The question is whether there are any animals whose whole substance lives on continuously and is not dissolved by its metabolism. That is clearly not the case with the protozoa. We are, therefore, not justified in drawing a line between the unicellulars and multicellulars, and saying that the former are immortal and the latter not.

However, the protozoa are not the lowest organisms. In them the living matter is already differentiated, particularly into nucleus and cell-body. In our view there must have been animals from the beginning of life in which there was no differentiation. It is a question whether there are now any unnucleated organisms of this kind, as a nucleus has been found even in the smallest animals. That is, of course, not conclusive, because the simplest living things may be below the limit of visibility. However that may be, we can at least picture to ourselves animals whose reproduction consists merely in dividing without leaving any residue, and in which there is not any amphimixis. We must not forget, of course, that even in such animals the living matter as such is not immortal, 
since it is its property to be always breaking up.

There cannot, therefore, be any living thing of which the substance, as such, is lifted above time. Yet we speak of immortality, because there is a continuity of life. Our own body is breaking up constantly throughout life, yet we do not speak of this as death; in fact, we hardly perceive the constant process.

In the seventh chapter we dealt with the activity of the living matter, of the biogens. These have to break up, it is true, but they have the power to build up one or more new biogens before they die, and this secures a continuity of the life. We can picture to ourselves the activity of the biogens, in the growth and decay of an organisation, in something like the following way. At first they create several of their kind before they break up, and thus effect the growth of the animal. Then each produces only one biogen, and thus they maintain the organism at its height. Finally, they are unable to make any new biogens before they decay, and so they bring about the death of the organism.

Life can only continue to exist because there are biogens the action of which is never paralysed in all their generations. There are biogens that can maintain life in continuity, and so bring about an immortality of life. But in the multicellulars and unicellulars this can only be done permanently by some of the biogens; by the others it can only be done to a certain point-until death. We can, however, conceive living things of the simplest character, the bodies of which consist entirely of such biogens. These animals might not improperly 
be called immortal, because no part of their body perishes without providing a substitute ; in other words, no part forms a corpse.

We know too little of the biogens and their activity to be able to say why all biogens are not indefatigable in creating a substitute. It has been suggested that the temporary biogens can only achieve this by drawing on their own energy. They differ so much in the structure of their elements that some irregularity is unavoidable in the co-operation of the various parts. In the course of their life these irregularities increase, and at last a time must come when the biogens are shaken to the foundations of their structure. They then break up. That is the meaning of death.

We are led to conclude, then, that the introduction of death into the world was useful, because the living matter was bound to give up all claim to eternal continuity before it could be so differentiated that its possessor could escape violent death. However, some of the biogens had to retain the power of continuous creation, in order to maintain life upon the earth.

Just as death was introduced by natural selection, so the moment of its occurrence is carefully regulated. In each animal species natural death only sets in when the maintenance of the species is secured. The duration of life is strictly proportioned in all organisms to their reproductive powers. But I have not space to discuss this in detail here.

Life will not continue for ever on the earth. A time will come when the earth will course through space, a frozen mass, and a violent end will come to all 
organisms. ${ }^{1} \quad$ The moon already shows us what the fate of our planet will be. And as the earth will necessarily change until it becomes incapable of supporting organic life, so there must have been a moment in its past development when no plant or animal could be found on it. In this case it was the glowing heatin the former the icy cold-that precluded the presence of life. Neither extreme can be borne by life; it can only maintain itself between the two poles, and will perish if one of them approaches nearer. We may now ask when life made its appearance, and whence it came.

We saw that the living substance is continually being built up out of inorganic matter, but that this can only be effected by living matter already in existence. If we go far back in the history of the earth we come to a point when it was a molten mass and could not possibly contain life. Whence did this come, then? It might be possible for life to be conveyed from some other body to the earth after it had cooled down. A few scientists have suggested this, ${ }^{2}$ supposing that it may have been brought to the earth by meteorites. It has been replied to them that delicate organisms could hardly endure the icy cold of space, and then the incandescent heat of the meteor as it passes through the earth's atmosphere. The objection is not entirely sound. Particles of charcoal and soil have often been

I Verworn urges this as a difficulty against Weismann, but he is clearly wrong. The cooling of the earth causes a violent death, and is not inconsistent with potential immortality, or a capacity for enduring life. This naturally presupposes external conditions.

2 Lord Kelvin, Richter, and Helmholtz. 
found inside meteorites, and if these could stand the heat we may grant that also of the living substance. Nor is the fact that the meteorites provide no food or water a reason for denying that they might contain life. Grains of seed can remain a long time without water or food.

It has also been said that this "cosmozoic theory" does not answer the question of the origin of life, but only postpones it. If we put life off to another planet, we have to ask how it was born there.

But this also is wrong. It might be said that life was not born on that other planet, but brought from a third one. In a word, it might be said that the living substance has existed from all eternity, like matter and motion. This theory, that life had no beginning, that it is eternal, gives an answer to the question.

But there are more effective objections to the cosmozoic theory. In the first place, we see that the plants build up living matter from inorganic matter every day. If the living substance can thus be created daily, it cannot be eternal. Still less will we believe in the eternity of the organic substance if we reflect that organisms can perish. An eternal matter ought to be imperishable. Inorganic matter, which is eternal, cannot be entirely destroyed. It changes-we can do what we will with it-into another form of inorganic matter, but this also is eternal. It is otherwise with living matter. This can be destroyed as living matter; it does not then change into another form of living matter, but into inorganic matter.

As we see every day with our own eyes how living 
substance is formed from lifeless, and changes back into it, we may assume that it had its first origin in inorganic matter. We have the more right to do this since no element has yet been found in living matter that is not found in the inorganic world. There is no essential difference between the albuminoids and other compounds. Finally, we know that all compounds are made up of simple elements. The whole of science is based on this fact. It would be contrary to all experience if compounds suddenly appeared that were not formed from others, but had existed for all eternity without any connection with nature, as it were. $^{1}$

We are thus driven, by a number of considerations, to the conclusion that life was born on our planet. And as there can only have been inorganic matter on our planet from the first, life must have been evolved from it; nothing can be made out of nothing. It is no objection against our theory that we have not yet succeeded in artificially producing living matter or animals. How could we hope to do this when we know neither the structure of living albumen nor the forces that create it. The fact that no living matter has yet been produced artificially only shows that a certain

1 There is still another important theory of the origin of life, that of Preyer. This takes the idea of life in a wider sense than we usually do. It regards the molten planet as a living organism, and so postulates a continuity of life. In the form to which we now give the name of living matter, Preyer himself admits that it was formed by spontaneous generation. It is a question whether we should be justified in speaking of the movement of inorganic masses as life. It is a question of terms, and we will not enlarge on it. 
experiment has failed; it does not show that there may not be other unknown methods by which living albumen can be constructed. In a word, we can quite understand the failure of all the attempts made up to the present to create living matter, because in the actual condition of our knowledge of life they are merely shots in the dark.

It is possible, in fact, that life could only be formed on our planet when it was at a certain stage of development that has long since passed away. The distinguished physiologist Pflüger has formulated and firmly established a theory in that sense. He believes that the first steps towards life could only be taken when the earth was still entirely or partially in a molten condition. This would be a justification of the old saying that life was born from fire.

I cannot, unfortunately, go into Pflüger's theory at any length, as it requires a thorough knowlege of chemistry. I will merely give a general outline of it.

There are certain elaborate compounds, known as "cyanic compounds," which are easily broken up, and have a good deal of analogy with living matter. These compounds are only formed at an incandescent heat. They may, therefore, have been formed when the earth was still incandescent at its surface. In consequence of their decomposibility they soon entered into relations with other compounds. And when the steam descended on the earth, and the masses of water began to form, the cyanic compounds combined with the fluid element and the salts dissolved in it, and thus gave rise to the living 
albuminoids. These were very simple at first, and not yet differentiated into cells; but they had from the beginning the faculty of metabolism.

Thus the origin of life was determined by the condition of the earth. The living substance is part of the matter of the earth, and has been formed therefrom by spontaneous generation. It was just as necessary an evolution as that of the rocks, when the conditions of it were given. Throughout the whole universe there is an endless chain of causes and effects, and the origin of life comes within this inexorable chain. The further development of the living substance and the moulding of it into the more advanced plants and animals was another necessary consequence of the condition of the earth at the time. These transformations were effects of causes that in turn sprang from other causes. We have long known that all that happens in organic nature is determined by necessary, endless chains of cause and effect. It is the immortal merit of Darwin to have brought life also within this series.

We may now picture to ourselves the first development of life. We begin with the living substance, the origin of which we have outlined above. In the beginning were the biogens. These must be conceived in the form of living things with a metabolism like that of the actual plant. Their constant break-up would have led to the destruction of all life if they had not had the power of creating their like out of inorganic matter. They cannot, of course, have had any chlorophyll, the green substance that effects the construction of organic matter from inorganic in most of our actual plants. 
Chlorophyll is much too complex a structure for us to suppose it to have been present from the first. No, these biogens were clearly like the actual nitrogenous bacteria, very simple organisms, that can convert lifeless into living matter.

The next step in the development of life was that the biogens, which were at first quite homogeneous, clustered together like stars. External conditions were acting constantly on all these primitive beings, because it is the nature of the living substance to be flexible and modifiable. We can thus understand that the activity of the biogens, in creating their like before they broke up, would be greater in warm and well-lit places than in less favourable ones. Here we have the first cause of differentiation. If we further remember the great diversity of the earth's surface, we can see that this of itself would lead to a considerable variety among the living things, since each locality would have a different effect on the changeable living matter. Thus the Lamarckian principle was active at the beginning of biological evolution. Even when a group of biogens divided and formed two, the halves retained the modifications that had been imprinted on the parent by external conditions.

But it would be otherwise when a differentiation set in among the biogens in a given group. The moment a favourable division of labour was introduced amongst them, the organism would be in a better position, and would be picked out by natural selection. By this division of labour one biogen would be better able to discharge one vital function, a second another one, and 
so on. The advance of this division of labour was more and more favoured, and at length the organism was so much differentiated that when it divided it gave rise, not to two homogeneous halves, which could at once become complete organisms in turn, but to two different halves, each of which, in order to form the parts wanting in it, and found in the other half, needed a sort of depot, in which were found the biogens that could create the half that was wanting. This store is the nucleus of the cell ; in this are the basic particles of each section, and thus we come to the stage of cellular animals.

As from this stage the missing parts were formed by the basic particles at cleavage, which were contained in the halved nucleus, the Lamarckian principle ceased to act. However much the protoplasm of a protozoon is modified, the daughter-cells do not receive any part of the modified substance at cleavage; it is the basic particles that build up the protoplastic parts as it grows into the mature animal. And if the protoplastic parts are formed afresh at each segmentation by the basic particles, they can only change when there is a change of the latter. But we have seen that the basic particles change of themselves, and are not modified by bodily stimuli.

The basic particles consist of living matter, and so can change, grow and divide. In the earliest nucleated organisms there can only have been a few of them, and when changes occurred in them by chance, they created different organisms. Let us take the case of a simple protozoon with a cell-body containing four different 
parts. On our theory there were four basic particles in the nucleus of this animal, and these would form the four protoplastic sections. Now, if one of these four particles divided into two, and the one resulting particle differed somewhat from the other, we should have five basic particles; and in the next protozoic cleavage we should have protozoa with cell-bodies containing five different parts.

We can conceive in this way that the multiplication and differentiation of the basic particles would give rise to more and more complex organisms right up to the vertebrates. The root of the variations is, therefore, in the basic particles. The more complex their composition becomes, the more highly differentiated will be the organism whose organs they construct during the embryonic development. But we can say nothing very confidently as to the causes of their alteration and multiplication. Weismann, to whom we owe the whole of this theory of heredity, believes that the food that must be supplied to them, as to all organic substance, whether in the nucleus of the ovum or of the protozoon, may vary in quantity from some accident or other, and that a basic particle changes, multiplies, or disappears, according to this variation in its supply of nourishment. With it must vary the section of the body that it builds up.

Thus the basic particles are never created afresh, but are always formed from pre-existing ones. When they have constructed an organism, their variations come to light in it and in the struggle for life, because the form of the particular organism is changed in harmony with 
their change. It is then settled whether the variation is to survive or not. If it is of such a character that the organism can sustain the struggle for life, it is preserved and transmitted to offspring; if not, the animal perishes, and with it disappear the variations of its basic particles. Thus in the course of time those of the innumerable variations of the basic particles will survive that prove useful in the developed organism.

There is only one more reflection to make. What is the conduct of the basic particles during amphimixis? As the ovum contains the basic particles of the mother and her ancestors, and the spermatozoon those of the father and his ancestors, the number of them must be doubled when they unite. It will be fourfold at the next amphimixis, and so on, until at last they fill the cell-nucleus in immense numbers. We saw in the seventh chapter that there are several basic particles in the ovum for each organ, and that both the ovum and the spermatozoon are capable of constructing several different beings. We saw further that there is a force which, in a way unknown to us, always selects the one basic particle of each organ that is to build up the particular organ. But even if this force prevents the doubling or tripling of an organ in the developing body, nevertheless the basic particles must increase so much in a few generations by the eternal doubling at amphimixis that there will at last be no room for them in the nucleus.

To fix a limit to this indefinite increase of the basic particles there must be some arrangement of the germ- 
cells. ${ }^{1}$ Both the ovum and the spermatozoon must pass through a maturing process before union, the essential point of which is that it reduces the basic particles by one half. In the ovum and spermatozoon before union half of the basic particles are expelled from the cell, so that when the fusion has taken place, there is only the normal number, and this is preserved in the same way at each successive amphimixis. If we suppose that a male cell contains ten basic particles and the corresponding female cell the same number, amphimixis would produce twenty, the next fusion forty, and so on, if there were nothing to prevent the increase. But as five particles have been eliminated from the spermatozoon and ovum respectively before amphimixis, they remain ten in number after union. The same process has been observed in the protozoa.

We have now formed some idea of the origin and evolution of life. We have seen that certain biogens in a continuous series have the power of producing other biogens before they break up, so that the continuity of life is maintained. Whether this power is really lifted above time, or whether the living substance, which had a beginning, will also of its own nature have an end, in the sense that in the end - though after an incalculable period-even the

1 Weismann pointed out the well-known reduction cleavage of the ovum of this character. He postulated the same process for the sperm-cell, because in his opinion the basic particles must be reduced by half in this also before amphimixis. His theory was soon verified, and the reduction cleavage of the spermatozoon was discovered. 
strongest biogens will age, and thus bring life to a natural termination, we do not know. But we can affirm with some confidence that one day a violent death will make an end of all terrestrial life. The cooling of our planet is proceeding with inexorable necessity, and the day will come when the warm earth of our time will course through space as a cold and waterless sphere. All life will perish in this state of icy rigidity. 


\section{CHAPTER X}

\section{EXTENSIONS OF THE THEORY OF SELECTION AND \\ OTHER EVOLUTIONARY THEORIES}

Why there are numerous species to-day. Isolation facilitates the divergence of species. Modification of isolated animals. Movement and alteration of animals. Are species formed by isolation even without the aid of natural selection? Definite variations. Germinal selection. Changes in the nutrition of the embryo are the foundation of variations. Do useless organs disappear through germinal selection? Refutation of germinal selection. Effect of external influences as modifying principle. Orthogenesis. Rejection of same. The mutation theory. Variations and mutations. Do variations proceed indefinitely? Is there a formative energy in organisms? Mechanicism and vitalism. How are the form and purposiveness of organisms explained? What is to be understood by chance. Absence of purpose in living things. The will to live, the instinct of self-preservation.

We can now picture to ourselves how life began on our planet, and how it has been evolved. In virtue of the fundamental property of organic substance, variability, a process of transformation has been possible that maintained organisms even amid the changing conditions of the surface of the earth. We recognised natural selection as the power that continuously adapted living things to their new environment. And as we came to the conclusion that organisms arose entirely, or at least mainly, from adaptations, we are bound to say that selection alone has done all the work of transforming life. 
However, we saw at an early stage that the theory of selection will not explain everything in the present condition of science. It could not satisfactorily explain the various characters that are peculiar to one sex. The auxiliary principle, sexual selection, which we called to our aid, was so unsatisfactory that we sought to reduce it again to natural selection. We also failed to explain many of the rudimentary organs because we had to reject, on the strength of Weismann's objections, the Lamarckian principle that might have shed light on them. On the other hand, when we came to the question why there are sharply distinct species, we discovered an agency that really solved the problem-amphimixis.

However, there seemed to be other difficulties in the way of amphimixis. The origin of one species from another - in other words, the divergence of species - seemed to be inconsistent with it. How can a new property, even when it only arises amongst one section of a species, maintain itself and lead to the founding of a new species, if the differently constituted individuals are always crossing with the modified ones? The new feature ought to be absorbed by the majority in this general crossing.

But we have had frequent occasion to remind the reader of a power that can prevent crossing, and so maintain the incipient specific character. This agency is isolation. We will now deal with the importance of isolation in the formation of species, to which attention was first drawn by Moritz Wagner.

The most common effect of isolation is that a 
number of animals are separated spatially from the great mass of their fellows, so that there can be no further crossing. If these isolated animals come into a different environment, selection will modify them in a different direction from that taken by their distant fellows. Remember the origin of land vertebrates. As the fishes dispersed, passed up the rivers, and reached their higher waters, some of them may have swum into a piece of water that was not usually connected with the rivers. When the water fell once more, the wanderers were cut off from their species. Selection had another effect in their new home. In the hot season most of the water dried up, and this was the occasion of the conversion of the swimming bladder into lungs.

It must have happened very frequently during the millions of years of the earth's history that wandering animals were cut off from their fellows. In this way floods and evaporation must have given occasion over and over again to the formation of new species of aquatic animals. Land-animals also must have been separated by inundations. Suppose, for instance, that the overflow of the Rhine into a certain valley killed all the deer in it, and only left survivors on the mountains at each side. When the water subsides again, the deer will remain in their separate localities, because we know that they keep always to a rather restricted area, and do not willingly leave it. Gradually, the increase of the animals on the mountains will bring some of them down into the valley once more. But if they had a different environment on one range 
of mountains from on the other, each species will have been changed by natural selection, possibly so much that they can no longer be crossed, or not with any effect. Thus there will be two different species of deer in this Rhine valley.

Inundations will often cover a large area, and this must have happened more frequently in former years when there was no regulation of rivers. These floods would certainly often drive animals into a new environment. If, for instance, a river floods half a wooded region, and only spares the extreme corner of it which borders on a wide steppe, the animals in the part of the wood that has not been flooded will remain forest animals, but those that live in the narrow strip of wood will gradually become steppe animals, because their continued expansion will drive them on to the open grass. It is not necessary for the animals to be driven into other regions by the flood in order to be modified; it is enough if they find a new enemy in their new home. In the struggle with this enemy, the branch species will be made to differ from the parental species, which will not be affected by the same agency.

If we bear in mind the continuous geological changes that have taken place in the earth's surface since the enormously remote period of the origin of life, we can understand that the isolations must have been frequent enough to account for the infinite variety of organic species. Lands have sunk beneath the sea, others have emerged from the waves; at one place mountain ranges have been elevated, at another great valleys scooped out. Land joined on to land and water to water, then 
separated afresh, and reunited later on. Storms swept over the earth. Violent hurricanes rooted up whole forests. Desert-storms buried whole stretches of green land under sand. Tropical heat alternated with arctic cold : floods with drought.

When animals that had long been separated came together again, they were generally so different in structure and appearance that they could no longer cross in such a way as to mingle the characters of one species with those of the other. Even minute changes in the spermatozoa of the male prevent it from penetrating any longer into the ovum and fertilising it. Moreover, animals are most apt to unite with those of their own species ; they have a sort of racial feeling that generally prevents them from crossing with animals of a different form. An unfamiliar appearance or scent restrains animals from mixing, and this is especially true of animals that come together after a long separation. We know that mammals and birds that have been kept in captivity for only a brief period have not only no love to expect from their kind when they are released, but are actually persecuted. Even the finest changes in animals often act powerfully on the sense-organs of their free-living fellows.

It is not only geological alterations of the earth's surface that lead to the division of animal species by isolation, but organisms may be transported into regions from which they cannot return to their old home and their fellows. In modern times animals have often enough been transplanted by men into distant localities. The Porto-Santo rabbit is a proof of the fact that a 
species can be so altered by isolation as to be incapable of crossing with the parental species. In fact, long before man crossed the waves on his vessels, organisms were conveyed into remote districts. Sometimes small water-snails clung to the legs and feathers of swimming birds, and were taken far across the sea to strange islands, where they entered the water once more and found their proper conditions. In the same way other aquatic animals travelled far and wide-the minute eggs, especially, that were easily caught in the feathery coats of the swimming birds and taken away unconsciously. Land animals also could be dispersed by birds in this way.

It was by no means necessary to have living vehicles to convey animals into distant and isolated districts. It might often happen that a branch of a tree with small animals sitting on it would fall into the river, be carried out to sea, and be borne by the currents to distant localities. In this way, as a matter of fact, branches have come from America to the coast of Europe. The eggs, especially, which are comparatively insensitive to external influences, and the seeds of plants, might be conveyed in this way. It is certain that many newlyformed islands have been thus populated.

Not only may the sea transport germs in this way, but many a flying animal has been taken a considerable way by stormy winds. Insects and birds often get into currents of air that carry them to distant localities, and they often find such a favourable environment there that they do not think of returning even when it is possible to do so. 
The transport of animals into distant lands is often very useful for their extension. Especially when the wanderers reach an island that offers them a virgin habitat-one that has few or no animal species in itthey may spread in all directions. And as there are all kinds of spots in the new district, their descendants in turn may separate into new species, each locality modifying its inhabitants in a different respect. This will happen particularly to slow-moving animals, such as the snails, every valley and every wood giving a specific modification to its inhabitants. There is no reason to fear the levelling of the new characters by crossing with their kind of other districts in the case of such slow animals, as they have long coupled with others like themselves before they reach a different territory.

There are many other means of isolation besides these. The isolation may only hold during the period of reproduction; birds, for instance, that otherwise mingle together in quest of food may rear their young in remote districts. In such cases a differently coloured ground may change the colour of the animals. It was an isolation of this kind that gave rise to the migratory birds. The isolation need not always involve an absolute separation of the daughter species from the parental species. It is enough if one part of a species leaves its proper territory, and takes up residence in a contiguous one of different characters, that meets its needs. Although there is still a good deal of crossing at the frontier, there will as a rule be a steady and pure development of the new species away from it. 
$\mathrm{Up}$ to the present we have only seen a preparatory principle in isolation, which makes possible the formation of new species. This formation may be brought about by natural selection after the isolation.

There are also cases in which isolation alone may lead to the formation of a new species. If a fertilised female is forced into an isolated district and lays her eggs there, the young developed from them will not, as a rule, differ from the parental species. But if the female happens to have some peculiar characteristic, it will transmit it to the offspring; in time the feature will become a characteristic of the isolated animals, as it can no longer be absorbed by crossing. In this way isolation may lead to the formation of a new species without the aid of natural selection. The isolated variety would be still more strongly modified if the characteristic in question were to be accentuated in the offspring; in other words, if there were some force in the organisms that caused variations to advance in a definite direction in the offspring. We have already found several times that the transformation of species would be brought about much more speedily by a principle of this kind than without it, and we will now inquire whether or no we may infer the existence of such a force.

We have spoken of selective value in the seventh chapter and seen that it is difficult to conceive how every little variation can be helpful to its possessor in the struggle for life. If that is not the case, how can the variation be preserved and increased? How could the elephant's trunk be developed from the original nose, 
since even the most favourable variation of the latter could not perform a single function of the trunk?

The whole difficulty would be avoided if we could suppose that variations that have once arisen have in themselves a tendency to advance in the same direction in each generation; in that case, if the elephant's nose happened to be rather longer than those of its fellows, it would be still longer in this elephant's offspring, and if the family became isolated, each succeeding generation would have longer noses. In the end a point would be reached when the nose would be long enough to be of service. Then selection would set in, and still further develop it.

If there were definitely directed variations, it would be easier to solve a number of other problems. The importance of amphimixis would be greatly enhanced. By means of it different directions of variation would be brought together in one individual, and co-adaptations would be effected much more quickly. At the same time, amphimixis would convey both upward and downward variations to a number of individuals, and thus generalise useful characteristics, and prevent injurious ones from spreading, with fatal consequences to their possessors.

There are many advantages in the theory of definitely directed variations. Many scientists, in fact, believe we need the hypothesis, as the theory of selection is, they say, unable without it to explain the origin of species. We will now see if there is sound reason for crediting nature with definitely directed variations.

The expert who has made most use of the principle of 
selection, Weismann, has attempted to apply it to the germ-cells. ${ }^{1}$ He thinks that here also there is a selection at work-"germinal selection." The result of this is to preserve definite directions of variation in the germs.

We have already seen several times that there are in the germ-cells, which an animal has in its sexual glands, tiny particles that represent the rudiments of the future organs, in the sense that, if an animal is developed from the germ-cell, they determine the several parts of the body and stimulate their construction. Hence every part of an animal's frame is present rudimentarily in the germ-cell.

These basic particles, which Weismann calls determinants, because they afterwards determine an organ

1 Weismann was influenced by the "theory of histological selection" of Wilhelm Roux. Roux attributed the purposive structure in the histological, microscopic texture of animals to "a struggle among their elements." We know that sustained exercise or stimulation in the life of the individual strengthens. The cells are enabled to grow better under stimuli. Hence when we find a graceful framework in the bones of the leg, the arches of which always run in the direction of the greatest pressure and strain, as in the construction of an edifice, it must have been brought about by the fact that the cells which lay in the direction of the pressure and strain were most stimulated, and so formed the strongest bony matter. On the other hand, the intermediate cells were less stimulated, would grow and act less, and the nourishment they needed would be absorbed by the better situated cells, so that they would eventually perish. It is thus that the curves in the osseous structure run only in the direction of the greatest strain. The cells that lie there have an advantage in the struggle of parts, as they grow under the constant stimulation, and build up bony substance at the expense of the adjacent cells, which gradually die off.

Histological selection gives us a luminous explanation of microscopic structure. But in our opinion it only acts during individual development. What it accomplishes is not inherited, but has to be created afresh in each organism. 
of the body, consist of living matter, and so must receive nourishment. Their food must be matter that is found in the germ-cell, or passes into it from the body. This matter must, of course, be fluid and must flow round the determinants.

Nowhere in nature do we find absolute equality, and so the fluid nutriment will not equally reach all parts of the germ-cell. Hence a determinant will receive sometimes a fuller and at other times a thinner supply of food. If it finds plenty of food, it will grow strong and sound, as all living matter does when it is well nourished. Another determinant will chance to have a worse supply of food, and become weaker.

When the determinant is thus enfeebled by happening to receive a poor supply of nourishment, it will, if an animal is developed from the germ, have less power to build up the organ it represents, and the organ also will be feeble. And when a determinant is strengthened in the germ by a plentiful supply of food, it will afterwards build up its particular organ in greater strength. Thus we see that the variations we find in children of the same mother at birth are due to chance differences in the supply of food to the ova. While the ova lay undeveloped within the mother's body, the determinants were differently fed by the varying stream of nourishment, and when they afterwards come into action they show differences in the building up of their respective organs. Hence the accidental irregularities in the supply of food in the germ are the roots of variations.

All living matter is able to accomplish work in proportion as it is strengthened by food. We can thus 
conceive that a determinant, which has increased in size within the mother through the good supply of food, will, by reason of its size, attract more food to itself in the daughter. When the mother's germ-cell divides to form the daughter-cells, we know that in the earlier segmentations of the ovum all the determinants are split into halves, because first of all must be formed the germ-cells of the daughters, and these must contain all the basic particles. When the determinants come into action in the later segmentations, and gradually build up the body of the daughters, some of the first cells divided, the germ-cells retain all their determinants in a quiescent state. Hence if a determinant became larger in the mother owing to a good supply of food, it maintained this size in the germ-cells of the daughters as well, as after cleavage it always grew again to its normal size. And, being larger, it needed more nourishment than the neighbouring determinants that remained small. Owing to its volume it, as it were, drew to itself the stream of food circulating in the germ. On account of this supply of food it became still larger, and retained its size in the ovum of the grand-daughter, where it again attracted food, and became larger still. The size increased in each generation, the determinant grew larger and larger, and hence the part of the body that it built up showed a corresponding steady increase or, in other words, a definitely directed variation.

Does this enlargement of a determinant and the corresponding organ proceed indefinitely? If this were the case, there could be no such thing as a specific type. As the nutrition is exposed to irregularities 
at each part of the germ, one part of the innumerable determinants would become steadily larger and the other part constantly smaller. In the same way the organs of the developed animal would change in all directions simultaneously. It would be impossible, in view of this eternal ebb and flow of the determinants, for an animal species to remain the same for a considerable period, as we actually find.

Hence Weismann is compelled to attribute to the germ-substance a faculty of self-correction; that is to say, generally speaking, a determinant will, if it receives a somewhat richer supply of food, check it by its own force, so that it will be neglected, and the determinant in question will become weaker again. By this selfregulation the determinants save themselves from changing incessantly with every variation in the foodsupply. The force of self-correction is only overcome in rare and exceptional cases of the access of a heavy stream of nourishment. Then they grow constantly larger, and with them the organs they bring into existence.

If the enlargement of the particular organ is useful for the organism, its possessor is preserved by natural selection, and therefore also the growing determinant. As the individuals that vary in this way are selected they come in time to dominate the species. But if the enlargement of the organ is injurious, the animal in question is destroyed and the upward movement of the determinant is cut off.

$\mathrm{Up}_{\mathrm{p}}$ to the present we have only considered the quantitative changes of the determinants and their organs. 
Irregularities in the food-supply may also lead the determinants to vary in quality, and so give rise to qualitative variations in the parts of the body subsequently. This is believed to be brought about by a difference in the growth within a determinant of the many biogens that compose it; this leads to an alteration of the structure of the determinants.

Germinal selection thus seems to explain the disappearance of useless organs. These also have, of course, one or rather several ${ }^{1}$ determinants in the germ-plasm. And while decreasing determinants of the necessary organs are rooted out with the animals they are in, as they are insufficiently equipped for the struggle for life with their undersized necessary organs, on the other hand the decreasing tendency is preserved in useless organs, because their possessors are not extinguished by selection. In this case enlargements of useless determinants are cut off. Such growing determinants take the nourishment away from the others, and cause them to be smaller. But they must not become smaller, since they build up important and indispensable organs. Hence rising tendencies in the determinants of useless organs are cut off, and only those are preserved that keep them down and reduce them in size. In this way the determinants and their organ must gradually disappear within the species.

Here we have the principle of selection. There is a kind of struggle for nourishment among the determinants in the germ. If one of them has become large

${ }^{1}$ The eye, for instance, must have several determinants, otherwise each part could not vary of itself. Hence there must be an immense number of determinants in the germ. 
owing to some chance increase in its food-supply, it is particularly favoured in the struggle. If it becomes smaller, it is gradually crushed out, because the food is taken from it by its neighbours.

Hence on this theory there can only be a limited amount of nourishment in the germ. If it were inexhaustible, a tendency to increase in the determinant of a useless organ would not be prejudicial to its neighbours, as they also would have sufficient food. In this way organs would not be reduced to a rudimentary condition, since the rising and falling variations of the determinants would neutralise each other in the general crossing, as we have already seen.

According to the theory of germinal selection, therefore, the amount of nourishment in the germ is limited. But each determinant must have enough to maintain itself. When, therefore, the determinant of a useless organ becomes weaker and weaker in each succeeding generation, what becomes of the food that formerly went to it? As we saw that a determinant only becomes stronger by taking food away from its neighbours, so when they become weaker, it must mean that their neighbours have taken food from them. Thus the determinants that are contiguous to the determinant of a useless organ will absorb the nutrition that formerly went to it. They will grow; and as they become stronger they will, according to the theory, continue to grow, and so will their respective organs. Hence, on this theory, the parts adjacent to a rudimentary organ in the body must steadily increase in size. For the same reason the parts surrounding a growing organ 
must decrease in size, though not to such an extent as to cause injury to the organism. But there is no trace to be found in reality of either process. Therefore, the hypothesis of a germinal selection cannot be sound.

A number of experts have raised objections to this hypothesis of germinal selection. ${ }^{1}$ It has been pointed out that we must assume that a determinant which has increased in size owing to an accidental addition to its food-supply will sink to its old level as soon as this addition ceases. It is quite arbitrary to ascribe to a living force-such as the determinant is-the power to retain the increased size it has obtained from a better food-supply when this supply has diminished. If a gymnast strengthens his arm by exercise, it will not remain at its full strength if he afterwards abandons daily practice. If such complex structures as the muscles of the arm are not able to maintain the force they have acquired in this way when the exercise is abandoned, how much less will this be possible for a minute particle of living matter, which is so much exposed to vacillations in its supply of food?

It is just as arbitrary to identify size and force. A determinant that has increased in size owing to better nourishment has not necessarily acquired a greater power of obtaining food than the neighbouring determinants that have remained small. We should be equally justified in assuming that the shrinking determinants are so much the "hungrier." There is no direct physiological relation between force and size.

${ }^{1}$ Professor Emery of Bologna and Professor Thomson of Aberdeen are the only two distinguished authorities who have fully subscribed to the theory. 
We might put a long list of questions to germinal selection. Whence comes the greater amount of nourishment that overcomes the self-regulation of the determinants, and thus represents the real source of the variations? To what extent can a determinant grow without injuring its neighbours? How is it that irregularities of the food-supply within a determinant do not often lead to a complete transformation of it, instead of merely altering its quality a little?

But we have seen that we must reject the theory of germinal selection, and may quit the subject. In the next chapter we will return to it for a moment, in order to disprove it once more from a different point of view.

Let us now look about us for other principles to explain how organs reach a certain height owing to constant definitely directed variations, so that at some stage they acquire selective value and may be further advanced by selection.

There are experts who say that external infuences may not only affect an organism in the course of the individual life, but that these modifications are trans. mitted in a weaker form to its offspring, and are accentuated in these, since they remain exposed to the same influences. Thus in the course of generations the external agency, which always remains the same, will modify the animal more and more in a definite direction. This steady variation in one direction owing to external influences is called orthogenesis.

Orthogenesis is, clearly, a subdivision of the 
Lamarckian principle, and as we have rejected the one, we need not linger in discussing the other. However, we will say a few words about orthogenesis, as in speaking of the Lamarckian principle we dealt almost exclusively with the inheritance of changes brought about by the actions of the animals, their energy and efforts.

Animals are said to be permanently affected chiefly by the following external agencies: climate, the character of the soil, and food. Thus the stimulus of cold may provoke a thicker coat of hair in many animals. This will be transmitted to the young, and as the cold continues to affect them in turn the hair will grow longer and longer. In this way the animals will vary in one definite direction as long as the stimulus lasts.

It has been alleged in support of this view that many poisons make organisms more sensitive the longer they act on them. That, however, only shows an increase of the action of a stimulus during the individual life, not that the increase is inherited.

But there is an experiment that seems to prove the inheritance of a stimulated effect. In this the pupæ of a butterfly, the large tortoise-shell, were exposed to a cold of $15^{\circ} \mathrm{Fahr}$. The butterflies that were developed from them were much darker than the normal specimens. A couple of these modified animals were crossed, and from the ova, which were developed under entirely natural conditions, came caterpillars that afterwards changed into tortoise-shells of a shade similar to that of the parents, or slightly lighter.

Had the modification ot the parents by cold been 
transmitted to the offspring? It is not necessary to suppose this. We can just as well imagine that the lower temperature affected the whole pupa, and even penetrated to the germ-cells contained in it. As the wings especially were affected by the cold, that may have been the case with their determinants in the germ-cells; these being so profoundly influenced that even after the cessation of the cold they brought about modified wings. "Medium influences," such as climate, for instance, can often not only modify an animal, but also penetrate it and modify its determinants.

Thus the experiment does not prove that the modifications of an organ brought about by a stimulus will on their side influence the corresponding determinants in the germ; the stimulus may reach them directly. We do not know how far or how often these medium influences on the germ may act, and so we will not linger over this principle, once it has helped us to take away an apparent support of the Lamarckian theory.

The explanations offered us by the hypothesis of an orthogenetic action of constant stimuli are not satisfactory. The Lamarckians say, for instance, that certain mammals, such as whales and walruses, have almost entirely lost their hairy coat owing to the constant action of the water. In other animals the water is said to have formed horny plates on the mucous lining of the palate, as in the tortoises, the duck-bills, and the whales. We may ask, then, why the water has not reduced the fur of the otter, the beaver, the seal, and the water-rat, and why we find 
no horny plates on the palate of the crocodile, the dolphin, and other aquatic animals? The external influence is the same in the case of all these animals. Why is there a different reaction in the various animals?

And there is yet another question. What is the extent of the influence of external stimuli? If the water causes horny plates on the palate of certain animals, they must continue to grow indefinitely. If apes have acquired certain protuberances by sitting, these will go on growing until they become monstrous swellings, if the effect of the stimulus is increased with each generation.

It has been said in reply that an organism at length inures itself to these permanent stimuli, and ceases to react on them. But this only raises another difficulty. What is the basis of this power of adaptation? Perhaps it will be said that it depends on a certain adaptive power of the body. But how did this come about? And when the animal has become inured in this way what is the service of it ? Moreover, it must last for a longer or shorter period in different animals.

In a word, we see that the action of external stimuli in the transformation of organisms must be very slight. The real force must lie within the animals themselves. It is due to this that the body responds to external stimuli in so far as it is to the interest of the animal. The adaptiveness of living things, which must have a scientific explanation, puts out of court all the Lamarckian hypotheses, and therefore also orthogenesis.

It is the opinion of many authorities that natural 
selection alone does not suffice to explain the origin of species, and that we are compelled to postulate a purposive internal formative energy in organisms. But before we deal with these writers, we will describe a recent theory which does not directly reject natural selection, but greatly restricts its sphere of influence. This is the "mutation theory" of the botanist, Hugo de Vries.

De Vries questions especially whether the actual forms of life are due to ordinary variations. He says that they are not inherited pure, and appeals to artificial selection, as, for instance, in many kinds of grain. These are never independent of selection, because as soon as cultivators cease to watch and select them, they quickly return to the parental species. Thus no character can be fixed by natural selection to such an extent that it will remain as a permanent quality of the new species when selection has ceased.

There is a second reason why natural selection cannot have created the actual forms of life from variations. The variations, he says, are restricted; they cannot increase indefinitely, and can at the most only double the original character. We have, for instance, considerably increased the amount of sugar in the beet by selection, but that is all. Further, there has been no increase in the size of gooseberries since 1852 , though one cannot see any reason why they should not have become as large as pumpkins. There must be an internal limit to variability.

Hence de Vries believes that ordinary variations cannot have produced the actual species. They must 
be due to special variations, which he calls mutations. These mutations have long been recognised; they rarely occur, and the feature of them is that the organism is modified by them at a bound, in several directions at once. Thus, amongst a number of plants that de Vries was cultivating, most of which varied in the usual manner, there were some that departed from the species in several directions simultaneously, and so were very conspicuously altered. When de Vries crossed these "mutations" with each other they produced plants of just the same kind. In other words, contrary to the variations, the mutations retained their new characters from the beginning when purelycultivated.

Species have been brought about, he thinks, by these mutations. Owing to certain internal causes the species have, he thinks, suddenly divided into several with a number of new characters which they all retained. These mutations take no particular direction; they are partly useful, partly indifferent, partly injurious to the organism. Natural selection weeds out the unfit, but has no influence on the survivors. It cannot improve the latter; it must take the individuals as they are, modified simultaneously in several directions.

Thus, whereas we have so far considered the transformation of species to be due to the fact that each organ was slowly modified in connection with its environment, in the sense of adaptation, this new theory suddenly shatters the whole conception. When we reflect on this we are disposed to join those who reject the mutations as the formers of species. We know that the species are made up of adaptations, and these 
can only gradually have been evolved from variations. The complete adaptations cannot possibly have arisen from a modification of the organism by mutation; that would be an excessive trust in the fortune of chance. On this theory a mutation of a butterfly's wing would imply that all its parts suddenly developed different colours. But we must not expect that in this haphazard variation the colours would harmonise in such a way as to form a picture of a leaf! Even if an imperfect leaf-design were formed, it would not be improved at the next mutation, as the colours of all the parts would change at once ; even if the colours that were wanting before now made their appearance, the parts that had been rightly coloured would be destroyed. Let us recall our illustration of the twenty dice. Suppose the adaptation consisted in all the dice showing the six. The shaking of them in the cup and throwing them would represent a mutation. However many times we try the experiment we shall scarcely succeed in making all the dice show the six. It can only be done by throwing each die separately until it gives a six, and then letting it stand. But that is just the way in which variations occur, and the fixing of them is left to natural selection.

Another objection to the theory of de Vries is that the mutations must be neutralised by amphimixis with normal animals, as they occur in so few individuals. It will very rarely happen for them to be of so favourable a character and at the same time for such a crisis to come upon the species that all the individuals without the mutation will perish. 
Hence the multiplicity of our actual species cannot be due to mutations. What can we say to de Vries's objections to variations?

It has been rightly pointed out that these objections are unsound. In the first place, we have really produced new races of dogs and pigeons by artificial selection, and these have retained their new characters when crossed with their own kind. We may therefore assume that in natural selection also the modified animals will retain their characteristics when the selection has ceased. But even that is not necessary. Selection does not cease to act even in pronounced species; it watches unceasingly over the animals, and continues to act on them. Hence the variations, even if they had a tendency constantly to slip back, must lead to new species, as natural selection always cuts off all instances of reversion.

Secondly, even if after a time we reach a limit that we cannot pass in artificial selection, it does not follow that this is the case in nature as well. We can only continue to select as long as the harmony of the various parts is preserved, and we do not know what other parts of the body we must attend to in our selection if the object we are breeding is to have unusual features. If we want to increase the gooseberry to the size of a pumpkin, it is certainly not enough to select the trees that have the largest berries. If we want very large berries we must also have changes in the plant's fibres for conveying water and sap, the branches must be thicker-in a word, there must be a number of changes that are not entirely within our knowledge or control. 
But if we reflect on monstrosities in nature, the parasites, and the deep-sea animals (some of which have mouths of extraordinary proportions, others have stomachs that can take in a larger fish than the devourer, and others have eyes on the end of long stalks), we must ascribe to variations a faculty of indefinite advance. Natural selection may produce the greatest monstrosities if they are capable of life and are adapted to their environment. Japanese breeders have even succeeded in creating cocks with tail-feathers four yards long by artificial selection.

We turn now to those writers who ascribe the development of the organic world to a formative energy that was present in living matter from the beginning. This energy is supposed entirely of itself to impel organisms to assume more and more advanced forms. Living things would have the forms they exhibit to-day, on the whole, even if they had been subject to quite different influences, and if the geological changes of the earth had been different. Natural selection, they say, does not create species by adapting animals to new conditions, but the animal forms were built up by the internal force, without any influence from external conditions. This was done by the species diverging from each other in characteristics of no value in animal life.

We need not delay long with this theory, because we know that the foundation of it is unsound. We have seen that the species is first and foremost a collection of adaptations. But adaptations cannot arise from some independent formative energy working on its own 
account. It is of their very essence that they be in harmony with the external conditions of life, and these are brought about by a totally different force-the force that effects the geological changes of the earth. As it is a fact that the organisms have always been modified in correspondence with the geological changes of the earth's surface, since the adaptations always harmonise with the new condition of the earth, the two forces must go together like two mutually regulated clocks. And as the forces have nothing to do with each other, we can only explain their agreement by postulating a third force that controlled them from the start. If we do this we abandon all attempt at scientific explanation.

If we want to explain a phenomenon satisfactorily we have to bring it into line with a more general and better known phenomenon within our experience. But we must not ascribe to this phenomenon any characteristics which we do not really know to be present in it; and in experience we are only acquainted with the corporeal and with movement, matter and force, the material of chemistry and physics.

What do we mean by reducing one phenomenon to another? It means that we can show the one to be a necessary consequence of the other. The phenomenon to be explained must have a cause, of which it is the necessary effect. We have, therefore, satisfactorily explained a phenomenon when we show that it is the effect of another of which we know by experience that under certain known conditions it is bound to produce the effect in question, and that these circumstances are actually given. Thus we explain the luminosity of 
lightning by showing that electricity is generated by the friction of certain bodies, that from this a luminous spark must arise, and that these conditions are realised in a storm.

In the same way we give the most satisfactory explanation of the phenomena of life when we trace them to the known processes of physics and chemistry. However, our actual biological knowledge is much too scanty for us to give this explanation in full. But we may ask if it is possible in a general way to give a physico-chemical explanation of the processes of life, or if it is not in the very nature of life to elude such an explanation. Here we find two contradictory opinions. One holds that a physico-chemical explanation of life is possible; that is mechanism. The other denies that it is possible; this system is known as vitalism.

All that we have said hitherto was based on the mechanical conception. The principle of natural selection, which we have chiefly employed, enabled us to give a mechanical interpretation of the organic world. If living things came into existence and were transformed by natural selection, we need only physicochemical forces to explain the process.

The Vitalists say, however, that natural selection is just as incapable as any other mechanical principle to explain life. Let us see which property of organisms it is that the Vitalists declare to be particularly inexplicable by physico-chemical means.

In the first place, they object that the Mechanicists have never yet succeeded in giving a purely physicochemical explanation of the vital phenomena. But this 
merely implies that our present means and knowledge do not suffice for constructing a mechanical explanation; it does not follow that there will always be insuperable difficulties in the way of it. On the contrary, we have already good reason to say that a mechanical explanation of life is possible. We have already given a physicochemical analysis of some aspects of the vital processes which were formerly attributed to a vital force. There are certain substances that are only found in the living body, yet have been artificially produced by chemistry. Uric acid is the best known of these.

The Vitalists reply that we must put outside the category of real vital phenomena all aspects of the vital processes that can be conceived as purely mechanical. But it has been rightly pointed out to them that the problem before us is: Can the vital processes be conceived as physico-chemical? If the Vitalists say it is the characteristic of vital phenomena to be incapable of being conceived as physico-chemical, they are begging the whole question.

I have already said that we do not know under what conditions the chief elements of the organic body, the albuminoids, are produced. Living albumen is still an unsolved problem for us. Hence our knowledge of the living substance is as yet much too scanty for us to construct successfully a mechanical explanation of the vital processes.

It has been established by careful research that the same amount of force is used up by an adult organism in its vital activity as is taken into it with its food. Hence all the actions of the body are exactly 
proportioned to the amount of force contained in the food taken. But if these actions proceeded from a special vital force, the amount of energy introduced in the food would be superfluous in the body.

Thus Vitalism is inconsistent with the law of the conservation of energy. It has, therefore, been modified into what is known as Neo-Vitalism. Generally speaking, this theory admits that the same physicochemical forces are at work in living things as in inorganic nature. But while the mechanical processes alone are found in the inorganic world, living things are also subject to other principles which are not found in inorganic nature.

We shall see something of this "teleological" governing force in the next chapter. Here we will only say that a unified conception of the organic and inorganic worlds is preferable to the Vitalistic, especially as we know only mechanical events as facts. The Vitalists do not help us to understand the organic world. They only question whether the problem can be solved mechanically.

There are, they say, two characteristics of organisms in particular that cannot be understood mechanicallytheir form and their purposiveness.

It is true that all living things have a form, not only the individuals as a whole, but even in their smallest parts. The forms of organisms are conditions of equilibrium. If we recall the simplest forms of living things, those of the tiny protozoa, we find that they are generally globular. The round shape is the form of equilibrium of a fluid body, and we saw at an earlier 
stage that protoplasm is fluid. Thus the form of the lowest organisms may be compared to that of a drop of water. The shapes of other protozoa are explained by the membranes that cover them, which cause the departures from the globular form by their inequality in thickness and extensibility. The forms of the lowest organisms are, therefore, parallel to forms in the inorganic world. In fact, in the latter there are forms that are far more difficult to understand than those of the protozoa-the crystals.

But how do we explain the forms of the higher organisms?

We have seen that these forms have been developed from the lower ones. No extraordinary forces were employed in this evolution; the new organisms were in each case the outcome of an accidental, local coincidence of physico-chemical conditions.

But is not chance itself incapable of being understood mechanically?

No. Chance, in our sense of the word, has nothing to do with the miraculous. Every accident, on which we count, is the ultimate effect of a whole chain of successive causes and effects, in all of which only natural forces are at work. We are, therefore, quite convinced that "chance" is to be explained physicochemically; though we grant that the causes which have determined it are not known to us. We have an excellent illustration of the matter in a ball that has been thrown on the ground. Chance determines at what spot it will stop rolling; in other words, the spot cannot be calculated in advance, because the various 
forces and conditions that impel the ball towards it are not known to us.

The Vitalists say that none of the marvellous forms of the organic world can have been brought about by chance, any more than the chance agencies that effected the geological changes of the earth's surface could have constructed a Parthenon or a steam-engine. But it has been pointed out that even these structures owe their origin to chance. Did James Watt go to work with the idea of making a steam-engine? Not at all. He came by his first thought by chancing to observe the pressure of the steam in lifting up the lid of a kettle. He then confirmed his observations by assiduous experiments, and so he and his successors erected machines that advanced step by step, always selecting the useful and rejecting the useless. The Greek style of architecture arose in the same way. Natural selection acts analogously. We will, therefore, regard its explanation of the forms of the higher organisms as satisfactory.

Does the purposive reaction of organisms to external stimuli point to the presence of an internal vital force?

It is suggesed that such a force, independent and self-existent, must react purposively on all influences, just as a magnet attracts all pieces of iron. But we know that this purposive force often fails in living things. An amœba will take into its body and retain for some time a particle of stone lying in its path, just as it does with food. The relation of flowers and insects also is often unsuitable. Many animals have died out because they could not adapt themselves 
suitably to their suddenly altered conditions of life. We saw that, generally speaking, animals have the power of suitable reaction or adaptation only in their customary environment. A mole-cricket tries to bury itself in a glass plate instead of running away; a bee stings a human being, though the sting will be fatal to itself, and so on. If the purposive reaction in the vital force of animals were independent of the external world they would be armed against all contingencies; and that is not the case. Far more probable is our hypothesis that the animal's power of adaptation has arisen by gradual development under the controlling influence of external agencies.

Matter and force determine the series of cause and effect, as we know from experience. To this no exception has been found. On the other hand there are many exceptions to the purposive power of organisms; and that shows it is not determined by any internal law.

We have a proof of non-purposive development in the rudimentary organisms. Humanity would be far better off if the human frame contained no cœcum. How frequently, moreover, the "purposive power" goes astray during embryonic development, and brings into the world hydrocephalous children and other deformities. Then there is the power of regeneration; it would be of great service to all animals, but is found well developed in very few. Do not some animals have a larger measure of it than others? Why, then, are they particularly favoured? In a word, the vital force raises so many new difficulties that are not raised by 
the mechanical conception that we are bound to prefer the latter. Selection is precisely proved in a most striking way by the imperfectness of the adaptations.

Finally, the objection has been raised against the mechanical theory that all evolution pre-supposes something that cannot be explained physico-chemically. This is the will to live. The struggle for life is not imposed from without on organisms; it is rooted in their own will. Selection would accomplish nothingit would effect no improvement if living things did not strive to maintain themselves and reproduce.

We cannot accept this view. The will to live is synonymous with the impulse of self-preservation. This is an instinct, and we said that there is no difficulty in attributing the origin of instincts to natural selection. Moreover, the will to live and to reproduce is not primary. It is certainly not present in the lowest protozoa. These have no will to nourish themselves. They travel about and take into their bodies everything that comes in their way. If the particles are digestible they are used for building up the animal; if not, there was no use in absorbing them. When the lowest mobile algæ swim towards the light, they do not do this in virtue of a will to live, but because an attractive force has been developed in their frame by selection that impels them towards the light, which is important to them.

Still less can we speak of a will to reproduce. The cleavage of an amœba clearly means merely that when it has absorbed a certain quantity of food it breaks up of itself, just as steam on the window runs down at length in drops. 
A considerable number of animal characteristics have been produced by a purely passive selection. Protective colours, for instance, are of this kind. In this case the least conspicuous animals are preserved without any action on their part.

Now that we have shown the untenability of the bases of this theory, we need not go into its consequences in detail. When it is said that the basic particles were fully developed by their impulse to act, that the action of the will in the body leaves behind it an hereditary disposition, and that the animal organisation is embodied volition, we can only say that these statements postulate the Lamarckian principle which we have rejected.

We conclude, therefore, that the value of natural selection consists in its enabling us to form a unified and mechanical view of the world. In order to appreciate this fully, we will now go on to consider the nature and the significance of mechanism. 


\section{CHAPTER XI}

THE MECHANICAL SYSTEM AND ITS LIMITS

An attempt to refute the theory of evolution. Establishment of theories and investigation of details. Causes and effects. Infinity of same. Impotence of science. Infinite variety in the products of organs. The infinite diversity of the universe. Purpose. Mechanical and teleological causes. There is no end in the development of animals. Sexual selection, orthogenesis, and germinal selection are teleological. Purification of the theory of selection from teleological elements. There are no higher and lower animals. A high grade of organisation gives no more advantage to an animal than a lower. Natural selection is not an absolute principle of betterment. The scientific method of research. Infinite diversity of the universe. Comprehension of same by concepts. Abstraction of the universal. What a natural law is. Ultimate constituents of bodies. Comprehension of the world by ultimate elements. Mathematics. An ether without properties enables us to grasp the world. Does ether exist? Are psychic processes to be conceived corporeally? The methods of psychology. Consciousness. The world and the soul are only to be conceived as contents of consciousness. Transition from science to theory of knowledge.

As we have in the previous chapter refuted the objections to the theory of selection, we may now state our position in the following theses:

The present living inhabitants of our planet have been gradually developed from the simplest forms in the course of long terrestrial epochs. The latter themselves have been developed from inorganic matter.

The evolution was and is the work of natural selection, a principle that rests on the general laws of nature, and 
so enables us to understand organisms on a mechanical basis.

We have already observed several times that there is no longer any serious objection urged against our first thesis, or against the general theory of evolution. It is true that objections continue to be raised by a few men of science. A book appeared recently in Germany that spoke of "the break-up of the theory of evolution." But the gist of the work was merely that we cannot establish with certainty the descent of the various classes of animals. The objection overlooks the fact that the theory of selection has done enough as a scientific theory when it shows in a general way the reasons why we must suppose one species to have been evolved from another; of this we have plenty of instances. The fact that we cannot for the moment determine the stages of development of the various classes makes no difference to the general theory; in fact, even if it were true that we could not reconstruct, even in broad outline, the genealogical tree of an animal group, this would not in the least affect the truth of the theory of selection. The detailed efforts to construct the genealogical trees of the animals lie outside its province; they are not scientific at all in the same sense. They come within the range of a totally different science-history. We shall see this better if we consider the historical side of the theory of evolution.

Objections of this kind, therefore, do not injure the theory of selection or of evolution; they merely show that in many cases it is difficult, if not impossible, to trace the ancestry of an animal. But no reasonable 
man of science has denied this. The transformation of one species into another can only be established with certainty in a few cases-such as that of the PortoSanto rabbit. That is natural enough, as this transformation lasts far too long and is far too gradual to come under human observation. We may, therefore, readily grant that we cannot establish the selective value of variations in particular cases. We cannot do this solely because we do not know what is of value in the life of the animal. And if that is impossible with living animals the conditions of whose life are known to us, how can we be expected to show the selective value of variations in animals that have evolved to their present forms in earlier ages. We do not know the accidentsthe isolations-that determined selection to modify them in a particular direction, and so cannot know what has selective value for this particular direction. All that we can say is that a variation will have selective value if it favourably influences the strength of the particular animal, as that will lead to an increased multiplication which must be gradually prepared. It is clear, at all events, that there must be a large number of small variations with selective value, and that it is incorrect to say that there are hardly any variations with selective value.

The action of natural selection cannot be directly observed in nature, we must admit. But this admission does not cover a defect of the theory of selection. There are many theories the truth of which cannot be established by direct observation. It is said that light is due to the vibration of the minute particles 
that fill the universe. But has anyone ever seen this vibrating ether? It is the same with the theories that explain the nature of electricity and magnetism. The value of scientific theories is not that they can be verified by direct observation, but that they bring all the material under one point of view, and so make it intelligible. Natural selection prevails wherever there is life.

Can science make the whole world intelligible to us, then?

When a man of science seeks to explain a phenomenon he looks for the cause of it. When he has discovered this cause his task is not over; the question then arises, what was the cause of this cause? Even when this is settled the work is not ended. Every cause is at the same time the effect of another cause. We never reach an ultimate cause that is cause only and not effect, because the chain of cause and effect, the various links of which are the phenomena of the universe, is infinite.

We have, for instance, discovered the cause of the erosion of the sea-coast in many places to be the waves of the sea, the cause of these to be the liftingup of the surface of the water, and the cause of this again to be the attraction of the sun and moon. Science presses onward, and brings more and more links of the chain of causes out of the depths of the perplexing ocean of events. Will the whole chain ever be brought to light? No, that can never be. 
It is the very nature of the infinite that we can set no limit to it, before or after.

We may go further. The distance from the earth to the sun is very considerable, but it can be expressed by a definite figure, and so is finite. When the sun is at its zenith and we stand on a chair, we are really a little nearer to it, but may say that the difference is insignificant in view of the colossal distance. However, the cosmic chain of causes is really infinite. No matter how many causes we determine, we do not come a single step nearer to infinity. Hence the results of scientific research are, in comparison with the reality, not only very slight, but almost nothing, and will ever remain so.

When we inquire into the nature of the matter that composes the whole world we are face to face with infinity once more. However much we subdivide bodies we always come to other bodies, and never to anything that gives us an insight into their essence. That is easily understood, as it is the property of every body to be divisible; hence the smallest particles must always be bodies and nothing else.

Hence bodies are divisible to infinity. And in this process we encounter a second infinity. No part of a body is like another, so that when we break up matter, we discover an infinite diversity of its particles. It may be said that that is not true; that when we analyse matter we come to the elements, some seventy in number, of which all matter is composed. 
Thus the ultimate particles of bodies would not be infinitely varied. But who can tell us that these ultimate elements, the atoms, do not differ from each other? No one has ever seen an atom. We know, at all events, that when we break up an element such as gold we do not produce absolutely identical particles; they always differ in contour, in size, or other characters, as we see clearly when we examine them carefully, if possible with a microscope. It is true that they have much in common, but they are not therefore equal. If it is said that their differences are so slight that we may overlook them, the statement is arbitrary, and not based on the nature of things. It is not at all evident in nature that the general is more important than the individual.

When we see a couple of horses at a distance they often seem to be alike, but we find on going nearer that they are different. It is certain that the particles of the elements differ more from each other than our feeble eyes can detect. Finally, for all we know it may be that if we pushed our analysis far enough we should come to elements with nothing in common.

The third infinity is the diversity of phenomena and bodies that meets our eyes. A science that would investigate the world cannot master its material; the infinitely numerous and varied bodies and processes cannot be described in detail, much less investigated.

Must we then fold our arms? Can we never grasp reality as it is.

No. No human mind can grasp the world as it is. 
It must first make it intelligible-must transform it. Then it may succeed in grasping the world.

Mechanism endeavours to understand the world, and has succeeded to a certain extent. But before we inquire how it solves the riddle of the universe, we must first make clear the unity of the world, even in relation to organisms, which it implies. We have, therefore, to exclude entirely from the organic world the nonmechanical theory.

We saw something in the previous chapter of theories that deny the identity of living with lifeless matter. We rejected these theories. Now we will deal with the common ground-work of them all.

They hold that the chief characteristic of living substance is its aiming at an end. They think that there is latent in every ovum a force that comes into play in the development of the ovum, and controls the evolution so as to attain the end-the fully-formed organism. In the same way, they say, there was a force in living matter from the start that aimed at advancement, and has continually realised its end-the creation of higher formsuntil it produced man as the crown of its work.

We give the name of teleology to the view that the evolution of living things was controlled by a plan or end.

There is, of course, causality in the teleological system. But it differs from that we have already considered. In ordinary causality the cause thrusts the effect from it, as it were; causes and effects follow each other eternally, 
without there being any aim that influences the whole series. What often seems to us to be the goal or end of the series is only a link in it, followed uninterruptedly by other links. Thus, for instance, the construction of a living thing from the ovum is not a halting-place in the series of causes; they continue their endless course beyond it.

But in teleological causality there is such a thing as an end or purpose. It is true that here also cause and effect follow necessarily on each other, but the end has the power of attracting causes and effects to itself so that they do not run beyond but realise it. According to the teleological view the construction of an organism is the end which the whole embryonic development is aiming to realise. The end, as it were, observes and controls the series of causes, and is realised in the ultimate effect. The very first causes were controlled by a fact that was still in the future. The ordinary causes, which we have discussed, can only produce an effect when they themselves have already been brought into existence as an effect. Teleological causes or ends act before they are themselves realised.

We rejected in the previous chapter the notion that organisms aim at the realisation of ends. Seeking an end would be the greatest conceivable form of purposiveness. But the rudimentary organs, the erratic instincts, and the many imperfections in nature prove that the evolution of animals is not wholly controlled by purposiveness. Moreover, how is it that an end is merely sought in some animals and realised in others? We 
may recall, for instance, the vascular system of the amphibians and birds; the former have clearly a much more ingeniously constructed heart than the latter.

In the individual development of an animal, where there seems to be an end, the processes are regulated by natural selection, a mechanical principle. The germ cells give rise to others in unbroken succession and also the bodies surrounding them, which are continually dissolved again into inorganic matter. Thus the causal series of the living matter continually sends out side-branches, as it were. The main trunk endures uninterruptedly as life; the effects of the side-branches lead into the inorganic world and continue indefinitely there as lifeless processes.

If the construction of a living thing were the aim of the germ cells, impelling them to realise it by their development, how is it that it so often fails? Why are there mis-births? Why, above all, is the "end" no longer fully attained when natural selection has ceased to act? Surely the degenerations effected in panmixis show clearly enough that the ontogenesis is not aiming at an immutable purpose. If natural selection ceases, the harmony of development is always, though gradually, disturbed, and some misshapen object formed. Civilised man is always inferior in strength, hearing, and sight to his ancestors and his savage fellows. How is it that the end has suddenly lost its force in his case?

It is clear, therefore, from panmixis that there is no end controlling the development of animals with a view to its own realisation. Such an end would not be 
dependent on natural selection, a principle that it really excludes. The development of civilised man is becoming less and less purposive; the fact that men are not yet more short-sighted and weaker is because panmixis has not yet lasted long enough to bring about conspicuous degenerations, and because natural selection has not entirelyabandoned man even in regard to his bodily frame, as in the majority of cases excessive weakness or shortsightedness prevents a man from earning his living and so from reproducing. The majority are always contributing new blood to the "higher orders," and this improves the corporeal debility that distinguishes the latter on account of their condition and occupations.

Science, especially, has no need of teleology, because it cannot regard as facts causes that act before they are themselves realised. According to the teleological view the evolution of the actual organisms must aim at a remote end, and this end must accomplish their transformations. If that were so we should have to give up all idea of a scientific investigation of the organic world. We could not study this end, as the future does not exist, and so we can never determine in what way the end regulates the modifications of animals; we cannot detect their real causes.

For these reasons we must reject the teleological causes that are supposed to influence the beginning from the end, these "final causes" as they are called in opposition to the "efficient causes," which proceed gradually onward. We can safely do this, because the principle of selection enables us to give a purely 
mechanical explanation of the evolution of living hings.

We know that the theory of selection is a mechanical principle. Just as the pebbles are rolled about in the stream, the smaller ones going farther and the larger remaining behind, so we find the action of natural selection. Chance-or causes and effects that are unknown to us, but which we know to be of a mechanical nature - determines whether the whole species is to be transformed or whether it divides.

The principle of selection itself has been generally recognised as mechanical. But this has been denied of its two postulates. It has been said that the variations are not universal, or do not diverge in all directions, but only in a few. If the variations were universal why could we not produce, for instance, a cock's spur on a pigeon by selection?

We need not delay with this difficulty, as we settled it in dealing with the mutation-theory in the previous chapter. We cannot breed a spur on the pigeon because we do not know what varieties of pigeons to select for the purpose. That the occurrence of variations is not the same in every species is clear from the fact that many animals of very different classes have assumed the same form. I need only mention the parasitism of the spiders, crabs, and worms. ${ }^{1}$

1 If we wish to form a scientific and harmonious conception of the world, we can only use mechanical principles in explaining it. Mechanical natural selection can do nothing without postulating variations. Hence if we wish to explain the organic world mechani- 


\section{Against heredity the objection has been raised that} ordinary variations were not preserved, and that it was cally, the variations must depend absolutely on mechanical grounds. If it is assumed that the variations only follow definite directions and are restricted-if, in other words, there are limits in the organisation of animals that prevent the variations from passing a certain measurethey are no longer mechanical; in that case there is a force in organisms that avoids unserviceable and aimless changes-a purposive, teleological force. Variations do not then depend on chance-which alone would be mechanical-but are directed according to definite internal principles.

Thus we see that variations cease to be mechanical as soon as they are assumed to be definitely directed and limited. Natural selection is then no longer a mechanical principle, and a unified conception of the world is impossible. As soon as a Mechanist recognises variations of that kind he abandons the possibility of a harmonious system, and is no longer a Mechanist. It is just the same if he recognises other principles that can be shown to be teleological, as we shall show presently of sexual selection and the Lamarckian principle. If he would remain a Mechanist he must abandon them in this case. That is mere logic and consistency. But even if one holds the mechanical system to be impossible and unattainable, these theories are none the less useless, if they are teleological. He considers the development of living things to be due to a purposive internal force, and so must regard natural selection, the Lamarckian principle, etc., as merely subsidiary. These theories have real value only for a Mechanist, and they must, therefore, be mechanical.

It is said that if there are no limits fixed in the nature of the animals, natural selection would be able to equip the horse with wings and create all the fantastic forms of our legends and fairy tales. How do we know that it cannot? Is the legendary dragon more wonderful than the ichthyosaurus or the plesiosaurus? Does it not show an unlimited capacity when a sort of tape-worm is developed from a spider, and a being that scarcely looks like an animal out of a crab? The point is worthless on other grounds. The transformations of the animal world are due to the fact that those survive which are most in harmony with their conditions at the time. Hence when it is said that certain animals ought to have arisen, one must have had some knowledge of the conditions of life of the evolving speci $s$ at the time. But we do not know them-in the case of the horse, for instance. Horses with wings would only be developed if the conditions of the horse were such that the best leapers survived (compare the or gin of the insects). But that can hardly have been the case. 
not the adaptations, but the indifferent characters, that were retained in the species. We have already settled these difficulties.

Hence natural selection with its two postulates is a purely mechanical principle that has never been unsettled by any solid objections. And as we have concluded that it alone accounts for the evolution of living things, we can answer "yes" to the question whether the organic world can be conceived in a purely mechanical sense and whether it can form part of a unified cosmic system. At the same time we admit that it is not yet possible to give a satisfactory explanation of the vital phenomena.

However, it is only pure natural selection that serves to explain the organic world. All the auxiliary theories are teleological.

This is true in the first place of sexual selection, or at least of the second category of sexual selection-choice on the part of the female. In this instance we should have an end acting before it is realised. When a musical apparatus was developed in the cricket, for instance, we may very well ask how the females came to be attracted by this particular sound at its first occurrence, while they take to flight at all other sounds? Even if it is said that curiosity drew them to the new sound, it has not yet been explained how it is that the females yield more readily to the fiddling crickets than to their silent fellows. In every case we have to assume that the chirping sound pleased the females. The same must be done when it is sought to explain any of the other masculine characteristics. The females must have 
some sense for them before they are developed, if they are to be recognised at once and selected; and they must be equally sensitive to any increase in the characters. Hence the male characteristics act before they exist; in other words, sexual selection even in its simplest form is teleological. ${ }^{1}$

The Lamarckian principle, also orthogenesis, rest on teleological foundations. The statement that certain organs have attained their higher development by inheriting the effects of exercise supposes that the organism in question acts consciously, and that there is a special disposition in the animal's body. And when explanations are offered us such as that pressure causes the skin to become thicker in some animals and thinner in others, that is to credit the organism in question with a purposive adaptability and regulate this so as to attain the end that is to be explained. The Lamarckian principle postulates a force in animals, in each case, that strives to attain an end, and exercise and other agencies merely help it to attain it.

The third auxiliary theory to natural selection, germinal selection, may also be described as a teleological principle. In the first place this hypothesis supposes that the germ has a purposive faculty of selfcorrection, controlling the advancing and retreating movements of the determinants in most cases. But purposive forces within a determinant must above all things prevent too unequal a nourishment of the various

${ }^{1}$ We have already shown on p. 82 that female choice seeks to attain an end. 
biogens that compose the determinant. Irregularity in the nourishment of the biogens of a determinant would alter their quality. But why does the unequal growth of the biogens, owing to irregularities of nutrition, never disturb the harmony in the determinant, as is the case with panmixis? In fact, the harmony of the parts should be far more profoundly disturbed in the determinants than in degenerating organs. In the latter case the controlling influence of natural selection never entirely ceases, while irregularities in the food-supply of the determinants can never be controlled by natural selection, as they only give occasion to selection to come into play when they give rise to variations: in other words, they always precede selection. Hence when we see, for instance, that the determinants of a bird's feather are almost never modified in such a way as to produce scales or other malformations instead of a feather, we must assume that there is $1 \mathrm{a}$ purposive force in the determinants also that ensures the harmony of the biogens.

But our task is not completed when we reject the teleological auxiliary theories from natural selection in order to have a purely mechanical principle. Teleological phrases and terms are only too easily slipped into the theory of selection itself. In fact, we ourselves have not been quite exact in our expressions in the nine preceding chapters. We had to do this so as not to confuse the reader by using unfamiliar phrases. The teleological always comes more naturally to us than 
the mechanical, as we are accustomed to looking for ends and purposes. But as we have given only mechanical processes in the character of facts, we need now merely rectify our form of expression.

In the first place we must give up the term "purposive." There can be no question of "purposes" in a scientific investigation. We can only speak of a structure in an organism as purposive in the sense that the animal has the faculty of self-preservation in its momentary circumstances.

We must also be careful in using the word "evolution." When we speak of the evolution of the animal world, the thought involuntarily forces itself on us that they have advanced from lower to higher forms. But we have no right to speak of "lower" or "higher" forms. We should in that case have to suppose that there was from the first a principle in the living substance that gradually creates the higher forms, and we have rejected that view. By higher and lower animals we can only mean more complex and simpler.

Natural selection is not a principle of progress, always creating higher animals. Selection merely seeks to adapt organisms better to their environment. But greater complexity of organisation has no relation to good adaptation. We pointed out previously that man is not better adapted than the bacillus. From the point of view of the birds man must be a very imperfect being.

If greater intricacy of structure were the same thing as better adaptation, natural selection would gradually 
have to give all animals a complex organisation, since it always seeks the better adaptation of all animals. But we still have protozoa living in a drop of water. In fact, many highly organised animals have become extinct, while their more simply constructed relatives have survived.

There may be occasions in which the more complex organisms are at a disadvantage in comparison with the simpler. Natural selection will then modify organisms in the direction of greater simplicity. In our view of the development of the earth there will really be such a time one day. The water on our planet is constantly decreasing, and the time will come when there will not be sufficient left to support human life, when the bones of the last man will bleach in the unclouded glare of the sun. But in the last drops that will linger in holes in the vast desert of the earth there will certainly still be infusoria. After a time even these creatures will not find water enough; they will perish, and only simpler organisms still will be maintained, until at last all living matter has returned to its mother and changes into lifeless mineral once more.

The fact that there are to-day animals at such different stages of organisation is due, as we now know, to special accidents that isolated certain animals. Even the step that seems greatest to us, the formation of multicellular organisms, must have taken place at a particular locality - whether it was that certain protozoa reached running water and so the connected ones were less easily washed away, or that they reached a pond 
that was poor in oxygen and could only make a sufficient use of the oxygen by sticking together. The imagination has a wide field in these problems, but we cannot say whether the construction of multicellulars only took place once or on several occasions.

As natural selection is not a force that of itself creates more complex organisms, so it is not an absolute principle of progress. It is scientifically illogical to say that animals are "improved" by natural selection. "Good" and "bad" are antithetic and dualistic terms that have no place in a unified conception of the world. The word "improve" would only have a meaning if we recognised any value in the nature of animals. But that is entirely wrong. The man of science has only to determine the processes of the world and discover their causes. For him there are only changes in the world. There can only be an "improvement" if we recognise an end, the good. Mechanism has nothing to do with ends.

Even if we could recognise value in the nature of animals, we could never say whether certain changes that we observe in animals are improvements or no. Selection adapts animals to their environment at the moment, and we do not know if these will not change, in which case the opposite modifications will have to be selected. For instance, if the animals with the thickest coats survive in a very cold climate, we cannot say that the selection of the thick coat is an improvement for the animals. If that were so the cold would have to remain unchanged, whereas the climate may become 
warm again. If it does the animals with the thinnest coats will be in the best position.

When we reflect on the past history of animals and find that a long time ago thick-coated animals were selected because the cold persisted, we cannot even then speak of an improvement. We have not to consider the chains of cause and effect in relation to what they eventually lead to, as that would be teleological. We have to look on each change only as the effect of a past cause. When we are studying the past, we must leave the present out of account. It would be unscientific to predict the persistence of the cold.

We have now purified the theory of selection of all teleological elements and prepared it for incorporation in Mechanism. We may now return to the question from which we started, and ask if Mechanism gives us a satisfactory explanation of the world and how it does so. We have to examine its method, and as this is at the same time the method of all natural science - in its higher forms-we shall learn to appreciate scientific method generally.

We have already seen that it is the infinity of the world that prevents the human mind from comprehending it. We will now go more fully into the point.

When the man of science approaches the object of his investigation, the world, he feels himself surrounded by a bewildering wealth of forms that he can never compass. The corporeal world is infinite in its variety and inexhaustible. No one thing is like another; everything 
represents an object that can never be entirely replaced by another. Quite apart from the incalculable distance of the stars, one cannot even count in detail the bodies contained within a limited space. No stone is quite like any other, no tree like another, no leaf, indeed, exactly like another. It is, therefore, quite impossible to describe every single thing in the world.

But even when we abandon the idea of grasping the whole universe, and turn to the study of a small part of it, we encounter insuperable difficulties. Every part of the world, no matter how small, has so many differences latent in it that they cannot be counted. The more thoroughly we study a single body the more vast do we find the number of differences in it. If we continue to analyse a body, we bring to light at each analysis new things that were unknown to us. And as each surface has its colour, and this always differs, we can never exhaust the shades of colour of even the smallest surface.

This enormous diversity in nature not only prevents science from comprehending the world, but no human being could orientate himself in the world if language did not come to his assistance. Language enables the human mind to take in a large number of details by imposing the same name on them all. The whole infinitely varied population of the earth, differing in each individual, can be grasped by the term "man"; so those predatory animals of the forest, not one of which is quite like another, by the term "wolf." We gather together all the objects in inorganic nature by means of 
names, just as we take certain metals of which there are only pieces that differ in size, shape, contour, and colour, under the name "iron."

How is this comprehension of individually different bodies possible? By regarding only that which objects have in common and overlooking the individual features. When, for instance, we give the name "gold" to a large number of objects, we look merely to the common brilliance, the colour, and the weight, and do not take account of the difference of the pieces of gold in size, angles, surfaces, etc.

Science continues the work of language, as it were. It brings together a number of bodies by regarding merely what they have in common. In this way it creates scientific concepts. A certain number of the countless particular things in the world, which have certain common features, are "conceived." But science has something further to do. It must give definite formulæ to its concepts, so that we may know what is the common element in the particulars that the concept embodies. That is done by a number of propositions or judgments. The scientific conception must always be capable of conversion into judgments. Judgments of this kind on the concept "diamond," for instance, would run : transparency, refraction, hardness, definite angles of the surfaces, etc.

A good deal is accomplished by these concepts. Large numbers of diverse things have been made comprehensible. But the number of these concepts, in turn, is immense, and science would have done 
only half its work if it were content with these. There must be subordinating concepts, expressing the common element in a certain number of concepts. Thus gold, silver, iron, and other minerals are grouped together as "metals." As science extends its range, and looks to the common element in the subordinating concepts themselves, it seeks at last to pursue its method to a point where it is impossible for direct observations to determine the common features. Thus we not only conceive the seventy elements to consist of homogeneous atoms, but also that these seventy different kinds of atoms are at bottom composed of the same particles, or primitive atoms [such as electrons]. The diversity in the structure of the elements is due to a difference in the grouping of these in the atom of the element. Hence the ultimate particles make up the whole material world. They are the common element in all matter.

Not only the bodies, but also the phenomena, in nature are infinitely varied. When we speak of "storms," we are grouping together a large number of different phenomena, with respect to the common feature in them. Phenomena also are grasped by science through general concepts, which express the common element in them.

However, these concepts require something further. They must be free from space and time, if they are really to embody all that has happened, is happening, or will happen, in the world. They must have a universal application, because it is only then that they 
can express an infinite number of phenomena, and it is precisely infinity that has to be overcome by the formation of concepts. We can, of course, only form our concepts in a limited number of instances, but we must make them capable of expressing all phenomena of the kind; they must apply universally. To the concepts which take the form of judgments and apply to certain phenomena of all time we give the name of natural lawes. A natural law embraces an infinite variety of particular processes, and embodies what it is important for us to know in them.

Just as a large number of concepts of things are arranged under one comprehensive object-concept, so we find in the case of law-concepts, or natural laws. In the end science comes to formulate one ultimate law, which embraces all the phenomena of all time. The other laws are only special cases of this law.

Thus the final outcome of science is the formulation of an ultimate object-concept, which is common to all bodies, and an ultimate natural law, that embraces all phenomena. When that is accomplished, the infinite diversity of the world is overcome. We have then no longer to grasp endless series of causes and effects; we merely conceive the one law that dominates the whole series. Our mind no longer needs to arrange in itself the incalculable number of different bodies and occurrences-a task it could never accomplish; it has now to deal with one body and one phenomenon. Thus the infinity of the world is mastered. We can now make all the bodies in the universe intelligible at any time by means of a certain 
combination of ultimate things; in other words, we can express all bodies in arithmetic formulæ. Numbers are always comprehensible; they have no particular features in themselves, and so lack the diversity of forms that is found in reality. We know, especially, that we can count in a series as long as we like, and we will never come to anything essentially new. Like bodies, we can also represent all phenomena by certain arithmetic formulations of the one law, which is all we have to grasp.

But this comprehension of the world will only be possible if the "ultimate things" are fundamentally distinct from the bodies that we know. All the objects known to us change. Each of these changes passes through an incalculable number of stages, and the ultimate things, which must be calculable, cannot be changeable. They must not be transitory. They must also be indivisible, as all division is change. Finally, they must be exactly alike in size and quality. Each ultimate thing must be capable of being replaced by another without the least change taking place; otherwise they cannot be used in mathematical formulæ.

Mechanism endeavours to realise this ideal of knowledge. There is only one thing that is common to all others and enters into the composition of all that begins to exist-ether. There is only one law that embraces all phenomena - the movements of ether. Ether is a space-filling but imponderable medium, consisting of minute particles, which are simple, immutable, indivisible and homogeneous. All the phenomena in the 
world, electricity, light, and the rest, are special forms of ether-movement; even matter is to be regarded as an ether-movement, since the ultimate particles that make up all bodies are centres of condensation in the ether. It is the task of science, therefore, to determine the various categories of ether-movement, and to express light, electricity, and even matter in mathematical formulæ.

Will it ever be possible to analyse bodies so finely as to bring the ether-particles to light? No. Apart from the fact that every portion of a body must be itself a body, not incorporeal ether, the latter entity has no features of reality. In the reality that surrounds us there are only divisible and transitory things, of which no one absolutely resembles another. Each body, however small, has its individuality; this becomes all the clearer the more thoroughly we study it. Thus the apparently similar grains of sand betray their individual differences under the microscope. But the etherparticles cannot have individual characteristics, and so they are quite unimaginable. The world speaks to us through all our senses with its infinite characteristics, ${ }^{1}$ and we cannot picture to ourselves bodies without properties, such as the ether-particles must be.

${ }_{1}^{1}$ Thus the ether-particles explain phenomena and matter. But the ultimate elements of matter also, the primitive atoms, are something unreal, because they must be absolutely identical, and because no further body can be produced by subdividing them. In fact, the atoms themselves cannot have individuality. But we know that there cannot be anything that is not individual, and that no body is absolutely identical with another. We must, therefore, regard even the atoms only as a device of knowledge. We see here the value of such a contrivance. Chemistry has made marvellous achievements precisely through its atomic theory. 
They are in contradiction with the reality that we know.

It has been said that when we exhaust the air under a glass-bell and the light remains in it, we see the vibrating ether. But it has been rightly answered that even then we do not see ether, but light alone.

There is no ether, because there is nothing in the world without properties. Ether can never be the object of research; it is only a means of understanding the world.

We come to the following important conclusion. Natural science does not represent reality to us as it is. Reality, as it reveals itself in the world, is absolutely incomprehensible to any science or any human being, because it is infinite. Science cannot deal with it as it is ; it has to transform and simplify it. It does that at the very outset of its work. Its first concepts do not picture reality, but apply to it ; this is done by leaving out of account a part of what distinguishes reality-the individuality of each particular thing. As this work of transforming to render intelligible proceeds, and more of the individual characters fall out in the higher concepts, science departs further and further from the visible reality. Its ultimate concept, which has to embrace all, and so must have nothing individual about it, can have nothing in common with reality. It is not a reality, but an indispensably necessary means for grasping the whole world.

Natural science is occupied with bodies, and forms 
its concepts on these, so that they exclude anything incorporeal. Hence it has nothing to do with psychic phenomena. These can never be understood from the observation of bodies and their processes, because the corporeal can never explain anything but the corporeal. Science can never tell us how the simplest sensation comes about. Even if we had an exact knowledge of the mechanism of the brain, even if we knew all the movements of the atoms in feelings of desire and pain, we should only be witnessing the movements and shocks of bodies. It is true that the sensations are connected with these, but they tell us nothing about the origin and nature of the sensations. Being incorporeal, the sensations lie beyond our range of observation.

The psychic processes are dealt with by psychology. This science, again, is confronted with an infinite variety. No one can dream of picturing to himself all his pains and pleasures, his ideas and judgments. Each psychic process occupies a certain time, and so passes through an incalculable number of stages.

In order to master this diversity, psychology forms concepts in relation to the universal in the particular psychic processes. It endeavours to find the elements, or the simplest constituents, of the psychic life, of which we must conceive all the psychic phenomena to be composed. "Sensations" have been advanced as these elements, and it is said that the will and the ideas, in fact, all the psychic processes, are made up of these elements. But experience knows nothing of "sensations" that may constitute such diverse processes as 
will and ideas. Hence in this sense the sensations are merely scientific devices, like the ether-particles of the physical scientist.

We saw that Mechanism has accomplished its task in making the world intelligible to us. Psychology makes a similiar effort to solve its problem, but, being a younger science it has not achieved nearly so much as physical science. We may now ask whether it is not possible to bring together the ultimate concepts of both these worlds, and so attain a perfectly unified and harmonious knowledge.

We have rejected the opinion of the materialists who hold the psychic processes to be the object of physical science. Can we say the reverse of this? Does not the corporeal world consist of psychic processes?

The reader who has never reflected on problems of this kind will think the very question is an absurd one. We are accustomed to regard the world about us as existing quite independently of us, But that is certainly not the case.

All our knowledge of the material world comes through our senses. But all that passes through our senses can only give us sensations. The various properties that make up the complete image of a body are merely so many sensations within ourselves. A piece of gold seems to be a body, but this body is made up of the sensations of yellow, hard, heavy, cold, etc. $^{1}$ It is the same with all bodies. Hence men in

${ }^{1}$ These sensations, of course, must not be confused with the psychic sensations that make up will and ideas in the sense described above. 
whom one sense is missing have a totally different idea of the world from ourselves. If the missing sense is restored to them by an operation, they can hardly recognise their world with it. A blind man whose sight has been restored cannot recognise the bodies about him until he has touched them.

Sensations give us information of the external world when they reach our consciousness. How often do we not look at our watch without noticing the position of the hands, or touch an object without perceiving its existence! When we are asleep the world has ceased to exist for us.

When other men tell me that the world continued to exist while I was asleep, their movements and voices create nothing in me but sensations, and of these I only know what reaches my consciousness. Even my own body is only known to me by processes of consciousness; when I am not conscious of it, it does not exist for me.

There is no sense, no reality, in the world that we can bring into opposition to consciousness. There is nothing that is not a content of consciousness. That is a truth that cannot be shaken; in fact, it seems to be the eternal immutable foundation of the clashing structures of theories about knowledge. All that we experience and live, all that we see and feel, consists of conscious processes.

Here we refer to ordinary, individual sensations, familiar to everyone under this name. We shall not go into the question whether there are conscious and unconscious sensations. When it is said that the sensations must reach our consciousness, we are merely following the usual form of speech. 
This is not the place to treat the question whether the processes of consciousness bring the external world before us as it really is, or whether this real corporeal world, the "thing in itself," is not something quite different from what we imagine; whether it does not merely set our conscious processes in motion without revealing itself. Or whether in the end conscious processes can only be evoked by other conscious processes; whether there is no external world corresponding to them, and its causes and effects only exist in our thoughts. These questions would lead us into endless controversies. We have only raised the point to see whether Mechanism can be reconciled with psychological science, or whether it dissolves in it.

That is not the case at all events. The material world is a process of consciousness, it is true, but so are the psychic phenomena. We may make it clear in the following way.

The material world can only be conceived as a content of consciousness. Consciousness is, as it were, the subject and bodies are the objects; that is to say, the bodies are the objects to be known and consciousness is the perceiver. But my consciousness perceives not only the bodies apart from my own body, but also this itself ; it may even become an object of knowledge itself. But that is not the whole function of the knowing subject. My whole psychic life with all its processes may become the object of the cognitive faculty of consciousness, otherwise there could be no psychology, which needs objects to investigate. Thus we see that 
consciousness encloses in itself not only the whole corporeal world, but also the whole life of the soul. This cognitive power is devoid of all personality. But we cannot suppose that the all-embracing, impersonal subject, which enfolds the whole of existence, appears in isolation; for us it is always connected with a part of the psychic life. In this sense one might call psychology a higher science than physical science. But the reason is merely that we cannot study the whole of the psychic life simultaneously, and make it the object of knowledge. However, we will not go any further into this difficult question.

We have seen that reality contains two separate provinces, the material world and the psychic life, nature and mind. Either province may become the material or the object of science, and the scientific method may be applied to either-the method that enables us to grasp the enormous diversity of objects by grouping many of them together with respect to their common features. As the two sciences proceed to form more and more comprehensive concepts in this way, each of them comes at length to the ultimate and all-embracing conceptether for the material world and psychic sensations for the spiritual world. In this way physical science and psychology put the keystone on their respective structures, and have then to elaborate and develop their systems in detail. To throw light on and reconcile the two ultimate concepts is the task of a new science, which has to bring reality into unity without taking into account the antithesis of body 
and soul. It is consciousness that encloses in itself all existence, the material and the spiritual world, since both provinces can only be conceived as processes or states of consciousness. In consciousness we have a unity and a truly "monistic" stand-point. But consciousness, the all-perceiving subject, can never become the object of an empirical science. When we wish to study it, we have to leave aside the scientific method and turn to philosophy. This is the last and the highest science. It is the foundation on which every theory that aims at comprehending reality must rest. It is the undying merit of Immanuel Kant to have shown us the way to it. 


\section{CHAPTER XII}

\section{NATURE, HISTORY, AND ETHICS}

Truth of scientific ideas. Why the universal seems to us more essential than the individual. The ideas of animals. Why we take ideas for realities. Thinking reality into ideas. Is there a real world, lying behind the phenomenal world? Natural science itself is a human product and pursues an aim. It must not regard itself as the only sound branch of science. The historical sciences. Their method. The historical elements in natural science. The laws justify historical research. The science of evolution rests on probabilities. The origin of the human mind. Had consciousness a beginning? There never were absolutely simple bodies. History and sociology. Origin and development of primitive man. Origin of good and evil. Origin of conscience. Advance of civilisation by tradition. Language. Conflict of nations. Scientific ethics. Restricted and inverted selection in civilisation. The evils of war and militarism. Nietzsche's egoism. Darwinian ideas of the social future. Insipidity of the Darwinian ideal. Social man according to Nietzsche. Natural science knows no idea of duty. It knows nothing of values, and can therefore frame no ethic. Preservation of existence is not preservation of value. Is there a sense of life? Monism. Presuppositions of science. The idea of duty is the beginning of all knowledge. Conclusion.

THE world is infinite and immeasurable, and no science will ever be in a position to describe it. Science would not yet have accomplished anything if its work had merely consisted in describing or picturing the world. It could only attain to a knowledge of the world by transforming reality and simplifying it so as to make it 
intelligible to the human mind. But it follows from our theses that reality is infinitely varied on the one hand, and that scientific theory stands higher in proportion to its simplicity on the other, or that scientific theory is the more perfect the less reality it reflects in its concepts.

This statement in no way diminishes the importance and objectivity of science. Although the scientific concepts are not pictures of reality they are very closely related to it. There cannot be any unscientific arbitrariness in science because its concepts are universally valid. They are unconditionally true, not because they depict reality but because they apply to it.

How is it, then, that it is not obvious to everyone that ideas do not correspond to individuals? How is it that so many people think there is some reality corresponding to the idea "wolf," whereas the idea has only been found by the mind transforming the reality in order to grasp it?

It is because, in the first place, man's senses have only a limited power of discrimination. Widely differing objects often seem to us to be alike; even on closer examination we often see only their common features, and do not see their individuality until we look carefully for it. Many bodies, such as grains of sand, seem alike to us however closely we examine them; it takes a lens or a microscope to show that not one of them is absolutely similar to another. But that our senses perceive common features first and foremost, and that our intelligence always recognises first the common features of the objects about us, is clearly a faculty that 
we owe to natural selection. How could we orientate ourselves in the world if every single object about us were something peculiar and had its special name? We should have to describe and count so much that we could never make ourselves known to another; he would, in fact, never have a clear idea of the body we were speaking of, unless we could bring before him a number of bodies which are familiar to him in their common features. There would be no language if there were no general terms.

We must assume that the nerve-centre that receives a sense-impression was so constituted from the first, even in the animals, as to perceive especially the common features. The fox must have general ideas of "hare" and "man," in order to know which to pursue and which to flee. If all things appeared to him to be unlike each other, everything he met would be something new, and he would not know how to act in relation to it.

The simpler the life of an animal is, the less advanced are its senses and the more comprehensive its concepts. For the frog there are only "stationary" and " moving" things, and of the latter only "large" and "small." The former it avoids, the latter it pounces on.

The development of an animal's senses is always in proportion to its habits of life. Hence there are animal senses that can detect the individual better than the corresponding sense in man. Take, for instance, the dog's sense of smell. As a general rule animals recognise individual realities better the more advanced their senses are. Man has created devices for improving 
his senses, optical instruments, which enable him to detect the special features even in the smallest bodies.

However, common features always come much more naturally to man's perception than special ones, because his senses are adapted to them. Thus it seems to him that the general features alone are essential, and physical science is thought to be the most natural of all sciences because it starts from the proper nature of the sense-impressions.

Hence in order that man may orientate himself in the world, numbers of things have to be brought together in virtue of their common features and provided with a common name. And as most things have not a very great interest individually, because this is not necessary for the purposes of human life, they generally have only generic and not proper or individual names. When we speak of the individual we have only the generic name - "wolf," for instance-and so this name or concept seems to us really to coincide with the individual in question.

But there are also things in the world that have an individual interest. They have generic names, but also proper names, and in this case it is clear that the concepts are not perfect images of the individuals. We see this especially in the case of man. If we try to express the individual "Shakespeare" by the idea "poet" or "man," we see at once that these ideas do not represent the great poet, and do not embody precisely those features that make Shakespeare Shakespeare. When we say "poet" instead of Shakespeare we are really doing just the same as when we say "wolf" of a 
particular wolf, or when we express a certain plant or a certain piece of gold by the corresponding concepts. There are also stones that have an individual interest, and here again it is clear that they are not fully expressed by their generic ideas. Take, for instance, the diamonds Orloff, Star of the South, or Kohinoor.

The concepts are not definite pictures, because they do not mirror reality; but we think this into them, and thus they appear to be pictures. When we speak of wolves, we always think involuntarily of a particular wolf. When we say "man," we think of a particular man-with a medium-sized, straight nose and other definite features, just as when we make sketches of the objects.

Thus the reality is always forcing its way into our narrower concepts, but it does this less in the case of those with wider range. It must be difficult to imagine a "vertebrate"-impossible, if one has never seen one. Try to form a mental picture of an "animal," without thinking of the features of the protozoa, worms, insects, birds, or other organisms.

Thus we see that the concepts are less definite and depart more from the reality the "better" or more comprehensive they are. The ultimate concepts, that embrace everything, cannot become mental pictures; there is nothing of reality in them.

It is true that when we think of "ether," we picture to ourselves tiny balls, pushing and attracting each other, and in a state of perpetual motion; such an idea enables us to grasp a mechanical process in the world. 
But we must never forget that when we do this we think something into ether that is really not in it. The ether-particles cannot be balls, otherwise they would differ in size and be divisible; they would, in fact, be bodies with the properties of bodies, and that is just what we must avoid. The ether-particles must have nothing individual about them, and therefore they are unimaginable, and have nothing in common with reality; they lie behind reality, and are metaphysical. Their movements also are unimaginable, as we can only picture to ourselves movements of bodies; we know no such thing as movements of incorporeal things.

But, it may be objected, is not reality only apparently individual? Is there not, behind the reality that we see, something that represents the true reality? And may not this be simple and non-individual? If that were so, it would be the task of science to pass from the apparent world which we see to the true homogeneous world beyond.

But such a statement has little value, since no one can prove it. On the contrary, it is highly improbable. The commencement and the advance of the scientific formation of concepts is-as no one will question-an artificial modification of reality. Only the individual exists, only that appears at a definite spot, is never repeated, and is gone for ever once it is destroyed. When the human mind brings together a number of these bodies, by looking only to their common features, it has no idea of picturing them altogether. How could 
it happen that after forming higher and higher concepts, depicting less and less of the things comprised, suddenly, when the whole thought-process was over, the "ultimate things" once more contained the complete reality? When man began and continued to form concepts, he regarded the world from which he started as the sole reality ; he by no means sought after a "metaphysical," true reality. It would be a piece of good fortune that we would have to put down to magic if at the conclusion of his process of thought the final result represented the true and differentand hitherto unimagined reality.

No, it is incredible. We must assume that science, which ever presses on, and must press on, towards greater simplicity, and so is always analysing bodies afresh without ever coming to an end, imagines the process of division to be complete. In that case we need not assume that in the continued disintegration of bodies we shall come at length to parts that are not bodies. We shall then see that the ether-particles were created by the human understanding, because it needed them in its effort to understand nature.

Physical science is described as empirical, and the designation is correct. But we must not on that account suppose that science never goes beyond the range of experience. It deals with probabilities as well as exact observations. When it deduces a "law" from a number of phenomena that it has observed, it assumes that this law will hold also for other phenomena of the same category; and this assumption in turn implies 
that there are general laws which apply universally and unconditionally. This, of course, can never be proved.

It is possible that new observations might be made that compel science to rearrange all its laws. However that may be, physical science is not absolute and unconditional, because it supposes that what is true in a thousand cases will not prove untrue in the next one. ${ }^{1}$

Thus science is influenced by considerations that do not arise of themselves from reality; it is also a product of the human mind, and endeavours to achieve its task of making reality intelligible. Hence physical science has no right to oppose other sciences which modify reality in order to attain their ends.

The concepts which are formed with regard to the universal alone cannot contain the particular. As the laws of physical science deal with what applies always and everywhere they cannot answer the question, what exists at a particular point of space, what happens in detail, and how that which exists came into being.

These questions are dealt with by the historical sciences-or history, in the widest sense of the word. Physical and historical science complete each other. Hence we find scientific elements in history and historical elements in science.

The historical elements increase in physical science in proportion as its ideas approach reality and depart

${ }^{1}$ The laws of science must not admit a single exception. In their case the law is not confirmed, but completely destroyed, by the exception. 
from individual things. There is absolutely no historical element in the idea of ether, because even if it represented something real it would be useless to raise any historical question about it. Every etherparticle must contain just the same as the others, and so it is absurd to seek the particular features of one of them.

However, even in scientific concepts which are very comprehensive, but not all-embracing, there are historical elements. The sciences that deal with these concepts start, in a sense, from a historical fact. Optics, for instance, treats of light. But if we have had some experience of light, we always think of the light we know in that way. If there were anyone who had never seen light, he could form absolutely no idea of its real nature, no matter how accurately he knew the figures and formulæ that represent the vibration of ether when it causes light. The further question arises, moreover, when and where light came into existence. Such questions cannot be settled by the methods of physical science.

We could show in greater detail how the historical elements in natural science increase in proportion as the various parts of the total science decrease in comprehensiveness. But we have not space to do this, and will be content to consider the sciences that deal with life.

The problem with which we are concerned, the origin of species, is of an historical character. It is a question of a process that once took place. Hence 
when we seek to determine this process of evolution in detail we have to use a different method from that of physical science. We must act on the historical method. In point of fact, we rely on documents, as the historian does. They share the character of all documents of being less valuable the more remote they are. ${ }^{1}$

It is not our purpose here to study the principles of the historical method. The historian is equally unable to represent the incalculable diversity of reality. $\mathrm{He}$ must select definite points. $\mathrm{He}$ will choose particular events - or, as every individual thing is itself too vast to comprehend - certain particular events.

${ }^{1}$ The objection is raised that Professor Haeckel has been endeavouring for some forty years, with very moderate success, to have the natural sciences called "historical" instead of merely "descriptive"; in other words, that it is the chief part of their task to tell us, not the actual nature of things, but how they became what they are. The reader who has followed me so far will see for himself the error of this objection. In the first place, ether can never be studied historically, because it had no origin. Anyone who'takes up a manual of physics or chemistry will see that in these it is nearly always a question of what the law is - what is valid independently of time-not what has come into being. There are, of course, historical questions in these sciences, but very rarely; their investigations are almost always purely scientific. On the other hand, zoology and botany use both methods. In my contrast of the two methods, I aim merely at a logical appreciation of them; I am not bringing into opposition sciences that differ according to their material. I merely say that all our sciences may employ both methods, but that one finds the one method more suitable, another the other method. The first method determines what holds good independently of all time, by discovering the common element in phenomena; the second determines what has taken place once, regarding, not the common but the individual features, and interpreting it according to the documents. The two methods are, therefore, of a precisely opposite character. 
The historian first chooses his theme. This is usually a fact or event that interests him and seems worth study. He then examines the antecedents of this event, and selects those that have a bearing on his subject. Thus a student who is writing a history of the preparatory period of the Reformation will not speak of fashions in dress or the price of food, but will confine himself to the points that have some relation to the Reformation. Again, the evolutionist who is studying the origin of the vertebrates will only describe those of the innumerable changes in the animal world that may be regarded as stages in the formation of the vertebrates. That is not an unscientific procedure-not teleology in the sense we described above. The historian neither forces the chain of causes towards his aim, nor fancies that they sought this end from the first; he merely studies only those meshes in the network of causes and effects that lie before the phenomenon whose origin he is investigating. This way of studying it arranges agencies in a straight line, and makes them seem to be aiming at a certain result.

The evidence for the evolution of animals differs from that we consult in human history. Most of it is of such a character that we have first to justify our action in regarding it as evidence. This justification is furnished by the laws of science. The law which says that organisms are constantly changing, and that every living thing descends from some other one, gives us the right to regard the remains of the different 
animals of earlier ages as the ancestors of living animals, and to determine the historical lines of development. The law which says that animals resemble each other in proportion to their bloodrelationship gives us the right to take their structure as evidence of their ancestral history. And there are still other laws.

However, these laws only justify historical investigation; they do not supply the place of it. They apply wherever there are organisms, and therefore they cannot discuss the particular process of the modification of a species. A law that has only held good in one particular case is an impossibility, because every law is formulated by regarding the common element in a number of phenomena. Hence the laws of science can never bridge over the interval between two distinct stages of organic evolution; indeed, one might be acquainted with all the laws that apply to organic evolution yet have no idea of the real course of this development.

The laws can never tell us, for instance, how birds were developed from reptiles. Again, if there were a law which said that in the rise of a nation there were always great men who led the people, we should not understand from this law alone why Luther in particular appeared at the Reformation, or Bismarck at the rise of modern Germany, and why these special individuals led the people.

It is in the very nature of the evidence for animal evolution to be grounded on greater or less probabilities. 
On that account we shall always find differences of opinion as to the value of the historical investigation into the transformations of animals. There are recent zoologists, for instance, who would confine their science to the establishment of laws, and would reject all "galleries of ancestors" as not affording any explanation.

But that is a one-sided and unjustifiable appreciation of science. Even probable transformations in the organic world are certainly very interesting. As long as man reflects on himself, he will long to know something of his earlier history. Every discovery will be welcomed that throws light on the obscure condition of primitive man.

In the nine preceding chapters we have made simultaneous use of scientific and historical methods of research.

We have, on the one hand, investigated the common features in the particular evolutions of living things, and thus formulated laws. The most comprehensive law that we discovered was that those organisms especially survive which are best adapted in their structure to their actual environment. ${ }^{1}$ This is the principle of selection. We found that it holds good wherever there are living things. We next tried to prove that other laws of evolution do not hold. We

Natural selection is a law because it presents the common element in all evolutions, and it applies wherever there are organisms; but it differs from other scientific laws in not definitely presenting the common element. It has to use the qualifying clauses "on the average," or "as a general rule." 
therefore concluded that it must be the sole agency that effects the modification of animals.

On the other hand we sought to determine the particular processes of animal evolution by means of historical inquiry. For this purpose we used such evidence as the structure of animals, fossil remains, and so on. We were given the right to do so in virtue of natural laws. In this way we succeeded in determining the period-if only approximately-and the locality in which a certain modification of animals must have taken place, and to some extent we were able to follow the course of this transformation.

The provinces of natural science and psychology are entirely distinct, as the one forms its concepts on phenomena that occupy space and the other does not, but the distinction does not hold in regard to historical investigation, Bodily and mental phenomena are in time, change, pass through stages, and are individual.

As we have adopted the view that man has animal ancestors, we must trace his mind also to them, though it is at least a lower stage of development in the animals. We saw in the second chapter that, as a matter of fact, man's mental processes are found in a more rudimentary form in the animal.

As we cannot admit that the mind is formed in any animal out of nothing, we must ascribe psychic phenomena to the protists. We must even go further. We have accepted the view that living things were developed from inorganic matter. Did psychic phenomena begin at once with the appearance of living substance? That 
is scarcely possible. Living matter, we believe, evolved from lifeless. But the psychic processes cannot have developed from it, because we know that bodies alone can be formed from bodies, never anything spiritual.

Thus we are forced to ascribe psychic phenomena even to inorganic matter. Why they are not recognisable in it, or why they are so different even in the lowest animals, it is impossible for us to say. They are subject to transformations which become so considerable in the course of long ages that something entirely new seems to have come into existence. That is all we can say.

But this process of transformation only applies to the psychic processes, not to consciousness. It is absurd to conceive consciousness as evolving from material things, and as having any beginning at all. We know that we cannot imagine anything either corporeal or spiritual, anything real at all, that is not a content of consciousness. Time and space exist only in consciousness. How, then, can consciousness, without which time cannot be conceived, have arisen in time? How can bodies and psychic phenomena, which always pre-suppose consciousness, have given birth to it?

It will be clear to every one who has properly conceived the world as existing in time and space only as a content of consciousness that the creative power cannot arise from the thing created, the subject from the object, the perceptive power from the thing perceived.

Consciousness cannot be imagined, because it is itself the imaginative force. Consciousness is the 
cognitive force, which creates the objects of its knowledge in the very act of perceiving them. Its knowledge is action. ${ }^{1}$

It is not our purpose to go into philosophical questions. We merely wish to point out the limits of the theory of evolution, and show that there is something that cannot be subjected to either scientific or historical investigation.

There is one more point that we must make clear. We were justified in accepting the view that the more complex animals have descended from the less complex. The multicellular have been evolved from the unicellular, these from unnucleated animals, and these in turn from inorganic matter. But we must not forget that even the simplest organisms possess an infinite diversity, and that each of them has its individuality, which can never be completely replaced

${ }^{1}$ The reader who has never reflected on these questions will do well to think of himself. What do $I$ know of the world? What is absolutely real and certain about it ? It is absolutely certain that there are sensations in me, but that is all. The world, my fellows, and all they tell me, are so many sensations in me. It might all be a dream! I know for certain only that something is taking place, that I have sensations. I can imagine that I am dreaming of the world, my life, and my fellows. This figure should be most helpful to conceive the matter.

My own body and my whole psychic life are only sensations in me. This comprehensive sensation, embracing all that occurs, is consciousness. It is impersonal, and not bound up with any particular man, for his very individuality is a content of consciousness.

This view does not do away with the reality of the world. The world holds its reality as a content of consciousness. All its phenomena remain as we know them, and the relations of its various parts and phenomena to each other remain, because consciousness dominates the whole. 
by another. Even in inorganic matter every particle is an "individual." It has innumerable properties and diversities, and does not entirely resemble any other particle. All bodies have been formed from other bodies, or-more correctly-all bodies are constantly changing, yet never lose their nature as bodies. Hence in nature we have only processes of transformation. If a protozoon seems to be simpler than a human being, and an element still simpler than a protozoon, we must never forget that even the "simplest" bodies are much too complex to be grasped by us just as they are, without any mental modification. No theory of evolution, therefore, enables us to understand the nature of matter; that can only be done by a mental process of transformation.

There is a further province of evolution that we must touch on before we conclude-the evolution of the human race, the history of civilisation.

The scientific method has been applied here also, and we give the name of "sociology" to this treatment of the history of civilisation. The aim of this science is to gather the common features of the various forms of human society, and formulate laws in virtue of these.

Thus we can study the common elements in the evolution of different races, and draw in laws which apply wherever there are nations. In fact, as these laws must be independent of time, they must be valid in the past and the future, and they enable us, to some 
extent, to forecast the future of the human race and to lay down certain guiding rules that may be useful in preparing the future.

Sociology cannot, indeed, ever replace or displace history. It can never tell us the real course of particular racial developments. For instance, a sociological law to the effect that races living on the sea-coast must utilise the sea, because that is their only chance of survival, cannot give us any information on the interesting questions, how the first boat was built, who was its inventor, and what gave him the idea.

Nevertheless, in human history natural laws, which include the laws of sociology, give us the right to use certain evidence, so that we can reconstruct, in its general outlines, a history of humanity that has a high degree of probability. Let us try to determine the basis of this history, which is of considerable importance to us.

The first men lived in isolation or in families. Their special habits-we need not go into them in detailwere such that those had the advantage who entered into close relations with their fellows, as they could then help each other, and take better care of their offspring. Thus natural selection would favour the more coherent social groups.

In this way men of a greater social disposition were always selected. Those who continued to wander singly through the forests were not so well placed in the struggle for existence as those in community, and they gradually but steadily disappeared. Again amongst the social groups those individuals were constantly weeded 
out who menaced the communal life. If they were too numerous the whole community collapsed, either from internal troubles or in conflict with more coherent groups. If these individuals were few, they were driven away or destroyed by their fellows, and were unable to sustain the struggle in isolation. Thus it is the first condition of all social life that no member shall endanger the life of another. Hence all primitive men that had murderous thoughts against their fellows would be gradually weeded out.

The more coherent the communities, the more complex the social instincts would become by means of selection. The property of one's fellows would come to be respected as well as their persons, and it was not long before thieves were put to death. In a word, all variations with lower social instincts came to be destroyed, and only the most social variations preserved.

Thus from the start those individuals were selected whose instincts were the most useful to the community. When one of these individuals committed murder, he acted contrary to his instinct, and an action contrary to one's instinct is always, even in the animals, accompanied by a feeling of pain, as we saw in the second chapter. This feeling may have been the beginning of conscience. The closer the co-operation in the community, the more confidently were those preserved who did not disturb the communal life-those, in other words, whose feeling of discomfort was strongest if they ever acted against the social instinct. In this way an increasing number of 
men were selected whose conscience was pricked, not only if they committed murder, but also if they were guilty of theft or any other crime against the community. That they were able to act at all against the instinct was due to the fact that selection favoured not only the more social, but also the more intelligent, members. Intelligence-and intelligence alone-can bring a man to act against instinct; just as in the case of the animals it is only the most sagacious, such as the dog, that can act contrary to their instincts. However, this disadvantage of intelligence is insignificant in comparison with its many advantages.

Hence in the first human societies "good" and "bad" were synonymous with socially useful and prejudicial. Primitive men would not be conscious of such ideas. The "good" acted unconsciously on their instinct; they were chosen by selection, and the "better" were favoured amongst their descendants. As the human intelligence continued to develop, and gave birth to speech, to think and act in a socially useful way became a matter of course to them, to such an extent that they would regard social conduct as the rule in life, as moral or "good," without being conscious of its utility. They then endeavoured to foster " good " conduct by punishment and education, and here again they were assisted by selection, which favoured the "best" races.

The origin of conscience by natural selection is confirmed when we turn to study the races that are still at a low level of culture. Amongst these, "good" and "bad" often mean something quite different from what 
they do with us, and conscience pricks them in regard to other actions. It is not necessary to go into details. One can read in any manual of anthropology that in many races murder, pillage, and even theft are not regarded as evil; that an Indian will feel remorse, for instance, because he has not killed anyone, but never because he has done so. Adultery, again, is often so general that the neglect of it is regarded as a disgrace, and it is well known how the men offer their wives to their guests in many races. The cannibal never feels remorse for having eaten anyone. On the other hand, many savages feel remorse for an action that is in our eyes indifferent or even good. In fine, one needs little acquaintance with ethnography to see that "good" or "bad" have not a common value for all men, and that all men have not got an inner voice that tells them what is "good."

Educated people have a more sensitive conscience than those of a lower condition, and this again is explained by natural selection. They usually marry refined partners; at all events they rarely choose those with crude feelings and a disposition to gross conduct without the check of remorse. Thus, amongst the educated, the individuals with the gentler instincts are always selected for reproduction, and therefore those in whom any violent deed will be followed by remorse.

We could expand this idea much further, but that is not our purpose. We wished merely to show that conscience offers no difficulty to the man who accepts 
natural selection. It can be understood as an instinct, and instincts arise and grow by natural selection.

But we should be one-sided if we tried to explain the higher civilisation solely by selection of the more socially disposed and the more intelligent. There is a second factor to be considered, even a more important one. This is tradition.

Tradition is found almost exclusively amongst human beings. It may be that among the higher animals a method of catching prey, or building the nest, or singing, is maintained by tradition, perhaps even furthered by it, the young learning from the old; but this hardly calls for consideration. It is quite otherwise with man. In his case tradition has a solid foundation in speech, in drawings and the work of the hand. It is due to this that the skill which one man has acquired during life is not lost when he dies, but taught to his descendants; they can learn it in a short time, and advance it in their turn. In this way tradition brings about a certain mental transmission of acquired characters, though this has nothing to do with the Lamarckian principle, since nothing is inherited.

Let us take an instance.

In a certain coast-land a man worked throughout his whole life at some contrivance for enabling people to travel on the sea. Towards the close of his life he invented a boat. If there were no tradition, the invention would die with him, and the human race would have to wait until some germ-variation happened to occur that qualified the man developing from it to 
build a boat once more. Tradition made it possible, not only for others to copy the boat, and for their children to learn the art, so that it became a lasting possession of the people, but also for improvements to be made, since the children did not need to reflect all their lives on how to make a boat, like the first inventor; they learned the work in a shorter time, and were thus able to devote their lives afterwards to improving it, and could transmit this knowledge to their descendants.

The whole of our higher civilisation would be impossible without tradition. Our books inform us of the achievements of former ages, and inscriptions and drawings acquaint us with long extinct races. The objects of civilisation are our property, and we build further upon them. We have implements from the very dawn of humanity the essential parts of which still represent the foundation of all creative work. Language, like a great river, brings on its waves the achievements of earlier generations down to our own time; it unites all generations in an unbroken chain. All this is so obvious that we need say no more of the subject.

What has been attained through tradition may be modified and improved by natural selection. Let us return to our illustration of the boat. It is quite clear that the race whose boats have been improved owing to tradition beyond those of a neighbouring, hostile race, will be able to defeat the latter in a sea-fight, and so spread into its territory. With the people will go the traditional possession, the better boat. Thus in a sense this has conquered the inferior outcome of tradition. 
To give another instance, let us suppose that a race has acquired by tradition such admirable political and juridical forms that its co-operation is lifted to a higher level. If a neighbouring race lives under worse political and juridical conditions, it is probable that the first race will conquer when war breaks out, because its more coherent nature leads to more energetic and harmonious operations on the part of its army. If the law of the conquerors is forced upon the losers, this survives, while the inferior law disappears.

The struggle of traditionary benefits may, of course, be peaceful; the best acquirement may conquer without strife or blood-shed. Suppose, for instance, that the excellent position of a state leads to the prolific multiplication of its citizens ; this constantly increasing community will gradually oust its neighbours in the most peaceful way. With it survives its political system.

Thus it is possible to trace the probable course of the evolution of civilisation and ground it on scientific laws. Opinions will differ as to the value of the attempt. On the one hand it will not be entirely convincing because it is no more than probable; on the other hand it will be very difficult to provide it with a purely scientific foundation. Words like "improve," "valuable" and "progress" will be only too apt to creep into it, and these meanings will involuntarily be imputed to the laws of evolution. We are accustomed enough to regard nature in the light of what is "valuable " and "valueless," and will be much more apt to use these terms in dealing with civilisation. It is a question if we can ever speak 
of changes of civilisation-which is the only way to put it scientifically-without considering them in relation to some standard of value that is regarded as generally valid.

However, we may grant the possibility of a history of civilisation on scientific lines, but we must entirely reject the notion of a scientific ethics. It has been said that the laws of science must apply always, even in the future, as they are independent of time. Hence we should be able to determine the laws of evolution in virtue of which the human race has not only changed, but will continue to change. We know that the fittest survive in the struggle for existence. The point is, therefore, to establish what is the fittest in particular cases. When that has been done, men will be disposed to aim at that particular adaptation in order that they may survive. We must, of course, also determine the general direction of human development, and must know what will be the best adaptation in ages to come. If we can obtain definite knowledge on these points, laws must be framed, States constructed, and the social order regulated, in relation to them. That is the language of the sociologist.

Above all things, nothing must be done in opposition to natural selection, because it is this that always confers their greatest advantages on living things. It is a false humanity to spare those with hereditary disease, as in this way the disease is spread. It is not necessary to put them to death, but merely to prevent them from marrying, so that the disease-germs may die with them. If, for instance, some years ago, all consumptives had 
been prevented from having children, there would soon be no people with unsound lungs. We look too much to the individual. We ought to care for the soundness of the species, as nature does, and then the individuals also would be sounder.

Other institutions show us an inverted selection. War brings about a "survival of the weakest," as it is precisely the strongest elements that perish in them, while the weaklings can continue to bring forth their puny children in peace at home. It is, therefore, unspeakably perverse and ridiculous to say that a little blood-letting from time to time does a nation good, and keeps down over-population. Apart from the fact that with the vast sums spent on the army waste lands might be cultivated, and numbers of families provided with new and secure dwellings, this blood-letting deprives the nation of its soundest blood, and every battle lessens the vital force of the next generation.

Our whole military system should be abandoned. From the fact that the strongest enter military service, they generally lose the time for founding a family, while the less strong civilians have young earlier. Thus the weaker children come earlier and are more numerous, and this gradually enfeebles the race.

Finally, we have a case of inverted selection in the Catholic principle of clerical celibacy. In Catholic countries the stupid survive, as a glance at such lands is said to show. As a general rule in a Catholic country, those are chosen for the clergy who are above the average of intelligence that suffices for peasants 
and artisans. But these more intelligent men are prevented from reproducing. In this way for centuries the more intelligent have been taken out of each generation, and their better germ-qualities have perished with them, because they were forbidden to have children. Thus the intelligent were continuously selected for destruction, the stupid were enabled to pass on their inferior germ-qualities to the next generation, and the mental level of the race was bound to be gradually lowered. ${ }^{1}$

However, the scientific treatment of the evils of our time seems to be fairly justified. What must we make of the positive moral laws of sociology?

We must point out in the first place that there is a view which predicts the greatest future, not for society, but for the individual. This is the well-known philosophy of Friedrich Nietzsche, though founded before him by Max Stirner.

${ }^{1}$ We may regard celibacy from another, I would almost say a more fitting-point of view. We are told that the peasants give to the clergy those of their sons who are least suitable for agricultural work. In other words, the weaker are selected for barrenness, and so celibacy must tend to strengthen the next generation. In the same way it may be contended that military training is of great service to our young men. It would certainly be better for humanity if nations did not face each other armed to the teeth, but we are still very far from this, and standing armies are at present inevitable. Moreover, it may be objected to the proposal to condemn weaklings and the diseased to infertility that it is impracticable. In my opinion all these questions should be settled by the historical method, because the work of natural science is merely the theoretical interpretation of the world. This will be made clear in what follows.

I was, therefore, surprised when a reviewer in a New York Journal observed that my point of view-which he calls Darwinian-ethicalcan hardly be maintained on practical grounds. That is not my point of view, as I think I have clearly stated. 
We see from this that Darwinism may not only lead to the prosperity, but also to the decadence, of a society, as Nietzsche's "egoism" is built up rigorously on a basis of selection. In fact he attributes a more energetic action to selection than the social Darwinists do. Nietzsche especially rejects the precept of love of one's neighbour as "a morality of slaves." It is hatred alone that makes the fittest to survive. "The strong drift just as necessarily away from each other as the weak do towards each other." Strong and masterful men must arise who feel themselves bound by no restrictions and follow unsparingly the primitive instinct of man towards violence, with no regard for science or morality. Science bids fair to-day to rob man of all his self-esteem. Astronomy dwarfs him by reducing him to insignificance in the great universe. Away with science, then, since it hinders the development of man and the beyond-man! "Nothing is true; all is permitted."

The State is an evil. Men cannot give the rein to their violence in it, until they at last turn it against themselves and mutilate themselves. This was the origin of conscience, another evil, according to Nietzsche. The primitive human instinct to fierceness cannot express itself externally and is reflected inwards.

But a time is coming when men will live as masters once more. When one great State embraces the whole world and no enemies threaten it, the older selection will no longer be a condition of existence. Then 
morality will have survived; men will dare to express their individuality, and their long repressed egoisms will explode. There will be a fierce struggle for the light of the sun. No values will be recognised. The day of the beyond-man will have come.

We will not go further into the subject, as this is not the place to deal with the ideas of Nietzsche. We merely wanted to point out that they are based on selection. As a matter of fact, little can be said against them from the scientific point of view. The Darwinist believes that the struggle for life creates the best-let the phrase pass for the moment-and is most effective when it is most destructive. Away, then, with whatever limits the struggle! Away with the State and the whole of civilisation! Away with our physicians and hospitals, which run counter to selection, by preserving the weak! Epidemic diseases are the most drastic selective agencies; they suffer only the very soundest to survive, and the generation that follows their ravages is the healthiest conceivable.

How will it be when one state embraces the whole world? Then all selection will cease, and everything will be done in accordance with laws framed by men for the attainment of certain ends. But the laws of Nature that they interrupt can achieve more than man. Hence we ought to prevent the formation of such a state and all institutions that restrict the struggle for life.

Can Nature's eternal laws be corrected or suppressed by the puny hand of man? A natural law is some- 
thing that holds good everywhere and at all times, and cannot be suddenly destroyed by the very objects to which it applies.

It is true that the laws of nature hold good always, and cannot be influenced by civilisation. Selection would act even in a state that covered the whole world. It merely demands that those shall survive who are most in harmony with their actual environment. In a universal state the conditions would be different from what they are to-day. Selection would then allow those individuals to multiply most who are best and quickest able to secure maintenance and found a family. Even if the state extends equal care to all its members there will always be variations in the fertility of the citizens, and the more fruitful will tend to predominate. Whether they will be the more intelligent is another question. It is, in fact, pretty clear that in such a universal state, where cleverness would be no advantage and would not put a man in a better position to found a family, and where selection would no longer favour men according to their degree of intelligence, ability would diminish. In the end the citizens might become too stupid to maintain the state. It would break up, and then selection would once more favour the more intelligent; they in turn would build up a state, which would meet the same fate, and so on in an endless cycle.

However that may be, we can see clearly how difficult it is to build up a science of morality, or ethics, on the principal of selection. We can hardly determine what is "better" for our own time; how much less 
can we do it for the future. How can we say with any confidence what the conditions of life will be in the future with which the coming race will have to harmonise.

The Darwinists who would deduce a system of ethics from their theory say that moral laws are only safely established when they are natural laws. We have seen how a law of nature is formulated. Individual phenomena are considered in their common features, and these are then embodied in a law. Moral laws must be framed in the same way. The individuals have then to range themselves under the law, like an example of a genius under the generic title. Hence a scientific ethics would have to demand that everyone should be as far as possible an "average man." Only what he has in common with his fellows is essential; his individual and distinctive traits must be as slight as possible, if he is to be as moral as possible-in the scientific sense. Science, which overlooks individuality in the formation of its concepts and regards it as unessential, must demand that the men who would realise its ideal shall have little or no individuality.

As a matter of fact, we find confirmation of this when we read about future states and Darwinian ideals. No account can be taken of the individual; he must merge into the general. The "general" or common interest is the basket of the "social" state.

Nietzsche has given us a masterly description of the Darwinian ideal of the coming race in his "last men." It shows the complete insipidity of the theory that looks 
only to the common interest and suppresses the individual. ${ }^{1}$

"The earth will then have become unimportant, and the ultimate man, who makes everything important, will hop about on it. His species is ineradicable, like that of the flea; the ultimate man lives longest.

“'We have devised happiness' - say the ultimate men, and wink knowingly.

"They have left the regions where it was hard to live; for warmth is required. They still love their neighbour, and rub against him ; for warmth is required.

"It is regarded by them as sinful to turn sick or be mistrustful; they walk warily. It is only the fool who still stumbles over stones and men!

"A little poison now and then-that makes pleasant dreams. And much poison at last, for a pleasant death. "They still labour, for labour is an entertainment. But they take care that the entertainment does not hurt them.

"They no longer become poor or rich; both are too troublesome. Who of them still wants to rule? Who of them still wants to obey? Both are too troublesome.

"No herdsman, but one herd! All want the same. All are equal. He who thinks otherwise goes voluntarily into the madhouse.

" "Formerly all the world was insane'-say the most subtle of them, and wink knowingly.

"They are wise, and know all that has happened;

? "Thus spoke Zarathustra" (Commons' translation). 
so there is no end of their derision. They still fall out, but are soon reconciled-otherwise it would spoil their stomachs.

"They have their little pleasures for the day, and their little pleasures for the night; but they have a regard for health."

This is the pass that things will come to if the Darwinian-ethical ideals are realised. A "deadly generalness" will dominate the world. Happiness and unhappiness are antitheses, and there should be no antitheses in the scientific world of ideals. Nothing low-but nothing high: no hatred-but no love: no depth-but no altitude: an eternally monotonous life, without struggle and without victory.

We see, then, that the ideal of a scientific guidance of men means, to everyone who esteems individuality, an intolerable mediocrity. But that is not the only objection to a scientific ethics. It can be shown that it has no right to exist at all.

Every system of ethics must prescribe something to a man; it must tell him his duty. That is evident. If moral laws are to be laws of nature, they must, like the latter, have a universal validity. They then show what exists, and must exist, everywhere; it is the very essence of natural laws that they act neccessarily. But if moral laws, being natural laws, must be realised of themselves always and everywhere, there is absolutely no purpose in directing a man to act according to them. If a thing is so, it is superfluous to make it a duty for a man to bring it about. 
In reality the world has no place for duty from the scientific point of view. The cosmic process goes on inexorably. There are no ends towards which the eternal changes are working; and there is no force that can arrest or control the rolling whee's.

The stars travel on in the infinite universe. They exist at one moment of the world's history, and are gone the next. On a small body in a corner of the universe certain beings were produced in one of these moments, to grow rigid for ever with their planet in the next. Such is the story of mankind.

How ridiculous and aimless it must be, in view of this conception of things, to direct a man how he shall act. As if he could make the slightest change in the inexorable march of cause and effect! How is it possible to set before a man aims that he shall strive to realise, when there is no "teleological" occurrence in the world, when even human actions are determined by causes that lie behind, not before them ? ${ }^{1}$ The utmost that science can say is that an ethic, a setting-up of ends to be attained, has no meaning. It can only direct a man to let himself be borne in peace on the stream of cause and effect, without doing anything, because his action could have no aim and no result. The only possible scientific ethic is resignation.

Is it true that the laws of Nature are the sole ${ }^{1}$ There can, of course, be no question of free will to the scientifically-minded man. 
moral laws because they alone lead to ever-increasing values? We have already rejected this idea so often that we need not enlarge on it here. The principle of selection is not a principle of progress. It does not lead up inevitably to the "highest being," to man; he is the accidental outcome of one branch of the organic system. Even in the evolutionary series, of which man is the terminus, we cannot speak of progress; it would not be scientific, but anthropomorphic. In the eyes of science man is not "higher" than the other animals. It is precisely one of the elements of the success of the scientific view that it brings man into level with other living things. It is illogical suddenly to raise him again to the position of the "highest being."

Further, it is entirely wrong to say that selection gives increasing value to the frames of animals, because it makes them increasingly fit to maintain their existence. Maintenance of existence has nothing to do with maintenance of value. Science has only attained its great results by studying the world independently of all considerations of value. It sees nothing but changes. Certainly, its organisation will seem valuable to an animal when it sees that it fares better in life than its fellows owing to it. In the same way, man will attribute value to everything that is useful to himself. But this way of thinking is not scientific. The scientist has only to determine that there are human beings and animals, and that some survive and others perish on account of their bodily character- 
istics. He cannot wish that certain animals, or even man, may maintain their existence as long as possible. Worth is only conceivable as the opposite to worthlessness. Dualistic ideas of that kind should have no place in a monistic system. ${ }^{1}$

We have now reached the fundamental objection to all scientific ethics. Science regards cosmic processes merely as changes, and pays no attention to values. It abandons its methods entirely and contradicts itself when it begins to recognise values. Hence it cannot have an ethics, because this has no meaning unless the moral laws that it sets up, and especially the life of man and the improvement of it, are regarded as having worth.

Thus for science-to repeat our conclusion-there is no such thing as an aim, an end, or a value in the world. There are only changes in accordance with eternal laws. The laws are beyond the control of any human being. The whole history of humanity consists of certain changes that take place on a speck of dust, and occupy only a second of the world's time. All man's actions, all his struggles and efforts, are so many phenomena that follow necessarily upon other phenomena; they are as void of worth as the fall of the meteor, or the roll of pebbles on the beach.

The whole cosmic process is aimless. There is no such thing as a sense of life.

"For the same reason, the phrase "worthy of selection" is unfortunate. It does not give one a very scientific impression when we find sociological writers speaking incessantly of values. 
Yes, in a scientific conception of the world there is no sense of life. But that does not mean that there is no such thing anywhere as a sense of life. If science affirms that, it is passing beyond its sphere.

We have seen that the scientific conception of the world does not present reality itself, but an interpretation of it. We have also seen that there is a second way of conceiving it-the historical. History looks first and foremost to individuals, and shows that in reality no individual can be substituted for another. History has a perfect right to read an ethic from reality - an ethic that lays on each personality the task that he alone and no other can perform. But it is not our place to enlarge on this.

If science tells us to reject the historical conception of life it is illogical. When it censures the historical method, it assumes it to be of less value than its own, and thus once more oversteps its province.

Briefly, we see on all sides that science lands itself in contradictions the moment it goes beyond its sphere. Its task is merely to give us a knowledge of the world. In doing this consistently it has attained marvellous results, and has formed a "monistic" or unified view of the world. The foundation of the monistic structure and all the columns and buttresses that support it imply a disregard of all values. Hence monism cannot frame an ethic unless it abandons all its supports, which are inconsistent with values. In that case, monism breaks down.

When, therefore, we find practical counsels, aims, 
and values in monistic works, we have no longer monism before us, but dualism-dualism, in fact, of the most positive character. We cannot recognise two systems as equally valid; we must leave only one standing. But we destroy it when we turn to the second, even though we demand that it shall be based on the first.

There is one further point.

Not only has empirical science, which recognises no values, no right to deny worth and the sense of life generally, but it is itself subordinate to the sciences that endeavour to determine values. Before it begins its work some standard of value has to determine whether its procedure is to have any meaning. This standard is the value of truth. Knowledge of the world must be of value to a man before he applies himself to the empirical sciences that help him to attain it. And the methods of acquiring this knowledge, which disregard all values, must have a value for him.

Thus all science presupposes a will to attain the truth, a will to reach the goal of knowledge. Over the portals of every science are inscribed the words:

\section{Thou Shalt.}

We have now reached the end.

These last considerations have shown us that we are justified in believing in a sense of life, and that there must be duties, since the idea of duty precedes all knowledge. 
But science has nothing to do with these problems. It is of its very nature to pass no judgment on the value of other methods of investigation.

It presses on to its goal, the comprehension of the world, regardless of all else. It gives an impulse to the human mind that bears it on to ever greater heights. The vision steadily enlarges. The individual disappears; the world lies at the feet of the spectator in its broadest outlines.

But we press onward. It bears us beyond the world to a height whence we can survey the entire universe. He who would see over the whole world must pass beyond it.

There, in pure ether, the mind is able at last to grasp the infinite all. 


\section{INDEX}

Achtheres percarum, 247

Adaptation, law of, I I 8

Aim not known in science, 425

Air-sacs in birds, 100

Algæ, 236

Albumen, 237

Albuminoids, 23I

Alpine hare, adaptation of, 54

American notions, 47

Amœbæ, 292, 294

Amphimixis, uses of, 256-6I

Analysis, chemical, 23I

," the task of science, 396

Angiosperms, 236

Annelides, 264

Antennæ of the crustacea, 245

Antlers, 84, 89

Ants, 285-6

of the giant stag, 207-I 3

Archæopteryx, 39, 121, 157

Arctic hare, evolution of the, 32, 54

Argus butterfly, the, 195

Aristolochia, 200

Art, analysis of, $7 \mathrm{I}$

" animal destitute of, 7 I

Articulates, I84

Artificial selection, 29, 166

Asexual germ-cells, 302

Atoms, 365

Attention in animals, 76

Aulostomum gulo, 268

BAcIllus, adaptation of the, 373

Bacteria, nitrogenous, 318

Balloons, birds dropped from, 102

Barbel, the, 176

Basic particles in the germ, 319

Bee hawk-moth, the, I94

, queens and workers, 213

", state, origin of the, 214

Bees and plants, 200

Beetles, wings of, 203

Beyond-man, the, 417

Bitharzia hamatobia, 282

Biocœenosis, 23, 42

Biogenetic law, the, 17 I, 247

Biogens, 232-4, 3 I I

, $\quad$ evolution of the, 317
Bird, anatomy of the, 100

, evolution of the, $38,1_{36}$

", life of the, 52

", song of the, 78, 94-6

, soul of the, 79

Bittern, the, 96

Black-arches, the, 43,160

Blackbird, the, 48

Black-cock, the, 85,87

Blue-throat, the, ro7

Bombycidæ, the, 159

Bothriocephalus latus, 282

Brain and mind, 384

" development of the, 249

Branchiopods, 254

Brontosaurus, the, I 20

Bullfinch, the, 8I-2

Bull-head, the, I73, 174

Buttel-Reepen on the bees, 2 I 4

Butterflies, I87, I89-93

CabBage-Butterfly, the, I95

Callima, 194

Caprifoliaceæ, 200

Caracoideum, the, I 58

Carp, eggs of the, 26

Cast of the skin in insects, 187

Cat and the mouse, 67,68

", why its fur stands out, 88

Caterpillars, 188

Catholic clergy, 415

Causation, infinity of, 36I

Cause and effect, 349

Celibacy, evils of, 415

Cell, the, 289

cleavage of the, 294

Cellular animals, 319

Cellulose, 237

Cetiosaurus, the, 120

Chaffinch, the, 48

Chance, 353

Change of function in organs, 244

Chlorophyll, 235, 317

Choice, female, 80-7, 95

Chromatin, 289

Classification of animals, 117

Co-adaptations, 207 
Coat of insects, development of the, 205-7

Cock, spurs of the, 84

Cockchafer, the, 84

Cold, effect of, on butterflies, 34I

Cold-blooded animals, I 19

Colour as protection, $53-5$

Colours, animal, origin of, 9 I

" of a nimals and selection, 166 " of insects, 185

Combinations, chemical, 230

Common features expressed in ideas, 393

Concepts, 378

" of animals, 392

Conscience, evolution of, 408

"variations of, 410

Consciousness, 386

$"$ not evolved, 404

Cœcum, the, I59 unimaginable, 404

Co-operation in the body, 165

Copepoda, 252

Copper butterfly, the, 195

Coquetting, 86

Correlation, law of, 164

Cosmic process, the, 425

Cosmozoic theory, 314

Courtship of animals, 82-8

Coyness, 86

Crab, legs of the, 245

" pincers of the, 204-5

Craw-fish, the, 240, 245

Creation, theory of, 155

Cretaceous period, 119

Cricket, pairing of the, 196

Cries of birds, 94

Crocodile, age of the, 149

Cross-bill, the, 98

Crustacea, 184

Cuckoo, as destroyer of insects, 45 cry of the, 95

Curiosity in animals, 76

Cyanic theory, the, 316

Ciliated infusoria, 293

Circulation of blood in the bird, 156

Civilisation, effect of, "on animals, 42,47

Civilisation, evolution of, 406

DACHSHUND, the, 2 ro

Daphnidæ, 252

Darwin and over-production, 26

Darwinian ethic, the, 417, 420

Darwinism, definition of, 38

Death, nature of, 307-II

" utility of, 312
Definite variations in animals, 258, 332

Degeneration of organs, 1 56-8

Descartes on instinct, 64

Descent, theory of, 37

Descriptive science, 399

Design on butterflies' wings, I9r

Determinants, 333

De Vries, Hugo, 344

Differentiation of life-forms, 318

Dinosauri, the, I20, 129

Direction, sense of, in birds, I 10-12

Distomum hepaticum, 274, 283

Distomum macrostomum, 283

Divisibility of bodies, 362

Division of labour in organisms, 290

Dochmius duodenalis, 278

Dragon-fly, the, 19, 22, 194, 196

Dreams and art, 72

Dualism, 427

Duty, idea of, 422,427

EAR-BONES, the, 154

Earth, end of the, 312, 323

Earth's history, periods of the, 122

Earthworm, the, 238

" use of the, 266

" regeneration in the, 267 ", summer store of the, 56

Earwig, the, 202

Echinoderms, 263

Echinorhyncus, 272

Economy of nourishment, I68-70

Eel, reproduction of the, $178-80$

Eel-pout, the, I 72

Efficient causes, 367

Eggs, colours of, 92

" number in certain animals, 26

" of reptiles, 138

" poisonous, 176

". provision for development of, 59

Egoism, 417

Egyptian plants, 34

Egyptian seeds do not grow, 233

Elastic types, I 32

Elements, chemical, 229

Elephant, trunk of the, 241, 332

Embryo, development of the human, I7 I

Embryonic adaptations, 249-51 development, evolutionary aspect of, I70, 248-5 I

Empirical science, 396

End in organisms, 364

Eristalis, 193

Eternity of matter, 314

Ether, 381

," invisibility of, 382 
Ether-particles, metaphysical, 395

Ethics, 419

Evolution, the theory of, 37

" a slow process, 360

$" \quad$ based on probabilities, 4 or

" nature of evidence for, 400

" not a purposive process, 373

Evolution of life-forms, 318

External influence on organisms, 340 Extinction of species, causes of, I25-3I

FAKIR, sham death of the, 233

Falcon, the, 98

Feathers, origin of, 136

Feeling in the mammal and the bird, 53

Female choice, $8 \mathrm{r}-7$

Fertilisation of plants, 197-9

Fertility of animals, 26, 58

Fibula, the, I 68

Field-cricket, apparatus of the, 209

Field-mouse, the, 43

Final causes, 364

Fingers of the bird, 157

Fins, evolution of the, 154

Fishes, eggs of the, 59

Fitchet-weasel, the, 57

Flagellates, 292

Flea, the, 202, 270

Flesh-eating, beginning of, 238

Flight, instinct of, 66, 215

Flowers and insects, relation of, 197

Fluke, the, 282

Flying fish, the, 137

"squirrel, the, 137

Flying muscles of birds, 100

Food instincts, 66-8

Forestry and birds, 47

Formative energy in organisms, 344

Forms of living things, 352

Fossils, absence of early, 122-3

$"$ formation of, 123

Fox, the, 23, 28

Free will, 423

Freedom, sense of, in play and art, 73

Frog, the, 21

" adaptations in the, 145

Frog-spawn, 145

Fundulus heteroclitus, 177

Fungi, 235, 238

Future society, the Nietzschean forecast, 419

GALL-FLY, the 254

Galleries of ancestors, 402
Game, injuries done by, 43

Games, nature of, $60-377$

Gätke, H., 79

$"$ on speed of migration, 98 , IOI

Genealogical trees, 359

General concepts, 379

" terms, use of, 392

Generic names, 393

Geology, evidence of, 35

Geological succession of animals, 35-6

Geometer-moth caterpillars, 193

Germ-cells, 255, 297

, not teleological, 366

$"$ selection in the, 333

Germ-plasm theory, the, 296

Germinal selection, $333-40$

Gill-clefts in the human embryo, 171

Gills, evolution of the, 156

" of snails, 244

Good and bad, meaning of, 375

Gordius aquaticus, 268

Gourd-worm, the, 274, 283

Graeser, Kurt, on migration, 105

Grant Allen on heredity, 306

Grasshopper, the, $137,185,187$

Groos, Professor, on animal play, 60

Growth of insects, 186

Glyptodont, the, 126.8

Haeckel, Professor, 399

Haemopis vorax, 268

Hairy coat, disappearance of, 342

Hamster, winter sleep of the, 56

Hare, the, 23, 28, 31

Harmful animals, 43

Harmonious adaptations, 207

Hawk-moth caterpillar, the, 188

Hawks, 43

Hearing in the fish, 176-7

Heart, the, 155

Heliconides, the, 194

Heligoland, migratory birds of, 98 , 102

Henry II., falcon of, 98

Hereditary disease not to be spared, 414

Heredity, 4I, 256

" law of, 118

n nature of, 298

Hermaphrodism, 275

Hermit-crab, the, 225 in the plant, 199

Heron, the, 212

Hibernating animals, 55-7

Highest being, man as the, 424 
Histological selection, 333

Historian, work of the, 399

Historical science, 397

History of civilisation, $4 \mathrm{I} 4$

Honey in plants, 199

Horse, evolution of the, 39

, toes of the, 157

Horse-leech, the, 268

Humanity, true and false, 4I4

Hydra, 285

ICHNEUMON-FLIES, 44

Ichthyosauria, the, 120

Iguanodon, the, 120

Lmago, 185,187

Imagination, 71

Imbauba, 286

Imitation, instinct of, 64,75

Immortality of the germ-cells, 306

" ," protozoa, 307-10

Incomprehensibility of the world, 377

Indifferent marks of organisms, 163

Individuality, 406

Individual the only reality, 395

Infection of germs, 223

Infertility of mixed crossing, 328

Infinity, 362

Infusoria, 293

" will survive man, 374

Inheritance of acquired characters, 204, 222-4

Inheritance of impressions, 340

Inherited habits, 214

Inorganic matter has psychic phenomena, 404

Insects, adaptations of, 185

$$
\text { " growth of, I86 }
$$

" origin of wings of, 137

Insectivorous birds, 43-5

Instinct and intelligence compared, 66-7

Instinct, nature of, 64-6

Instincts, origin of, 214

Instrumental music of birds, 96

Intelligence, animal, 55

" and instinct, 66-7

$"$ of insects, 216

Intermaxillary bones, the, I 54

Intestinal worms, eggs of the, 26

Isolation as an evolutionary factor, 26I, 325-3I

JAY, song of the, 96

Japan, no singing birds in, 78

Judgments, 378

Jurassic period, II9
KANT, 389

Kingfisher, the, 45,46

LAMARCK, theory of, 40

Lamarckian principle, the, 167 , 19r, 203-227

Lamarckian principle, the teleological, 37 I

Language, scientific value of, 377

Lappet-moth, the, 193

Larvæ, 185, 187

Last men, the, 420

Laws of science, 397,401

Leaf-cutter ants, 286

Leech, the, 268

Legs, development of, I68

Leptocephalus brevirostris, I79

Lepus Huxleyi, 34

Leuckart, R., on parasites, 269

Libellula depressa, 195

Lichen, the, 286

Life, duration of, 312

," origin of, 3I $3-6$

" historical conception of, 426

", nature of, 232

" phenomena of, 233

Limbs, evolution of the, I 57

Linnean principle, the, 34

Lion, mane of the, 88

Living substance, 232

Lizard, intelligence of the, 138 tail of the, 141

Love-dance, the, 85,87

Love-play, 76

Lumbriculus, 267

Lungs, origin of the, 152

" of snails, 240,244

MACHERODUS, the, I26-8

Magnetic sense in the bird, 108

Males, fights of the, 84

Mammal and the bird compared, 52

Man and the animal not specifically different, 77

Mantis, the, 196, 216

Marmot, the, 107

Marten, the, 29

Masticators, evolution of, 202

$$
" \text { of the crustacea, } 246
$$

Mastodonsauri, the, I 2 I

Material world, a process of consciousness, 387

Materialism, 385

Maturing of the gernn-cells, 322

Maw-worm, the, 265, 272

May-flies, 19, 22 eggs of the, 26

Meadow-sage, the, 201 
Measle-worms, 280

Mechanism, 350, 369

Mediterranean, former bridge over the, 110

Medium influences, 342

Megalosauri, the, 120

Memory of birds, I I I

" of fishes, 176

Memory prodigies, 112

Metabolism, 233

Middendorf, 108

Migration of birds, 98-1 I5

$\begin{array}{llll}" & \text { " } & \text { altitude of, } 99-103 \\ " & " & \text { " cause of, I03-5 }\end{array}$

Migrations of animals, 328

Migration routes, 109-10

Migratory instinct, the, I03-I 5 $" \quad$ origin of the, 103-7

Military system, evils of the, 415

Mimicry, 193-4, 216

Mind and matter, $387-8$

, in the animal, 77

Mixtures, chemical, 230

Mole-cricket, the, 185,203

Monism, 389, 425, 426

Monstrosities, 348

Moral laws, 422

" sense, evolution of the, 408

Morality, science of, $4 \mathrm{I} 9$

Mortality greater in males than females, $8 \mathrm{I}$

Mosaic narrative, 38

Moth, the, 187, 190

Moustache, the military, 90

Mucus of the snail, 239, 242

Mud-fish, the, 151, 177

Mussels, parthenogenetic, 254

Mutation theory, the, 344

Mutilations, not inherited, 222

Mutilation of animals, $140-5$

Myoxus glis, 56

Natural laws, 380

$" \quad$ selection, 28-9, 40
" and sexual selection, 79-82

$"$ selection, description of, $4 \mathrm{t}$

" selection, is it omnipotent?, 132

" selection, mechanical, 368

Nauplius-larva, the, 246, 251

Neanderthal skull, the, 125

Nematodes, 27 I, 277

Neo-Vitalısm, 352

Nerve-tracks, 65

Nerves, motor and sensory, 64

Nesting-places of birds, 48
Newt, regeneration in the, 142

Nietzsche, F., 416

Nightingale, disappearance of the, 47

Novelty, stimulus of, 82

Nucleus, importance of the, 295

Nut-hatch, the, 52

ONTOGENY, 247

Optics, 398

Organisation, degrees of, 374

Orgyia, the, 226

Origin of life, 313-18

" of species, 398

Orthogenesis, 340

," teleological, 37 I

Ova, number and development of, 26, 359

Over-production, 25

Ovum, the, 255, 303

Owl, the, 43

structure of the, 223

Oxyuris, the, 277

PAINTER's gaper, the, 175

Pairing-cries, 95

Pairing of insects, 196

" season, date of the, 57

Pandorina, the, 297

Panmixis, I6I

Parasites, alimentary organs of, 272

, respiratory organs of, 272

" sexual organs of, 273

Parasitism, 246, 269-84

Parthenogenesis, 253-7

Passive selection, 357

Peacock's-eye butterfly, the, I 89,220

Peacock, tail of the, 87,93

Pentastomum tanioides, 270

Perch, the, 172

Perch-pike, the, 172

Peripatus, 264

Persistent types, 132

Pflüger on the origin of life, 316

Phylloxera, the, 43, 254

Phylogeny, 247

Physical changes of the earth, 327

" conditions of life, 22, 49

" science, 396

Pigeons, species of, $29-30$

Pike, the, 172

Pineal body, the, 158

Pine lappet-moth, 43

Plagues of animals, 46

Plant-eating animals, 237

Plant, evolution of the, 197-9

", importance of the, 235

Plastic types, 132 
Plate on heredity, 225

Platodes, 263, 279

Play, analysis of, $60-77$

" animal, 60-77

Plural variations, 259

Plesiosaurus, the, 120

Plectognathic fishes, 177

Poisoning of germs, 223

Poisonous butterflies, 148

, organisms, colours of, 147

" snakes, 139, 143

Polar animals, colour of, 54-5

Political systems, development of, 413

Pollen, 197

Polyp, the, 284, 291

Pond, inhabitants of the, 21

Pond-mussel, the, 175

Pond-snail, the, 239

Porto Santo rabbit, the, 34

Potential immortality, 307

Presentiment of the bird, 107

Preyer on the nature of life, 315

Proboscis of butterfly, 20I-2

Processional butterfly, 43

Proper names, 393

Protective colours of insects, 189

Protoplasm, 289

Protozoa, the, 170, 263, 292

Psychic phenomena, 384 " " in inorganic matter, 404

Psychic phenomena in the protists, 403

Psychology, 384

Pterodactyl, the, I2I

Pterosauri, the, I20, I 30

Pupa, the, 188, 206

Purpose in organisms, 354

$" \quad$ in science, 373

RACIAL colours, cause of, 165

Reality, nature of, 395

" not given in natural science, 383

Recreation not the essence of play, $6 \mathrm{I}$

Red breast in birds, 81,82

Redstart, the, 45

Reduction cleavage, $32 \mathrm{I}$

Reflex action, 64,214

Regeneration of organs, 142

Regions of nature, 20

Regulation of rivers, 177

Reproduction, essence of, 294 Reptiles, age of, 135 , 58

Rhine salmon, 48
Rhodeus, the, 175

Richard's pipit, the, 109

Rigid types, 132

Ringed adder, the, 139,148

Rivers, artificial control of, 48

Rock-pigeon, the, 30

Rudimentary organs, 158-70

Ruffe," the, I78

parts in germs, 295

Rut of animals, 57

Succulina, 246

Salamander, the, 37

$$
\text { , and fire, } 146
$$

Salmon, spawning of the, I80-I

Satyridæ, the, 188

Scar in the egg, 304

Scars, use of, 144

Scented butterflies, 195

Schiller on play, 62

Science, objectivity of, 391

Scientific explanation, nature of, 361

Scolices, 280.1

Sea-anemones, 285

Seed of plants, 198

Selective value, 329

Self-correction of determinants, 336

Self-deception in play and art, 7 1-2

Self-preservation, instinct of, 356

Scnsations as psychic elements, 384

Sense-impressions, 65

Sense of life, 426-7

Senses, action of the, 391

Serpent, habits of the, 138

" movements of the, 140

Sexual characters, 82-5

" generation, nature of, 299

" selection, 8o-3

" $"$ teleological, 370

" union, reasons for, 256

Shad, the, 173

Shamming death, 193, 216

Shell of the snails, origin of the, $24 \mathrm{r}$

Silurian strata, animals in the, 121

Skeleton of the articulates, 203

Skull, development of the, I 53

Smooth adder, the, 141

Snail, the, 239

" breathing of the, 244

Snails with small shells, 168

Snipe, noise of the, 96

Social instincts, culture of, 408

" instinct in birds, I I 2

Society, growth of, 407

Sociology, 406

" laws of, 407

Species, nature of $\mathrm{a}, 33, \mathbf{I} \mathbf{I 7}$

persistence of, I $32-3,135$ 
Species, characters of, 93.5

Spencer, H., on play, 62

Spermatozoa, 255, 303

Spider, the, 217

Spiracles, I 85

pairing of the, 197

Spiritual world, the, 388

Spontaneous generation, 315, 317

Spring as the love-season, 57

Squirrel, winter store of the, 56

Stag, antlers of the, 84, 89, 207-13

Stag-beetle, the, 89

$$
\text { " larva of the, } 219
$$

State, Nietzsche's idea of the, 417

Stegocephala, the, 121

Steinheim snails, the, 125

Stickleback, the, 174

Stigma, the, 197

Sting of the bee, 221

, of insects, 193

Stirner, Max, 416

Stork, the, 46

, noise made by, 96

Strepsitera, 202

Struggle for life, the, 25, 27

Styloid bones, I57

Stylops melitta, 202

Subjectivity of knowledge, 405

Sudden changes in nature, 131

Survival of the fittest, 28

Swimming-bladder of fishes, I 50-1

Symbiosis, 284

TADPOLE, the, 2 I

Tania echinococcus, 281

Tania saginata, 279, 280

Tania solium, 279, 280

Tape-worm, the, 279-82

$$
\text { " development of the, 26-7 }
$$

Teleological principles, 352

Teleology, 364

Temperature of ancient Europe, 119

Thing in itself, the, 387

"Thus spoke Zarathustra," 421

Tibia, the, 168

Tiger-moth, the, rgo

Tozd, age of the, 149

, secretion of the, 146

Tortoise, the, 14.3

Tortoise-shell butterfly, the, 189, 191, 193

Tracheæ, 184

Tradition, 411

Trance, 233

Transformism, 37

Transitional forms, 264

Tree of life, the, 37
Tree-frog, the, 148

Tree-locust, the, 185

Trichina, the, 276

Tropical frogs, 119

Trout, eggs of the, 26

Trunk-fish, the, 177

Truth, the will to attain, 427

Turkey, the, 88,89

Types of animals, 132

Ultimate concepts, 394

" elements, 379, 38 I

Universal concepts, 380

Unnucleated organisms, 308

Uric acid, 351

Use and disuse, effects of, 223, 225

VALUE, idea of, 413

" no standard of, in science, 375

Variations are in all directions, 368

,, not definitely directed, 369

" in organisms, 40

,4 plus and minus, 162

, roots of, 334

Variety, nature of a, 33

Vermiform appendage, 158

Vertebrates, similarity of, 153

Viper, the, 140

Vital force, 355

Vitalism, 350

Voluntary action, 214

Volvox, the, 297

Vorticellæ, 293

Wallace, Dr. A. R., on sexual selection, 8 I

War-dance of animals, 89

War, evils of, 415

Wart-hog, the, 89

Wasmann, Father, 38

Wasps, predatory, 218

Water-beetle, the, 218

Water-flea, the, 20, 22, 229, 236, 252

Water-ousel, the, 97

Water-polyp, 284

Wasmann on co-adaptations, 213

" on heredity, 299
$"$ on instinct, 64
species, 127 the extinction of

Whale, rudimentary organs of the, I 59

Wild cocks, 9 I

Will to live, the, 356

Willow, fertilisation of the, 198

Willow-wren, song of the, 96

Winged horses, possibility of, 369

Wings, 100 
Wings, evolution of, 136-7, 157

Winter sleep of animals, 55-7

Womb, development in the, 59-60

Wood-chat, song of the, 97

Woodpecker, the, 18, 21

" noise of the, 96

Work and play, 6I

"mental and physical, 6r-2
World, infinity of the, 390

Wren, the, 97

Xylina vetusta, 193, 216

YELLOW as warning colour, 147 Yolk of the egg, 247, 304

ZOEA, 25 I

THE END 

THE LIBRARY

\section{UNIVERSITY OF CALIFORNIA}

Santa Barbara

THIS BOOK IS DUE ON THE LAST DATE STAMPED BELOW. 
UC SOUTHERN REGIONNL LIBRARY FACLITY 
